\title{
Next to best health decisions
}

\author{
Citation for published version (APA):
}

Romijnders, K. (2020). Next to best health decisions: exploring two cases: smoking behavior and childhood vaccination. [Doctoral Thesis, Maastricht University]. GVO drukkers \& vormgevers B.V. https://doi.org/10.26481/dis.20200910kr

\section{Document status and date:}

Published: 01/01/2020

DOI:

10.26481/dis.20200910kr

Document Version:

Publisher's PDF, also known as Version of record

\section{Please check the document version of this publication:}

- A submitted manuscript is the version of the article upon submission and before peer-review. There can be important differences between the submitted version and the official published version of record.

People interested in the research are advised to contact the author for the final version of the publication, or visit the DOI to the publisher's website.

- The final author version and the galley proof are versions of the publication after peer review.

- The final published version features the final layout of the paper including the volume, issue and page numbers.

Link to publication

\footnotetext{
General rights rights.

- You may freely distribute the URL identifying the publication in the public portal. please follow below link for the End User Agreement:

www.umlib.nl/taverne-license

Take down policy

If you believe that this document breaches copyright please contact us at:

repository@maastrichtuniversity.nl

providing details and we will investigate your claim.
}

Copyright and moral rights for the publications made accessible in the public portal are retained by the authors and/or other copyright owners and it is a condition of accessing publications that users recognise and abide by the legal requirements associated with these

- Users may download and print one copy of any publication from the public portal for the purpose of private study or research.

- You may not further distribute the material or use it for any profit-making activity or commercial gain

If the publication is distributed under the terms of Article $25 \mathrm{fa}$ of the Dutch Copyright Act, indicated by the "Taverne" license above, 


\title{
Next to best health decisions
}

\author{
Citation for published version (APA):
}

Romijnders, K. A. G. J. (2020). Next to best health decisions: exploring two cases: smoking behavior and childhood vaccination. GVO drukkers \& vormgevers B.V. https://doi.org/10.26481/dis.20200910kr

Document status and date:

Published: 01/01/2020

DOI:

10.26481/dis.20200910kr

Document Version:

Publisher's PDF, also known as Version of record

\section{Please check the document version of this publication:}

- A submitted manuscript is the version of the article upon submission and before peer-review. There can be important differences between the submitted version and the official published version of record.

People interested in the research are advised to contact the author for the final version of the publication, or visit the DOI to the publisher's website.

- The final author version and the galley proof are versions of the publication after peer review.

- The final published version features the final layout of the paper including the volume, issue and page numbers.

Link to publication

\footnotetext{
General rights rights.

- You may freely distribute the URL identifying the publication in the public portal. please follow below link for the End User Agreement:

www.umlib.nl/taverne-license

Take down policy

If you believe that this document breaches copyright please contact us at:

repository@maastrichtuniversity.nl

providing details and we will investigate your claim.
}

Copyright and moral rights for the publications made accessible in the public portal are retained by the authors and/or other copyright owners and it is a condition of accessing publications that users recognise and abide by the legal requirements associated with these

- Users may download and print one copy of any publication from the public portal for the purpose of private study or research.

- You may not further distribute the material or use it for any profit-making activity or commercial gain

If the publication is distributed under the terms of Article 25fa of the Dutch Copyright Act, indicated by the "Taverne" license above, 


\title{
NEXT TO BEST HEALTH DECISIONS
}

\author{
Exploring two cases: smoking behavior and \\ childhood vaccination.
}

Kim Romijnders 
cover design by

layout by

printed by

ISBN
Marloes van der Linde

Loes Kema

GVO drukkers \& vormgevers, NL

$978-94-6332-650-6$

Copyright () Kim Romijnders, Maastricht 2020

All rights are reserved. No parts of this book may be reproduced or transmitted in any form or by any means, without the written permission of the author.

The research presented in this dissertation was conducted at the Dutch National Institute for Public Health and the Environment (RIVM) as part of the Strategic Program of the RIVM (SPR). This SPR-program is focused on research, innovation, and knowledge dissemination. This project was a collaboration with the School for Public Health and Primary Care (CAPHRI), Department of Health Promotion, Maastricht University. CAPHRI participates in the Netherlands School of Primary Care Research (CaRE). This PhD project was financially supported by the RIVM. 


\title{
NEXT TO BEST HEALTH DECISIONS
}

\author{
Exploring two cases: smoking behavior and \\ childhood vaccination.
}

\begin{abstract}
PROEFSCHRIFT
Ter verkrijging van de graad van doctor aan de Universiteit Maastricht, op gezag van de Rector Magnificus, Prof.dr. Rianne M. Letschert volgens het besluit van het College van Decanen, in het openbaar te verdedigen op donderdag 10 september 2020 om 12.00 uur
\end{abstract}

door

Kim Anne Gerardus Johanna Romijnders

Geboren op 14 januari 1992

Nijmegen, Nederland 


\section{Promotor}

Prof. dr. Hein de Vries

\section{Copromotors}

Dr. Ir. Liesbeth Mollema, Rijksinstituut voor Volksgezondheid en Milieu

Dr. Liesbeth van Osch

Dr. Reinskje Talhout, Rijksinstituut voor Volksgezondheid en Milieu

\section{Beoordelingscommissie}

Prof. dr. Stef Kremers (voorzitter)

Prof. dr. Johannes Brug, Rijksinstituut voor Volksgezondheid en Milieu

Dr. Esther Croes, Trimbos-instituut

Prof. dr. Christian Hoebe

Prof. dr. Trudy van der Weijden 
'For a choice is always a choice among possible alternatives; and it is a rare agent for whom everything is possible.

Nussbaum MC. The fragility of goodness: Luck and ethics in Greek tragedy and philosophy. Cambridge University Press; 2001. 


\section{Contents}

Chapter 1 General Introduction

Part 1

Chapter 2 Perceptions and Reasons Regarding E-Cigarette Use among Users and Never-users: A Narrative Literature Review

Chapter 3 A Deliberate Choice? Exploring the Decision to Switch from Cigarettes to E-Cigarettes

Chapter 4 E-liquid flavor preferences and individual factors related to vaping: a survey among Dutch never-users, smokers, dual users, and exclusive vapers

Chapter 5 A Combination of Factors Related to Smoking Behavior, Attractive Product Characteristics, and Socio-Cognitive Factors are Important to Distinguish a Dual User from an Exclusive E-Cigarette User

Part 2

Chapter 6 A deliberate choice? Exploring factors related to informed decision-making about childhood vaccination among acceptors, refusers, and partial acceptors

Chapter 7 Deciding on childhood vaccination: differences in decisional conflict and determinants between parents who accepted, refused, and partially accepted childhood vaccination

part 3

Chapter 8 Exploring differences in knowledge, attitude, and deliberation: an illustration of next to best health decisions in the cases of childhood vaccination and smoking behavior.

Chapter 9 General Discussion 
Volarization

Summary

Samenvatting

249

Curriculum Vitae

257

Publication list

Publications in this thesis

Additional publications

Acknowledgements

265

Appendices 



\section{CHAPTER 1}

General introduction 

According to the World Health Organization (WHO), public health is a discipline that aims to prevent disease, prolong life, and promote health and general wellbeing by working with and in society. ${ }^{1}$ Through organized preventive efforts, public health experts aim to foster their goal of a healthy population. ${ }^{2}$ Public health experts aim to inform and empower society to make healthy decisions that prevent disease, prolong life, and promote health since informed and empowered individuals are more able to take responsibility over their health. ${ }^{2-4}$

In daily life, people make decisions about their health and the health of others, as is for instance the case in parental decision-making about childhood vaccination. ${ }^{5}$ When making health-related decisions, there can be different options to choose from. For instance, a parent can decide to accept, refuse, or partially accept childhood vaccinations; or a smoker can decide to quit smoking or switch from smoking regular cigarettes to electronic cigarettes (e-cigarettes). Public health professionals often inform individuals only about a recommended option, i.e. the option that is scientifically proven to be the healthiest. For example, they provide a brochure in order to inform parents about vaccinating their children according to the National Immunization Program (NIP) schedule. ${ }^{6,7}$ However, this recommended option might not be suitable for all individuals due to different personal values, priorities with regard to health, experiences, opinions, and the norms of their social environment. Consequently, in these cases people can choose options that match their individual values and goals but that are considered by public health professionals as, for example, 'next to best'. Next to best health options are - from a public health and scientific point of view less harmful or less healthy than the unrecommended health option, but not less harmful or less healthy compared to the recommended health option. Another option people may choose is the unrecommended option, which is considered as being unhealthy by public health experts and science.

Acknowledging that people may choose other options than the recommended health option as defined by public health experts, and wanting to support decisionmaking, raises an interesting question for public health: should public health experts communicate about all health options, or should they focus their efforts on the recommended health option? Communicating about all three options could result in those who preferred an unrecommended option to switch to the recommended or next to best option, resulting in public health gain. However, it could also result in those who preferred the recommended health option or next to best health option to switch to the unrecommended health option, which could potentially mean a public health loss. These potentially different outcomes result in a dilemma for public health experts regarding whether they should communicate about these options in order to support decision-making and improve public health. In order to provide insight into the consequences of either communicating about all health options or only the recommended health option, and to ultimately develop evidence-based health communication, it is first important to understand how people decide on these health options, an area that will be addressed in this thesis. 
Two cases, namely, smoking behavior and childhood vaccination, will be the focus in this thesis. We have chosen these two exemplary cases since an increase in next to best health options - partially accepting childhood vaccinations and e-cigarette use - was observed for both cases in recent years. ${ }^{7-18}$ In the case of smoking behavior, a next to best option for quitting or refraining from smoking could be deciding to use e-cigarettes, as these are in general considered less harmful than tobacco cigarettes (i.e. the unrecommended option), although certainly not harmless. ${ }^{10,16,18-22}$ In the case of childhood vaccination, accepting all childhood vaccinations according to the NIP can be considered the recommended health option, partially accepting childhood vaccinations can be considered a next to best option, and refusing all vaccinations is regarded as the unrecommended option from a public health perspective. This chapter provides the context of decision-making in public health, introduces the two cases, and presents the outline of this thesis. We start by describing two prevailing narratives, stereotypes as it were, to explain a societal shift from law-abiding citizens to decision empowerment.

\section{History of informed health-related decisions}

Prior to 1950, the public could be characterized as law-abiding citizens who followed the government, religious leaders, a monarch, or a physician. These relationships were based on trust. Physicians - who were perceived as all-knowing beings at the center of the health care system - have long determined which course of action best fitted healthy behavior and served the common good. ${ }^{23-26}$ The main responsibility of the physician was to bestow trust in the course of action determined. It was believed that informing patients about risks, consequences, and alternatives of treatment would destroy the trusting relationship between the physician and the patient. ${ }^{23-26}$ Since physicians had this knowledge, they knew the best option for the patient's well-being. 23,26 The information and knowledge asymmetry between the patient and the health care provider changed in the US and several other countries after 1950. ${ }^{27}$ From then on, physicians were obligated by law to offer information about the risks, consequences, nature, and alternatives to the treatment and explain it, ${ }^{26}$ and individuals have since had the right to be informed and the right for self-determination. ${ }^{23}$ The right to be informed and the right for self-determination were defined as the right to make an informed choice in the form of an informed consent. ${ }^{23,27}$ In the Netherlands, this right was established in $1994 .{ }^{28}$ In the informed decision approach to health care $^{25}$, patients had to be informed about the risks, consequences, nature, and alternatives to the treatment in order to make a decision that reflects scientific evidence, and the decision-maker's values and preferences. ${ }^{23,25,29}$ At the same time that the informed decision approach in health care progressively developed, disease prevention decisions, such as exercising and not smoking, were more and more regarded as individual decisions rather than a public responsibility. ${ }^{30}$ 


\section{Informed decisions in public health}

In the $19^{\text {th }}$ century, health and lifestyle were seen by hygienists (i.e. public health experts) as a collective responsibility to prevent disease and improve health on a local level via such means as effective sewage systems and clean drinking water. ${ }^{30}$ The success of public health in the $19^{\text {th }}$ century was the result of a very strong moral responsibility for prevention of disease and the efforts of public health experts which, although organized on a local level, were enforced by the government. ${ }^{30}$ The (implicit) underlying assumption was that by disseminating knowledge from the "all-knowing" experts to the public, the public would be motivated to make healthy decisions and change their unhealthy behavior. ${ }^{4,25,31-35}$ However, and as demonstrated by previous research,4,32,36-43 knowledge dissemination alone often does not change people's unhealthy behavior. In the Netherlands, a change could be observed in the 1970s resulting in fewer obedient citizens who did not question authority. 4,30,31,44 From then on, public health experts increasingly aimed to empower and inform the public to make healthy, autonomous, informed decisions by working with and in society. ${ }^{1,2,29,45-48}$ Public health experts were the main source providing (scientific) information to present information the general public needed. 4,49,50 With the rapid growth of the internet in the 1990s, information became easily available for the public, allowing the general public to pro-actively look for and verify information, which also resulted in the objectivity of scientific evidence being offered by public health experts no longer being taken for granted by everyone. ${ }^{30,51,52}$ Due to largescale information sharing and statements that science could be regarded as just another opinion, ${ }^{44}$ the veracity and objectivity of scientific evidence and health professionals ${ }^{51,52}$ are no longer taken for granted. People can look for information from different sources, including information provided by parties with a vested interest, ${ }^{53}$ which can sometimes be categorized as untrustworthy information. ${ }^{54-58}$

\section{Conceptualization of informed decision-making}

To support informed decision-making among the public, it is important to investigate what constitutes informed decision-making and what the consequences of not making an informed decision could be. Originating from a Rational Decision model, $, 5,60$ there are multiple definitions of what makes a decision informed. Several definitions suggest that individuals need to be informed about the risks, consequences, nature, and alternatives about the decision subject with correct scientific evidence, and a decision should reflect decision-makers' values and preferences. ${ }^{45,61-70}$ In this thesis we use the definition of informed decision-making of van den Berg et al. ${ }^{71}$ This definition states that a choice can be classified as informed if the decision-maker has made the decision based on relevant evidence-based knowledge about the subject, made a choice that reflects their attitude (i.e. they are value-consistent), and has deliberated the different choice options. ${ }^{64,65,67,68,71,72}$ For our studies, although we used this definition to conceptualize the criteria of informed decision-making, 
no classification of informed or uninformed decisions were made based on this definition because this dichotomization is a crude distinction that does not reflect the variety of levels of informed and uninformed decisions. ${ }^{31,71,73}$

This latter criterion, the process of deliberation, is an important step in informed decision-making, in which the decision-maker weighs the pros and cons of each available option, and deliberates alternatives to determine the expected utility of an outcome. ${ }^{59}$ For example, the decisional balance of considering the perceived susceptibility to lung cancer later in life if a smoker were to quit smoking, or considering the pros and cons of smoking cessation before making a decision, is a deliberation process. ${ }^{42,74-80}$ This deliberation of available information has been identified in several decision-making theories as key to an informed decisionmaking process. ${ }^{36-40}$ In addition, socio-cognitive theories, such as the health belief model, ${ }_{14776}$ the protection motivation theory, ${ }^{77,78}$ and the Integrated Behavioral Model ${ }^{42,79,80}$ also recognize the importance of deliberation in health decisions.

In addition, supporting informed decision-making may reduce decisional conflict, and reducing decisional conflict may support decision-making. ${ }^{45,81,82}$ With regard to childhood vaccination, increasing informed decision-making and decreasing decisional conflict may reduce vaccine hesitancy ${ }^{83-85}$ and may positively affect intention to accept childhood vaccinations, and thus also positively affect the vaccination coverage. ${ }^{47}$ With regard to smoking behavior, increasing informed decision-making about smoking cessation and lowering decisional conflict regarding smoking cessation may support smokers in their efforts to quit smoking. ${ }^{86}$ According to the Elaboration Likelihood Model ${ }^{87}$, people can make a decision through two types of routes: the central route or the peripheral route..$^{87}$ To make an informed decision, it is important that people use the central route of processing since this could lead to decisions that are less vulnerable to unobjective information ${ }^{51,52}$ or decisional regret ${ }^{45}$, and to more maintenance of sticking to a healthy choice. ${ }^{87}$

For both smoking behavior and childhood vaccination, the Dutch National Institute for Public Health and the Environment (RIVM) offers information to the public. Research is needed to provide insight into how people decide on the recommended, unrecommended, or next to best health option, and how decision-making could be supported. These insights may also shed light on whether public health experts should communicate about various health options in addition to the recommended option, and how to communicate about next to best options. We will now present the next to best options in smoking behavior and childhood vaccination.

\section{Next to best health decisions E-cigarette use}

Electronic Nicotine Delivery Systems (ENDS) are devices that vaporize a solution of additives, glycerin, and propylene glycol that is inhaled by the user. ${ }^{13-15,88}$ 
The solution may, or may not, contain nicotine. ${ }^{13-15,88}$ Electronic cigarettes are the most common type of ENDS. The variety of electronic cigarette (e-cigarette) devices available on the market is rapidly increasing. While early models mimic conventional cigarettes (in shape and size), newer models vary in product specifications (shape, size, battery, and tanks) ${ }^{14,15,88-90}$.

In addition to product specifications, such as wattage and resistance, design and flavor characteristics are increasingly elaborate and appealing. ${ }^{91-93}$ Research in recent years has demonstrated that since their introduction in 2003 on the market, the appeal of e-cigarettes has increased rapidly. ${ }^{14,15,88-90,94,95}$ The prevalence of e-cigarette use is increasing in the United States, mostly among cigarette smokers, but recent research suggests that e-cigarette use is also increasing among non-smokers, and may even be a gateway to smoking. ${ }^{14,88,93,96-107}$ The majority of the e-cigarette users are currently former cigarette smokers that either switched completely to e-cigarettes or use e-cigarettes in addition to tobacco cigarettes. ${ }^{10-15}$ Concerns exist that e-cigarette use may attract (adolescent) neverusers and thus affect public health adversely, and even lead to dual use and a nicotine addiction. ${ }^{16-18}$ Indeed, a recent study in the US showed that e-cigarette use is very popular among youth. ${ }^{108}$

\section{E-cigarette use in the Netherlands}

The number of people who smoke in the Netherlands is decreasing. ${ }^{109,110}$ In $2017,23 \%$ of the adult Dutch population smoked cigarettes. ${ }^{110}$ Of these $23 \%$, $75 \%$ smoke daily. Of all smokers, higher educated people smoke less often (17\%) compared to middle (27\%) or lower (26\%) educated people; more men smoke (27\%) than women (19\%). ${ }^{110}$ Of the Dutch population, young adults, 20 - 24 years old, smoke more often than older adults. Sixteen percent of the Dutch adult smoking population are considered heavy smokers (i.e. smoking more than 20 cigarettes a day). ${ }^{110}$ Three percent of Dutch adults use an e-cigarette. Of Dutch adults, higher educated people use e-cigarettes less often (2.5\%), compared to middle (3.7\%) and low (3.0\%) educated people. ${ }^{110}$ Ten percent of the current smokers sometimes use an e-cigarette, and daily smokers (12\%) compared to non-daily smokers (4\%) use an e-cigarette more often. Of the $3 \%$ of e-cigarette users, seventy-five percent of the e-cigarette users also smoke. ${ }^{110}$

\section{Types of users and frequency of use}

Definitions of types of users and frequency of use differ. For the purpose of this thesis, four groups were defined. Never-users are individuals who reported to have never smoked or used e-cigarettes. Smokers are participants who reported to currently exclusively use cigarettes on a daily or weekly basis. Dual users are individuals who reported concurrently using cigarettes and e-cigarettes on a daily or weekly basis. ${ }^{111}$ E-cigarette users are individuals who reported to be currently exclusively using e-cigarettes on a daily or weekly basis. ${ }^{111}$ 
In the Netherlands, the RIVM investigates the harmfulness of cigarettes and e-cigarettes for public health in order to inform the public. ${ }^{112}$ Although not using tobacco or nicotine products would be most beneficial for all types of users, exclusive e-cigarette use ${ }^{111}$ - and not dual use of both cigarettes and e-cigarettes, which has an adverse public health effect ${ }^{14,16,111}$ - has potential health benefits for smokers compared to cigarette smoking. ${ }^{22,113-116}$ However, exclusive e-cigarette use is not without risks itself. Consequently, from a public health point of view it is recommended to prevent e-cigarette use among non-smokers. ${ }^{16}$ Motives for e-cigarette use among smokers have been investigated. ${ }^{90,117-127}$ In addition, other research on e-cigarette use focused on e-cigarettes as a tool for smoking cessation or changing smoking behavior with behavior change techniques. ${ }^{128-131}$ Since decision-making about e-cigarette use is largely uninvestigated, it is unclear how people make a decision about refraining from cigarette or e-cigarette use, smoking, or e-cigarette use. This thesis investigates decisions about never-use, smoking, and e-cigarette use among never-users and users about these specific decisions in order to develop health communication aimed to support these decisions.

\section{Partially accepting childhood vaccinations}

Childhood vaccinations are very successful interventions to protect against vaccine-preventable diseases (VPDs). ${ }^{33,132-134}$ In the Netherlands, the National Immunization Program (NIP) offers vaccinations free of charge and on a voluntary basis since 1957.7 Currently, within the NIP, vaccinations are offered against 12 childhood diseases (polio (IPV), diphtheria (D), tetanus (T), pertussis (aP), rubella (R), measles (M), mumps (M), disease caused by Haemophilus influenzae type b (Hib), meningococcal ACWY disease (MenACWY), hepatitis B (HBV), pneumococcal disease (PCV) and cervical cancer caused by human papillomavirus (HPV), see Figure 1.1.7 The RIVM is responsible for organizing the NIP and for offering information about the NIP in the Netherlands. The vaccines itself are administered in primary care facilities (Child Welfare Centers i.e. CWCs) specialized in child health care ${ }^{6}$. These centers provide children from zero to four years old with health check-ups and administer vaccines according to the vaccination schedule. When the child is four to six weeks old, the parents receive an invitation for the first consult at the CWC with information on vaccination including the NIP schedule, VPDs, and side-effects and practical information. The vaccination status of children is recorded in a national register at the RIVM, called Praeventis.

\section{Vaccination coverage in the Netherlands}

Every year, the RIVM publishes a report on the vaccination coverage in the Netherlands. The latest figures showed that the vaccination coverage seemed to be stabilizing compared to a decline in previous years. At age two, born in 2014, 91.2\% of all Dutch two-year-olds received all vaccines according to the NIP, 3.6\% did not receive any vaccines according to the NIP and $5.2 \%$ received or delayed some vaccines (i.e. the next to best option). ${ }^{135}$ At age two, born in $2015,92.4 \%$ of the children received the DTaP vaccine and $92.9 \%$ of the children received the MMR vaccine. ${ }^{135}$ In addition, $90.2 \%$ of all Dutch two-year-olds, born in 2015, 
received all vaccines according to the NIP, $4.6 \%$ did not receive any vaccines according to NIP and $5.2 \%$ received or delayed some vaccines (i.e. the next to best option). ${ }^{135}$ These figures seem to be stabilizing, since of all Dutch two-yearolds born in 2016 90.2\% received all vaccines according to the NIP, 4.6\% did not receive any vaccines according to the NIP and $5.2 \%$ received or delayed some vaccines (i.e. the next to best option). ${ }^{135}$

However, the vaccination coverage alone does not provide insight into whether parents have questions or doubts regarding their decision. For example, parents who accept all childhood vaccinations, may still have doubts about their decision or even experience regret. ${ }^{83,85,136}$ This is why it is important to investigate decisionmaking regarding childhood vaccination.

\section{Parents' decision regarding childhood vaccination}

For the purpose of this study we chose to include parents of children born between 2013-2015 to be able to classify parents in three groups based on their decision about the five vaccination moments in the first two years of life (see figure 1.1): acceptors, refusers, and partial acceptors. Acceptors are parents of children who received all vaccinations according to the Dutch NIP schedule. Refusers are parents of children who did not receive any vaccinations according to the Dutch NIP schedule. Partial acceptors are parents who refuse or delay some vaccines for their child. For example, some of these children did not receive any vaccine against PCV, but they did receive all four doses of the DTaPIPV-Hib-HBV vaccine, or their first DTaP-IPV-Hib-HBV vaccine was delayed.

In the Netherlands, the RIVM monitors the NIP, and informs the public about childhood vaccinations. ${ }^{112}$ The RIVM is responsible for presenting the public with information about childhood vaccination, for example through an information brochure and a website. ${ }^{6,7}$ Although accepting childhood vaccinations would be most beneficial for public health, ${ }^{137}$ partially accepting childhood vaccination and not refusing all vaccines of the NIP, which has an adverse public health and possible adverse individual effect - has potential individual and public health benefits compared to refusing all vaccines. ${ }^{137-139}$ However, partially accepting childhood vaccinations leads to lower herd immunity and may not be without risks for the individual. ${ }^{140,141}$ Consequently, it is not recommended from a public health point of view. The motives for accepting or refusing childhood vaccinations have been investigated from a behavioral perspective with sociocognitive models, $33,138,142-148$, and to a lesser extent also the motives for partially accepting childhood vaccination. In addition, while some research looked into decision-making about accepting childhood vaccinations, ${ }^{143,149-152}$ decisionmaking about refusing and partially accepting childhood vaccinations among those who accept, partly accept or refuse vaccination has not been studied. This thesis focusses on decision-making regarding accepting, refusing, and partially accepting childhood vaccination by asking all parents questions concerning accepting, refusing, and partially accepting childhood vaccination. By focusing 
on these decisions, we increase our understanding of these decisions so that we can develop health communication aimed to support decision-making.

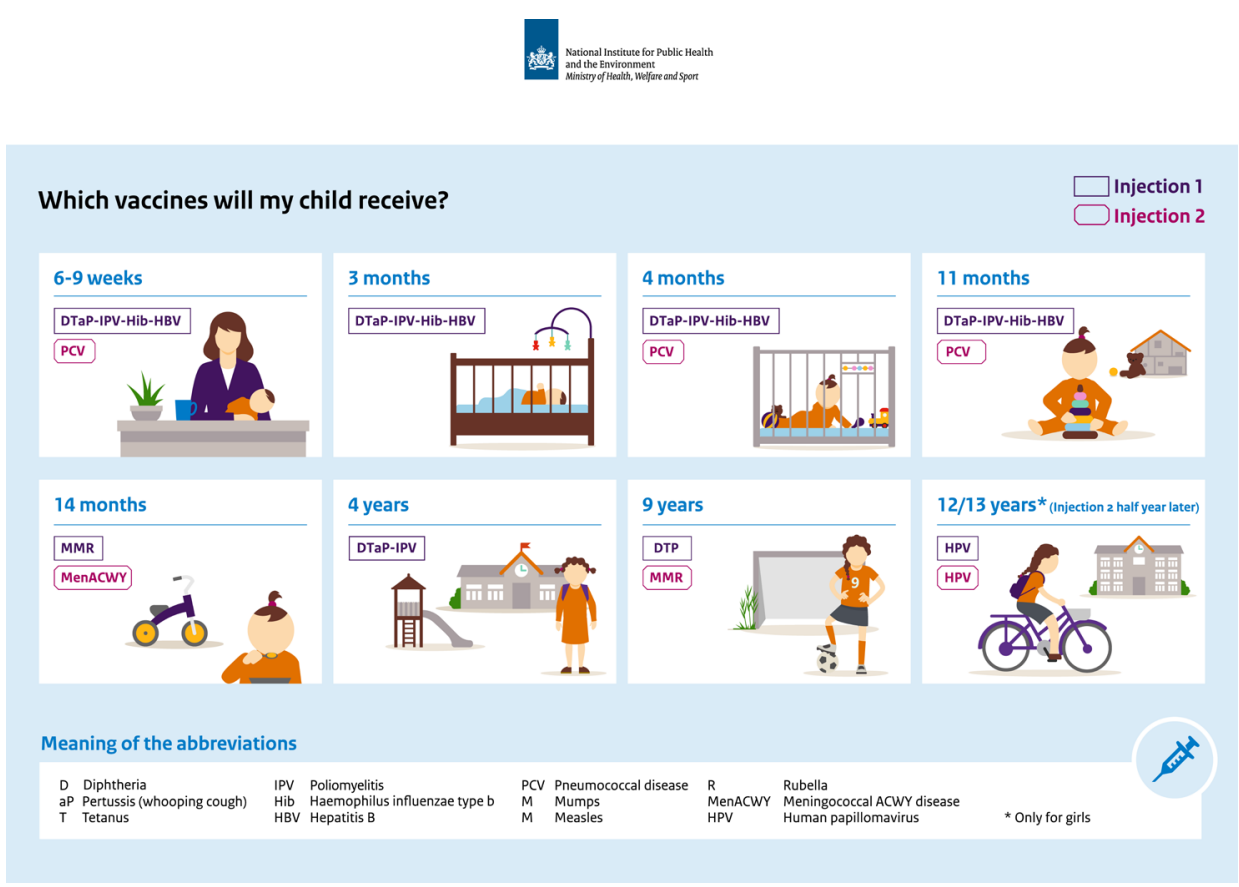

Figure 1.1 Schedule of the Dutch National Immunization Program.

Picture copyright 2018 (c) RIVM. Centre for infectious disease control ${ }^{7}$

Note, the schedule of the Dutch NIP changed due to the introduction of maternal pertussis vaccine in 2019.

\section{Thesis outline}

To understand decision-making about smoking behavior and childhood vaccination, we present two objectives. First, we aimed to explore determinants of the decisions about smoking behavior and childhood vaccination, both qualitatively and quantitatively. Second, we aimed to provide insight into the extent to which decisions about smoking behavior and childhood vaccination adhere to the criteria of informed decision-making as defined in this thesis. With this aim in mind we investigated the level of knowledge, attitudes, and valueconsistency toward a decision about the various choice options and levels of deliberation with regard to smoking behavior or childhood vaccination. These objectives are addressed in three parts through a series of studies (figure 1.2). The following section outlines the studies conducted.

Part 1 of this dissertation presents information on factors related to decisions 
about never-use, smoking, and vaping. Chapter 2 starts by offering an overview in the form of a systematic narrative review of reasons of use and perceptions among never-users, smokers, exclusive e-cigarette users, and dual users concerning e-cigarettes. The overview presented in chapter 2 and the conceptualization of informed decision-making based on a Rational Decision Model ${ }^{71}$ was used to develop the interview protocol used in a semi-structured focus group study among never-users, smokers, and e-cigarette users. Chapter 3 describes the results of this qualitative study concerning decisions with regard to smoking behavior among never-users, smokers, and e-cigarette users. The results of the qualitative study presented in chapter 3 were used to develop a questionnaire about the recommended, unrecommended, and next to best health options with regard to smoking behavior to investigate socio-cognitive factors related to informed decision-making among never-users and users. In order to examine the role played by flavors in the decision regarding e-cigarette use, chapter 4 presents the results of a quantitative analysis into the interplay of individual flavor choice and socio-cognitive factors related to e-cigarette use. Chapter 5 provides insights into features that distinguish a dual user from an exclusive e-cigarette user, derived from a quantitative survey.

\section{Chapter 1 General Introduction}

Part 1 Exploring factors related to decision-making about smoking behavior.

Chapter 2: Overview of reasons and perceptions regarding e-cigarettes.

Chapter 3: Exploring factors mentioned by never-users, smokers and e-cigarette users regarding decision-making about never-use, smoking, and switching from cigarettes to e-cigarettes.

Chapter 4: Exploring attractive aspects of e-cigarettes among neversmokers and never-users, smokers, and e-cigarette users.

Chapter 5: Exploring features to distinguish a dual user from an exclusive e-cigarette user.

Part 2 Exploring factors related to decision-making about childhood vaccination.

Chapter 6: Exploring factors mentioned by acceptors, refusers, and partial acceptors regarding decision-making about accepting, refusing, and partially accepting childhood vaccinations.

Chapter 7: Exploring determinants and decisional conflict among acceptors, refusers, and partial acceptors regarding their decision about childhood vaccinations.

Part 3 Exploring whether the decisions about smoking behavior and childhood vaccinations adhere to informed decision-making criteria

Chapter 8: Exploring knowledge, attitudes, and deliberation of those who opted for the recommended, unrecommended, and next to best health options

Chapter 9 General Discussion

Figure 1.2 Schematic outline of this thesis 
Part 2 of this dissertation presents information on factors related to the decisions concerning childhood vaccination among parents who accept, refuse, or partially accept childhood vaccinations for their child with regard to these three health options. Chapter 6 starts by providing insights into socio-cognitive factors related to the decisions regarding childhood vaccinations among vaccine acceptors, refusers, and partial acceptors gained by means of focus groups. The results of the qualitative study presented in chapter 6 were used to develop a questionnaire to investigate the identified factors related to decision-making about childhood vaccination among parents. In addition, to conceptualize the uncertainty about this decision, decisional conflict among parents was investigated. Chapter 7 explores differences in determinants and decisional conflict experienced by parents who accepted, partially accepted, or refused childhood vaccinations, with regard to these three health options.

Part 3 of this dissertation discusses whether the decisions regarding smoking behavior and childhood vaccination adhere to the conceptualization of informed decision-making. For this study, we used the quantitative survey results from parts 1 and 2. Chapter 8 describes whether the decisions about the recommended, unrecommended, and next to best health options in the case of smoking behavior and childhood vaccinations adhered to the criteria of informed decision-making: knowledge, attitudes, and deliberation.

Finally, chapter 9 summarizes and discusses the major findings of the studies presented in this thesis. Practical recommendations and suggestions for further research are given. 


\section{References}

1. Acheson D. Public health in England: the report of the Committee of Inquiry into the Future Development of the Public Health Function. London: The Stationery Office; 1988.

2. Tulchinsky TH, Varavikova E. chapter 2: Expanding the Concept of Public Health. TheNewPublic Health:AnIntroductionforthe21stCentury:Academic Press; 2008.

3. World Health Organization. European Action Plan for Strengthening Public Health Capacities and Services. Malta: WHO,;2012.

4. Horstman K. Kanttekeningen bij de moraal van 'meer bewegen'. Huisarts en Wetenschap. 2011;2011(2):103-105.

5. Damnjanovic K, llic S, Pavlovic I, Novkovic V. Refinement of Outcome Bias Measurement in the Parental Decision-Making Context. Eur $J$ Psychol. 2019;15(1):41-58.

6. E.A. van Lier, Geraedts JLE, P.J. Oomen, et al. [Vaccine Coverage of NIP in the Netherlands]. Bilthoven: National Institute for Public Health and the Environment;2018.

7. National Institute for Public Health and the Environment (RIVM). [National Immunization Program]. History 2018. http://www.rijksvaccinatieprogramma.nl/ Over_Rijksvaccinatieprogramma/Geschiedenis. Accessed June 19, 2018.

8. E.A. van Lier, Geraedts JLE, P.J. Oomen, et al. [Vaccine Coverage of NIP in the Netherlands]. Bilthoven: National Instituut of Public Health and the Environment;2017.

9. Filippidis FT, Laverty AA, Gerovasili V, Vardavas Cl. Two-year trends and predictors of e-cigarette use in 27 European Union member states. Tob Control. 2017;26(1):98-104.

10. McMillen RC, Gottlieb MA, Shaefer RM, Winickoff JP, Klein JD. Trends in Electronic Cigarette Use Among U.S. Adults: Use is Increasing in Both Smokers and Nonsmokers. Nicotine Tob Res. 2015;17(10):1195-1202.

11. Cullen KA, Ambrose BK, Gentzke AS, et al. Notes from the Field: Use of Electronic Cigarettes and Any Tobacco Product Among Middle and High School Students - United States, 2011-2018. MMWR Morb Mortal Wkly Rep. 2018;67(45):12761277.

12. Miech R, Johnston L, O'Malley PM, Bachman JG, Patrick ME. Adolescent Vaping and Nicotine Use in 2017-2018 - U.S. National Estimates. N Engl J Med. 2019;380(2):192-193.

13. World Health Organization. Tobacco Free Initiative (TFI). Electronic cigarettes (ecigarettes) or electronic nicotine delivery systems 2015. http://www.who.int/ tobacco/communications/statements/eletronic_cigarettes/en/. Accessed July $12,2017,2016$.

14. Glasser AM, Collins L, Pearson JL, et al. Overview of Electronic Nicotine Delivery Systems: A Systematic Review. Am J Prev Med. 2017;52(2):e33-e66.

15. Hajek P, Etter JF, Benowitz N, Eissenberg T, McRobbie H. Electronic cigarettes: review of use, content, safety, effects on smokers and potential for harm and benefit. Addiction. 2014;109(11):1801-1810. 
16. Stratton K, Kwan L, Y., Eaton DL. Public health consequences of e-cigarettes. Washington, DC, United States: National Academies Press;2018.9780309468343.

17. Smith DM, Gawron M, Balwicki L, et al. Exclusive versus dual use of tobacco and electronic cigarettes among adolescents in Poland, 2010-2016. Addict Behav. 2019;90:341-348.

18. Soneji S, Barrington-Trimis JL, Wills TA, et al. Association Between Initial Use of e-Cigarettes and Subsequent Cigarette Smoking Among Adolescents and Young Adults: A Systematic Review and Meta-analysis. JAMA Pediatr. 2017. doi:10.1001/jamapediatrics.2017.1488.

19. Prochaska JJ. The public health consequences of e-cigarettes: a review by the National Academies of Sciences. A call for more research, a need for regulatory action. Addiction. 2019;114(4):587-589.

20. Kinouani S, Pereira E, Tzourio C. Electronic Cigarette Use in Students and Its Relation with Tobacco-Smoking: A Cross-Sectional Analysis of the i-Share Study. Int J Environ Res Public Health. 2017;14(11):1345.

21. Liu X, Lugo A, Davoli E, et al. Electronic cigarettes in Italy: a tool for harm reduction or a gateway to smoking tobacco? Tob Control. 2019.

22. McRobbie H. Modelling the Population Health Effects of E-Cigarettes Use: Current Data Can Help Guide Future Policy Decisions. Nicotine Tob Res. 2017;19(2):131-132.

23. Capron AM. "Informed Decisionmaking in Genetic Counseling: A Dissent to the ""Wrongful Life". Indiana Law Journal. 1973;48(4).

24. Thomasma DC. Beyond medical paternalism and patient autonomy: a model of physician conscience for the physician-patient relationship. Ann Intern Med. 1983;98(2):243-248.

25. Emanuel EJ, Emanuel LL. Four models of the physician-patient relationship. JAMA. 1992;267(16):2221-2226.

26. Supreme Court of Kansas. Natanson v. Kline. 186 Kan. 393. Vol No. 41,476. Kansas 1960.

27. Murray PM. The History of Informed Consent. lowa Orthop J. 1990;10:104-109.

28. Misterie van Volksgezondheid WeS. De overeenkomst inzake geneeskundige behandeling. Vol Afdeling 5 Burgelijk Wetboek Boek 71994.

29. Charles C, Gafni A, Whelan TJSs. Shared decision-making in the medical encounter: what does it mean?(or it takes at least two to tango). Social Science medicine. 1997;44(5):681-692.

30. Houwaart E. Preventiebeleid vraagt om geheugen. Tijdschrift voor gezondheidswetenschappen. 2012;89(3):136-138.

31. Timmermans D. [What motivates the decision-maker? The meaning of a deliberate and informed decision for public health and prevention] VU medisch centrum 2013.

32. Kasten $S$, van Osch $L$, Candel M, de Vries $H$. The influence of pre-motivational factors on behavior via motivational factors: a test of the I-Change model. BMC Psychol. 2019;7(1):7. 
33. Lehmann BA, de Melker HE, Timmermans DRM, Mollema L. Informed decision making in the context of childhood immunization. Patient Educ Couns. 2017;100(12):2339-2345.

34. Hoek J, Ball J, Gray R, Tautolo ES. Smoking as an 'informed choice': implications for endgame strategies. Tob Control. 2017;26(6):669-673.

35. Gray RJ, Hoek J, Edwards R. A qualitative analysis of 'informed choice' among young adult smokers. Tob Control. 2016;25(1):46-51.

36. Andreas $G$, Tilmann B. Modelling option and strategy choices with connectionist networks. Judgment and Decision Making. 2008;3(NA):215-228.

37. Beach LR, Mitchell TR. Image theory: Principles, goals, and plans in decision making. Acta Psychologica. 1987;66(3):201-220.

38. Fischhoff B. Assessing adolescent decision-making competence. Developmental Review. 2008;28(1):12-28.

39. Montgomery $\mathrm{H}$. The search for a dominance structure in decision making: Examining the evidence. In: Klein GA, Orasanu JE, Calderwood RE, Zsambok C, eds. Decision making in action: Models methods: AblexPublishing; 1989:182-188.

40. Svenson O. Values, Affect, and Processes in Human Decision Making: A differentiation and consolidation theory perspective. In: Schneider SL, Shanteau J, eds. Emerging Perspectives on Judment and Decision research. Cambrigde: Cambridge University Press; 2003:287-326.

41. Champion VL, Skinner CS. The Health Belief Model. In: Glanz K, Rimer BK, Viswanath K, eds. Health Behavior and Health Education: Theory, Research and Practice. 4th ed. New Jersey: John Wiley \& Sons; 2008:45-66.

42. Montano DE, Kasprzyk D. Theory of Reasoned Action, Theory of Planned Behavior, and the Integrated Behavioral Model. In: Glanz K, Rimer BK, Viswanath $\mathrm{K}$, eds. Health Behavior and Health Education: Theory, Research and Practice. 4th ed. New Jersey: John Wiley \& Sons; 2008:67-96.

43. Norman P, Boer H, Seydel ER. Protection motivation theory. In: Conner M, Normal P, eds. Predicting health behaviour: RESEARCH AND PRACTICE WITH SOCIAL COGNITION MODELS. Vol 81. 2nd ed. Maidenhead, Berkshire: Open University Press; 2005:81-126.

44. Higgins K. Post-truth: a guide for the perplexed. Nature. 2016;540(7631):9.

45. O'Connor AM. Validation of a decisional conflict scale. Med Decis Making. 1995;15(1):25-30.

46. Pot M, Ruiter RAC, Paulussen T, et al. Systematically Developing a Web-Based Tailored Intervention Promoting HPV-Vaccination Acceptability Among Mothers of Invited Girls Using Intervention Mapping. Front Public Health. 2018;6:226.

47. Pot M, Paulussen TG, Ruiter RA, et al. Effectiveness of a Web-Based Tailored Intervention With Virtual Assistants Promoting the Acceptability of HPV Vaccination Among Mothers of Invited Girls: Randomized Controlled Trial. J Med Internet Res. 2017;19(9):e312.

48. Wegwarth O, Kurzenhauser-Carstens S, Gigerenzer G. Overcoming the knowledge-behavior gap: The effect of evidence-based HPV vaccination leaflets on understanding, intention, and actual vaccination decision. Vaccine. 2014;32(12):1388-1393. 
49. Horstman K. Een kwestie van betekenissen. Tijdschrift voor gezondheidswetenschappen. 2016;94(8):281-282.

50. Horstman K. Fat children, burnout employees, and weird viruses. Philosophy of Public Health in the $21^{\text {st }}$ century [Inaugural speech]. Maastricht: Faculty of Health, Medicine and Life Sciences, Maastricht University; 2010.

51. Pajor EM, Eggers SM, Curfs KCJ, Oenema A, de Vries H. Why do Dutch people use dietary supplements? Exploring the role of socio-cognitive and psychosocial determinants. Appetite. 2017;114:161-168.

52. Pajor EM. DIETARY SUPPLEMENT USE: Reasons, decisions, and health communication [Doctoral Thesis]. Maastricht: CAPHRI - Promoting Health \& Personalised Care Health promotion, Maastricht University; 2019.

53. Morgan MG, Fischhoff B, Bostrom A, Atman CJ. Risk communication: A mental models approach. Cambridge University Press; 2002.

54. Sommariva S, Martinez Tyson D. Spreading the (Fake) News: Exploring Health Messages on Social Media and the Implications for Health Professionals Using a Case Study. American Journal of Health Education. 2018;49(4):246-255.

55. Fernandez-Luque L, Bau T. Health and social media: perfect storm of information. Healthcare informatics research. 2015;21(2):67-73.

56. Fernandez-Luque L, Karlsen R, Bonander J. Review of extracting information from the Social Web for health personalization. J Med Internet Res. 2011;13(1):e15.

57. Yom-Tov E, Fernandez-Luque L. Information is in the eye of the beholder: Seeking information on the MMR vaccine through an Internet search engine. AMIA Annu Symp Proc. 2014;2014:1238-1247.

58. Chiou L, Tucker C, National Bureau of Economic R. Fake news and advertising on social media : a study of the anti-vaccination movement. Cambridge, Mass.: National Bureau of Economic Research; 2018: http://www.library.yorku.ca/e/ resolver/id/287744606.

59. Baron J. Thinking and Deciding. 4th ed. Cambridge: Cambridge University Press; 2007.

60. Simon HA. A behavioral model of rational choice. The quarterly journal of economics. 1955;69(1):99-118.

61. Summers AM. Informed choice in prenatal screening. Can Fam Physician. 1994;40:1688-1691, 1694-1687.

62. Bekker H. Genetic screening: facilitating informed choices. In: Cooper DN, Thomas N, eds. Encyclopaedia of the Human Genome2001:926-930.

63. Marteau TM, Dormandy E, Michie S. A measure of informed choice. Health Expect. 2001;4(2):99-108.

64. Kohut RJ, Dewey D, Love EJ. Women's knowledge of prenatal ultrasound and informed choice. J Genet Couns. 2002;11(4):265-276.

65. Bekker HL, Hewison J, Thornton JG. Applying decision analysis to facilitate informed decision making about prenatal diagnosis for Down syndrome: a randomised controlled trial. Prenat Diagn. 2004;24(4):265-275.

66. Briss $P$, Rimer $B$, Reilley $B$, et al. Promoting informed decisions about cancer screening in communities and healthcare systems. American Journal of Preventive Medicine. 2004;26(1):67-80. 
67. Green JM, Hewison J, Bekker HL, Bryant LD, Cuckle HS. Psychosocial aspects of genetic screening of pregnant women and newborns: a systematic review. NIHR Health Technology Assessment programme: Executive Summaries: NIHR Journals Library; 2004.

68. Rimer BK, Briss PA, Zeller PK, Chan ECY, Woolf SH. Informed decision making: What is its role in cancer screening? Cancer. 2004;101(5 SUPPL.):1214-1228.

69. Michie S, Dormandy E, Marteau TM. The multi-dimensional measure of informed choice: a validation study. Patient Educ Couns. 2002;48(1):87-91.

70. Michie S, Dormandy E, Marteau TM. Informed choice: understanding knowledge in the context of screening uptake. Patient Educ Couns. 2003;50(3):247-253.

71. van den Berg M, Timmermans DR, ten Kate LP, van Vugt JM, van der Wal G. Informed decision making in the context of prenatal screening. Patient Educ Couns. 2006;63(1-2):110-117.

72. Tepper AM, Kaslow FW. Informed decision-making capacity: a patient's ability to participate in treatment determinations. Law Psychol Rev. 1981;6:49-67.

73. Douma LN. Colorectal Cancer Screening: Yes or No? Insights into public opinion and the individual decision-making process [Doctoral]. Amsterdam: Faculteit der Geneeskunde, Vrije Universiteit Amsterdam; 2019.

74. Hochbaum GM, United States. Public Health Service. Division of Special Health S. Public participation in medical screening programs; a socio-psychological study. [Washington]1958.

75. Rosenstock IM. What Research in Motivation Suggests for Public Health1960.

76. Rosenstock IM. The health belief model and preventive health behavior. [S.I.]: [s.n.]; 1974.

77. Rogers RW. A Protection Motivation Theory of Fear Appeals and Attitude Change1. J Psychol. 1975;91(1):93-114.

78. Rogers RW. Cognitive and physiological processes in fear appeals and attitude change: a revised theory of protection and motivation. In: Cacioppo JT, Petty RE, eds. Social Psychophysiiological: A Source Book. New York: Guilford Press; 1983:1533-1176.

79. Fishbein M, Ajzen I. Predicting and changing behavior: The reasoned action approach. Psychology press; 2011.

80. Kasprzyk D, Montano DE, Fishbein M. Application of an Integrated Behavioral Model to Predict Condom Use: A Prospective Study Among High HIV Risk Groups1. Journal of Applied Social Psychology. 1998;28(17):1557-1583.

81. Pot M. Improving HPV vaccination Acceptability by a web-based tailored intervetion [dissertation]. Amsterdam: Work and Social Psychology, Maastricht University; 2018.

82. O'Connor A. user Manual - Decisional Conflict Scale. 1993 [updated 2010].

83. Bedford $H$, Attwell K, Danchin $M$, et al. Vaccine hesitancy, refusal and access barriers: The need for clarity in terminology. Vaccine. 2018;36(44):6556-6558.

84. MacDonald N, Dube E, Butler R. Vaccine hesitancy terminology: A response to Bedford et al. Vaccine. 2019;37(30):3947-3948.

85. MacDonald NE, Hesitancy SWGoV. Vaccine hesitancy: Definition, scope and determinants. Vaccine. 2015;33(34):4161-4164. 
86. BinDhim NF, McGeechan K, Trevena L. Smartphone Smoking Cessation Application (SSC App) trial: a multicountry double-blind automated randomised controlled trial of a smoking cessation decision-aid 'app'. BMJ Open. 2018;8(1):e017105.

87. Petty RR, Barden J, Wheeler SC. The Elaboration Likelihood Model of Pursuasion: Developing health promotions for sustained behavioral change. In: Diclimente RJ, Crosby RA, Kegler M, eds. Emerging theories in health promotion practice and research. $2^{\text {nd }}$ ed. San Francisco: Jossey-Bass; 2009:185-214.

88. Grana R, Benowitz N, Glantz SA. E-cigarettes: a scientific review. Circulation. 2014;129(19):1972-1986.

89. Visser W, Geraets L, Klerx W, et al. The health risks of using e-cigarettes. Bilthoven, the Netherlands: National Institute for Public Health and the Environment (RIVM);2015.

90. Pepper JK, Brewer NT. Electronic nicotine delivery system (electronic cigarette) awareness, use, reactions and beliefs: a systematic review. Tob Control. 2014;23(5):375-384.

91. Padon AA, Maloney EK, Cappella JN. Youth-Targeted E-cigarette Marketing in the US. Tob Regul Sci. 2017;3(1):95-101. doi:10.18001/TRS.3.1.9.

92. Laverty AA, Vardavas $\mathrm{Cl}$, Filippidis FT. Design and marketing features influencing choice ofe-cigarettesand tobaccointheEU. EurJPublicHealth.2016;26(5):838-841.

93. Feirman SP, Lock D, Cohen JE, Holtgrave DR, Li T. Flavored Tobacco Products in the United States: A Systematic Review Assessing Use and Attitudes. Nicotine Tob Res. 2016;18(5):739-749.

94. Xu Y, Guo Y, Liu K, Liu Z, Wang X. E-Cigarette Awareness, Use, and Harm Perception among Adults: A Meta-Analysis of Observational Studies. PLoS One. 2016;11(11):e0165938.

95. King BA, Alam S, Promoff G, Arrazola R, Dube SR. Awareness and ever-use of electronic cigarettes among U.S. adults, 2010-2011. Nicotine Tob Res. 2013;15(9):1623-1627.

96. Czoli CD, Hammond D, White CM. Electronic cigarettes in Canada: prevalence of use and perceptions among youth and young adults. Can J Public Health. 2014;105(2):e97-e102.

97. Donzelli A. E-cigarettes May Impair Ability to Quit, but Other Explanations Are Possible. Am J Public Health. 2015;105(11):e1. doi:10.2105/AJPH.2015.302813.

98. El Dib R, Suzumura EA, Akl EA, et al. Electronic nicotine delivery systems and/ or electronic non-nicotine delivery systems for tobacco smoking cessation or reduction: a systematic review and meta-analysis. BMJ Open. 2017;7(2):e012680.

99. Etter JF. Electronic cigarette: a longitudinal study of regular vapers. Nicotine Tob Res. 2017. doi:10.1093/ntr/ntx132.

100. Fairchild AL, Bayer R, Colgrove J. The renormalization of smoking? E-cigarettes and the tobacco "endgame". N Engl J Med. 2014;370(4):293-295.

101. Hartmann-Boyce J, McRobbie H, Bullen C, et al. Electronic cigarettes for smoking cessation. Cochrane Database Syst Rev. 2016;9:CD010216.

102. Hastings $G$, de Andrade M, Moodie C. Tobacco harm reduction: the devil is in the deployment. BMJ. 2012;345(7889):e8412. 
103. Kings College London. All evidence shows that e-cigarettes have potential to reduce the harms caused by smoking. 2015. http://www.kcl.ac.uk/ioppn/news/ records/2015/August/ecigarettes.aspx. Accessed March 30, 2017, 2017.

104. Miech R, Patrick ME, O'Malley PM, Johnston LD. E-cigarette use as a predictor of cigarette smoking: results from a 1-year follow-up of a national sample of 12th grade students. Tob Control. 2017. doi:10.1136/tobaccocontrol-2016-053291.

105. Soneji S, Barrington-Trimis JL, Wills TA, et al. Association Between Initial Use of e-Cigarettes and Subsequent Cigarette Smoking Among Adolescents and Young Adults: A Systematic Review and Meta-analysis. JAMA Pediatr. 2017;171(8):788-797.

106. Watkins SL, Glantz SA, Chaffee BW. Association of Noncigarette Tobacco Product Use With Future Cigarette Smoking Among Youth in the Population Assessment of Tobacco and Health (PATH) Study, 2013-2015. JAMA Pediatr. 2018;172(2):181-187.

107. Morean ME, Butler ER, Bold KW, et al. Preferring more e-cigarette flavors is associated with e-cigarette use frequency among adolescents but not adults. PLoS One. 2018;13(1):e0189015.

108. Cullen KA, Gentzke AS, Sawdey MD, et al. e-Cigarette Use Among Youth in the United States, 2019. JAMA. 2019.

109. Centraal Bureau voor Statistiek (CBS). Gezondheid belangrijkste reden om te stoppen met roken. 2017. https://www.cbs.nl/nl-nl/nieuws/2017/44/ gezondheid-belangrijkste-reden-om-te-stoppen-met-roken.

110. Springvloet L, Bommele J, Willemsen M, van Laar M. KERNCIJFERS ROKEN 2017. Utrecht Trimbos-instituut;2018.

111. Borland R, Murray K, Gravely S, et al. A new classification system for describing concurrent use of nicotine vaping products alongside cigarettes (so-called 'dual use'): findings from the ITC-4 Country Smoking and Vaping wave 1 Survey. Addiction. 2019;114 Suppl 1:24-34.

112. National Institute for Public Health and the Environment (RIVM). Tobacco and Drugs. 2019. https://www.rivm.nl/rivm/kennis-en-kunde/expertisevelden/tabaken-drugs. Accessed October 28, 2019.

113. World Health Organization. Tobacco. Factsheet 2017. http://www.who.int/ mediacentre/factsheets/fs339/en/. Accessed November 30, 2018, 2018.

114. Goniewicz ML, Gawron M, Smith DM, et al. Exposure to Nicotine and Selected Toxicants in Cigarette Smokers Who Switched to Electronic Cigarettes: A Longitudinal Within-Subjects Observational Study. Nicotine Tob Res. 2017;19(2):160-167.

115. Levy DT, Borland R, Lindblom EN, et al. Potential deaths averted in USA by replacing cigarettes with e-cigarettes. Tob Control. 2018;27(1):18-25.

116. Levy DT, Borland R, Villanti AC, et al. The Application of a Decision-Theoretic Model to Estimate the Public Health Impact of Vaporized Nicotine Product Initiation in the United States. Nicotine Tob Res. 2017;19(2):149-159. 
117. Berg CJ, Barr DB, Stratton E, Escoffery C, Kegler M. Attitudes toward E-Cigarettes, Reasons for Initiating E-Cigarette Use, and Changes in Smoking Behavior after Initiation: A Pilot Longitudinal Study of Regular Cigarette Smokers. Open Journal of Preventive Medicine. 2014;04(10):789-800.

118. Pokhrel P, Herzog TA, Muranaka N, Fagan P. Young adult e-cigarette users' reasons for liking and not liking e-cigarettes: A qualitative study. Psychol Health. 2015;30(12):1450-1469.

119. Rutten LJ, Blake KD, Agunwamba AA, et al. Use of E-Cigarettes Among Current Smokers: Associations Among Reasons for Use, Quit Intentions, and Current Tobacco Use. Nicotine Tob Res. 2015;17(10):1228-1234.

120. Suris JC, Berchtold A, Akre C. Reasons to use e-cigarettes and associations with other substances among adolescents in Switzerland. Drug Alcohol Depend. 2015;153:140-144.

121. Berg CJ. Preferred flavors and reasons for e-cigarette use and discontinued use among never, current, and former smokers. Int J Public Health. 2016;61(2):225-236.

122. Bold KW, Kong G, Cavallo DA, Camenga DR, Krishnan-Sarin S. Reasons for Trying E-cigarettes and Risk of Continued Use. Pediatrics. 2016;138(3).

123. Mendelsohn CP. How are tobacco smokers using e-cigarettes? Patterns of use, reasons for use and places of purchase in New South Wales. Med J Aust. 2016;205(7):335-336.

124. Patel D, Davis KC, Cox S, et al. Reasons for current E-cigarette use among U.S. adults. Prev Med. 2016;93:14-20.

125. Wackowski OA, Bover Manderski MT, Delnevo CD, Giovenco DP, Lewis MJ. Smokers' Early E-cigarette Experiences, Reasons for Use, and Use Intentions. Tob Regul Sci. 2016;2(2):133-145.

126. Bold KW KG, Cavallo DA, Camenga DR, Krishnan-Sarin S. . Bold KW, Kong G, CavalloDA, CamengaDR, Krishnan-SarinS. ReasonsforTrying E-cigarettesand Risk of Continued Use. Pediatrics. 2016;138(3):e20160895. Pediatrics. 2018;142(6).

127. Nicksic NE, Snell LM, Barnes AJ. Reasons to use e-cigarettes among adults and youth in the Population Assessment of Tobacco and Health (PATH) study. Addict Behav. 2019;93:93-99.

128. Schoren C, Hummel K, Vries H. Electronic cigarette use: comparing smokers, vapers, and dual users on characteristics and motivational factors. Tobacco Prevention \& Cessation. 2017;3(April). doi:10.18332/tpc/69392.

129. Ruther T, Wissen F, Linhardt A, et al. Electronic Cigarettes-Attitudes and Use in Germany. Nicotine Tob Res. 2016;18(5):660-669.

130. Berry KM, Reynolds LM, Collins JM, et al. E-cigarette initiation and associated changes in smoking cessation and reduction: the Population Assessment of Tobacco and Health Study, 2013-2015. Tob Control. 2019;28(1):42-49.

131. Nagelhout GE, Wiebing MA, van den Putte B, et al. 'I bet I can do it!' - Reach and effectiveness of a television show about smoking cessation among low, moderate, and high educated smokers. TSG. 2014;92(2):84-92.

132. E.A. van Lier, P.J. Oomen, H. Giesbers, et al. Vaccine Coverage of NIP in the Netherlands. Bilthoven: National Instituut of Public Health and the Environment;2016. 
133. Brewer NT, Chapman GB, Gibbons FX, et al. Meta-analysis of the relationship between risk perception and health behavior: the example of vaccination. Health Psychol. 2007;26(2):136-145.

134. World Health Organization. Immunization Coverage. Immunization, Vaccines and Biologicals 2018. http://www.who.int/en/news-room/fact-sheets/detail/ immunization-coverage. Accessed June, 26, 2018.

135. E.A. van Lier, P.J. Oomen, H. Giesbers, et al. Vaccine Coverage of NIP in the Netherlands 2018. Bilthoven: National Institute for Public Health and the Environment;2019.

136. Harmsen IA, Mollema L, Ruiter RA, et al. Why parents refuse childhood vaccination: a qualitative study using online focus groups. BMC Public Health. 2013;13(1):1183.

137. Jackson ML. Challenges in comparing the safety of different vaccination schedules. Vaccine. 2013;31(17):2126-2129.

138. Saada A, Lieu TA, Morain SR, Zikmund-Fisher BJ, Wittenberg E. Parents' choices and rationales for alternative vaccination schedules: a qualitative study. Clin Pediatr (Phila). 2015;54(3):236-243.

139. Nadeau JA, Bednarczyk RA, Masawi MR, et al. Vaccinating my way--use of alternativevaccination schedulesin NewYorkState. J Pediatr.2015;166(1):151-156.

140. Feemster KA, Offit P. Delaying vaccination is not a safer choice. JAMA Pediatr. 2013;167(12):1097-1098.

141. Glanz JM, Newcomer SR, Narwaney KJ, et al. A population-based cohort study of undervaccination in 8 managed care organizations across the United States. JAMA Pediatr. 2013;167(3):274-281.

142. Harmsen IA, Ruiter R, Paulussen T, et al. Development of a monitoring system to evaluate the acceptance of childhood vaccination. Bilthoven: RIVM; 2014.

143. Paulussen TG, Hoekstra F, Lanting Cl, Buijs GB, Hirasing RA. Determinants of Dutch parents' decisions to vaccinate their child. Vaccine. 2006;24(5):644-651.

144. Aggarwal A. Childhood Vaccine Refusal and Hesitancy -Reasons. Indian J Pediatr. 2019;86(1):5-6.

145. Facciola A, Visalli G, Orlando A, et al. Vaccine hesitancy: An overview on parents' opinions about vaccination and possible reasons of vaccine refusal. J Public Health Res. 2019;8(1):1436.

146. Paterson P, Chantler T, Larson HJ. Reasons for non-vaccination: Parental vaccine hesitancy and the childhood influenza vaccination school pilot programme in England. Vaccine. 2018;36(36):5397-5401.

147. Swaney SE, Burns S. Exploring reasons for vaccine-hesitancy among higher-SES parents in Perth, Western Australia. Health Promot J Austr. 2019;30(2):143-152.

148. Ruijs WL, Hautvast JL, van IJzendoorn G, et al. How orthodox protestant parents decide on the vaccination of their children: a qualitative study. BMC Public Health. 2012;12(1):408.

149. Benin AL, Wisler-Scher DJ, Colson E, Shapiro ED, Holmboe ES. Qualitative analysis of mothers' decision-making about vaccines for infants: the importance of trust. Pediatrics. 2006;117(5):1532-1541.

150. Serpell L, Green J. Parental decision-making in childhood vaccination. Vaccine. 2006;24(19):4041-4046. 
151. Tickner S, Leman PJ, Woodcock A. 'It's just the normal thing to do': exploring parental decision-making about the 'five-in-one' vaccine. Vaccine. 2007;25(42):7399-7409.

152. Brunson EK. How parents make decisions about their children's vaccinations. Vaccine. 2013;31(46):5466-5470. 

PART 1 



\section{CHAPTER 2}

\section{Perceptions and Reasons Regarding E-Cigarette Use among Users and Never-users: A Narrative Literature Review}

Romijnders K van Osch $L$ de Vries $\mathrm{H}$ Talhout R

Perceptions and Reasons Regarding E-Cigarette Use among Users and Non-Users: A Narrative Literature Review.

Int J Environ Res Public Health. 2018;15(6). 


\section{Abstract}

This paper aims to provide an in-depth understanding of the attractiveness of e-cigarettes for several different groups. For this purpose, perceptions of and reasons for e-cigarette use were systematically reviewed as reported by e-cigarette users, cigarette smokers, dual users, and never-users, among both adults and youth. MEDLINE® (Please define if appropriate) and Scopus were used to search for relevant articles, and references of included studies were also investigated. Two reviewers screened all titles and abstracts independently, blinded to authors and journal titles (Cohen's Kappa $=0.83$ ), resulting in 72 eligible articles. Risk perceptions, perceived benefits, and reasons for e-cigarette use were categorized in themes and sub-themes. Risk perceptions included harmfulness in general, and specific health risks. Perceived benefits included improved taste and smell, and safety for bystanders. Reasons for use included (health) benefits, curiosity, smoking cessation, and friends using e-cigarettes. The findings highlight that there is a variety of perceptions and reasons mentioned by adult and youth e-cigarette users, cigarette smokers, dual users, and neverusers. As such, this overview provides valuable information for scientists, public health professionals, behavior change experts, and regulators to improve future research, risk communication, and possibilities to effectively regulate e-cigarettes. 


\section{Introduction}

Electronic Nicotine Delivery Systems (ENDS) are devices that vaporize a solution of nicotine, additives, glycerin, and propylene glycol that is inhaled by the user. ${ }^{1-4}$ Electronic cigarettes are the most common type of ENDS. The variety of electronic cigarette (e-cigarette) devices available on the market is rapidly increasing. While early models mimic conventional cigarettes (in shape and size), newer models vary in product specifications (shape, size, battery, and tanks). ${ }^{2-6}$ In addition to product specifications, design and flavor characteristics are increasingly elaborate and appealing. ${ }^{7-9}$ Research in recent years has demonstrated that the appeal of e-cigarettes has increased rapidly. ${ }^{2-6,10}$ The prevalence of e-cigarette use is increasing, mostly among cigarette smokers, but recent research suggests that e-cigarette use is also increasing among nonsmokers, and may even be a gateway to smoking. ${ }^{2,3,9,11-22}$ Glasser et al. ${ }^{3}$ noted that, regardless of smoking status, e-cigarettes are perceived as less harmful and addictive, and effective as a smoking cessation aid. Nevertheless, risk perceptions and perceived benefits for e-cigarette use might be different for e-cigarette users than never-users. Moreover, ${ }^{6}$ and Glasser et al. ${ }^{3}$ indicated that reasons for e-cigarette use go beyond smoking cessation ${ }^{23}$ among e-cigarette users. However, as the appeal of e-cigarettes is increasing among never-users, it is interesting to study the reasons never-users report that could lead them to initiate e-cigarette use, and whether these reasons differ from cigarette smokers switching to e-cigarettes. In order to better understand the process of switching from cigarettes to e-cigarettes or experimenting with e-cigarettes, it is important to have an insight into perceptions of e-cigarettes and reasons for use among different types of users. 6,11,19-26 This paper therefore provides an overview of such perceptions and reasons among adult and youth e-cigarette users, cigarette smokers, dual users, and never-users.

The current overview provides scientists, public health professionals, behavior change experts, and regulators with key constructs for the development and validation of measures to assess perceptions of e-cigarettes and reasons for e-cigarette use. Public health professionals are able to use the overview on perceptions and reasons when developing health education and behavior change programs. On a population level, policy makers are able to use this inclusive overview to intensify smoking bans to avoid dual use and to target product characteristics of e-cigarettes attractive for specific user groups.

\section{Methods Search}

The search strategy developed for the purpose of this narrative review aimed to retrieve articles focusing on perceptions and reasons related to e-cigarette use without any restrictions on location. Databases searched (and interfaces) 
were MEDLINE (Ovid) and Scopus (without date restrictions) till February 2018. Concepts included in the search were "electronic cigarette", "perception", "reason", "opinion", and "smoking cessation" (see Appendix 1 for the full search strategy). The references of all included articles in our review were examined for additional references. To check the completeness of our search strategy, the final list of records was checked for inclusion of prior identified relevant research.

\section{Study Selection}

Following the Preferred Reporting Items for Systematic Reviews and Metaanalyses (PRISMA) guidelines (see Figure 2.1. The PRISMA flow diagram), retrieved citations were screened, duplicates were eliminated, and the remaining citations were organized in EndNote. ${ }^{27}$ Authors Kim A.G.J. Romijnders and Reinskje Talhout reviewed all titles using a previously agreed-upon exclusion criteria list (see Appendix 2). First, they independently screened a random sample of 86 titles and abstracts in which they were blinded to authors and journal titles, and reached strong agreement (Cohen's Kappa $=0.83$ ) ${ }^{28}$. Second, two authors (Kim A.G.J. Romijnders, Reinskje Talhout) independently screened all titles and abstracts, still blinded to authors and journal titles, using an Excel workbook designed specifically for screening..$^{29}$ Exclusion criteria were hierarchical in order, meaning that if the first exclusion criterion applies, the other exclusion criteria were not checked. Exclusion criteria were the following: (1) The article was not about e-cigarettes; (2) The article discussed toxicology and vaping behavior; (3) The article was an opinion piece; (4) The article discussed the market or marketing of e-cigarettes; (5) The article was about harm reduction; (6) The topic of the article was regulation; (7) The article did not include subjective reports; (8) The article described the gateway effect; or (9) It was not an article. ${ }^{27}$ The full exclusion decision tree can be found in Appendix 2. Full-text articles were reviewed to determine final eligibility with the same exclusion decision tree (Appendix 2), ${ }^{30}$ but two additional exclusion criteria applied: (10) Conflict of interest, and (11) Age restrictions. To make a distinction between adults $(>18)$ and youth $(<18)$, studies needed to apply clearly defined age restrictions (adults $>18$ and youth $<18$ ). An article was considered for inclusion if it was a quantitative or qualitative study focusing on subjective reports of participants, reporting on perceptions and/or reasons for e-cigarette use. The Excel workbooks are available upon request from the first author. 


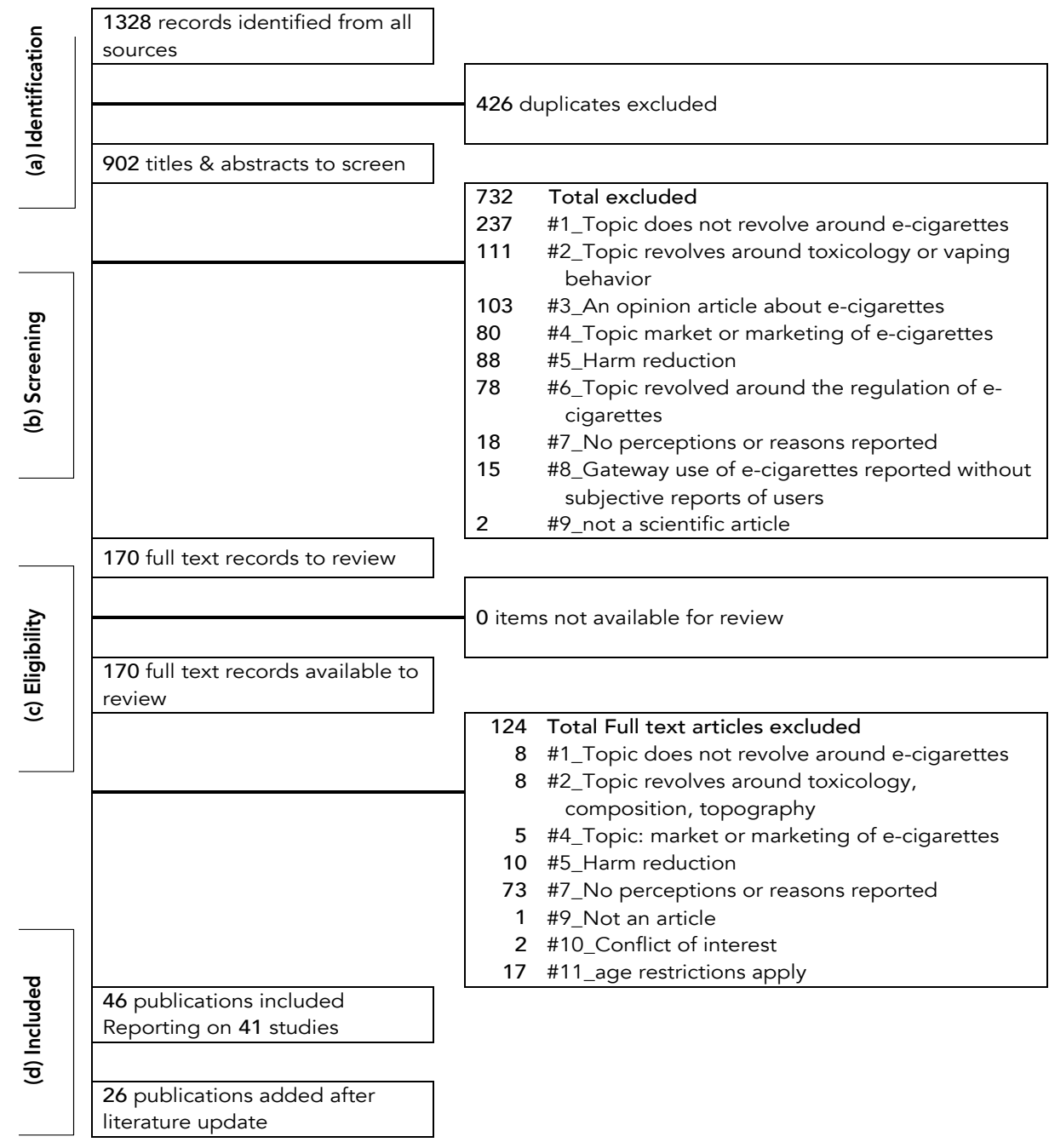

Figure 2.1 The Preferred Reporting Items for Systematic Reviews and Meta-analyses (PRISMA) guidelines. (a) Identification contains all records identified during the search. (b) Screening lists all reasons why articles were excluded based on title and abstract. (c) Eligibility records all the records available for full-text review. (d) Included reports all exclusion criteria used during full-text review.

\section{Data Extraction}

Kim A.G.J. Romijnders extracted all relevant findings from the included studies (see Appendix 3). Due to the variety in research designs, it was not possible to generate a single quality score according to STROBE. ${ }^{31}$ A single quality score, 
generated by the STROBE checklist, would limit the scope of this narrative review for generating an extensive list of perceptions and reasons regarding e-cigarettes. The results were not limited to cross-sectional surveys with probability samples, or close-ended response options, but also include qualitative work. A deductive thematic analysis was performed to identify themes that appeared salient to the constructs: perceptions regarding e-cigarettes and reasons for e-cigarette use. The main constructs "Perceptions" and "Reasons" were used to categorize the major relevant findings in Appendix 3. The themes (for example, for reasons for e-cigarette use: "expected benefits" and "social environment") were used to extract major relevant findings (Appendix 3). Kim A.G.J. Romijnders and Reinskje Talhout formulated sub-themes after extracting relevant findings for perceptions about e-cigarettes and reasons for e-cigarette use. The sub-themes were salient to the themes, for example, for the theme "perceived safety of use", the sub-theme "perceived safety of ingredients" emerged as pertinent from the major relevant findings. Kim A.G.J. Romijnders coded the major relevant findings found in Appendix 3 according to the themes and sub-themes (e.g., for theme "expected benefits" the sub-themes "weight control" and "helps with concentration" were applied). Kim A.G.J. Romijnders and Reinskje Talhout agreed upon the themes and sub-themes before the coding of the major relevant findings took place. The coding led to an overview of perceptions of risks of e-cigarettes, perceived benefits of e-cigarettes, and reasons for e-cigarette use. To ensure the reliability of the meaning of themes and sub-themes during coding of articles, triangulation was used.

After coding, results were stratified by type of user and age. Adults were categorized as eighteen years or older, and youth were categorized as younger than eighteen years old. For each type of user, there was variability in reporting. For example, some studies report current use of e-cigarettes among current cigarette smokers without categorizing them as dual users, whereas other studies reported the current use of e-cigarettes with simultaneous current tobacco cigarette use as dual use ${ }^{32,33}$ Therefore, measures for type of user were recorded for each included study as defined by the respective authors (Appendix 3). This review categorized perceptions and reasons regarding e-cigarettes using the classification of users as stated in the original study. E-cigarette users are users of e-cigarettes without differentiating for frequency of use, co-current use or past use of cigarettes. Similarly, no distinction was made among cigarette smokers concerning frequency, lifetime use, co-current or past use of other tobacco products or e-cigarettes. If an included study mentioned perceptions or reasons regarding e-cigarettes among dual users, this review categorized these perceptions and reasons among dual users. Similarly, never-users were classified as not using e-cigarettes or cigarettes. No distinction was made between former users or users that had never smoked. Summarizing, type of users were categorized according to their original type of user classification without an attempt to synthesize type of user across studies. 


\section{Results}

A total of 65 studies from 72 articles met the eligibility criteria (see Figure 2.1). ${ }^{25,32-}$ 102 Articles report perceptions and reasons regarding e-cigarettes in 49 studies among e-cigarette users, 39 studies among cigarette smokers, 11 studies among dual users, and 19 studies among never-users, which are listed in an overview. The sample size ranged from 14 to 25,029 respondents. Most studies were conducted in the U.S. $(n=49)$, but studies were also conducted in the UK ( $n$ $=11)$, New Zealand $(n=6)$, Canada $(n=4)$, France $(n=2)$, Switzerland $(n=3)$, Australia $(n=2)$, and Belgium $(n=1)$ (see Appendix 3 for a full overview). Fiftyfive articles reported data on adults, and seventeen on youth. Thirty-four studies had a cross-sectional design, seventeen had a qualitative design, three had a mixed methods approach, six were longitudinal, and twelve were cohort studies (see Appendix 3). Due to a variety of research designs, sample size, and changes over time, this paper is not a synthesis of most cited, most important, or most expressed perceptions and reasons by participants. ${ }^{23}$ This section provides an overview of risk perceptions, perceived benefits, and reasons for e-cigarette use.

\section{Risk Perceptions Related to E-Cigarettes}

Perceived risks pertained to risks for individual e-cigarette users (e.g., unsafe components of e-liquids), and risks for the social environment of these users (e.g., risks for bystanders and the risk for an unborn child if used during

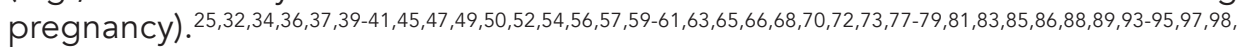
101,102 Table 2.1 summarizes the different risk perception themes and sub-themes identified. This section reports perceptions mentioned by user groups. First, studies suggest that, compared to cigarettes, e-cigarettes were perceived by all user groups as being healthier, safer, and less addictive, as well as being safer for one's social environment, and safer to use during pregnancy than cigarettes. ${ }^{32,37,39-41,43,44,47-49,57,59,61,63,65,68,73,76,81,85,88,89,94,95,102}$ Second, studies performed in earlier years showed that e-cigarettes were perceived as being overall less harmful than cigarettes, while in later years this reduced harm perception changed. $25,32,34,36,37,39-41,45,47,49,50,52,54,56,57,59-61,63,65,66,68,70,72,73,77-79,81,83,85,86,88,89,93-95,97,98,101,102$ In more recent studies e-cigarettes were perceived as equally or more harmful than cigarettes among adult cigarette smokers, ${ }^{25,36,37,47,52,59,66}$ never-users, ${ }^{54,60,72,73,85,93,94}$ as well as youth cigarette smokers, ${ }^{25,36,37,52,56,59,66}$ and never-users. ${ }^{25,47,52}$ Third, specific flavors (candy and fruit flavors) were considered less harmful than other (tobacco) flavors among adult ${ }^{49}$ and youth ${ }^{56}$ e-cigarette users, adult ${ }^{78}$ and youth ${ }^{25,56}$ cigarette smokers, and never-users ${ }^{56}$. Summarizing, different themes and subthemes with regard to perceived risks for the individual e-cigarette user and risks for their social environment were specified. Flavors influence the risk perception of e-cigarettes among both adults and youth, and current data show that the risk perception of e-cigarettes increased compared to previous years. 
Table 2.1 Risk perceptions about e-cigarettes reported by individual studies, clustered by type of user.

\begin{tabular}{|c|c|c|c|c|c|c|c|c|}
\hline \multirow{2}{*}{$\begin{array}{l}\text { Themes and Sub- } \\
\text { themes of Risk } \\
\text { Perceptions }\end{array}$} & \multicolumn{2}{|c|}{ Never-users ${ }^{d}$} & \multicolumn{2}{|c|}{ Smokers ${ }^{b}$} & \multicolumn{2}{|c|}{ Dual Users ${ }^{\mathrm{c}}$} & \multicolumn{2}{|c|}{$\begin{array}{l}\text { E-Cigarette } \\
\text { Users a }\end{array}$} \\
\hline & Adults & Youth & Adults & Youth & Adults & Youth & Adults & Youth \\
\hline \multicolumn{9}{|c|}{ Risk Perceptions for the User } \\
\hline Harmfulness & $\begin{array}{l}54,60,72 \\
73,85\end{array}$ & $25,47,52$ & $\begin{array}{l}34,39,41,45 \\
, 50,54,59,6 \\
0,70,72,77 \\
83,85,88,93 \\
, 97,98,101\end{array}$ & $\begin{array}{l}25,36,37 \\
52,56,59, \\
66\end{array}$ & 32 & & $\begin{array}{l}40,49,54 \\
57,59,73 \\
79,85,86 \\
94\end{array}$ & $\begin{array}{l}25,36,37, \\
47,52,59, \\
66\end{array}$ \\
\hline $\begin{array}{l}\text { Harmfulness of } \\
\text { flavors }\end{array}$ & & 56 & 78 & 25,56 & & & 49 & 56 \\
\hline \multicolumn{9}{|c|}{$\begin{array}{l}\text { Secondary harm as } 94 \\
\text { a gateway drug }\end{array}$} \\
\hline Health risks & & & 65 & & & & 49,65 & 37,47 \\
\hline $\begin{array}{l}\text { Reduced athletic } \\
\text { performance }\end{array}$ & & & & & & & 49 & \\
\hline $\begin{array}{l}\text { Trouble breathing/ } \\
\text { Coughing }\end{array}$ & & & & & & & 49 & 47 \\
\hline Cancer & & & & & & & 49 & 47 \\
\hline Hearth attack & & & & & & & 49 & \\
\hline $\begin{array}{l}\text { Dental health } \\
\text { issues }\end{array}$ & & & & & & & 49 & \\
\hline Safety of use & & & $\begin{array}{l}63,68,88, \\
89\end{array}$ & 37,59 & 63 & & $\begin{array}{l}37,40,57 \\
59,102\end{array}$ & 37,59 \\
\hline $\begin{array}{l}\text { Lack of safety of } \\
\text { ingredients liquids }\end{array}$ & & & & 59 & & & & 59 \\
\hline \multicolumn{9}{|c|}{ Risk Perception for the Social Environment of a user } \\
\hline $\begin{array}{l}\text { Harmful for } \\
\text { bystanders }\end{array}$ & 85 & & & & & & $\begin{array}{l}40,57,81 \\
85\end{array}$ & \\
\hline $\begin{array}{l}\text { Safety of use } \\
\text { during pregnancy }\end{array}$ & 61,73 & & & & & & & \\
\hline
\end{tabular}

Note: " "E-cigarette users" are users of e-cigarettes as defined in the original study. For example, Bold, Kong, Cavallo, Camenga, Krishnan-Sarin ${ }^{44}$ included only ever users of e-cigarettes in their study, without differentiating for frequency of use, co-current use or past use of cigarettes. " "Smokers" are those who smoke cigarettes as defined in the original studies. For example, Biener, Song, Sutfin, Spangler, Wolfson ${ }^{43}$ defined cigarette smokers as those who had smoked at least 100 cigarettes in their lifetime and smoked every day or some days. No distinction is made among cigarette smokers concerning frequency, lifetime use, co-current or past use of other tobacco products or e-cigarettes. c "Dual users" are those who use e-cigarettes and cigarettes simultaneously as defined in the original studies. For example, Cheney, Gowin, Wann ${ }^{48}$ defined dual users as 
current use of both e-cigarettes and cigarettes within the past week. If an included study mentioned perceptions or reasons regarding e-cigarettes among dual users, this review categorized these perceptions and reasons among dual users. " "Never-users" are those who did not use e-cigarettes or cigarettes at the time of included study as defined in the original study. For example, Patel, Davis, Cox, et al. ${ }^{76}$ defined never-users as those who report "not at all" to the question whether they had smoked cigarettes or used e-cigarettes. Never-users were classified as not using e-cigarettes or cigarettes, and no difference was made between former users and never users.

\section{Perceived Benefits of E-Cigarettes}

Perceived benefits of e-cigarettes mentioned in the literature are summarized in Table 2.2 and include (expected and actual) positive experiences (such as taste), social acceptance, avoidance of smoking restrictions, a cool and fashionable product, an effective smoking aid, and the safety for bystanders. In this section, perceived benefits of e-cigarettes for the user groups are shown. First, adult e-cigarette users $40,49,57,58,73,81,88,90,102$ and adult cigarette smokers $37,39,42,50,63,68,70,78$ $, 88,89,99$ noted health benefits and positive experiences of e-cigarette use. Dual users and never-users did not identify health benefits or positive experiences, although they did note some benefits for reducing cravings and safety for the e-cigarette user compared to cigarette smokers. Second, adult e-cigarette users, ${ }^{40,41,49,57,81,85}$ dual users ${ }^{81}$, and never-users $58,85,94,95$ also saw benefits for bystanders of e-cigarette users. Third, youth noted only a few perceived benefits of e-cigarette use for individual use. They perceived e-cigarettes as safe to use for e-cigarette users and fashionable (youth e-cigarette users, 37,47,59 youth cigarette smokers, ${ }^{37,59}$ and youth never-users $\left.{ }^{47,55}\right)$. Summarizing, individual user benefits revolved around convenience and attractiveness of the product, health benefits, positive experiences, safety, smoking cessation benefits, and social acceptability. Perceived benefits for the social environment of the user were mentioned by adult user groups (safety for bystanders and the environment). 
Table 2.2 Perceived benefits of e-cigarettes reported by individual studies, categorized by type of user.

\begin{tabular}{|c|c|c|c|c|c|c|c|}
\hline \multicolumn{8}{|c|}{ Perceived Benefits for Users } \\
\hline \multirow{2}{*}{$\begin{array}{l}\text { Themes and Sub- } \\
\text { themes of Perceived } \\
\text { Benefits }\end{array}$} & \multicolumn{2}{|c|}{ Never-users ${ }^{d}$} & \multicolumn{2}{|c|}{ Smokers ${ }^{b}$} & Dual users $^{c}$ & \multicolumn{2}{|c|}{$\begin{array}{l}\text { E-Cigarette } \\
\text { Users }{ }^{a}\end{array}$} \\
\hline & Adults & Youth & Adults & Youth & Adults Youth & Adults & Youth \\
\hline \multirow[t]{2}{*}{ Addictiveness } & \multicolumn{2}{|c|}{$\begin{array}{l}\text { Perceived as } \\
\text { equally } \\
\text { addictive }\end{array}$} & \multicolumn{2}{|c|}{$\begin{array}{l}\text { Perceived as } \\
\text { equally } \\
\text { addictive }\end{array}$} & $\begin{array}{l}\text { Perceived as } \\
\text { less addictive }\end{array}$ & \multicolumn{2}{|c|}{$\begin{array}{l}\text { Perceived as } \\
\text { less addictive }\end{array}$} \\
\hline & 73,94 & 47 & 39,41 & 59 & 32,81 & $73,81,94$ & 47,59 \\
\hline $\begin{array}{l}\text { Avoidance of smoking } \\
\text { restrictions }\end{array}$ & 73 & & $\begin{array}{l}50,63,68 \\
88,89\end{array}$ & 37 & 63 & 49 & 37 \\
\hline $\begin{array}{l}\text { A cool and fashionable } \\
\text { product }\end{array}$ & 73 & 47,55 & & 37 & & 73 & 37,47 \\
\hline Health benefits & & & & & & 90 & \\
\hline Healthier than cigarettes & & & 42 & 37 & & & 37 \\
\hline Improved breathing & & & 63 & & 63 & & \\
\hline $\begin{array}{l}\text { Improved general well- } \\
\text { being }\end{array}$ & & & 63,78 & & 63 & & \\
\hline Decreased coughing & & & 63 & & 63 & & \\
\hline $\begin{array}{l}\text { Less likely to cause } \\
\text { cancer }\end{array}$ & & & 78 & & & & \\
\hline $\begin{array}{l}\text { Lower costs compared } \\
\text { to cigarettes }\end{array}$ & & & 50 & & & & \\
\hline \multicolumn{8}{|l|}{ Positive experiences } \\
\hline Mimics smoking routine & & 55 & 37 & 37 & & & 37 \\
\hline Enjoyable taste & 73 & & & & 81 & 81 & \\
\hline Throat hit & & & & & 81 & 81 & \\
\hline Weight control & & & & & 81 & 81 & \\
\hline Increases concentration & & & & & & & 47 \\
\hline Safety of use & & & $\begin{array}{l}63,68,88 \\
89\end{array}$ & 37,59 & 63 & $40,57,102$ & 37,59 \\
\hline $\begin{array}{l}\text { Safety of ingredients } \\
\text { liquids }\end{array}$ & & 47,55 & & 59 & & 73 & 59 \\
\hline \multicolumn{8}{|l|}{$\begin{array}{l}\text { Smoking cessation } \\
\text { purposes }\end{array}$} \\
\hline $\begin{array}{l}\text { Nicotine replacement } \\
\text { therapy }\end{array}$ & $\begin{array}{l}58,61,73 \\
88,94 \\
\end{array}$ & & $\begin{array}{l}39,50,70 \\
99\end{array}$ & & 32,89 & $49,58,73,88$ & \\
\hline
\end{tabular}

Perceived Benefits for Users 


\begin{tabular}{|c|c|c|c|c|c|c|c|c|}
\hline \multirow{2}{*}{$\begin{array}{l}\text { Themes and Sub- } \\
\text { themes of Perceived } \\
\text { Benefits }\end{array}$} & \multicolumn{2}{|c|}{ Never-users $^{d}$} & \multicolumn{2}{|c|}{ Smokers ${ }^{b}$} & \multicolumn{2}{|c|}{ Dual users ${ }^{c}$} & \multicolumn{2}{|c|}{$\begin{array}{l}\text { E-Cigarette } \\
\text { Users }^{a}\end{array}$} \\
\hline & Adults & Youth & Adults & Youth & Adults & Youth & Adults & Youth \\
\hline Cut back on cigarettes & & & 50 & & & & & \\
\hline Deal with cravings & 58 & & & & 89 & & & \\
\hline Social acceptability & $58,94,95$ & & & & 81 & & $41,49,81$ & \\
\hline \multicolumn{9}{|c|}{ Perceived Benefits for the Social Environment of a User } \\
\hline Safer for bystanders & 85 & & & & 81 & & $40,57,81,85$ & \\
\hline $\begin{array}{l}\text { Safer for the environ- } \\
\text { ment (less pollution) }\end{array}$ & & & & & & & 57 & \\
\hline
\end{tabular}

Note: a "E-cigarette users" are users of e-cigarettes as defined in the original study. For example, Bold, Kong, Cavallo, Camenga, Krishnan-Sarin ${ }^{44}$ included only ever users of e-cigarettes in their study, without differentiating for frequency of use, co-current use or past use of cigarettes. $b$ "Smokers" are those who smoke cigarettes as defined in the original studies. For example, Biener, Song, Sutfin, Spangler, Wolfson ${ }^{43}$ defined cigarette smokers as those who had at least smoked 100 cigarettes in their lifetime and smoked every day or some days. No distinction is made among cigarette smokers concerning frequency, lifetime use, co-current or past use of other tobacco products or e-cigarettes. c "Dual users" are those who use e-cigarettes and cigarettes simultaneously as defined in the original studies. For example, Cheney, Gowin, Wann ${ }^{48}$ defined dual users as current users of both e-cigarettes and cigarettes within the past week. If an included study mentioned perceptions or reasons regarding e-cigarettes among dual users, this review categorized these perceptions and reasons among dual users. $d$ "Never-users" are those who did not use e-cigarettes or cigarettes at the time of included study as defined in the original study. For example, Patel, Davis, Cox, et al. ${ }^{76}$ defined never-users as those who report "not at all" to the question of whether they had smoked cigarettes or used e-cigarettes. Never-users were classified as not using e-cigarettes or cigarettes, and no difference was made between former users or never user

\section{Reasons for E-Cigarette Use}

This section reports reasons for use among e-cigarette users, cigarette smokers, dual users, and never-users. Never-users were asked about possible reasons for them to personally initiate e-cigarette use. Reasons for explaining the appeal of e-cigarettes go beyond smoking cessation (Table 2.3 32,33,35,37,39-44,46,48-51,53,54,57,62,64$67,69-71,74-76,79,81-86,90,91,98,102$ ). Other reasons include expected benefits (enjoyable taste and a variety of flavors), experienced benefits (reduces stress and enables control of weight gain), avoidance of smoking restrictions by dual use of tobacco products and e-cigarettes, convenience of the product, curiosity, and influences from the social environment (e.g., recommended by friends). Smoking cessation was the most often reported reason for initiation of e-cigarette use among adult e-cigarette users, ${ }^{33,35,40-42,44,48,49,51,53,54,57,62,64-66,69,75,76,79,81,82,85,86,90,91,102}$ 
cigarette smokers, ${ }^{39,42,43,46,50,69-71,76,83,84,98}$ dual users, ${ }^{32,33,67,81,82}$ and never-users ${ }^{76}$. In addition, other expected benefits were reported by adult $\mathrm{t}^{35,40,41,48,49,53,65,76,79,81,90}$ and youth $44,59,75$ e-cigarette users, adult $46,76,84$ and youth ${ }^{59}$ cigarette smokers, dual users, ${ }^{32,48}$, and adult never-users ${ }^{76}$ (see Table 2.3). In addition to expected benefits, adult $33,35,40,41,48,53,65,74,76,79,81,85,90,91$ and youth $44,59,75$ e-cigarette users and dual users $^{32,33,48,81}$ reported additional experienced benefits such as health benefits and finding a new hobby. In summary, reasons for e-cigarette use go beyond smoking cessation. While smoking cessation is the reason most often reported in large-scale population surveys, most other reported reasons revolved around the health benefits of e-cigarette use compared to smoking.

Table 2.3 Reasons for e-cigarette use as reported by individual studies by type of user.

$\begin{array}{llll}\begin{array}{l}\text { Themes and Sub- } \\ \text { themes of Reasons for } \\ \text { E-cigarette use }\end{array} & \text { Never-users d Smokers b } & \text { Dual Users c } & \begin{array}{l}\text { E-Cigarette } \\ \text { Users a }\end{array} \\ & \text { Adults Youth Adults Youth Adults Youth Adults Youth }\end{array}$

Expected benefits

Enjoyable taste

Expected health benefits

Healthier than cigarettes

Improved breathing

Increased concentration

Satisfy nicotine need

Availability of variety of 76

flavors

Weight control

Experienced benefits

Avoidance of smoking restrictions by dual use of tobacco products and e-cigarettes

Possibility to alter technical specifications

Weight control

Mimics smoking routine

$\begin{array}{lll} & 32 \\ 76,84 & 59 & 48\end{array}$

$42,43,50, \quad 37 \quad 82$

$69,76,83$,

84

48
$40,53,65$,

81

$33,40,41$

49,53,57,

81

91

37,47

32

$32 \quad 38,90$

$35,40,41, \quad 44,59$

$48,49,65$,

76,79

$41,81 \quad 75$

$35,65 \quad 37,92$

100

$40,74,90$

41,81

$33,40,49, \quad 37$

$54,79,91$

$33,40,48, \quad 37,75$

$49,53,81$

table continues 


\section{Themes and Sub- themes of Reasons for E-cigarette use}

Regain a sense of smell and taste

Improved breathing

Decreased coughing

Improved dental health

Increased athletic

performance

Increased alertness

New hobby (more friends)

Aid to concentration

Pleasure of product use

Reduces stress

Taste of flavors
Never-users d Smokers b

\section{Dual Users c E-Cigarette} Users a

Adults Youth Adults Youth Adults Youth Adults Youth

40,53

$33,48 \quad 33,48,91$

$47 \quad 32$

$33 \quad 33,40,53$

85,91

48,81

$35,40,41, \quad 44,59$

$48,65,76$,

79,81

40,81

Throat hit
Convenience of product

Easily accessible

84

81

91

$40,48,71$

91

Lower costs compared

to cigarettes

37

32,33

$33,38,40, \quad 37,75$,

$41,69,74, \quad 100$

$79,85,87$,

96

Discreet in use

(no lingering smell, able to hide use)

Practical in use (no 76 71,76

48,76

$40,48,71$, lighter, no ashtray, one puff, and able to store the device)

\section{Curiosity}

A cool product

$39,71,76$,

98

66

81

1

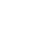

$\begin{array}{ll}35,69,76, & 44,47,66, \\ 79,81,87, & 100 \\ 96,98 & \end{array}$

$35,53,65, \quad 44,62,64$ $69,70,76, \quad 66,92$, $79,81,85 \quad 100$

table continues 


\begin{tabular}{|c|c|c|c|c|c|c|c|c|}
\hline \multirow{2}{*}{$\begin{array}{l}\text { Themes and Sub- } \\
\text { themes of Reasons for } \\
\text { E-cigarette use }\end{array}$} & \multicolumn{2}{|c|}{ Never-users d } & \multicolumn{2}{|c|}{ Smokers b } & \multicolumn{2}{|c|}{ Dual Users c } & \multicolumn{2}{|c|}{$\begin{array}{l}\text { E-Cigarette } \\
\text { Users a }\end{array}$} \\
\hline & Adults & Youth & Adults & Youth & Adults & Youth & Adults & Youth \\
\hline \multicolumn{9}{|l|}{$\begin{array}{l}\text { Smoking cessation } \\
\text { purposes }\end{array}$} \\
\hline $\begin{array}{l}\text { Alternative for smoking } \\
\text { cigarettes }\end{array}$ & & & 69 & & & & $38,57,86$ & \\
\hline $\begin{array}{l}\text { Avoidance of withdrawal } \\
\text { of nicotine }\end{array}$ & & & & & & & 38,53 & \\
\hline Cut back cigarettes & & & 50,83 & & $32,33,81$ & & $\begin{array}{l}33,42,79 \\
81,87,96\end{array}$ & $\begin{array}{l}75,92 \\
100\end{array}$ \\
\hline $\begin{array}{l}\text { Use as smoking } \\
\text { cessation aid }\end{array}$ & 76 & & $\begin{array}{l}39,42,43 \\
46,50,70 \\
76,83,84 \\
98\end{array}$ & 100 & $32,33,67$ & & $\begin{array}{l}33,35,38, \\
40-42,44 \\
51,53,54 \\
62,64-66, \\
69,75,76, \\
79,81,85 \\
87,90,91 \\
102\end{array}$ & $\begin{array}{l}44,51,62, \\
64,66,75, \\
92\end{array}$ \\
\hline Deal with cravings & 76 & & 71,76 & & $32,33,82$ & & $\begin{array}{l}40,54,76 \\
79,82,85 \\
96\end{array}$ & \\
\hline \multicolumn{9}{|l|}{ Social environment } \\
\hline Fitting in & & 47 & & & & & & \\
\hline $\begin{array}{l}\text { Pressure of social } \\
\text { environment }\end{array}$ & & 47 & [41] & & & & & \\
\hline $\begin{array}{l}\text { Recommended by } \\
\text { friends or family }\end{array}$ & & & 69 & & & & 96 & 92,100 \\
\hline $\begin{array}{l}\text { Role models use } \\
\text { e-cigarettes }\end{array}$ & & & & & & & 41,49 & 92 \\
\hline
\end{tabular}

Note: a "E-cigarette users" are users of e-cigarettes as defined in the original study. For example, Bold, Kong, Cavallo, Camenga, Krishnan-Sarin ${ }^{44}$ included only ever users of e-cigarettes in their study, without differentiating for frequency of use, co-current use or past use of cigarettes. b "Smokers" are those who smoke cigarettes as defined in the original studies. For example, Biener, Song, Sutfin, Spangler, Wolfson ${ }^{43}$ defined cigarette smokers as those who had at least smoked 100 cigarettes in their lifetime and smoked every day or some days. No distinction is made among cigarette smokers concerning frequency, lifetime use, co-current or past use of other tobacco products or e-cigarettes. c "Dual users" are those who use e-cigarettes and cigarettes simultaneously as defined in the original studies. For example, Cheney, Gowin, Wann ${ }^{48}$ defined dual users as current use of both e-cigarettes and cigarettes within the past week. If an included study mentioned perceptions or reasons regarding e-cigarettes among dual users, this review categorized these perceptions and reasons among dual users. $d$ "Never-users" are those who did not use e-cigarettes or cigarettes at the time of included study as defined in the original study. For example, Patel, Davis, Cox, et al. ${ }^{76}$ defined never-users as those 
who report "not at all" to the question of whether they had smoked cigarettes or used e-cigarettes. Never-users were classified as not using e-cigarettes or cigarettes, and no difference was made between former users and never users.

\section{Discussion}

This review provides a comprehensive overview of risk perceptions, perceived benefits, and reasons for use of e-cigarettes, as reported in Tables 2.1 - 2.3.

\section{Perceptions and Reasons Among Users and Never-users}

Current data showed a variety of perceptions about e-cigarettes and reasons for e-cigarette use reported by e-cigarette users, cigarette smokers, dual users, and never-users. For example, e-cigarettes were perceived as being less harmful by e-cigarette users. This perception of reduced harm could lead to use or, vice versa, by initiating e-cigarette use, the perception of harm may decrease. However, research showed that the perceived harm of e-cigarettes as compared to tobacco cigarettes has increased among all types of users over the years, ${ }^{3}$ and e-cigarettes are currently perceived as equally or more harmful than cigarettes. With regard to available flavors, which were shown to influence risk perceptions, fruit or candy flavored e-liquids were perceived as less risky compared to tobacco flavored e-liquids. E-cigarette users and cigarette smokers perceived benefits of e-cigarettes. In addition, adult e-cigarette users, dual users, and never-users noted advantages for the social environment when switching from cigarette smoking to e-cigarette use. Youth highlighted the trendiness of e-cigarettes as a perceived benefit, and perceived less health benefits than adults. The overview in this paper shows several positive perceptions and reasons which influence the initiation of e-cigarette use.

Based on these findings, tailored communication on risks and benefits of e-cigarette use could increase awareness about risks and benefits of e-cigarette use among user groups. For example, targeted risk communication on risks of e-cigarette use for never-users, and benefits of e-cigarette use compared to smoking for cigarette smokers would increase factual knowledge about risks of e-cigarette use among these user groups. If the latter were to perceive e-cigarettes as less harmful, they may be more inclined to switch to e-cigarettes. Furthermore, if never-users were not to perceive fruit- and candy-flavored e-liquids as harmless, they might be less inclined to initiate e-cigarette use. Summarizing, risks and benefits could be communicated to increase knowledge about e-cigarette use among user groups.

E-cigarette users expected (before initiation) and experienced (after continuation of use) benefits from e-cigarette use. In addition, this paper noted that reasons for 
initiation of e-cigarette use evolved to reasons for continuation of e-cigarette use 14. When positive outcome expectancies (theme: expected benefits, see Table 2.3) 32,33,40-43,46,47,49,50,53,75,100,103 were realized by positive experiences when initiating e-cigarette use (theme: experienced benefits, see Table 2.3), ${ }^{32,33,40,41,49,53,75,84}$ people may continue using e-cigarettes. For example, all e-cigarette users expected health benefits from e-cigarette use compared to cigarettes. ${ }^{32,33,40-43,46,49,53,75,100}$ If health improvements are indeed experienced, this may lead to continued use of e-cigarettes and possibly quitting cigarette use $32,33,40,49,53,75$ (see Table 2.3).

Cigarette smokers and never-users also mentioned expected benefits from e-cigarette use. However, not all cigarette smokers continue with e-cigarette use after initiation or initiate e-cigarette use. In some cases, the expected benefits of e-cigarettes for cigarette smokers—the ability to mimic smoking behavior-did not result in the expected experience. Cigarette smokers who tried e-cigarettes often expressed the inability to mimic smoking behavior with an e-cigarette (e.g., as a result of taste, the weight of the device, not being able to hold the device in the same way as a tobacco cigarette). ${ }^{33,41-43,49}$ The experience of e-cigarettes did not live up to the outcome expectations of cigarette smokers. Consequently, managing outcome expectations (by assisting with device specifications choices or e-liquid flavors) in behavior change strategies for cigarette smokers may prevent dual use of e-cigarettes and cigarettes. Managing outcome expectations could also be used to prevent initiation among never-users, by focusing on expected disadvantages of use and negative experiences (such as stressing that it is not cool or fashionable to use e-cigarettes).

\section{Applications}

Perceptions and reasons regarding e-cigarette use provide additional input for public health education, behavioral change programs, and regulation. Regulation, such as warning labels on tobacco products, is used to target misperceptions regarding tobacco products on a population level. Public health education can use the overview, presented in this study of perceptions on risks and benefits, to highlight factual risks and benefits of e-cigarette use in tailored communication. For example, tailored risk communication on the reduced harmfulness of e-cigarettes compared to cigarettes may reduce misperceptions among cigarette smokers initiating e-cigarette use for smoking cessation purposes. With risk communication tailored to specific personal needs and personal outcome expectancies, behavior change experts are able to target these personal misperceptions and confirm factual risk perceptions and perceived benefits.

Policy makers can also use this overview for product regulation measures. For example, available e-liquid flavors play an important role in the initiation of e-cigarette use for both cigarette smokers looking for an alternative for cigarettes and for curious never-users. ${ }^{9}$ From a public health point of view, it is not desirable for never-users to be attracted by flavors in e-liquids, with the chance of initiat- 
ing e-cigarette use. Future research should therefore focus on differences and overlap in specific flavor preferences among cigarette smokers and never-users to facilitate switching from cigarettes to e-cigarettes and discourage initiation of e-cigarette use among never-users. ${ }^{22,25}$

\section{Future Research}

Heterogeneity in the reporting of types of users made it difficult to classify types of users. For future research, it is therefore of vital importance to formulate standard definitions for ever, current, and dual use of e-cigarettes to assess population effects of e-cigarette use. In defining e-cigarette use, it is important to distinguish between experimental and daily use. For example, asking about e-cigarette use during the previous 30 days does not distinguish between experimental and daily use.

This review noticed the lack of reporting on perceptions towards e-cigarettes and reasons for use among adult dual users and never-users, and youth never-users and dual users. Future research needs to identify the rates of dual use among youth. Overall, only perceptions of harm were assessed in extensive cross-sectional, cohort, and longitudinal studies compared to other risk perceptions, and less regarding perceptions in general.

E-cigarette use is a complex behavior, and response options in questionnaires assessing perceptions and reasons in general may not be representative for all users, cigarette smokers, dual users, and never-users. Our overview, in addition to the work of Gibson et al. ${ }^{26}$ and Pearson et al. ${ }^{24}$, validated measures such as the Fagerström test for nicotine dependence ${ }^{104}$ and the International Tobacco Control measures ${ }^{105}$, and adds insight into developing and validating items for measuring e-cigarette use, risk perceptions of e-cigarettes, perceived benefits of e-cigarettes, and reasons for e-cigarette use. Summarizing, validated measures provide insight into e-cigarette use to develop tailored information based on the needs of e-cigarette users, cigarette smokers, dual users, and never-users.

\section{Limitations}

Heterogeneity between the different papers in statistical methods and reporting makes it difficult to generalize findings across countries and study samples. Therefore, the results do not display analyses across countries. For this reason, the current paper was unable to display changes in risk perception over time. Due to the variability in reporting type of users and frequency of use, users were classified according to the classification of original articles. Consequently, this overview was unable to differentiate between former and never e-cigarette users, or to clearly differentiate between cigarette smokers and dual users, as not all cigarette smokers currently using e-cigarettes were classified in original studies as dual users of tobacco and e-cigarettes. In addition to a variety in study 
designs, more studies were found reporting on adult perceptions and reasons than youth, and cigarette smokers than never-users. This means that some perceptions and reasons regarding e-cigarettes could have been missed among the understudied user groups.

\section{Conclusions}

This study is an exploratory narrative review into perceptions and reasons regarding e-cigarette use. Different perceptions of risks and benefits, and reasons for e-cigarette use were summarized for different types of users in themes and sub-themes, such as convenience, social environment, and disadvantages. Adults' perceptions and reasons for e-cigarette use are often related to smoking cessation, while youth like the novelty of the product. Tailored information about e-cigarettes for the different user groups is necessary to correct misperceptions about e-cigarettes and highlight the risks and benefits of e-cigarette use.

For public health professionals, behavior change experts, and regulatory science, our overview of risk and benefit perceptions of e-cigarettes, and reasons for e-cigarette use provides insight into the initiation of e-cigarette use. 


\section{References}

1. World Health Organization. Tobacco Free Initiative (TFI). Electronic cigarettes (ecigarettes) or electronic nicotine delivery systems 2015. http://www.who.int/ tobacco/communications/statements/eletronic_cigarettes/en/. Accessed July 12, 2017, 2016.

2. Grana R, Benowitz N, Glantz SA. E-cigarettes: a scientific review. Circulation. 2014;129(19):1972-1986.

3. Glasser AM, Collins L, Pearson JL, et al. Overview of Electronic Nicotine Delivery Systems: A Systematic Review. Am J Prev Med. 2017;52(2):e33-e66.

4. Hajek P, Etter JF, Benowitz N, Eissenberg T, McRobbie H. Electronic cigarettes: review of use, content, safety, effects on smokers and potential for harm and benefit. Addiction. 2014;109(11):1801-1810.

5. Visser W, Geraets L, Klerx W, et al. The health risks of using e-cigarettes. Bilthoven, the Netherlands: National Institute for Public Health and the Environment (RIVM);2015.

6. Pepper JK, Brewer NT. Electronic nicotine delivery system (electronic cigarette) awareness, use, reactions and beliefs: a systematic review. Tob Control. 2014;23(5):375-384.

7. Padon AA, Maloney EK, Cappella JN. Youth-Targeted E-cigarette Marketing in the US. Tob Regul Sci. 2017;3(1):95-101. doi:10.18001/TRS.3.1.9.

8. Laverty AA, Vardavas Cl, Filippidis FT. Design and marketing features influencing choice of e-cigarettes and tobacco in the EU. Eur J Public Health. 2016;26(5):838-841.

9. Feirman SP, Lock D, Cohen JE, Holtgrave DR, Li T. Flavored Tobacco Products in the United States: A Systematic Review Assessing Use and Attitudes. Nicotine Tob Res. 2016;18(5):739-749.

10. Xu Y, Guo Y, Liu K, Liu Z, Wang X. E-Cigarette Awareness, Use, and Harm Perception among Adults: A Meta-Analysis of Observational Studies. PLoS One. 2016;11(11):e0165938.

11. Czoli CD, Hammond D, White CM. Electronic cigarettes in Canada: prevalence of use and perceptions among youth and young adults. Can J Public Health. 2014;105(2):e97-e102.

12. Donzelli A. E-cigarettes May Impair Ability to Quit, but Other Explanations Are Possible. Am J Public Health. 2015;105(11):e1. doi:10.2105/AJPH.2015.302813.

13. El Dib R, Suzumura EA, Akl EA, et al. Electronic nicotine delivery systems and/ or electronic non-nicotine delivery systems for tobacco smoking cessation or reduction: a systematic review and meta-analysis. BMJ Open. 2017;7(2):e012680.

14. Etter JF. Electronic cigarette: a longitudinal study of regular vapers. Nicotine Tob Res. 2017. doi:10.1093/ntr/ntx132.

15. Fairchild AL, Bayer R, Colgrove J. The renormalization of smoking? E-cigarettes and the tobacco "endgame". N Engl J Med. 2014;370(4):293-295.

16. Hartmann-Boyce J, McRobbie H, Bullen $\mathrm{C}$, et al. Electronic cigarettes for smoking cessation. Cochrane Database Syst Rev. 2016;9:CD010216. 
17. Hastings $G$, de Andrade M, Moodie C. Tobacco harm reduction: the devil is in the deployment. BMJ. 2012;345:e8412.

18. Kings College London. All evidence shows that e-cigarettes have potential to reduce the harms caused by smoking. 2015. http://www.kcl.ac.uk/ioppn/news/ records/2015/August/ecigarettes.aspx. Accessed March 30, 2017, 2017.

19. Miech R, Patrick ME, O'Malley PM, Johnston LD. E-cigarette use as a predictor of cigarette smoking: results from a 1-year follow-up of a national sample of 12th grade students. Tob Control. 2017. doi:10.1136/tobaccocontrol-2016-053291.

20. SonejiS,Barrington-TrimisJL,WillsTA, etal. Association Between InitialUseofe-Cigarettes and SubsequentCigaretteSmokingAmong Adolescents and Young Adults: A Systematic Review and Meta-analysis. JAMA Pediatr. 2017;171(8):788-797.

21. Watkins SL, Glantz SA, Chaffee BW. Association of Noncigarette Tobacco Product Use With Future Cigarette Smoking Among Youth in the Population Assessment of Tobacco and Health (PATH) Study, 2013-2015. JAMA Pediatr. 2018;172(2):181-187.

22. Morean ME, Butler ER, Bold KW, et al. Preferring more e-cigarette flavors is associated with e-cigarette use frequency among adolescents but not adults. PLoS One. 2018;13(1):e0189015.

23. Ayers JW, Leas EC, Allem JP, et al. Why do people use electronic nicotine delivery systems (electronic cigarettes)? A content analysis of Twitter, 2012-2015. PLoS One. 2017;12(3):e0170702.

24. Pearson JL, Hitchman SC, Brose LS, et al. Recommended core items to assess e-cigarette use in population-based surveys. Tob Control. 2017. doi:10.1136/ tobaccocontrol-2016-053541.

25. Pepper JK, Ribisl KM, Brewer NT. Adolescents' interest in trying flavoured e-cigarettes. Tob Control. 2016;25(Suppl 2):ii62-ii66.

26. Gibson LA, Creamer MR, Breland AB, et al. Measuring perceptions related to e-cigarettes: Important principles and next steps to enhance study validity. Addict Behav. 2018;79:219-225.

27. Moher D, Liberati A, Tetzlaff J, Altman DG, Group P. Preferred reporting items for systematic reviews and meta-analyses: the PRISMA statement. BMJ. 2009;339:b2535.

28. VonVille H. Excel Workbook to Calculate Cohen's kappa for Screener Inter-rater Reliability. Houston: University of Texas School of Public Health Libarary; 2015.

29. Vonville H. Excel Workbook for Screening Titles and Abstracts. Houston: University of Texas School of Public Health Library; 2015.

30. VonVille H. Excel Workbook for 2 Full Text Reviewers. Houston: The University of Texas School of Public Health Library; 2015.

31. von Elm E, Altman DG, Egger $M$, et al. The Strengthening the Reporting of Observational Studies in Epidemiology (STROBE) Statement: guidelines for reporting observational studies. Int J Surg. 2014;12(12):1495-1499. doi:10.1016/j. ijsu.2014.07.013.

32. Rass O, Pacek LR, Johnson PS, Johnson MW. Characterizing use patterns and perceptions of relative harm in dual users of electronic and tobacco cigarettes. Exp Clin Psychopharmacol. 2015;23(6):494-503. 
33. Pokhrel P, Herzog TA, Muranaka N, Fagan P. Young adult e-cigarette users' reasons for liking and not liking e-cigarettes: A qualitative study. Psychol Health. 2015;30(12):1450-1469.

34. Adkison SE, O'Connor RJ, Bansal-Travers M, et al. Electronic nicotine delivery systems: international tobacco control four-country survey. Am J Prev Med. 2013;44(3):207-215.

35. Amato MS, Boyle RG, Levy D. How to define e-cigarette prevalence? Finding clues in the use frequency distribution. Tob Control. 2016;25(e1):e24-29.

36. Ambrose BK, Rostron BL, Johnson SE, et al. Perceptions of the relative harm of cigarettes and e-cigarettes among U.S. youth. Am J Prev Med. 2014;47(2 Suppl 1):S53-60.

37. Anand V, McGinty KL, O'Brien K, et al. E-cigarette Use and Beliefs Among Urban Public High School Students in North Carolina. JAdolesc Health. 2015;57(1):46-51.

38. Aziz Ur R, Mohamad MHN, Jamshed S. Safety and effectiveness of electronic cigarette as vapers perspective: A qualitative approach. International Medical Journal. 2015;22(5):362-366.

39. Bauhoff S, Montero A, Scharf D. Perceptions of e-cigarettes: a comparison of adult smokers and non-smokers in a Mechanical Turk sample. The American journal of drug and alcohol abuse. 2017;43(3):311-323.

40. Baweja R, Curci KM, Yingst J, et al. Views of Experienced Electronic Cigarette Users. Addict Res Theory. 2016;24(1):80-88.

41. Berg CJ. Preferred flavors and reasons for e-cigarette use and discontinued use among never, current, and formersmokers. Int J Public Health. 2016;61(2):225-236.

42. Biener $L$, Hargraves JL. A longitudinal study of electronic cigarette use among a population-based sample of adult smokers: association with smoking cessation and motivation to quit. Nicotine Tob Res. 2015;17(2):127-133.

43. Biener L, Song E, Sutfin EL, Spangler J, Wolfson M. Electronic Cigarette Trial and Use among Young Adults: Reasons for Trial and Cessation of Vaping. Int $J$ Environ Res Public Health. 2015;12(12):16019-16026.

44. Bold KW, Kong G, Cavallo DA, Camenga DR, Krishnan-Sarin S. Reasons for Trying E-cigarettes and Risk of Continued Use. Pediatrics. 2016;138(3).

45. Brose LS, Brown J, Hitchman SC, McNeill A. Perceived relative harm of electronic cigarettes over time and impact on subsequent use. A survey with 1-year and 2-year follow-ups. Drug Alcohol Depend. 2015;157:106-111.

46. Brown J, West R, Beard E, et al. Prevalence and characteristics of e-cigarette users in Great Britain: Findings from a general population survey of smokers. Addict Behav. 2014;39(6):1120-1125.

47. ChaffeeBW,GanskySA, Halpern-FelsherB, etal. Conditional riskassessmentofadolescents' electronic cigarette perceptions. Am J Health Behav. 2015;39(3):421-432.

48. Cheney MK, Gowin M, Wann TF. Electronic Cigarette Use in Straight-to-Work Young Adults. Am J Health Behav. 2016;40(2):268-279.

49. Coleman BN, Johnson SE, Tessman GK, et al. "It's not smoke. It's not tar. It's not 4000 chemicals. Case closed": Exploring attitudes, beliefs, and perceived social norms of e-cigarette use among adult users. Drug Alcohol Depend. 2016;159:80-85. 
50. Dockrell M, Morrison R, Bauld L, McNeill A. E-cigarettes: prevalence and attitudes in Great Britain. Nicotine Tob Res. 2013;15(10):1737-1744.

51. Dutra LM, Glantz SA. Electronic cigarettes and conventional cigarette use among U.S. adolescents: a cross-sectional study. JAMA Pediatr. 2014;168(7):610-617.

52. Eastwood B, Dockrell MJ, Arnott D, et al. Electronic cigarette use in young people in Great Britain 2013-2014. Public Health. 2015;129(9):1150-1156.

53. Etter JF. Electronic cigarettes: a survey of users. BMC Public Health. 2010;10:231.

54. Etter JF, Bullen C. Electronic cigarette: users profile, utilization, satisfaction and perceived efficacy. Addiction. 2011;106(11):2017-2028.

55. Faletau J, Glover M, Nosa V, Pienaar F. Looks like smoking, is it smoking?: children's perceptions of cigarette-like nicotine delivery systems, smoking and cessation. Harm Reduct J. 2013;10:30.

56. Ford A, MacKintosh AM, Bauld L, Moodie C, Hastings G. Adolescents' responses to the promotion and flavouring of e-cigarettes. Int $J$ Public Health. 2016;61(2):215-224.

57. Gowin M, Cheney MK, Wann TF. Knowledge and Beliefs About E-Cigarettes in Straight-to-Work Young Adults. Nicotine Tob Res. 2017;19(2):208-214.

58. Hess CA, Antin TM, Annechino R, Hunt G. Perceptions of E-Cigarettes among Black Youth in California. Int J Environ Res Public Health. 2017;14(1):11.

59. Hilton S, Weishaar H, Sweeting H, Trevisan F, Katikireddi SV. E-cigarettes, a safer alternative for teenagers? A UK focus group study of teenagers' views. BMJ Open. 2016;6(11):e013271.

60. Huerta TR, Walker DM, Mullen D, Johnson TJ, Ford EW. Trends in E-Cigarette Awareness and Perceived Harmfulness in the U.S. Am J Prev Med. 2017;52(3):339-346.

61. Kahr MK, Padgett S, Shope CD, et al. A qualitative assessment of the perceived risks of electronic cigarette and hookah use in pregnancy. BMC Public Health. 2015;15(1):1273.

62. Khoury M, Manlhiot C, Fan CS, et al. Reported electronic cigarette use among adolescents in the Niagara region of Ontario. CMAJ. 2016;188(11):794-800.

63. Kim H, Davis AH, Dohack JL, Clark PI. E-Cigarettes Use Behavior and Experience of Adults: Qualitative Research Findings to Inform E-Cigarette Use Measure Development. Nicotine Tob Res. 2017;19(2):190-196.

64. Kinnunen JM, Ollila H, Lindfors PL, Rimpela AH. Changes in Electronic Cigarette Use from 2013 to 2015 and Reasons for Use among Finnish Adolescents. Int J Environ Res Public Health. 2016;13(11):09.

65. Kistler CE, Crutchfield TM, Sutfin EL, et al. Consumers' Preferences for Electronic Nicotine Delivery System Product Features: A Structured Content Analysis. Int J Environ Res Public Health. 2017;14(6):07.

66. Lee JA, Lee S, Cho HJ. The Relation between Frequency of E-Cigarette Use and Frequency and Intensity of Cigarette Smoking among South Korean Adolescents. Int J Environ Res Public Health. 2017;14(3):14.

67. LeVault K, Mueller-Luckey G, Waters EA, et al. E-cigarettes: Who's using them and why? The Journal of family practice. 2016;65(6):390-397. 
68. Li J, Bullen C, Newcombe R, Walker N, Walton D. The use and acceptability of electronic cigarettes among New Zealand smokers. N Z Med J. 2013;126(1375):48-57.

69. Li J, Newcombe R, Walton D. The prevalence, correlates and reasons for using electronic cigarettes among New Zealand adults. Addict Behav. 2015;45:245-251.

70. Lotrean LM. Use of electronic cigarettes among Romanian university students: a cross-sectional study. BMC Public Health. 2015;15:358.

71. Majeed BA, Stanton CA, Dube SR, et al. Electronic Cigarette Use among Current Smokers: A Pilot Qualitative Study. Health behavior and policy review. 2016;3(6):590-596.

72. Majeed BA, Weaver SR, Gregory KR, et al. Changing Perceptions of Harm of E-Cigarettes Among U.S. Adults, 2012-2015. Am J Prev Med. 2017;52(3):331-338.

73. Mark KS, Farquhar B, Chisolm MS, Coleman-Cowger VH, Terplan M. Knowledge, Attitudes, and Practice of Electronic Cigarette Use Among Pregnant Women. J Addict Med. 2015;9(4):266-272.

74. McKeganey N, Dickson T. Why Don't More Smokers Switch to Using E-Cigarettes: The Views of Confirmed Smokers. Int J Environ Res Public Health. 2017;14(6):16.

75. McQueen A, Tower S, Sumner W. Interviews with "vapers": implications for future research with electronic cigarettes. Nicotine Tob Res. 2011;13(9):860-867.

76. Patel D, Davis KC, Cox S, et al. Reasons for current E-cigarette use among U.S. adults. Prev Med. 2016;93:14-20.

77. Pearson JL, Richardson A, Niaura RS, Vallone DM, Abrams DB. e-Cigarette awareness, use, and harm perceptions in US adults. Am J Public Health. 2012;102(9):1758-1766.

78. Pepper JK, Emery SL, Ribisl KM, Rini CM, Brewer NT. How risky is it to use e-cigarettes? Smokers' beliefs about their health risks from using novel and traditional tobacco products. J Behav Med. 2015;38(2):318-326.

79. Pepper JK, Ribisl KM, Emery SL, Brewer NT. Reasons for starting and stopping electronic cigarette use. Int J Environ Res Public Health. 2014;11(10):1034510361.

80. Peters RJ, Jr., Meshack A, Lin MT, Hill M, Abughosh S. The social norms and beliefs of teenage male electronic cigarette use. J Ethn Subst Abuse. 2013;12(4):300-307.

81. Pineiro B, Correa JB, Simmons VN, et al. Gender differences in use and expectancies of e-cigarettes: Online survey results. Addict Behav. 2016;52:91-97.

82. Pokhrel P, Herzog TA, Muranaka N, Regmi S, Fagan P. Contexts of cigarette and e-cigarette use among dual users: a qualitative study. BMC Public Health. 2015; 15:859.

83. Richardson A, Pearson J, Xiao H, Stalgaitis C, Vallone D. Prevalence, harm perceptions, and reasons for using noncombustible tobacco products among current and former smokers. Am J Public Health. 2014;104(8):1437-1444.

84. Rutten LJ, Blake KD, Agunwamba AA, et al. Use of E-Cigarettes Among Current Smokers: Associations Among Reasons for Use, Quit Intentions, and Current Tobacco Use. Nicotine Tob Res. 2015;17(10):1228-1234. 
85. Saddleson ML, Kozlowski LT, Giovino GA, et al. Enjoyment and other reasons for electronic cigarette use: Results from college students in New York. Addict Behav. 2016;54:33-39.

86. Saddleson ML, Kozlowski LT, Giovino GA, et al. Risky behaviors, e-cigarette use and susceptibility of use among college students. Drug Alcohol Depend. 2015;149:25-30.

87. Schmidt L, Reidmohr A, Harwell TS, Helgerson SD. Prevalence and reasons for initiating use of electronic cigarettes among adults in Montana, 2013. Prev Chronic Dis. 2014;11:E204.

88. Sherratt FC, Marcus MW, Robinson J, Newson L, Field JK. Electronic cigarette use and risk perception in a Stop Smoking Service in England. Addiction Research \& Theory. 2015;23(4):336-342.

89. Sherratt FC, Newson L, Marcus MW, Field JK, Robinson J. Perceptions towards electronic cigarettes for smoking cessation among Stop Smoking Service users. Br J Health Psychol. 2016;21(2):421-433.

90. Simmons VN, Quinn GP, Harrell PT, et al. E-cigarette use in adults: a qualitative study of users' perceptions and future use intentions. Addict Res Theory. 2016;24(4):313-321.

91. Soule EK, Rosas SR, Nasim A. Reasons for electronic cigarette use beyond cigarette smoking cessation: A concept mapping approach. Addict Behav. 2016;56:41-50.

92. Suris JC, Berchtold A, Akre C. Reasons to use e-cigarettes and associations with other substances among adolescents in Switzerland. Drug Alcohol Depend. 2015;153:140-144.

93. Tan AS, Bigman CA. E-cigarette awareness and perceived harmfulness: prevalence and associations with smoking-cessation outcomes. Am J Prev Med. 2014;47(2):141-149.

94. Tan AS, Lee CJ, Bigman CA. Comparison of beliefs about e-cigarettes' harms and benefits among never users and ever users of e-cigarettes. Drug Alcohol Depend. 2016;158:67-75.

95. Trumbo CW, Harper R. Use and perception of electronic cigarettes among college students. J Am Coll Health. 2013;61(3):149-155.

96. Vickerman KA, Carpenter KM, Altman T, Nash CM, Zbikowski SM. Use of electronic cigarettes among state tobacco cessation quitline callers. Nicotine Tob Res. 2013;15(10):1787-1791.

97. Wackowski OA, Bover Manderski MT, Delnevo CD. Smokers' sources of e-cigarette awareness and risk information. Prev Med Rep. 2015;2:906-910.

98. Wackowski OA, Bover Manderski MT, Delnevo CD, Giovenco DP, Lewis MJ. Smokers' Early E-cigarette Experiences, Reasons for Use, and Use Intentions. Tob Regul Sci. 2016;2(2):133-145.

99. Wang MP, Li WH, Jiang N, et al. E-Cigarette Awareness, Perceptions and Use among Community-Recruited Smokers in Hong Kong. PLoS One. 2015;10(10):e0141683.

100. White J, Li J, Newcombe R, Walton D. Tripling use of electronic cigarettes among New Zealand adolescents between 2012 and 2014. J Adolesc Health. 2015;56(5):522-528. 
101. Yong HH, Borland R, Balmford J, et al. Prevalence and Correlates of the Belief That Electronic Cigarettes are a Lot Less Harmful Than Conventional Cigarettes Under the Different Regulatory Environments of Australia and the United Kingdom. Nicotine Tob Res. 2017;19(2):258-263.

102. Zhu SH, Gamst A, Lee M, et al. The use and perception of electronic cigarettes and snus among the U.S. population. PLoS One. 2013;8(10):e79332.

103. Wills TA, Knight R, Williams RJ, Pagano I, Sargent JD. Risk factors for exclusive e-cigarette use and dual e-cigarette use and tobacco use in adolescents. Pediatrics. 2015;135(1):e43-51.

104. Heatherton TF, Kozlowski LT, Frecker RC, Fagerstrom KO. The Fagerstrom Test for Nicotine Dependence: a revision of the Fagerstrom Tolerance Questionnaire. British journal of addiction. 1991;86(9):1119-1127.

105. International Tobacco Control Policy Evaluation Project. ITC Netherlands (NL11_ Pw). International Tobacco Control (ITC). 2017. https://www.itcproject.org/files/ ITC_NL11_Replenishment_S_web_Eng_Dut.pdf. Accessed 10, Jan, 2018, 2018. 



\section{CHAPTER 3}

\section{A Deliberate Choice? Exploring the Decision to Switch from Cigarettes to E-Cigarettes}

Romijnders K van Osch L de Vries $\mathrm{H}$ Talhout R

\section{A Deliberate Choice?}

Exploring the Decision to Switch from Cigarettes to E-Cigarettes. Int J Environ Res Public Health. 2019;16(4). 


\section{Abstract}

E-cigarettes are increasingly popular among both cigarette smokers and neverusers. Although smoking cessation yields the most individual and population health benefits, switching to exclusive e-cigarette use offers some individual health benefits for cigarette smokers. However, e-cigarette use is not harmless, and its use among non-cigarette smokers should be prevented. Our study aims to explore the decision-making process about e-cigarettes among an e-cigarette users, cigarette smokers, and never-users. We conducted 12 semistructured focus group interviews with e-cigarette users, cigarette smokers, and never-users. We performed a thematic analysis of the interview transcripts. First, knowledge reported by e-cigarette users was mainly based on other users' experiences. Second, cigarette smokers and never-users were more negative towards e-cigarettes than e-cigarette users. Third, e-cigarette users considered switching from cigarette smoking to e-cigarette use by deliberating relevant information, and weighing up the benefits and disadvantages of e-cigarette use versus smoking. Additionally, important factors in the decision-making process were a perception of risks and benefits of e-cigarettes compared to cigarettes, a supportive social environment about e-cigarette use, and trust in information offered about the risks and benefits of e-cigarettes. Our findings provide insight into what we can learn from the conscious decision-making process of e-cigarette users who switched from cigarettes to e-cigarettes. This information can be considered to develop targeted communications strategies to stimulate a conscious decision-making process, these may highlight benefits of switching to e-cigarettes for cigarette smokers, discussing the risks of smoking, and correcting misperceptions about the perceived risks and benefits of e-cigarette use. 


\section{Introduction}

Electronic cigarettes (e-cigarettes) vaporize a solution of glycerin, propylene glycol, additives, and sometimes nicotine ${ }^{1-5}$. While early models mimic conventional cigarettes (in shape, flavor, and size), the design characteristics of newer models and e-liquid flavors available are elaborate and attractive to both cigarette smokers and never-users. ${ }^{3,6-12}$ In 2018, 3.1\% of the Dutch population ever used an e-cigarette. In addition, $23.1 \%$ of the Dutch population were smokers, of which one-third were between twenty and twenty-four years old. ${ }^{13}$

E-cigarettes have the potential to reduce the harm of cigarette smoking on smokers' health. ${ }^{10}$ Recent studies have argued that-while quitting the use of tobacco and related products yields the most health benefits-the health effects associated with exclusive e-cigarette use (and not dual use of cigarettes and e-cigarettes) are less harmful than those related to cigarette smoking. ${ }^{11,14-19}$ Still, e-cigarette use is not harmless, and consequently, the initiation of e-cigarette use among never-users needs to be prevented. ${ }^{10,11,20-22}$ To aid tobacco control that yields the most public health benefits for cigarette smokers and never-users, insight into differences in the decision-making process of e-cigarette users, smokers, and never-users is needed about e-cigarette use initiation. In particular, it is important to know whether the decision made by former cigarette smokers to switch to e-cigarettes, or by never-users to refrain from e-cigarette use, is consciously deliberated.

Previous research among different types of users and different age groups has described differences in reasons why initiating e-cigarette use is attractive. ${ }^{23-25}$ For example, cigarette smokers have argued that the expected health benefits of e-cigarette use compared to cigarette smoking and design similarities with cigarettes are reasons to initiate e-cigarette use..$^{25-27}$ Non-using youth ( $<18$ years) have stated curiosity as a reason to initiate e-cigarette use. ${ }^{25}$ Despite previous research into reasons for initiating e-cigarette use, ${ }^{25,27}$ insight into the process of making a choice (decision-making) about e-cigarette use initiation lacks. This information is crucial to facilitate a conscious decision among cigarette smokers about switching to e-cigarettes and among never-users about refraining from experimenting with e-cigarettes.

A conscious decision-making process is defined by deliberating available and relevant information about the options, and by weighing advantages and disadvantages of the choice in the context of the decision-maker's attitudes ${ }^{28-30}$ Previous research found that smokers have not made a conscious and informed decision to initiate cigarette smoking, but that this decision is rather passive. ${ }^{28,29,31-34}$ Our study explores the deliberation process of successful switching among current e-cigarette users (former smokers), and the deliberation process of refraining from e-cigarette use among cigarette smokers and never-users. To the best of our knowledge, this is the first study to examine the decision-making process of 
e-cigarette use among cigarette smokers and never-users. We explored whether e-cigarette users, cigarette smokers, and never-users have similar knowledge and attitudes regarding e-cigarettes, and if they used this knowledge to consider pros and cons of switching to, or refraining from e-cigarette use. By comparing differences in this process of e-cigarette use initiation between e-cigarette users, cigarette smokers, and never-users, we offer new information on the views and experiences of e-cigarette users who switched from cigarettes to e-cigarettes.

\section{Methods}

To explore the decision-making process about e-cigarette use, we conducted focus groups with three homogeneous groups consisting of adult e-cigarette users, adult cigarette smokers, and adolescent never-users who used neither cigarettes nor e-cigarettes. For each of these types of users, four focus groups were conducted. The study was approved by the Medical Ethics Committee of Zuyderland-Zuyd (16-N-84).

\section{Recruitment}

In June 2016, participants were recruited in the Netherlands, through an advertisement on Facebook $\odot$, Instagram $\odot$, Twitter $\odot$, and scholieren.com (a website targeted at adolescents in the Netherlands). Inclusion criteria were: awareness of e-cigarettes, being a current smoker (18+), e-cigarette user (18+), or never-user (13 to 17 years old), and fluency in Dutch. Adolescent never-users were selected because previous research showed differences in reasons for e-cigarette initiation among adult e-cigarette users, adult cigarette smokers, and adolescent never-users. ${ }^{25}$ Appendix 4 shows the characteristics of included participants.

\section{Procedure}

The group discussions were based on a semi-structured protocol with openended questions and minimal steering to allow participants to freely discuss e-cigarettes. ${ }^{35}$ The topic list of this protocol was developed to investigate decisionmaking according to the definition of van den Berg, Timmermans, ten Kate, van Vugt, van der Wal ${ }^{29}$ and previous qualitative research conducted by Gray, Hoek, Edwards ${ }^{31}$ This topic list was tested in a pilot focus group and subsequently revised. While the same moderator (K.A.G.J.R.) led all group discussions, the observers varied. All focus groups were audio recorded, and flipcharts were used for participants to visualize the topics that had been discussed (see Appendix 5 for a detailed summary of the semi-structured protocol).

The focus groups were conducted between June and July 2016 and lasted approximately two hours. Informed consent was obtained before the start of 
the focus group and after participation, the participants received an incentive of 30 euros. The focus group started with a general introduction. The discussion proceeded in four steps exploring participants' knowledge regarding e-cigarettes, their attitude towards e-cigarettes, their deliberation regarding e-cigarette use initiation, and their information needs (see Appendix 5 for a detailed summary).

\section{Qualitative Coding and Analysis}

All group discussions were transcribed verbatim. Qualitative data analysis comprised of three phases. ${ }^{36}$ In the first phase, the first author applied descriptive level coding to a randomly selected focus group transcript, to deduce relevant themes and subthemes. The first author and the second coder (T.J.) then developed a descriptive thematic analysis. The second coder identified little additional text fragments to be relevant. In the second phase, the first and the second coder resolved minor differences in coding themes and subthemes to create a final coding taxonomy. A third coder (M.B.), who did not participate in the first phase of the coding process, reviewed the final coding taxonomy with the first author and minor adjustments were made. In the final and third phase, the first author and third coder coded all the transcribed focus groups.

\section{Results}

We conducted four focus groups with adult e-cigarette users ( $n=26)$, four focus groups with adult cigarette smokers $(n=17)$, and four focus groups adolescent never-users $(n=23)$. All e-cigarette users reported to be former smokers. Overall, the sample was $47 \%$ female and $53 \%$ male, the average age of adult participants was 29.3 years $( \pm 13.0, \min =18, \max =58)$, and adolescents $15.3( \pm 1.1, \min =13$, $\max =17$ ), and the sample was highly educated (applied sciences or university degree; 65\%). Table 3.1 summarizes the demographic variables for e-cigarette users, cigarette smokers, and never-users. The following section describes themes, which were considered important in the overall decision-making process of e-cigarette users, smokers and never-users with illustrative quotes. Because of the explorative and qualitative nature of this study, the results are not meant to convey generalizability beyond the studied population. To describe themes and patterns in the data, we distinguish between rarely and commonly mentioned aspects. ${ }^{37}$ 
Table 3.1 Demographic information of the study participants.

\begin{tabular}{llll}
\hline Demographics & Never-users & Cigarette smokers & E-cigarette users \\
\hline $\begin{array}{l}\text { Age } \mu( \pm) \\
\text { Education } \mathrm{n}(\%)\end{array}$ & $15.2( \pm 1.1)$ & $19.8( \pm 3.2)$ & $31.8( \pm 12.2)$ \\
High & $5(22 \%)$ & $7(41 \%)$ & $2(8 \%)$ \\
Middle & $8(35 \%)$ & $6(35 \%)$ & $15(58 \%)$ \\
Low & $10(43 \%)$ & $4(24 \%)$ & $9(35 \%)$ \\
Gender $\mathrm{n}(\%)$ & & & \\
Male & $8(35 \%)$ & $8(47 \%)$ & $19(73 \%$ \\
Female & $15(65 \%)$ & $9(53 \%)$ & $7(27 \%)$ \\
\hline
\end{tabular}

Note: Demographic information is displayed for each user group.

\section{Knowledge}

When participants were asked to talk about what they knew about e-cigarettes, many participants were able to mention some facts about e-cigarettes. For example, many participants stated the variety of e-liquid flavors available, the rechargeable batteries of e-cigarettes, the lack of a burning process and tar, the variety of devices, and the ability to avoid smoking bans (quote 1).

'You use an e-liquid, there are a lot of flavors, you can choose whether you want with or without nicotine, and there are many different types...' (\#3_smoker about e-cigarettes)

Compared to cigarette smokers and never-users, e-cigarette users described more detailed information about e-cigarettes. E-cigarette users reported to have acquired much information in order to make a decision about e-cigarette use initiation, for example, about product characteristics, ingredients of e-liquids, and legislation regarding e-cigarettes. Knowledge reported by e-cigarette users was mainly based on user experiences. When asked how informed they felt, cigarette smokers and never-users stated that they did not search for information about e-cigarettes and expressed they did not know much about e-cigarettes. E-cigarette users felt very informed.

\section{Attitude}

Participants shared experiences, both positive and negative, with e-cigarettes and cigarettes. Cigarette smokers and never-users, were negative towards e-cigarette use, in general mentioning it was 'weird' (quote 2):

'I think it's [e-cigarettes] really weird and pathetic. Everybody will be 
laughing at you.' (\#23_never-user)

All groups mentioned that using e-cigarettes has the advantage of avoiding smoking restrictions (quote 3 ).

'It [e-cigarettes] is really easy to use [...] and you can even use it inside, great if you're in the bus [...] Or you can use it for a just bit, instead of smoking an entire cigarette. I think I'd enjoy that...' (\#17_smoker)

Compared to e-cigarette users and never-users, many cigarette smokers were positive towards cigarette smoking. Regardless of the negative health effects associated with cigarette smoking, smokers expressed they really enjoy smoking. Several of the e-cigarette users reported a positive attitude about e-cigarettes and negative attitude towards smoking, based on knowledge acquired beforehand. In general, e-cigarette users emphasized the positive aspects of e-cigarette devices and positive experiences, such as the variety of flavors and the adjustability of nicotine levels.

\section{Deliberation}

Many e-cigarette users consciously deliberated initiation of e-cigarette use versus continuation of cigarette smoking by using knowledge acquired and weighing up the benefits of e-cigarette use and disadvantages of cigarette smoking. For example, the personal health benefits of e-cigarette use, and the negative health issues for their social environment associated with secondhand smoking. They described this decision process of switching from cigarette smoking to e-cigarette use as a deliberation of benefits and disadvantages (quote 4):

'Switching from cigarettes to e-cigarettes [...] it was a deliberate choice. I had an e-cigarette laying around and I tried it a few times. I liked the flavor and the satisfaction it gave me [throat hit from nicotine]. In the end I ordered a really nice one because I decided I was going to quit smoking. So yeah, it was a really deliberate choice...' (\#13_e-cigarette user)

Many cigarette smokers and never-users reported that they had not contemplated using e-cigarettes. Deliberation was often limited to brief passive moments when they were confronted with an e-cigarette in their environment (quote 5).

'One of my friends had one [e-cigarette] and I thought: That might be a way to quit smoking.' (\#14_smoker)

When asked to compare e-cigarette use initiation with cigarette smoking initiation, e-cigarette users and cigarette smokers agreed that cigarette smoking initiation was not a conscious or deliberate choice. Many cigarette smokers expressed they passively discovered themselves to be smokers months or years 
after they initiated smoking (quote 6).

'Everybody smoked, so I started too [...] there wasn't a point where I thought: OK, from now on I'm a smoker. All of a sudden, you just are one. Smoking is not a deliberate choice you make, something you really think about.' (\#1_smoker)

In general, never-users did not show an interest in e-cigarettes or cigarettes. Pros and cons were not actively deliberated among never-users, but sometimes curiosity was reason enough to passively experiment with e-cigarettes or cigarettes.

\section{Information Need of E-Cigarettes}

When asked about their information need, all three groups stated they had several unanswered questions, such as, 'Are e-cigarettes harmful?', 'What are the benefits of e-cigarette use compared to cigarette smoking?', and 'What are the negative long-term health effects of e-cigarette use?'. E-cigarette users, compared to smokers and never-users had more questions about product characteristics, such as 'Are there results of quality tests of e-liquids available?'. Cigarette smokers and never-users wanted to know more about the successful quit attempts with e-cigarettes. They wanted to see a risk-benefit analysis of e-cigarette use versus smoking, and they wanted to know what the average duration of use was for e-cigarette use as a smoking cessation tool. All groups agreed that this information should be communicated to the public to facilitate smoking cessation for cigarette smokers. Many participants explained that there is a large body of information available, but that it is difficult to filter useful and correct information from the internet.

\section{Additional aspects}

This section describes additional aspects participants mentioned that played a role in their decision about e-cigarette use.

\section{Risk perception}

The risks of e-cigarettes versus cigarettes were discussed. E-cigarette users did not perceive any health risks of e-cigarette use (quote 7).

'So I thought: 'it's just vape. That can't be really harmful for you or your lungs. So if I just vape, and I don't do it every day [...] that won't be so wrong.' (\#4_e-cigarette user)

Cigarette smokers stated that although they knew about the common risks of cigarettes, the specifics of how cigarettes cause smoking-related diseases were not clear. They also perceived the health risks of cigarettes as a problem for the 
distant future, something to worry about later, when they were older. E-cigarette users tended to deliberate the risks and severity of cigarette smoking related diseases and acknowledged that the risks applied to them as former long-time cigarette smokers (quote 8):

'My grandfather smoked, like me, and you can see his health is getting worse and worse. He suffers from emphysema, I don't want that. So I wanted to quit.' (E-cigarette user_\#26)

While never-users were aware of the risks of cigarette smoking, the risks of e-cigarettes were unclear to them. Similar to e-cigarette users, they mentioned that if it is just vape, it did not seem harmful (quote 7). E-cigarette users perceived e-cigarette use compared to cigarette smoking not as a risk, but as a lifestyle (quote 9):

'I often say that besides a hobby it's [e-cigarette use] also a lifestyle.' (\#21_e-cigarette user)

Similar to e-cigarette users, cigarette smokers perceived cigarette smoking as an addiction, and they described triggers for the desire to smoke, such as alcohol consumption. Never-users perceived both e-cigarette use and cigarette smoking as addictive behaviors.

\section{Social environment}

All groups described the importance of their social environment with regard to e-cigarette use and cigarette smoking. In the initiation of e-cigarette use, the social environment was an important factor for many e-cigarette users (quote 10).

'My mother had one [e-cigarette], so I tried it too.' (\#17_e-cigarette user)

Several e-cigarette users further noted that social support for e-cigarette use from their social environment grew after initiation of use, which they described as a sense of belonging to an e-cigarette community (quote 11):

'It's a community [...] Very similar to bikers! You know how they all greet each other on the road? The vaping community is the same.' (\#21_e-cigarette user)

In general, participants expressed it was more acceptable to smoke than to use e-cigarettes. While cigarette smokers and never-users categorized e-cigarette use as "weird", cigarette smoking was still considered as acceptable by the several of participants and their social environment. When asked about the role of their social environment in their decision to initiate cigarette smoking compared to switching to e-cigarette use, cigarette smokers expressed that friends who smoked often influenced their decision (quote 12): 
'One of my friends told me: 'Try a cigarette!' So I did, and I liked it and I continued smoking.' (\#15_smoker)

Cigarette smokers did not describe the influence of friends as pressure, but they did describe the disappointment their parents expressed in response to finding out about their smoking behavior as embarrassing (quote 13):

'I was really afraid to tell my parents that I smoke [...] they were so disappointed.' (\#11_smoker)

Never-users viewed e-cigarette use and cigarette smoking not as a social activity, but as peer pressure and addiction, not a choice. Never-users felt strongly about parental disappointment related to cigarette smoking and noted this as a specific reason why they would not start smoking cigarettes or start using e-cigarettes.

\section{Trust in information}

Due to the large body of information available about e-cigarettes, it was difficult for participants to make sure the available information is correct. E-cigarette users and cigarette smokers mistrusted evidence-based information, and relied on anecdotal user experiences (quote 14):

'Researchers often don't know what they are doing (\#20_e-cigarette user) [...] yes we need to know about the experiences of e-cigarette users.' (\#16_e-cigarette user)

Unlike e-cigarette users and cigarette smokers, never-users explained they rather receive scientific information because they trust this information to be true.

\section{Discussion}

We explored the decision-making process of e-cigarette use initiation among adult e-cigarette users, adult cigarette smokers, and adolescent never-users. Compared to e-cigarette users, cigarette smokers and never-users did not make a conscious decision to refrain from e-cigarette use. They have acquired different information and have different attitudes. Several of e-cigarette users perceived the risks of cigarette smoking as personally relevant. They acquired information and formed an attitude about e-cigarettes. Finally, their knowledge, attitudes, pros, and cons were deliberated and a conscious decision was made to initiate e-cigarette use. Additionally, lack of information seeking, perception of risk of smoking related diseases, perception of risks and benefits of e-cigarette use compared to cigarette smoking, support to switch to e-cigarettes, a sense of belonging to e-cigarette users, and trust in information offered about e-cigarettes showed to be important factors for a participant in a decision-making process about e-cigarette use. 
A possible barrier in the decision-making process is the large body of contradicting information available and lack of trust in scientific evidence. Although e-cigarettes users appear knowledgeable, their reported knowledge did not match scientific consensus. We categorized this type of knowledge as beliefs, and these beliefs were primarily based on anecdotal user experiences found online. This finding matches research that shows that experienced e-cigarette users are eager to share their advice and experiences about switching with cigarette smokers. ${ }^{38}$ Due to these beliefs, e-cigarette users perceived e-cigarettes as harmless. Research has showed that confirmation bias and online information may lead to misperceptions about the safety of e-cigarettes. ${ }^{39-42}$ These beliefs and misperceptions about the harmfulness of e-cigarettes may hinder the process of making a conscious and informed decision about e-cigarette use initiation. Thus, there is a clear need for further research on targeted communication strategies to facilitate the conscious deliberation of relevant and evidence-based information about e-cigarette use. These strategies need to highlight advantages and disadvantages of switching to, or refraining from e-cigarette use, and correcting misperceptions about perceived risks and benefits of e-cigarettes. ${ }^{43}$ This will emphasize the public and individual health benefits of e-cigarette use initiation for cigarette smokers and the disadvantages for never-users.

Cigarette smokers did not contemplate to switch to e-cigarettes, or consciously decide to continue smoking. Our results indicate that though cigarette smokers are aware of the health risks of cigarette smoking, they do not perceive the longterm health risks of smoking as personally relevant. Additionally, they perceive e-cigarettes as weird, smoking as a normal, social behavior, ${ }^{44}$ and, possibly due to their young age $(19.8( \pm 3.2))$, display an optimism bias about their ability to quit in time before serious health effects occur. ${ }^{30,45}$ This optimism bias greatly diminishes cigarette smokers' interest to acquire knowledge about the benefits and disadvantages of switching to exclusive e-cigarette use, and deliberate these pros and cons of e-cigarette use compared to smoking. ${ }^{30,45,46}$ Low perceived susceptibility and severity of risks associated with cigarette smoking, a lack of knowledge, and a social environment in which e-cigarette use is considered weird and smoking is considered normal or encouraged, hinders smokers to deliberate the pros and cons of switching to e-cigarettes or smoking cessation.

Similar to cigarette smokers, never-users did not actively deliberate e-cigarette use initiation. Adolescent never-users mentioned that if they were to start e-cigarette use, it would be out of curiosity. The risks of e-cigarette use were unclear to never-users, but because it was just vape, e-cigarette use was perceived as harmless. This lack of perceived personal risks of e-cigarette use may diminish the interest to acquire knowledge about the disadvantages of e-cigarette use. Without information seeking and information about advantages and disadvantages of e-cigarette use for never-users, no deliberation can take place. ${ }^{29} \mathrm{~A}$ lack of deliberation of the risks associated with e-cigarette use, and curiosity about e-cigarette use may result in a tendency to initiate experimenting 
with e-cigarettes among some adolescents. Low perceived risk of e-cigarettes and a lack of knowledge hinder never-users to make a deliberate decision to refrain from e-cigarette use.

This qualitative study shows that cigarette smokers and never-users did not consciously deliberate information about the risks and benefits of e-cigarettes use to make a decision to refrain from e-cigarette use initiation. The differences and similarities in the decision-making process of e-cigarette use among the different user groups raise a question. Namely, can insights into the conscious decision-making process of e-cigarettes users who switched from cigarette to e-cigarettes be used to stimulate cigarette smokers to consciously deliberate something they consider 'weird'? Further research is necessary to investigate how cigarette smokers can be stimulated to consciously deliberate a switch to e-cigarettes.

Because of the explorative nature of this study, the results are not meant to convey generalizability beyond the study population, and thus, these findings are limited to a specific geographic context and time. Respondents were asked to participate in a two-hour discussion, which may have attracted individuals more inclined to talk about cigarette smoking and e-cigarette use. Additionally, we asked e-cigarette users, cigarette smokers, and never-users to consider their decisions about initiation in retrospect, knowledge and attitudes may be different when first faced with the decision. Participants' knowledge, attitudes, and deliberation process might be influenced by their level of education, and living in different areas of the Netherlands. Further research is necessary to explore the impact of education on a decision about e-cigarettes.

\section{Conclusions}

To conclude, our exploration of the decision-making process of e-cigarette initiation identifies distinct differences between the decision-making process of current cigarette smokers, e-cigarette users, and never-users. Current e-cigarette users (former smokers) in this study made a conscious decision to switch from cigarettes to e-cigarettes, but current cigarette smokers and never-users did not contemplate or deliberate e-cigarette use initiation. E-cigarettes have a potential public and individual health benefit for cigarette smokers, as switching to exclusive e-cigarette use is less harmful than cigarette smoking. E-cigarette use is not harmless, initiation of e-cigarette use and cigarette smoking should thus be prevented among never-users. Several of the e-cigarette users deliberated personally relevant risks of cigarette smoking, which made them interested in switching to a less harmful alternative. These findings underline the importance to explore the possibility to learn from the decision-making process of e-cigarette users, in order to support cigarettes smokers with their decision about switching to e-cigarettes and never-users with their decision to refrain from e-cigarette use. 


\section{References}

1. World Health Organization. Tobacco Free Initiative (TFI). Electronic cigarettes (ecigarettes) or electronic nicotine delivery systems 2015. http://www.who.int/ tobacco/communications/statements/eletronic_cigarettes/en/. Accessed July 12, 2017, 2016.

2. Grana R, Benowitz N, Glantz SA. E-cigarettes: a scientific review. Circulation. 2014;129(19):1972-1986.

3. Glasser AM, Collins L, Pearson JL, et al. Overview of Electronic Nicotine Delivery Systems: A Systematic Review. Am J Prev Med. 2017;52(2):e33-e66.

4. Hajek P, Etter JF, Benowitz N, Eissenberg T, McRobbie H. Electronic cigarettes: review of use, content, safety, effects on smokers and potential for harm and benefit. Addiction. 2014;109(11):1801-1810.

5. Pearson JL, Amato MS, Wang X, et al. How US Smokers Refer to E-cigarettes: An Examination of User-Generated Posts From a Web-Based Smoking Cessation Intervention, 2008-2015. Nicotine \& Tobacco Research. 2017;19(2):253-257.

6. Visser W, Geraets L, Klerx W, et al. The health risks of using e-cigarettes. Bilthoven, the Netherlands: National Institute for Public Health and the Environment (RIVM);2015.

7. Xu Y, Guo Y, Liu K, Liu Z, Wang X. E-Cigarette Awareness, Use, and Harm Perception among Adults: A Meta-Analysis of Observational Studies. PLoS One. 2016;11(11):e0165938.

8. Feirman SP, Lock D, Cohen JE, Holtgrave DR, Li T. Flavored Tobacco Products in the United States: A Systematic Review Assessing Use and Attitudes. Nicotine Tob Res. 2016;18(5):739-749.

9. Laverty AA, Vardavas Cl, Filippidis FT. Design and marketing features influencing choice of e-cigarettes and tobacco in the EU. Eur J Public Health. 2016;26(5):838841.

10. McRobbie H. Modelling the Population Health Effects of E-Cigarettes Use: Current Data Can Help Guide Future Policy Decisions. Nicotine Tob Res. 2017;19(2):131-132.

11. Stratton K, Kwan L, Y., Eaton DL. Public health consequences of e-cigarettes. Washington, DC, United States: National Academies Press;2018. 9780309468343.

12. Chen J, Bullen C, Dirks K. A Comparative Health Risk Assessment of Electronic Cigarettes and Conventional Cigarettes. Int J Environ Res Public Health. $2017 ; 14(4)$.

13. Springvloet $L$, Bommele J, Willemsen $M$, van Laar M. KERNCIJFERS ROKEN 2017. Utrecht Trimbos-instituut; 2018.

14. World Health Organization. Tobacco. Factsheet 2017. http://www.who.int/ mediacentre/factsheets/fs339/en/. Accessed November 30, 2018, 2018.

15. Goniewicz ML, Gawron M, Smith DM, et al. Exposure to Nicotine and Selected Toxicants in Cigarette Smokers Who Switched to Electronic Cigarettes: A Longitudinal Within-Subjects Observational Study. Nicotine Tob Res. 2017;19(2):160-167. 
16. Ratajczak A, Feleszko W, Smith DM, Goniewicz M. How close are we to definitively identifying the respiratory health effects of e-cigarettes? Expert Rev Respir Med. 2018;12(7):549-556.

17. Levy DT, Borland R, Lindblom EN, et al. Potential deaths averted in USA by replacing cigarettes with e-cigarettes. Tob Control. 2018;27(1):18-25.

18. Burstyn I. Peering through the mist: systematic review of what the chemistry of contaminants in electronic cigarettes tells us about health risks. BMC Public Health. 2014;14(1):18.

19. Orr MS. Electronic cigarettes in the USA: a summary of available toxicology data and suggestions for the future. Tob Control. 2014;23 Suppl 2:ii18-22.

20. Soneji S, Barrington-Trimis JL, Wills TA, et al. Association Between Initial Use of e-Cigarettes and Subsequent Cigarette Smoking Among Adolescents and Young Adults: A Systematic Review and Meta-analysis. JAMA Pediatr. 2017;171(8):788-797.

21. Soneji S, Sung HY, Primack B, Pierce JP, Sargent J. Problematic Assessment of the Impact of Vaporized Nicotine Product Initiation in the United States. Nicotine Tob Res. 2017;19(2):264-265.

22. Li Volti G, Polosa R, Caruso M. Assessment of E-cigarette impact on smokers: The importance of experimental conditions relevant to human consumption. Proc Natl Acad Sci U S A. 2018;115(14):E3073-E3074.

23. Soule EK, Rosas SR, Nasim A. Reasons for electronic cigarette use beyond cigarette smoking cessation: A concept mapping approach. Addict Behav. 2016;56:41-50.

24. Ayers JW, Leas EC, Allem JP, et al. Why do people use electronic nicotine delivery systems (electronic cigarettes)? A content analysis of Twitter, 20122015. PLoS One. 2017;12(3):e0170702.

25. Romijnders $K$, van Osch L, de Vries $H$, Talhout R. Perceptions and Reasons Regarding E-Cigarette Use among Users and Non-Users: A Narrative Literature Review. Int J Environ Res Public Health. 2018;15(6).

26. Antognoli E, Koopman Gonzalez S, Trapl E, et al. Cigarettes, Little Cigars, and Cigarillos: Initiation, Motivation, and Decision-Making. Nicotine Tob Res. 2018;20(suppl_1):S5-S11.

27. Wadsworth E, Neale J, McNeill A, Hitchman SC. How and Why Do Smokers Start Using E-Cigarettes? Qualitative Study of Vapers in London, UK. Int J Environ Res Public Health. 2016;13(7).

28. Marteau TM, Dormandy E, Crockett R. Informed choice: why measuring behaviour is important. Arch Dis Child. 2005;90(5):546-547; author reply 546547.

29. van den Berg M, Timmermans DR, ten Kate LP, van Vugt JM, van der Wal G. Informed decision making in the context of prenatal screening. Patient Educ Couns. 2006;63(1-2):110-117.

30. Baron J. Thinking and Deciding. 4th ed. Cambridge: Cambridge University Press; 2007.

31. Gray RJ, Hoek J, Edwards R. A qualitative analysis of 'informed choice' among young adult smokers. Tob Control. 2016;25(1):46-51. 
32. Hoek J, Ball J, Gray R, Tautolo ES. Smoking as an 'informed choice': implications for endgame strategies. Tob Control. 2017;26(6):669-673.

33. Michie S, Dormandy E, Marteau TM. Informed choice: understanding knowledge in the context of screening uptake. Patient Educ Couns. 2003;50(3):247-253.

34. Chapman S, Liberman J. Ensuring smokers are adequately informed: reflections on consumer rights, manufacturer responsibilities, and policy implications. Tob Control. 2005;14 Suppl 2:ii8-13.

35. Dicicco-Bloom B, Crabtree BF. The qualitative research interview. Med Educ. 2006;40(4):314-321.

36. Vaismoradi M, Turunen $\mathrm{H}$, Bondas $\mathrm{T}$. Content analysis and thematic analysis: Implications for conducting a qualitative descriptive study. Nurs Health Sci. 2013;15(3):398-405.

37. Neale J, Miller P, West R. Reporting quantitative information in qualitative research: guidance for authors and reviewers. Addiction. 2014;109(2):175-176.

38. Russell C, Dickson T, McKeganey N. Advice From Former-Smoking E-Cigarette Users to Current Smokers on How to Use E-Cigarettes as Part of an Attempt to Quit Smoking. Nicotine Tob Res. 2018;20(8):977-984.

39. Betsch C, Renkewitz F, Betsch T, Ulshofer C. The influence of vaccine-critical websites on perceiving vaccination risks. J Health Psychol. 2010;15(3):446-455.

40. Palminteri S, Lefebvre G, Kilford EJ, Blakemore SJ. Confirmation bias in human reinforcement learning: Evidence from counterfactual feedback processing. PLoS Comput Biol. 2017;13(8):e1005684.

41. Glick M. Believing is seeing: Confirmation bias. J Am DentAssoc. 2017;148(3):131132.

42. Siegrist M, Stampfli N, Kastenholz H. Consumers' willingness to buy functional foods. The influence of carrier, benefit and trust. Appetite. 2008;51(3):526-529.

43. Compton J, Jackson B, Dimmock JA. Persuading Others to Avoid Persuasion: Inoculation Theory and Resistant Health Attitudes. Front Psychol. 2016;7:122.

44. Lucherini M, Rooke C, Amos A. "They're thinking, well it's not as bad, I probably won't get addicted to that. But it's still got the nicotine in it, so...": Maturity, Control, and Socializing: Negotiating Identities in Relation to Smoking and Vaping-A Qualitative Study of Young Adults in Scotland. Nicotine Tob Res. 2019;21(1):81-87.

45. Slovic P. What Does it Mean to Know a Cumulative Risk? Adolescents' Perception of Short-term and Long-term Consequences of Smoking. J Behav Dec Making. 2000;13:259-266.

46. Weinstein ND, Marcus SE, Moser RP. Smokers' unrealistic optimism about their risk. Tob Control. 2005;14(1):55-59. 



\section{CHAPTER 4}

\section{E-liquid flavor preferences and individual factors related to vaping: a survey among Dutch never-users, smokers, dual users, and exclusive vapers}

Romijnders KA

Krusemann EJ

Boesveldt S, et al.

E-Liquid Flavor Preferences and Individual Factors Related to Vaping: A Survey among Dutch Never-Users, Smokers, Dual Users, and Exclusive Vapers.

Int J Environ Res Public Health. 2019;16(23) 


\section{Abstract}

Appealing product characteristics, such as flavors, may stimulate e-cigarette use. While switching to e-cigarettes may reduce harm for smokers, concerns exist about e-cigarette use among never-smokers. The role of flavors in the decision to switch to or refrain from vaping is unclear. This study used a bottom-up approach to investigate the relation between flavor preferences and individual factors related to vaping between various user groups. A cross-sectional survey was conducted among never-users $(n=407)$, smokers $(n=138)$, dual users $(n=122)$, and exclusive vapers $(n=61)$ in the Netherlands. Demographics, attractiveness of product characteristics, flavor preferences, and individual factors related to vaping (knowledge, trust, perceived susceptibility, attitude, social influence, deliberation, and intention) were assessed. The availability of different flavors was the most attractive characteristic of e-cigarettes. Dual users and exclusive vapers had most often used tobacco and menthol/mint flavors when they first started vaping. Compared to dual users, exclusive vapers currently used more fruit and sweet flavors. Never-users who were interested in trying an e-liquid flavor had more knowledge about and a more positive attitude towards e-cigarettes. Smokers who were interested in trying a flavor had a more positive attitude towards e-cigarettes and experienced the social influence towards not using e-cigarettes as less strong than those who did not want to try any flavor. Hence, individual factors related to vaping differed depending on whether neverusers and smokers wanted to try an e-liquid flavor. This means that flavors may moderate differences found in individual factors related to vaping, or vice versa. 


\section{Introduction}

Although vaping prevalence in the Netherlands is currently rather low $(3 \%),{ }^{1}$ the use of electronic cigarettes (e-cigarettes) increased worldwide in recent years. ${ }^{2,3}$ The majority of e-cigarette users are former or current smokers ${ }^{4-6}$ and literature has showed that e-cigarette use (i.e., vaping) may be associated with smoking cessation and reduction. ${ }^{7.8}$ In the Netherlands, e-cigarettes are more often used by daily smokers (12\%) compared to non-daily smokers (4\%). Worldwide, vaping is also becoming increasingly popular among adolescent non- and never-smokers. ${ }^{3,9,10}$ The regulation of e-cigarettes in order to optimize public health benefits is challenging and is currently an important topic of debate. Compared to cigarette smoking, vaping may reduce harm among smokers, ${ }^{11-14}$ but literature showed that e-cigarettes contain toxic ingredients. ${ }^{11}$ In addition, concerns have been raised that vaping may contribute to nicotine addiction and the renormalization of cigarette smoking in adolescent never-smokers.,15-18 Consequently, from a public health perspective, the initiation of vaping by current non- and never-smokers and, thereby, exposure to potentially toxic ingredients should be prevented. ${ }^{18}$

Research is needed to better understand differences between the initiation of e-cigarette use by current smokers versus non-smokers in order to inform regulators about policy making regarding e-cigarettes in order to develop targeted health communication for smokers, non-smokers, and e-cigarette users. Previous studies found differences in individual factors related to e-cigarettes among never-users, smokers, dual users, and e-cigarette users. ${ }^{19}$ Individual factors that were found to differ included, for example, knowledge, perceived susceptibility, severity, trust, attitudes, deliberation, social influence, and intention. ${ }^{19-23}$ Furthermore, literature showed that the importance of product characteristics such as design, price, and flavors may differ between adult smokers and adolescent non-smokers. ${ }^{24-27}$ However, the relation between e-cigarette product characteristics and individual-level factors has been neglected.

A recent study hypothesized that there is an important interplay between individual-level factors and the characteristics of tobacco products. ${ }^{28}$ Since product characteristics (e.g., flavors, design, and price) influence e-cigarette appea ${ }^{24-27}$ and may influence a person's attitude towards e-cigarettes, ${ }^{24,28}$ such an interplay may also exist for e-cigarettes. However, thus far, most studies on e-cigarettes focused either on product characteristics, ${ }^{29}$ or on socio-cognitive factors related to vaping behavior. ${ }^{30}$ In contrast, researchers in the food and nutrition domain have already recognized the importance of the interaction between product characteristics and individual-level decision-making factors in food choice. ${ }^{31-33}$ For example, a model by Shepherd ${ }^{31}$ shows that food choice is influenced by the interaction between physical or chemical properties of food, such as flavors (product factor), and the individual's perception of and attitude towards those sensory properties (individual-level factors). Furthermore, flavors 
and other sensory properties are recognized as by far the most important factors in the acceptance and rejection of food products. ${ }^{32}$

Similarly, since e-liquid flavors are recognized as an important reason for e-cigarette use, ${ }^{24}$ flavors may interact with individual-level factors related to vaping. Moreover, the availability of many different, mostly sweet, e-liquid flavors is an important reason for vaping among different types of users. ${ }^{24,29}$ Research showed that for most e-cigarette users, and in particular for youth, the first and current e-liquid had a flavor other than tobacco. ${ }^{26,34,35}$ In addition, flavors increase the probability of choosing e-cigarettes in an online discrete choice experiment among youth, for both never-users and ever-users of e-cigarettes. ${ }^{36}$ Therefore, besides investigating product characteristics as reasons for e-cigarette use, additional research is needed to investigate the interaction between flavors as an e-cigarette product characteristic and individual factors related to vaping.

To increase our understanding of differences in e-cigarette appeal between user groups, this study firstly investigates which product characteristics are found attractive by Dutch never-users, smokers, dual users, and exclusive vapers. Secondly, we aim to determine the flavor preferences of Dutch never-users, smokers, dual users, and exclusive vapers. Thirdly, we aim to explore whether eight individual factors related to vaping differ between never-users and smokers who reported to be interested in trying an e-liquid flavor compared to those who reported not to be interested in trying any e-liquid flavor.

\section{Methods}

A cross-sectional survey was conducted in the Netherlands among never-users of e-cigarettes and cigarettes, cigarette smokers, dual users of e-cigarettes and cigarettes, and e-cigarette users. The survey was administered in May 2017 through the online survey panel Flycatcher, which is an ISO-certified independent research panel specialized in online research. ${ }^{37}$ The study was approved by the Medical Ethics Committee of Zuyderland - Zuyd (17-N-88). The recruitment, participant characteristics, and survey were previously described in Romijnders, Pennings, van Osch, de Vries, Talhout ${ }^{38}$.

\section{Recruitment and Participant Characteristics}

In total, 12,750 invitations were sent to panelists who met the following inclusion criteria: being able to understand Dutch; being aware of e-cigarettes; aged 13-17 years (adolescents) or 18 years and older (adults). Sample size was determined based on a power of $80 \%$ to identify a minimal difference of 1 on a 7-point Likert scale for attitude (based on previous literature ${ }^{39}$ ) as significant at $p<0.05$. The sample cannot be considered representative of the Dutch population, as oversampling for the smokers and e-cigarette users was 
performed in order to achieve sufficient observations. Participants were asked to provide consent before the start of the survey. Parents of panelists under the age of 18 had previously provided consent for participation of their child in research questionnaires. Overall, 1307 surveys were completed, and the response rate was $10.3 \%$ (69.7\% for adults, $n=694 ; 5.2 \%$ for adolescents, $n=613$ ). For the current study, respondents were eligible if they met the definition of one of the following user groups (see Appendix 6): never-users are participants who reported to never have smoked and never used an e-cigarette; smokers are participants who reported to currently exclusively use cigarettes on a daily or weekly basis; dual users are participants who reported to currently simultaneously use cigarettes on a daily or weekly basis and e-cigarettes on a daily or weekly basis; vapers are participants who reported to currently exclusively use e-cigarettes on a daily or weekly basis. ${ }^{40}$

It should be noted that these definitions, similar to studies performed before, ${ }^{39}$ includes individuals who had no history of smoking prior to becoming an exclusive vaper. In addition, and due to the cross-sectional nature of the data, no transitory phases for dual users and exclusive vapers can be determined. ${ }^{40}$ We aimed for mutually exclusive groups. Hence, as the group of exclusive vapers may also include former smokers and the group of exclusive smokers may also include former vapers, former users were not included as a separate group. An overview of the items used to determine whether respondents met our definitions can be found in Appendix 6. In total, 728 participants met the eligibility criteria of this study. Of those, 394 were adults (62.4\% female) and 334 were adolescents (46.7\% female).

\section{Survey}

The current study included measures on basic demographics, attractiveness of e-cigarettes, flavor preferences, and individual factors related to vaping. The survey included routing to ensure that participants were asked about relevant items only (e.g., never-users were not asked which flavor their first e-cigarette had). A full overview of the items and concepts is available in Appendix 6.

First, participants were asked about basic demographics, and smoking and vaping characteristics. ${ }^{19,24,40-44}$ Educational level was determined based on the Dutch version of the International Standard Classification of Education (ISCED) ${ }^{45}$

Second, participants were asked to evaluate the attractiveness of eight product characteristics of e-cigarettes from a predetermined list using a check all that apply (CATA) approach that was based on previous research 19,24. For the items that were used to assess demographics and attractiveness of product characteristics, see Appendix 6. 
Third, interest in trying an e-liquid flavor (for never-users and smokers), and the first and current e-liquid flavors used (for dual and e-cigarette users) were assessed. For the items that were used to assess flavor preferences, see Appendix 6. To assess flavor interest among never-users and smokers, multiple flavor categories ${ }^{46}$ (CATA) or the option "none of the flavors" were selected. If the latter answer option was selected, no flavor category could be selected simultaneously. E-cigarette users and dual users were asked about their current and first e-liquid flavor used: "Which flavor do you currently use most? If possible, please specify the name of the flavor" and "Which flavor did you try first? If possible, please specify the name of the flavor." For both current and first flavor used, dual users and e-cigarette users could select only one flavor category ${ }^{46}$ and had to specify their choice through an open question. The answer options for never-users, smokers, dual users and e-cigarette users were: tobacco, menthol/mint, nuts, herbs, spices, coffee/tea, cocktails, alcohol, other, sodas, sweet (chocolate, vanilla, desserts, or other), fruit, milk products, candy, floral, unflavored, and none of the flavors. The closed answer options that were used to assess flavor preference in all user groups were recoded according to the thirteen main categories of the recently published e-liquid flavor wheel, ${ }^{47}$ except for the option "none of the flavors". Recoding the reported flavor preferences resulted in the in the following thirteen main categories: tobacco (survey item: tobacco), menthol/mint (survey item: menthol/mint), nuts (survey item: nuts), spices (survey items: herbs, spices), coffee/tea (survey items: coffee; tea), alcohol (survey items: alcohol, cocktail; alcohol, other), other beverages (survey items: soda; sweet, other), fruit (survey item: fruit), dessert (survey items: sweet, dessert; milk product), other sweets (survey items: sweet, chocolate; sweet, vanilla), candy (survey items: sweet, candy), other flavors (survey items: floral; other) and unflavored (survey item: unflavored). Open answers from dual and e-cigarette users were assessed by two authors (KR and EK) to support recoding of the closed answers according to the categories of the e-liquid flavor wheel. ${ }^{47}$ In some cases, multiple survey items were associated with one flavor category (e.g., the survey answer options "sweet, chocolate" and "sweet, vanilla" were both recoded to the other sweets flavor category). For equal weight of the flavor categories, each participant could obtain a maximum score of "1" for each flavor category. Thus, participants who reported being interested in both chocolate- and vanillaflavored e-liquids received a total score of " 1 " for the other sweets flavor category.

Fourth, individual factors related to vaping were assessed (see Appendix 6 for the items that were used). Evidence-based knowledge about smoking and vaping was measured with 12 statements that were either correct or incorrect. We consider evidence-based knowledge as knowledge that is based on scientific consensus - that is, information provided by the Dutch National Institute of Public Health and the Environment (RIVM) and previous research. ${ }^{19,48,49}$ The knowledge items were summed ( $1=$ correct, $0=$ incorrect; 'I don't know' was categorized as incorrect). Furthermore, a 7-point Likert scale was used to assess trust in information (two items), ${ }^{50}$ perceived susceptibility towards e-cigarettes 
(three items: item $A$, item $B$, item C), ${ }^{51,52}$ severity related to vaping (four items ${ }^{51,52}$ ), attitude towards e-cigarettes (four items), ${ }^{39,48}$ social influence (one item), ${ }^{53}$ deliberation about vaping (three items), ${ }^{48}$ and intention to start using e-cigarettes (one item). A scale was computed for trust in information, severity related to vaping, attitude towards e-cigarettes, and deliberation of the pros and cons of vaping, by averaging the scores of the two items for trust (Cronbach's $a=0.915$ ), the four items for severity (Cronbach's $a=0.639$ ), the four items of attitude (Cronbach's $a=0.927$ ), and the three items for deliberation (Cronbach's $a=0.656$ ). No scale could be computed for perceived susceptibility towards e-cigarettes (Cronbach's $a \leq 0.6$ ) - thus, for each user group, the three mean scores for perceived susceptibility towards e-cigarettes and the three mean scores for perceived susceptibility towards cigarettes (for each individual survey item) were used. Similarly, for each user group, the mean score for each item regarding intention and social influence was determined.

\section{Data Analysis}

IBM statistics SPSS version 24 (IBM, Armonk, NY, USA) 54 was used for data analysis. No data were excluded. Attractiveness of product characteristics, and the e-liquid flavor categories preferred (for never-users and smokers, excluding those who selected the answer option "I don't want to try any flavor") and firstly and currently used (for dual and exclusive vapers) were analyzed using frequencies. Flavor preferences were presented in a pie chart as the percentage of the total number of responses.

Spearman correlation analyses showed that age $(p<0.05)$, gender, and level of education $(<0.05)$ were significantly associated with individual factors related to vaping. However, these Spearman correlations were small, ranging from -0.211 to 0.169 . Age, level of education, and gender were therefore excluded from further analyses due to small or non-significant correlations.

Individual factors were compared between both never-users and smokers interested in trying an e-liquid flavor and those not interested in trying a flavor (answer option: "none of the flavors") using $t$-tests. Results were considered significant if $p<0.05$.

\section{Results}

Of the 728 never-users, smokers, dual users, and exclusive e-cigarette users, $23.7 \%$ was highly educated $(50.0 \%$ low education level and $26.2 \%$ middle education level), and the average age was $34.1( \pm 20.2, \min =13, \max =84)$ (see Table 4.1). 
Table 4.1 Participants' demographics and the attractiveness of e-cigarette product characteristics. Data are presented for adult and adolescent never-users $(n=407)$, smokers $(n=138)$, dual users $(n=122)$, and exclusive vapers $(n=61)$.

\begin{tabular}{|c|c|c|c|c|c|}
\hline \multicolumn{2}{|c|}{$\begin{array}{l}\text { Participants' demographics and } \\
\text { the attractiveness of e-cigarette } \\
\text { product characteristics }\end{array}$} & $\begin{array}{l}\text { Never- } \\
\text { users } \\
(\boldsymbol{n}=407) \\
\end{array}$ & $\begin{array}{l}\text { Smokers }(\boldsymbol{n} \\
=138)\end{array}$ & $\begin{array}{l}\text { Dual users } \\
(\boldsymbol{n}=122)\end{array}$ & $\begin{array}{l}\text { Exclusive } \\
\text { vapers } \\
(\boldsymbol{n}=61) \\
\end{array}$ \\
\hline \multicolumn{2}{|l|}{$\begin{array}{l}\text { Mean age } \\
( \pm \text { SD })\end{array}$} & $31(18.6)^{D}$ & $35(20.6)$ & $37(18.8)^{N}$ & $37(19.4)$ \\
\hline \multirow[t]{2}{*}{ Gender } & Male & $44.0 \%$ & $37.7 \%$ & $53.3 \%$ & $49.2 \%$ \\
\hline & Female & $56.0 \%$ & $62.3 \%$ & $46.7 \%$ & $50.8 \%$ \\
\hline \multirow[t]{3}{*}{ Education } & Low & $52.1 \%$ & $52.9 \%$ & $43.4 \%$ & $39.3 \%$ \\
\hline & Middle & $20.6 \%$ D,E & $30.4 \%$ & $35.2 \% \mathrm{~N}$ & $44.3 \%{ }^{N}$ \\
\hline & High & $27.3 \%$ & $16.7 \%$ & $21.3 \%$ & $16.4 \%$ \\
\hline \multirow{8}{*}{$\begin{array}{l}\text { Attractive } \\
\text { characteristics } \\
\text { of e-cigarettes } \\
\text { (\%) }\end{array}$} & $\begin{array}{l}\text { All the different } \\
\text { flavors }\end{array}$ & $10.3 \%$ & $30.4 \%$ & $34.4 \%$ & $68.9 \%$ \\
\hline & $\begin{array}{l}\text { The product looks } \\
\text { nice }\end{array}$ & $6.6 \%$ & $19.6 \%$ & $22.1 \%$ & $44.3 \%$ \\
\hline & $\begin{array}{l}\text { The nicotine level } \\
\text { can be varied }\end{array}$ & $4.7 \%$ & $13.8 \%$ & $15.6 \%$ & $31.1 \%$ \\
\hline & $\begin{array}{l}\text { It is possible to } \\
\text { alter the setting of } \\
\text { the e-cigarette to } \\
\text { my wishes }\end{array}$ & $3.7 \%$ & $10.9 \%$ & $12.3 \%$ & $24.6 \%$ \\
\hline & Its varying designs & $3.2 \%$ & $9.4 \%$ & $10.7 \%$ & $21.3 \%$ \\
\hline & $\begin{array}{l}\text { You can blow nice } \\
\text { smoke clouds with } \\
\text { it (cloud chasing) }\end{array}$ & $2.5 \%$ & $7.2 \%$ & $8.2 \%$ & $16.4 \%$ \\
\hline & $\begin{array}{l}\text { Price of the } \\
\text { product }\end{array}$ & $2.0 \%$ & $5.8 \%$ & $6.6 \%$ & $13.1 \%$ \\
\hline & $\begin{array}{l}\text { Price of the } \\
\text { e-liquids }\end{array}$ & $2.0 \%$ & $5.8 \%$ & $6.6 \%$ & $13.1 \%$ \\
\hline
\end{tabular}

$N, D, E$ Superscripts indicate significant differences in a row between user groups $(p<0.05)$, with $N=$ never-users, $D=$ dual users, and $E=$ exclusive vapers. Significant differences between user groups were determined for age, gender, and education using Bonferroni post-hoc corrections. General note: due to rounding, percentages may not add up to $100 \%$.

\section{Attractiveness of Product Characteristics}

Table 4.1 shows attractiveness of e-cigarette product characteristics, stratified by user group. From the e-cigarette product characteristics assessed, all groups reported flavors as the most attractive. 


\section{E-Liquid Flavor Preferences}

Of the 407 never-users, 68\% selected the option "none of the flavors" ( $n=$ 278 participants) and $32 \%$ selected to be interested in trying one or more e-liquid flavor" and 32\% ( $n=248$ responses)). Of the 138 smokers, 20\% ( $n=27$ participants) were interested in none of the flavors and $80 \%$ ( $n=208$ responses) selected to be interested in trying one or more e-liquid flavor categories.

Figure 4.1 showse-liquidflavorpreferencesasthepercentage ofeachflavorcategory for never-users and smokers. Never-users were mostly interested in trying e-liquid flavors from the menthol/mint (19\% of 248 responses) and sweet categories, such as other sweets (19\%) and fruit (14\%). Smokers were mostly interested in e-liquids with tobacco flavor (30\%), followed by menthol/mint (18\%) and other sweets (9\%).

Of the 122 dual users, 120 reported the flavor of their first e-cigarette used and 121 reported the flavor they currently use (see Figure 4.2). Of the 61 exclusive vapers, 58 reported the flavor of both their first and current e-cigarette. Among dual users, the most frequently reported flavors of their current and first e-cigarette used were similar: tobacco (52\% vs. $53 \%)$, menthol/mint (26\% vs. $27 \%)$, other sweets (10\% vs. $11 \%)$, and fruit (7\% vs. $6 \%)$. Among exclusive vapers, differences were observed in the most frequently reported flavors of their current and first e-cigarette used: tobacco (43\% vs. 53\%), menthol/mint (19\% vs. $28 \%)$ ), and fruit (14\% vs. 9\%) and other sweets (14\% vs. $7 \%$ ).
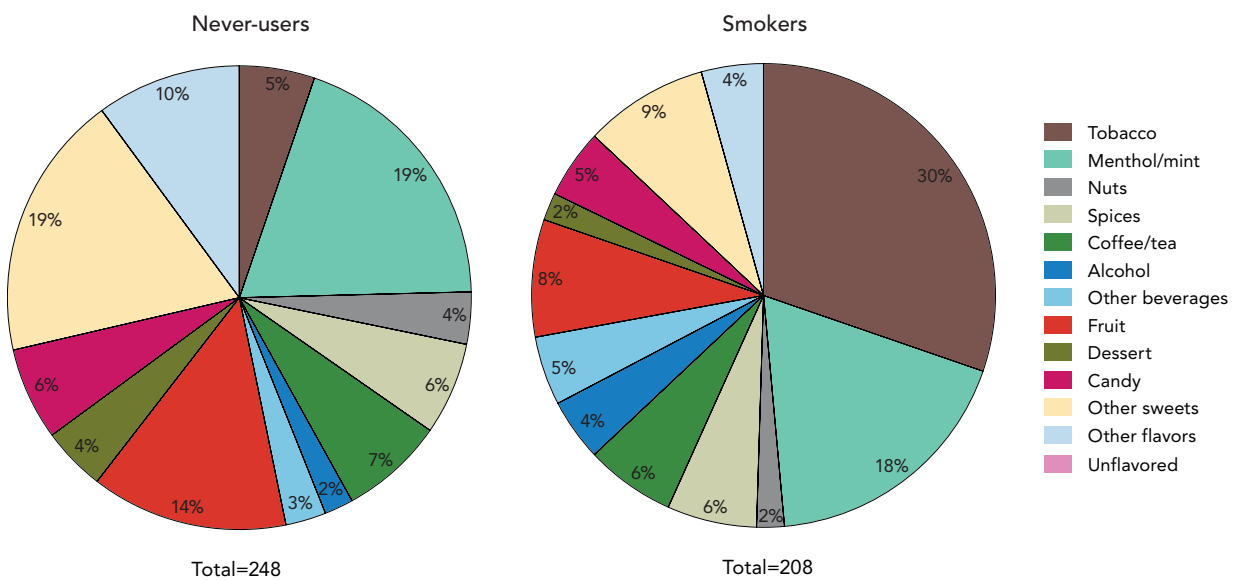

Figure 4.1 Interest in trying e-liquid flavors among never-users (left) and smokers (right). Never-users $(n=278 ; 68 \%)$ and smokers $(n=27 ; 20 \%)$ who selected the option "none of the flavors" were excluded from this visualization, and hence the pie charts visualize 248 responses from $32 \%$ of the never-users and 208 responses from $80 \%$ of the smokers. Data are presented as percentages of the total number of responses, not of the total sample sizes. 

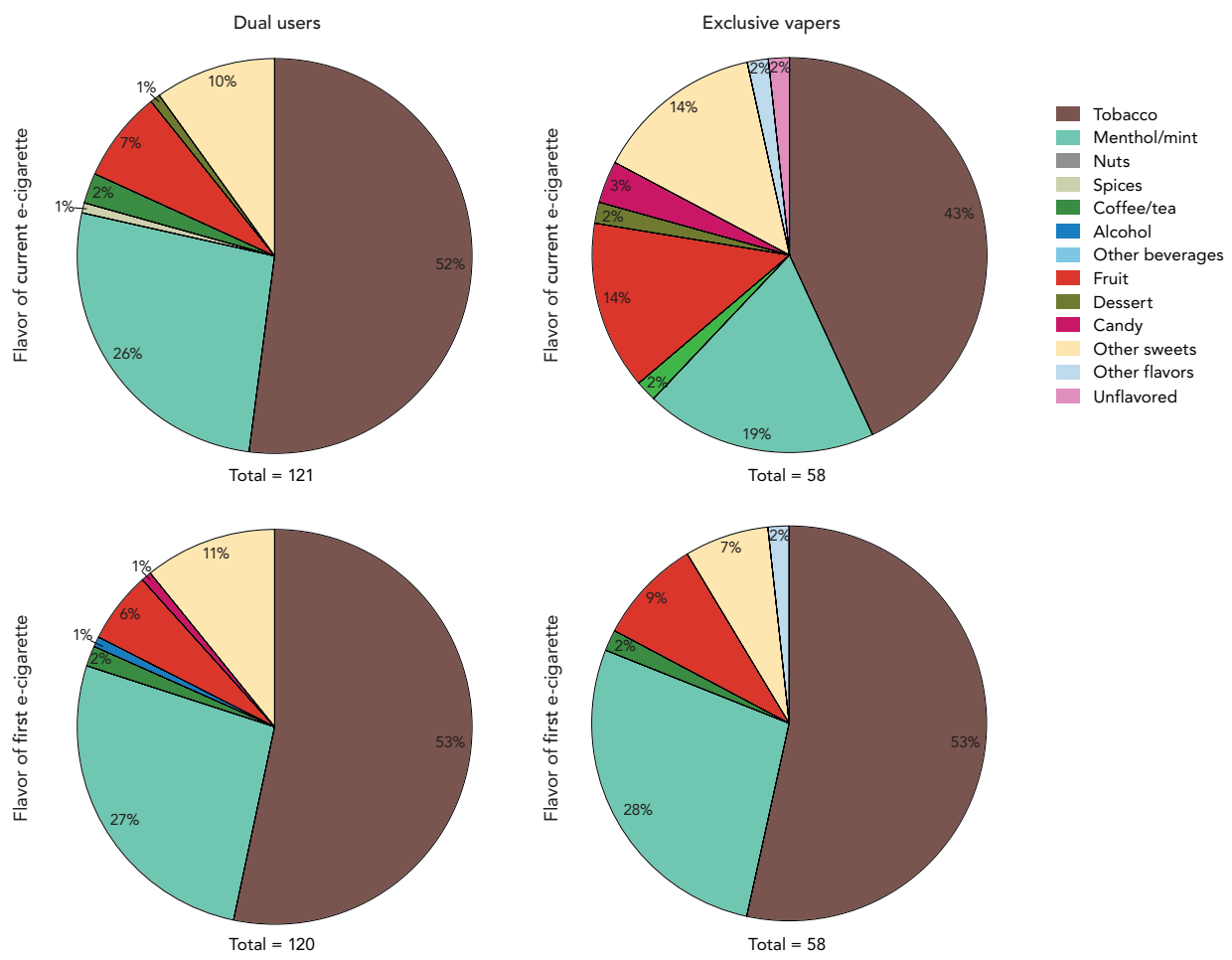

Figure 4.2 Flavors used on current (top) and first (bottom) e-cigarette exposure among dual (left) and exclusive vapers (right). Participants could select only one flavor category to indicate the flavor of their current and first e-cigarette used. Data are presented as percentages of the total number of responses, not of the total sample sizes.

\section{Individual Factors Related to Vaping}

Table 4.2 shows differences in individual factors related to vaping between never-users and smokers. In addition, differences within the groups of neverusers and smokers between those who were interested in trying an e-liquid flavor and those who did not want to try any flavor are shown. Never-users who were interested in trying a flavor had significantly less knowledge about e-cigarettes compared to never-users who did not want to try any e-liquid flavor $(p<0.05)$. Not surprisingly, never-users and smokers who were interested in trying a flavor were significantly more positive towards e-cigarettes and had a significant higher intention to start vaping, compared to never users and smokers who reported not wanting to try any e-liquid flavor $(p<0.05)$, within both never-users and smokers. Never-users who were interested in trying a flavor reported a lower perceived susceptibility (item $C$ ) than never-users who did not want to try a flavor $(p<0.05)$. In addition, smokers who were interested in trying a flavor considered the social influence towards not using e-cigarettes as less strong, which means 
that the smokers who were not interested in trying an e-cigarette flavor more often find that society thinks that one should not vape $(p<0.05)$.

Table 4.2 Individual factors related to vaping. Data are presented for never-users and smokers.

\begin{tabular}{|c|c|c|c|c|}
\hline $\begin{array}{l}\text { Individual factors } \\
\text { related to vaping }\end{array}$ & & & $\begin{array}{l}\text { Never-users } \\
(n=407)\end{array}$ & $\begin{array}{l}\text { Smokers } \\
(\boldsymbol{n}=138)\end{array}$ \\
\hline \multirow{3}{*}{$\begin{array}{l}\text { Knowledge about } \\
\text { e-cigarettes and } \\
\text { cigarettes }( \pm S D)\end{array}$} & & Overall & $9.3(1.5)$ * & $8.4(1.8)$ * \\
\hline & & Those interested in trying a flavor & $8.9(1.7)^{\circ}$ & $8.4(1.7)$ \\
\hline & & $\begin{array}{l}\text { Those who did not want to try } \\
\text { any flavor }\end{array}$ & $9.4(1.4)^{\circ}$ & $8.3(2.1)$ \\
\hline \multirow{3}{*}{$\begin{array}{l}\text { Trust in information } \\
( \pm \mathrm{SD})\end{array}$} & & Overall & $5.2(1.1)$ & $4.9(1.4)$ \\
\hline & & Those interested in trying a flavor & $5.2(1.0)$ & $4.9(1.4)$ \\
\hline & & $\begin{array}{l}\text { Those who did not want to try } \\
\text { any flavor }\end{array}$ & $5.2(1.4)$ & $5.1(1.5)$ \\
\hline \multirow{9}{*}{$\begin{array}{l}\text { Perceived } \\
\text { susceptibility about } \\
\text { vaping ( }(\mathrm{SD})\end{array}$} & A & Overall & $4.9(1.3)^{\star}$ & $4.3(1.2)$ * \\
\hline & & Those interested in trying a flavor & $4.8(1.3)$ & $4.2(1.2)$ \\
\hline & & $\begin{array}{l}\text { Those who did not want to try } \\
\text { any flavor }\end{array}$ & $4.9(1.3)$ & $4.4(1.2)$ \\
\hline & $\mathrm{B}$ & Overall & $5.0(1.2)^{*}$ & $4.3(1.2)$ * \\
\hline & & Those interested in trying a flavor & $4.8(1.2)$ & $4.3(1.2)$ \\
\hline & & $\begin{array}{l}\text { Those who did not want to try } \\
\text { any flavor }\end{array}$ & $5.1(1.2)$ & $4.5(1.2)$ \\
\hline & $\mathrm{C}$ & Overall & $4.9(1.2)^{*}$ & $4.3(1.2)^{*}$ \\
\hline & & Those interested in trying a flavor & $4.8(1.3)^{\circ}$ & $4.2(1.2)$ \\
\hline & & $\begin{array}{l}\text { Those who did not want to try } \\
\text { any flavor }\end{array}$ & $5.0(1.2)^{\circ}$ & $4.6(1.2)$ \\
\hline \multirow{3}{*}{\multicolumn{2}{|c|}{$\begin{array}{l}\text { Severity of vaping } \\
( \pm \text { SD) }\end{array}$}} & Overall & $4.6(1.1) *$ & $4.4(1.1)$ * \\
\hline & & Those interested in trying a flavor & $4.6(1.1)$ & $4.4(1.2)$ \\
\hline & & $\begin{array}{l}\text { Those who did not want to try } \\
\text { any flavor }\end{array}$ & $4.6(1.1)$ & $4.1(1.1)$ \\
\hline \multirow{3}{*}{\multicolumn{2}{|c|}{$\begin{array}{l}\text { Attitude towards } \\
\text { e-cigarettes }( \pm S D)\end{array}$}} & Overall & $2.1(1.1) *$ & $3.5(1.1)$ * \\
\hline & & Those interested in trying a flavor & $2.6(1.2)^{\circ}$ & $3.7(1.0)^{\circ}$ \\
\hline & & $\begin{array}{l}\text { Those who did not want to try } \\
\text { any flavor }\end{array}$ & $1.9(1.0)^{\circ}$ & $2.9(1.2)^{\circ}$ \\
\hline \multirow{3}{*}{$\begin{array}{l}\text { Social influence } \\
( \pm S D)\end{array}$} & & Overall & $5.1(1.7)^{*}$ & $4.4(1.5)^{N}$ \\
\hline & & Those interested in trying a flavor & $4.9(1.7)$ & $4.2(1.5)^{\circ}$ \\
\hline & & $\begin{array}{l}\text { Those who did not want to try } \\
\text { any flavor }\end{array}$ & $5.2(1.7)$ & $5.1(1.2)^{\circ}$ \\
\hline
\end{tabular}




\begin{tabular}{|c|c|c|c|}
\hline $\begin{array}{l}\text { Individual factors } \\
\text { related to vaping }\end{array}$ & & $\begin{array}{l}\text { Never-users } \\
(n=407)\end{array}$ & $\begin{array}{l}\text { Smokers } \\
(\boldsymbol{n}=138)\end{array}$ \\
\hline \multirow{3}{*}{$\begin{array}{l}\text { Deliberation on the } \\
\text { pros and cons of } \\
\text { e-cigarette use }( \pm S D)\end{array}$} & Overall & $2.8(1.5)$ & $3.0(1.5)$ \\
\hline & Those interested in trying a flavor & $2.9(1.6)$ & $3.1(1.4)$ \\
\hline & $\begin{array}{l}\text { Those who did not want to try } \\
\text { any flavor }\end{array}$ & $2.7(1.5)$ & $2.7(1.7)$ \\
\hline \multirow{3}{*}{$\begin{array}{l}\text { Intention to start } \\
\text { vaping }( \pm S D)\end{array}$} & Overall & $1.2( \pm 0.8)$ * & $2.5( \pm 1.7)$ * \\
\hline & Those interested in trying a flavor & $1.4(1.1)^{\circ}$ & $2.7(1.7)^{\circ}$ \\
\hline & $\begin{array}{l}\text { Those who did not want to try } \\
\text { any flavor }\end{array}$ & $1.1(0.6)^{\circ}$ & $1.6(1.4)^{\circ}$ \\
\hline
\end{tabular}

* Indicates significant differences $(p<0.05)$ in a row between user groups. ${ }^{\circ}$ Indicates a within-group significant difference $(p<0.05)$ between those who were interested in trying any e-liquid flavor and those who were not interested in trying any e-liquid flavor (only for never-users and smokers). Knowledge was determined using 12 statements. A higher score represents more knowledge, with $0=$ no correct answers and $12=$ correct answers for all statements. Trust was assessed with two items, using a 7-point Likert scale; 1 low to $7=$ high level of trust in information provided. Perceived susceptibility assessed the chance of developing cancer as a result of vaping with three statements: (A) If I vape, then my risk of developing some form of cancer during my lifetime is...; (B) I think that if I vape, my risk of developing some form of cancer during my lifetime is ...; (C) My feeling is that if I vape, the risk of developing some form of cancer during my lifetime is...; 1 = low to 7 = perception of cognitive risk of health risks related to e-cigarette use. Severity was assessed with four items, on a 7-point Likert scale ranging from very bad to not bad at all (1-7); Attitude was assessed with four items, using a 7-point Likert scale, with $1=$ very negative towards e-cigarette use and $7=$ very positive towards e-cigarette use. Deliberation was assessed with three items on a 7-point Likert scale, with $1=$ no deliberation about E-cigarette use to 7 = very extensive deliberation about E-cigarette use. Intention to start vaping was reported on a 7-point Likert scale, with $1=$ very low intention to start vaping and $7=$ very high intention to start vaping.

\section{Discussion}

This study shows that the availability of different flavors was reported to be the most attractive product characteristic of e-cigarettes by all user groups, and that flavor preferences differ between never-users, smokers, dual users, and exclusive vapers. The first e-cigarette used by dual users and vapers mostly had a tobacco or menthol/mint flavor, but compared to dual users, we observed that exclusive vapers use more sweet- and fruit-flavored e-liquids than dual users. While tobacco was the most appealing flavor category among smokers, neverusers were mostly interested in trying menthol- and sweet-flavored e-liquids. In addition, individual factors related to vaping differed within the groups of never-users and smokers. That is, never-users interested in trying a flavor had 
less knowledge about cigarettes and e-cigarettes than those who did not want to try any flavor. Attitude was more positive, and intention to start vaping was higher among both never-users and smokers who were interested in trying a flavor compared to those not interested in trying a flavor. Perceived susceptibility of health consequences was lower among never-users who were interested in trying a flavor, and social influence regarding not using e-cigarettes was lower among smokers who were interested in trying a flavor. Thus, similarly to the role of flavors in food choice, ${ }^{31,32}$ our results indicate that interest in flavors may moderate the differences in individual factors related to vaping.

While concerns have been raised about potential e-cigarette use among neverusers, $, 3,95$ the never-users in our study had a low intention to start vaping and more than two-third (68\%) of the never-users did not want to try any e-liquid flavor. However, nearly one-third of the never-users were still interested in trying an e-liquid flavor. Not surprisingly, they perceived a lower susceptibility towards negative health consequences of vaping, had a more positive attitude towards e-cigarettes, less knowledge about cigarettes and e-cigarettes, and a higher intention to start vaping than never-users who did not want to try any flavor. It should, however, be noted that a causal relation between these findings was not examined. For example, never-users could report to find e-liquid flavors interesting because they were already interested in trying e-cigarettes. On the other hand, they may have become interested in trying e-cigarettes because of the appealing flavors that they recognize from palatable food products. This means that being interested in flavors has a positive effect on the decision to start using e-cigarettes, or vice versa. Nevertheless, our findings regarding the interest of never-users in e-liquid flavors indicate that never-users may be vulnerable to flavor marketing of e-cigarettes. ${ }^{26,27,56,57}$ For example, marketing of appealing e-liquid flavors may make never-users even more positive towards vaping, thereby potentially influencing their choice to initiate or refrain from vaping. ${ }^{19}$ This suggests that the reverse can also be true: adapting product characteristics, for example restricting e-liquid flavors or regulating other product characteristics, may reduce attractiveness and consequently make never-users more negative about vaping. Some characteristics of e-liquids are currently regulated by Tobacco Regulation in the Netherlands. ${ }^{58,59}$ However, legislation regarding e-liquid flavors currently does not exist. Further research is needed to help regulators decide whether and how the regulation of e-liquid flavors can improve public health.

This study showed that smokers who were interested in trying an e-liquid flavor had a more positive attitude towards e-cigarettes than smokers who were not interested in trying a flavor. In addition, smokers who were interested in trying a flavor considered the social influence towards not using e-cigarettes as less strong, which means that the smokers who were not interested in trying an e-cigarette flavor more often find that society thinks that one should not vape. Furthermore, two-third of the smokers reported interest in an e-liquid flavor 
other than tobacco. This indicates that flavors could support the decision of smokers to switch to vaping, ${ }^{57}$ for example by allowing the marketing of e-liquid flavors and other product characteristics that smokers find attractive. ${ }^{4}$ The role of e-liquid flavors in supporting both the decision to switch towards e-cigarette use (for smokers) and to refrain from using e-cigarettes (for never-users) demonstrates the complexity of developing future regulations on e-liquid flavors.

Additional support for the interest in flavors moderating differences in individual factors related to vaping is provided by the different patterns of e-liquid flavors used by dual users and exclusive vapers. In line with previous research, both groups mostly used tobacco and mint flavored e-cigarettes at initiation, but exclusive vapers currently used more fruit and sweet e-liquid flavors than dual users. $5,34,60-62$ This could be interpreted as vapers switching from tobacco to nontobacco flavors over time, which is supported by a previous study. ${ }^{5}$ Because most adult exclusive vapers included in this study used e-cigarettes for 1 to 5 years and most dual users reported to vape for only less than 6 months (data not shown), it is possible that the dual users may switch to fruit or sweet e-liquid flavors in the future. Longitudinal research is needed to investigate whether and how e-liquid flavors could support dual users in their decision to switch to exclusive vaping. In addition, it would be interesting to investigate the process of e-liquid flavors (or other product characteristics) eventually not living up to dual users' expectation, thereby leaving them to quit vaping and relapse into exclusive cigarette smoking. This information could be used to, for example, stimulate an exchange of knowledge and experiences between exclusive vapers and dual users about the flavored e-liquids they use..$^{63}$

\section{Future Research}

Previous studies assessing individual factors related to vaping mostly focused their survey items on e-cigarettes in general. This means that participants are typically asked about their mental representation or beliefs of an unspecified e-cigarette, thereby not taking into account that the e-cigarette is a product that is available in various shapes, sizes, colors, flavors, and more. As our results suggest that flavors may moderate the differences in individual factors related to vaping, we recommend using survey items that represent a specific flavor or other product characteristic. For example, instead of only focusing on perceived susceptibility attitude towards e-cigarettes in general, ${ }^{64,65}$ researchers should also assess perceived susceptibility attitudes towards a specific e-liquid flavor categories, such as fruit, candy, and tobacco. ${ }^{47}$

In addition, as other product characteristics may moderate differences found in individual factors related to vaping, the impact of for example price, labeling, and packaging of e-cigarettes and e-liquids on individual factors related to vaping should be investigated in different user groups ${ }^{66}$ to determine which characteristics make up their "ideal" e-cigarette. 
Furthermore, it would be interesting to use sensory research to investigate differences in e-liquid flavor liking between user groups, and how this relates to individual factors related to vaping. Finally, research is needed to investigate the interaction between product characteristics and individual factors related to new and emerging products, such as heated tobacco products and products containing nicotine salts. This will provide insight into which specific product characteristics are most appealing to vulnerable user groups, such as never-users and youth, and thus need to be regulated.

\section{Limitations}

Ideally, our sample size would be large enough to stratify our sample into different age groups and different flavor categories. However, our sample size was too small to determine differences in the preference of specific flavor categories between age groups (adults vs. adolescents), and differences in individual factors related vaping between specific flavor categories. In addition, response rates among adolescents was very low, and the rather high education level of participants in this study was not be representative of the Dutch population. ${ }^{67,68}$ In addition, the sample cannot be considered representative of the Dutch population, as oversampling for the smokers and e-cigarette users was performed in order to have sufficient observations. As a result, the percentages of smokers and vapers in our study do not reflect the actual percentages of smokers and vapers in the Dutch population.

\section{Conclusions}

This study demonstrates that being interested in flavors moderates the differences in individual factors related to vaping for never-users and smokers, or vice versa. While the availability of different flavors was reported to be the most attractive product characteristic of e-cigarettes in all user groups, the specific flavor preferences varied between never-users, smokers, dual users, and exclusive vapers. Importantly, individual factors related to vaping (knowledge, perceived susceptibility attitude, social influence, and intention to start vaping) differed between never-users and/or smokers who were interested in trying an e-liquid flavor and those who did not want to try a flavor. Our results confirm the importance and complexity of regulating e-liquid flavors in a way that both the decision to switch towards vaping (for smokers) and the decision to refrain from vaping (for never-users) are supported. Ideally, regulation should allow marketing of e-liquid flavors that stimulate smokers and dual users to keep or start using e-cigarettes. To make never-users more negative about and keep them from using e-cigarettes, product appeal should be reduced by, for example, restricting the marketing and promotion of e-liquid flavors that they find particularly appealing. 


\section{References}

1. Springvloet $L$, Bommele J, Willemsen M, van Laar M. KERNCIJFERS ROKEN 2017. Utrecht Trimbos-instituut;2018.

2. Filippidis FT, Laverty AA, Gerovasili V, Vardavas Cl. Two-year trends and predictors of e-cigarette use in 27 European Union member states. Tob Control. 2017;26(1):98-104.

3. McMillen RC, Gottlieb MA, Shaefer RM, Winickoff JP, Klein JD. Trends in Electronic Cigarette Use Among U.S. Adults: Use is Increasing in Both Smokers and Nonsmokers. Nicotine Tob Res. 2015;17(10):1195-1202.

4. Diamantopoulou E, Barbouni A, Merakou K, Lagiou A, Farsalinos K. Patterns of e-cigarette use, biochemically verified smoking status and self-reported changes in health status of a random sample of vapeshops customers in Greece. Intern Emerg Med. 2019.

5. Russell C, McKeganey N, Dickson T, Nides M. Changing patterns of first e-cigarette flavor used and current flavors used by 20,836 adult frequent e-cigarette users in the USA. Harm Reduct J. 2018;15(1):33.

6. Nationaal Expertisecentrum Tabaksontmoediging (Trimbos-instituut). Kerncijfers Roken 2017. 2018. https://www.trimbos.nl/docs/cdade14e-20dc-462a-9f631b71ee995a84.pdf.

7. Rahman MA, Hann N, Wilson A, Mnatzaganian G, Worrall-Carter L. E-cigarettes and smoking cessation: evidence from a systematic review and meta-analysis. PLoS One. 2015;10(3):e0122544.

8. Chan G, Morphett K, Gartner C, et al. Predicting vaping uptake, vaping frequency and ongoing vaping among daily smokers using longitudinal data from the International Tobacco Control (ITC) Four Country Surveys. Addiction. 2018.

9. Miech R, Johnston L, O'Malley PM, Bachman JG, Patrick ME. Adolescent Vaping and Nicotine Use in 2017-2018 - U.S. National Estimates. N Engl J Med. 2019;380(2):192-193.

10. Cullen KA, Gentzke AS, Sawdey MD, et al. e-Cigarette Use Among Youth in the United States, 2019. JAMA. 2019.

11. Prochaska JJ. The public health consequences of e-cigarettes: a review by the National Academies of Sciences. A call for more research, a need for regulatory action. Addiction. 2019;114(4):587-589.

12. Chen J, Bullen C, Dirks K. A Comparative Health Risk Assessment of Electronic Cigarettes and Conventional Cigarettes. Int J Environ Res Public Health. 2017;14(4).

13. Goniewicz ML, Gawron M, Smith DM, et al. Exposure to Nicotine and Selected Toxicants in Cigarette Smokers Who Switched to Electronic Cigarettes: A Longitudinal Within-Subjects Observational Study. Nicotine Tob Res. 2017;19(2):160-167.

14. Levy DT, Borland R, Lindblom EN, et al. Potential deaths averted in USA by replacing cigarettes with e-cigarettes. Tob Control. 2018;27(1):18-25. 
15. Kinouani S, Pereira E, Tzourio C. Electronic Cigarette Use in Students and Its Relation with Tobacco-Smoking: A Cross-Sectional Analysis of the i-Share Study. Int J Environ Res Public Health. 2017;14(11).

16. Liu X, Lugo A, Davoli E, et al. Electronic cigarettes in Italy: a tool for harm reduction or a gateway to smoking tobacco? Tob Control. 2019.

17. Soneji S, Barrington-Trimis JL, Wills TA, et al. Association Between Initial Use of e-Cigarettes and Subsequent Cigarette Smoking Among Adolescents and Young Adults: A Systematic Review and Meta-analysis. JAMA Pediatr. 2017;171(8):788-797.

18. McRobbie H. Modelling the Population Health Effects of E-Cigarettes Use: Current Data Can Help Guide Future Policy Decisions. Nicotine Tob Res. 2017;19(2):131-132.

19. Romijnders K, van Osch L, de Vries H, Talhout R. A Deliberate Choice? Exploring the Decision to Switch from Cigarettes to E-Cigarettes. Int J Environ Res Public Health. 2019;16(4).

20. Marteau TM, Dormandy E, Crockett R. Informed choice: why measuring behaviour is important. Arch Dis Child. 2005;90(5):546-547; author reply 546-547.

21. van den Berg M, Timmermans DR, ten Kate LP, van Vugt JM, van der Wal G. Informed decision making in the context of prenatal screening. Patient Educ Couns. 2006;63(1-2):110-117.

22. Baron J. Thinking and Deciding. 4th ed. Cambridge: Cambridge University Press; 2007.

23. Gray RJ, Hoek J, Edwards R. A qualitative analysis of 'informed choice' among young adult smokers. Tob Control. 2016;25(1):46-51.

24. Romijnders K, van Osch $L$, de Vries $H$, Talhout R. Perceptions and Reasons Regarding E-Cigarette Use among Users and Non-Users: A Narrative Literature Review. Int J Environ Res Public Health. 2018;15(6).

25. Laverty AA, Vardavas $\mathrm{Cl}$, Filippidis FT. Design and marketing features influencing choice of e-cigarettes and tobacco in the EU. Eur J Public Health. 2016;26(5):838841.

26. Villanti AC, Johnson AL, Ambrose BK, et al. Flavored Tobacco Product Use in Youth and Adults: Findings From the First Wave of the PATH Study (2013-2014). Am J Prev Med. 2017;53(2):139-151.

27. Chen-Sankey JC, Kong G, Choi K. Perceived ease of flavored e-cigarette use and e-cigarette use progression among youth never tobacco users. PLoS One. 2019;14(2):e0212353.

28. McClernon FJ, Pacek LR, Wiley JL. A Conceptual Framework for Understanding Multiple Tobacco Product Use and the Impact of Regulatory Action. Nicotine \& Tobacco Research. 2018;21(3):268-277.

29. Zare S, Nemati M, Zheng Y. A systematic review of consumer preference for e-cigarette attributes: Flavor, nicotine strength, and type. PLoS One. 2018;13(3):e0194145.

30. Adriaens K, Van Gucht D, Baeyens F. Differences between Dual Users and Switchers Center around Vaping Behavior and Its Experiences Rather than Beliefs and Attitudes. Int J Environ Res Public Health. 2017;15(1). 
31. Shepherd R. Social determinants of food choice. Proc Nutr Soc. 1999;58(4):807812.

32. Rozin P, Fallon A. The psychological categorization of foods and non-foods: $A$ preliminary taxonomy of food rejections. Appetite. 1980;1(3):193-201.

33. Stafleu A, de Graaf C, Van Staveren WA, Burema J. Affective and cognitive determinants of intention to consume twenty foods that contribute to fat intake. Ecology of Food and Nutrition. 2001;40(3):193-214.

34. Harrell MB, Weaver SR, Loukas A, et al. Flavored e-cigarette use: Characterizing youth, young adult, and adult users. Preventive Medicine Reports. 2017;5:3340.

35. Huang LL, Baker HM, Meernik C, et al. Impact of non-menthol flavours in tobacco products on perceptions and use among youth, young adults and adults: a systematic review. Tob Control. 2017;26(6):709-719.

36. Shang C, Huang J, Chaloupka FJ, Emery SL. The impact of flavour, device type and warning messages on youth preferences for electronic nicotine delivery systems: evidence from an online discrete choice experiment. Tob Control. 2018;27(e2):e152-e159.

37. B.V. FIR. Voed de discussie met onderzoek dat zelf nooit ter discussie staat. 2017. https://www.flycatcher.eu/. Accessed aug 17th, 2018.

38. Romijnders K, Pennings JLA, van Osch L, de Vries H, Talhout R. A Combination of Factors Related to Smoking Behavior, Attractive Product Characteristics, and Socio-Cognitive Factors are Important to Distinguish a Dual User from an Exclusive E-Cigarette User. Int J Environ Res Public Health. 2019;16(21).

39. Schoren C, Hummel K, Vries H. Electronic cigarette use: comparing smokers, vapers, and dual users on characteristics and motivational factors. Tobacco Prevention \& Cessation. 2017;3(April). doi:10.18332/tpc/69392.

40. Borland R, Murray K, Gravely S, et al. A new classification system for describing concurrent use of nicotine vaping products alongside cigarettes (so-called 'dual use'): findings from the ITC-4 Country Smoking and Vaping wave 1 Survey. Addiction. 2019;114 Suppl 1:24-34.

41. Pearson JL, Hitchman SC, Brose LS, et al. Recommended core items to assess e-cigarette use in population-based surveys. Tob Control. 2018;27(3):341-346.

42. Amato MS, Boyle RG, Levy D. How to define e-cigarette prevalence? Finding clues in the use frequency distribution. Tob Control. 2016;25(e1):e24-29.

43. International Tobacco Control Policy Evaluation Project. ITC Netherlands (NL11_ Pw). International Tobacco Control (ITC). 2017. https://www.itcproject.org/files/ ITC_NL11_Replenishment_S_web_Eng_Dut.pdf. Accessed 10, Jan, 2018, 2018.

44. Heatherton TF, Kozlowski LT, Frecker RC, Fagerstrom KO. The Fagerstrom Test for Nicotine Dependence: a revision of the Fagerstrom Tolerance Questionnaire. British journal of addiction. 1991;86(9):1119-1127.

45. Centraal Bureau voor Statistiek (CBS). [International Standard Classification of Education (ISCED)]. Heerlen: Centraal Bureau voor Statistiek (CBS);2018.

46. Yingst JM, Veldheer S, Hammett E, Hrabovsky S, Foulds J. A Method for Classifying User-Reported Electronic Cigarette Liquid Flavors. Nicotine Tob Res. 2017;19(11):1381-1385. 
47. Krusemann EJZ, Boesveldt S, de Graaf K, Talhout R. An E-Liquid Flavor Wheel: A Shared Vocabulary Based on Systematically Reviewing E-Liquid Flavor Classifications in Literature. Nicotine Tob Res. 2019;21(10):1310-1319.

48. Lehmann BA, de Melker HE, Timmermans DRM, Mollema L. Informed decision making in the context of childhood immunization. Patient Educ Couns. 2017; 100(12):2339-2345.

49. National institute for Public Health and the Environment (RIVM). [Tobacco]. 2018. https://www.rivm.nl/tabak. Accessed June 19, 2019.

50. Siegrist M, Earle TC, Gutscher H. Test of a trust and confidence model in the applied context of electromagnetic field (EMF) risks. Risk Anal. 2003;23(4):705716.

51. Janssen $E$, van Osch $L$, Lechner $L$, Candel $M$, de Vries $H$. Thinking versus feeling: differentiating between cognitive and affective components of perceived cancer risk. Psychol Health. 2012;27(7):767-783.

52. de Vries H, van Osch L, Eijmael K, Smerecnik C, Candel M. The role of risk perception in explaining parental sunscreen use. Psychol Health. 2012;27(11):1342-1358.

53. Montano DE, Kasprzyk D. Theory of Reasoned Action, Theory of Planned Behavior, and the Integrated Behavioral Model. In: Glanz K, Rimer BK, Viswanath K, eds. Health Behavior and Health Education: Theory, Research and Practice. 4th ed. New Jersey: John Wiley \& Sons; 2008:67-96.

54. IBM SPSS Statistics for Windows [computer program]. Version 24.0. Armonk, NY: IBM Corp; Released 2017.

55. Cullen KA, Ambrose BK, Gentzke AS, et al. Notes from the Field: Use of Electronic Cigarettes and Any Tobacco Product Among Middle and High School Students United States, 2011-2018. MMWRMorbMortalWklyRep.2018;67(45):1276-1277.

56. Chen JC. Flavored E-cigarette Use and Cigarette Smoking Reduction and Cessation-A Large National Study among Young Adult Smokers. Subst Use Misuse. 2018;53(12):2017-2031.

57. Buu A, Hu YH, Piper ME, Lin HC. The association between e-cigarette use characteristics and combustible cigarette consumption and dependence symptoms: Resultsfromanationallongitudinalstudy. AddictBehav.2018;84:69-74.

58. THE EUROPEAN PARLIAMENT AND OF THE COUNCIL. Tobacco Products Directive 2014/04/EU. Vol DIRECTIVE 2014/40/EU. Brussels: THE EUROPEAN PARLIAMENT AND OF THE COUNCIL.; 2014:38.

59. de Raad van State. Tabaks- en rookwarenwet. In: de Raad van State, Volksgezondheid, Welzijn en Sport, eds. BWBR0004302/2019-11-17/0. Den Haag: de Raad van State, 2018.

60. Schneller LM, Bansal-Travers M, Goniewicz ML, et al. Use of flavored electronic cigarette refill liquids among adults and youth in the US-Results from Wave 2 of the Population Assessment of Tobacco and Health Study (2014-2015). PLoS One. 2018;13(8):e0202744.

61. O'Connor RJ, Fix BV, McNeill A, et al. Characteristics of nicotine vaping products used by participants in the 2016 ITC Four Country Smoking and Vaping Survey. Addiction. 2019. 
62. Berg CJ. Preferred flavors and reasons for e-cigarette use and discontinued use among never, current, and former smokers. International journal of public health. 2016;61(2):225-236.

63. Russell C, Dickson T, McKeganey N. Advice From Former-Smoking E-Cigarette Users to Current Smokers on How to Use E-Cigarettes as Part of an Attempt to Quit Smoking. Nicotine Tob Res. 2018;20(8):977-984.

64. Feirman SP, Lock D, Cohen JE, Holtgrave DR, Li T. Flavored Tobacco Products in the United States: A Systematic Review Assessing Use and Attitudes. Nicotine and Tobacco Research. 2016;18(5):739-749.

65. Camenga DR, Fiellin LE, Pendergrass T, et al. Adolescents' perceptions of flavored tobacco products, including E-cigarettes: A qualitative study to inform FDA tobacco education efforts through videogames. Addict Behav. 2018;82:189-194.

66. Buckell J, Sindelar JL. The impact of flavors, health risks, secondhand smoke and prices on young adults' cigarette and e-cigarette choices: a discrete choice experiment. Addiction. 2019.

67. Centraal Bureau voor Statistiek (CBS). [Society: numbers of level of education]. Trends in the Netherlands 2018 2018. https://longreads.cbs.nl/trends18/ maatschappij/cijfers/onderwijs/. Accessed March 1st, 2019.

68. Van Gelder M, Pijpe A. E-epidemiology: a comprehensive update. OA Epidemiology. 2013;1(5):1-7. 




\section{CHAPTER 5}

\section{A Combination of Factors Related to Smoking Behavior, Attractive Product Characteristics, and Socio- Cognitive Factors are Important to Distinguish a Dual User from an Exclusive E-Cigarette User}

Romijnders K Pennings JLA van Osch L de Vries $\mathrm{H}$ Talhout R

A Combination of Factors Related to Smoking Behavior, Attractive Product Characteristics, and Socio-Cognitive Factors are Important to Distinguish a Dual User from an Exclusive E-Cigarette User.

Int J Environ Res Public Health. 2019;16(21). 


\section{Abstract}

Although total cessation of nicotine and tobacco products would be most beneficial to improve public health, exclusive e-cigarette use has potential health benefits for smokers compared to cigarette smoking. This study investigated differences between dual users and exclusive e-cigarette users provide information to optimize health communication about smoking and vaping. A cross-sectional survey $(n=116)$ among 80 current, adult dual users and 36 current, adult-exclusive e-cigarette users was conducted in the Netherlands. The questionnaire assessed four clusters of factors: (1) Past and current smoking and vaping behavior, (2) product characteristics used, (3) attractiveness and reasons related to cigarettes and e-cigarettes, and (4) socio-cognitive factors regarding smoking, vaping, and not smoking or vaping. We used random forest-a machine learning algorithm - to identify distinguishing features between dual users and e-cigarette users. We are able to discern a dual user from an exclusive e-cigarette user with $86.2 \%$ accuracy based on seven factors: Social ties with other smokers, quantity of tobacco cigarettes smoked in the past (e-cigarette users) or currently (dual users), self-efficacy to not vape and smoke, unattractiveness of cigarettes, attitude towards e-cigarettes, barriers: accessibility of e-cigarettes, and intention to quit vaping (A). This combination of features provides information on how to improve health communication about smoking and vaping. 


\section{Introduction}

The use of electronic cigarettes (e-cigarettes) has increased worldwide in recent years. ${ }^{1,2}$ The majority of the e-cigarette users are currently former cigarette smokers that either switched completely to e-cigarettes or use e-cigarettes in addition to tobacco cigarettes. ${ }^{2-7}$ Concerns exist that e-cigarette use may attract (adolescent) never users, and thus, affect public health adversely, or even lead to dual use and a nicotine addiction..$^{8-10}$ Although never use or total cessation of all nicotine and tobacco products would be most beneficial for all, 8,11,12 exclusive e-cigarette use-and not dual use of both cigarettes and e-cigarettes, which has an adverse public health effect ${ }^{6,8,13}$ - has potential health benefits for smokers compared to cigarette smoking. ${ }^{13-18}$ However, exclusive e-cigarette use, especially among never-users, is not without risks itself. ${ }^{8}$ Consequently, it is recommended to be prevented among non-smokers. ${ }^{8}$ To improve public health, it is important to optimize health communication about smoking and vaping to the needs of never users, non-current users, exclusive smokers, dual users, and exclusive e-cigarette users. Since dual users and exclusive e-cigarette users are distinct groups, ${ }^{13}$ their information and communication needs are likely different. The present paper aims to increase our understanding of these two distinct groups and provide insight into factors that can be targeted with health communication.

Research has presented several differences between exclusive e-cigarette users and dual users, but the variability in results and definitions used makes it difficult to compare these differences. ${ }^{19}$ Review of relevant literature has identified four clusters of differences between dual users and e-cigarette users. ${ }^{9,13,19-34}$ While previous research looked at differences between dual users and exclusive e-cigarette users on an individual factor level or combined two clusters in an analysis, the goal of our study is to provide aggregated data by combining all the clusters of factors identified with machine learning. 9,13,19-34 First, differences were found in current smoking behavior among dual users or past smoking behavior among e-cigarette users, and current vaping behavior. Research has found that dual users smoked for a longer time (i.e., more pack years) compared to e-cigarette users.9,21 Additionally, the number of cigarettes smoked per day increased the likelihood of initiating e-cigarette use, 9,22 but no differences were found between dual users and e-cigarette users. ${ }^{23}$ Smith, Gawron, Balwicki, et al. ${ }^{9}$ have demonstrated that experimenting with e-cigarette use increased over time from 20\% in 2011 to $70 \%$ in 2016 in Poland, and while rates of exclusive daily smoking declined, rates of exclusive daily vaping increased.

Second, there is variability in differences reported in product characteristics of e-cigarettes used by dual users versus exclusive e-cigarette users. One study reported that dual users were more likely than exclusive e-cigarette users to use nicotine-containing e-liquids. ${ }^{9}$ In comparison, other studies found that nicotine concentration in e-liquids used did not differ between dual users and exclusive 
e-cigarette users. ${ }^{23,24}$ Similarly, this variability in reported differences is observed in e-liquid flavors used. While one study found no differences between dual users and e-cigarette users in flavors used, ${ }^{9}$ another study found that tobacco e-liquid flavors were more popular among dual users than e-cigarette users. ${ }^{25}$ These differences in product characteristics of e-cigarettes used may partly be explained by differences in regulations across countries. In the Netherlands, product characteristics of e-cigarettes, such as maximum levels of nicotine per e-liquid $(20 \mathrm{mg} / \mathrm{ml}$ in the Netherlands), and the maximum volume of e-liquids $\left(10 \mathrm{ml}\right.$ in the Netherlands) are regulated through the Tobacco regulation. ${ }^{35,36}$

Third, differences have been observed in the perceived attractiveness of product characteristics of cigarettes and e-cigarettes. ${ }^{19,25-28}$ Dual users and exclusive e-cigarette users differed in how they perceived the attractiveness of the ability to avoid smoking restrictions with e-cigarettes, ${ }^{29}$ lower costs of e-cigarettes compared to cigarettes, ${ }^{24}$ and the variety of e-liquid flavors available. ${ }^{19,26}$ These attractive aspects are a reason to initiate e-cigarette use and may influence a person's attitude towards e-cigarettes. ${ }^{32,33}$ Although attractiveness and reasons related to e-cigarette use have previously been reported to differ between dual users and exclusive e-cigarette users. ${ }^{19,21,23}$ Fourth, socio-cognitive determinants regarding e-cigarette use differed between dual users and exclusive e-cigarette users. Dual users were less positive towards e-cigarettes than exclusive e-cigarette users. ${ }^{19,24}$ In addition, dual users perceived fewer risks of e-cigarettes compared to smoking than exclusive e-cigarette users. ${ }^{21}$ Risk perception differed between dual users and exclusive e-cigarette users. ${ }^{19}$ More often, partners, family, friends, and colleagues of e-cigarette users were fellow e-cigarette users. ${ }^{24,30} \mathrm{E}$-cigarette users also had less desire for cigarette smoking than dual users, and they found

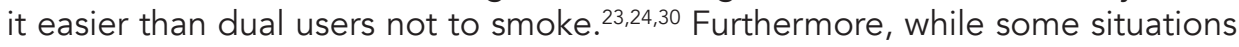
triggered dual users to smoke cigarettes, these situations did not trigger exclusive e-cigarette users. ${ }^{23,24,34}$ For example, if dual users experienced stress, were with friends, or had just eaten dinner, they preferred cigarette smoking over vaping. $23,24,34$ Dual users were found to be less motivated to quit cigarette smoking or quit nicotine intake altogether than exclusive e-cigarette users. ${ }^{24,25}$

While previous research looked at differences between dual users and exclusive e-cigarette users on an individual factor level or combined two clusters in an analysis, the goal of our study is to provide aggregated data ${ }^{37,38}$ from the combined four clusters of factors found in previous research with machine learning. 9,13,19-34 With machine learning, we are able to provide the most relevant features from a variety and a large number of factors identified in the four clusters. These aggregated data could provide information to support the development and improvement of health communication about e-cigarettes in order to prevent the adverse health effects of dual use. With insight into the most relevant features, health communication may be able to target the differences between dual users and exclusive e-cigarette users to aid dual users who would like to switch to exclusive use in the future, or prevent dual use among exclusive users. 
To explore relevant distinguishing features between adult dual users and adultexclusive e-cigarette users in a cross-sectional survey, the following four clusters were combined with random forest: (1) Past and current smoking and vaping behavior; (2) product characteristics used; (3) attractiveness and reasons related to cigarettes and e-cigarettes; and (4) socio-cognitive factors regarding smoking, vaping, and not smoking or vaping. 9,13,19-34

\section{Methods}

For the purpose of this study, a cross-sectional survey was conducted among adult (18+), current dual users; and adult (18+), current exclusive e-cigarette users. Adult individuals who currently smoke and use e-cigarettes (i.e., vape) concurrently on a daily or weekly basis, are defined as dual users in the current study. ${ }^{13}$ In contrast, adult individuals who exclusively use e-cigarettes on a daily or weekly basis are defined as exclusive e-cigarette users. ${ }^{13} \mathrm{~A}$ full overview of the items reflecting all four clusters of factors used can be found in Appendix 6. The study was approved by the Medical Ethics Committee of Zuyderland_Zuyd (17-N-88).

\section{Recruitment}

In June 2016, participants were recruited in the Netherlands through an online survey panel (Flycatcher). ${ }^{39}$ This online panel consists of more than 10,000 Dutch individuals and panel participants, who voluntary and actively opt-in (doubleactive-opt-in). Every year, panelists are asked to update their information. On average panelists complete eight surveys a year. Twelve thousand seven hundred fifty panelists were sent an invitation by email who met the inclusion criteria (being able to understand Dutch, being aware of e-cigarettes, being 13 years or older (adolescent (13-17 years old) and adults (18+))). The questionnaire was administered online, and participants were asked to provide consent before the start of the survey. With a response rate of 10.3\%, 1307 participants completed the survey. To distinguish a dual user from an exclusive e-cigarette user, participants were eligible for our current study if they were adults who met the definition of either a dual user or exclusive e-cigarette user. In total, 116 participants ( $n=80$ adult dual users; $n=36$ adult-exclusive e-cigarette users) of this subsample met the definition of dual users and exclusive e-cigarette users. User groups were determined with three questions: Type of user: 'I smoke or vape...'; frequency of use: 'How often do you smoke?'; and 'How often do you vape?' (see Appendix 6).

\section{Questionnaire}

The current study included measures (see Appendix 6) on basic demographics and the four identified clusters of differences. The questionnaire was only 
accessible to Flycatcher panel members with a personalized link. Participants first answered a verification question to make sure that the questionnaire was filled in by the selected participants. All items used were mandatory. Responses were checked on quality by: Time to fill in the questionnaire, consistency in responses, open answer options, and straight lining (e.g. if the same response is chosen in a series of the statement).

\section{Sociodemographic Measures}

Sociodemographic measures included age, gender, and education. Educational level was determined based on the Dutch version of the International Standard Classification of Education (ISCED) (see Appendix 6). ${ }^{40}$

\section{Past and Current Smoking and Vaping Behavior}

All participants were asked to report their vaping and smoking behavior. These measures included the type of user, lifetime smoking status, ${ }^{41}$ frequency of smoking and vaping, duration of smoking and vaping, and several others (see Appendix 6).

\section{Product Characteristics Used}

Product characteristics used were investigated by asking about e-liquid flavors used, nicotine concentrations, cigarette brands smoked and several others (see Appendix 6).

\section{Attractiveness and Reasons Related to Cigarettes and E-Cigarettes}

Attractiveness and reasons related to cigarette and e-cigarette users were investigated by asking: 'The E-cigarette is attractive because (more than one answer possible)'. Similar, reasons for cigarette use were investigated by asking: 'Which of the following statements applies to you? I smoke/l used to smoke: (More than one answer possible)' (see Appendix 6).

\section{Socio-Cognitive Factors}

To investigate socio-cognitive factors related to smoking, vaping, and not smoking and vaping, items were included in triplicate to investigate vaping, smoking behavior and not using e-cigarettes or cigarettes. For example, the attitude was assessed with four semantic-differentials about not smoking or vaping, cigarette smoking, and e-cigarette use by asking if participants thought 'not smoking or vaping was good or bad on a 7-point Likert scale'. To establish scales for attitude, deliberation, trust in information provision, social ties, selfefficacy, and barriers of accessibility of e-cigarettes a reliability analysis was performed to establish scales. If the reliability analysis showed sufficient internal consistency (Cronbach's alpha $a \geq 0.60$ ), then items were included in a scale. An overview of internal consistency of scales can be found in Appendix 6. Unless otherwise stated, all determinants used a 7-point Likert scale as answer options, such as either 1 equals totally disagree to 7 equals totally agree or semanticdifferentials, such as 1 equals really bad to 7 equals really good. 


\section{Data Analysis}

SPSS data were exported and further preprocessed in Microsoft Excel for statistical data analysis in R statistical software version 3.5.142 using the random Forest package. Descriptive analyses were performed to gain insight into the participant characteristics of the study sample. Chi-square tests and analyses of variance (t-tests) were performed to assess differences in characteristics between dual users and exclusive e-cigarette users.

To determine which aspects were important to distinguish a dual user from an e-cigarette user, analyses were performed using random forest. ${ }^{43}$ Random forest (RF) is a machine learning algorithm that classifies an outcome (dual use versus e-cigarette use) of an individual using an ensemble of decision trees with predictor variables (including demographics, smoking and vaping behavior, product characteristics, attractiveness and reasons related to cigarettes and e-cigarettes, and socio-cognitive factors). For the RF, a data table with 163 items and concepts (features) for 80 dual users and 36 exclusive e-cigarette users was used. Using 5-fold cross-validation, the data were randomly split into subsets containing approximately the same ratio of dual users and e-cigarette users: In a training set ( $80 \%$ of the data) and test set ( $20 \%$ of the data). In each crossvalidation the training set was used to build an RF classifying model consisting of 1000 trees to predict if a participant in the test set is either a dual user or an exclusive e-cigarette user, this was done five times. After the five cross-validation runs, the overall prediction accuracy was calculated. Additionally, RF assessed the relative importance of each prediction variable by determining how much the error increased as a result of random rearrangement of the data for that variable ( $R$ settings: Type $=1$, scale $=T R U E$ ). The resulting variable importance factor (averaged per factor across the five cross-validations) was used to calculate the corresponding $p$-value, which was adjusted to the Benjamini-Hochberg False Discovery Rate (FDR) ${ }^{44}$ to correct for multiple testing. The variables with FDR adjusted $p$-values (FDR $<0.05$ ) were used for a new round of RF classification to confirm the accuracy that could be obtained with these markers.

\section{Results}

\section{Participants Characteristics}

Of the 116 dual users and exclusive e-cigarette users, $43.1 \%$ was male and $56.9 \%$ female, $28.4 \%$ was highly educated $(26.7 \%$ low education level, and $44.8 \%$ middle education level), and the average age was $49.1( \pm 12.5, \mathrm{~min}=$ 21 , $\max =79$ ). Age did not significantly differ between dual users and exclusive e-cigarette users. 


\section{Differences between Dual Users and Exclusive E-Cigarette Users}

All differences between dual users and exclusive e-cigarettes on the 163 predictor variables included in our analysis are reported in Appendix 7. Table 5.1 reports the significant differences found between dual users and exclusive e-cigarette users.

\section{Differences in Past and Current Smoking and Vaping Behavior}

Significant differences in tobacco and e-cigarette behavior were observed (see table 5.1) between dual users (that currently both smoke and vape) and exclusive e-cigarette users (former smokers that are currently only vaper-only) concerning onset of tobacco smoking, quantity of tobacco cigarettes smoked in their past or current smoking behavior, and lifetime status of tobacco smoking (Fägerstrom index) $(p<0.05)$. All exclusive e-cigarette users smoked more than 100 cigarettes in their lifetime. The onset of smoking was longer ago among e-cigarette users (i.e., more pack years) than dual users. In addition, when they still smoked ( $n=36$, all current e-cigarette users have a history of smoking), exclusive e-cigarette users smoked more cigarettes a day than current dual users smoke at the moment of the survey $(p<0.05)$. No differences were observed in how long dual users and exclusive e-cigarette users have been vaping (i.e., onset of vaping).

\section{Differences in Product Characteristics Used}

No significant differences between dual users and exclusive e-cigarette users were observed in product characteristics used, such as current or first used concentrations of nicotine in e-liquids, or e-liquid flavors (see Appendix 7).

\section{Differences in Attractiveness and Reasons Related to Cigarettes and E-Cigarettes}

Differences were observed between dual users and exclusive e-cigarette users in the perceived attractiveness of e-cigarettes (see table 5.1). Compared to exclusive e-cigarette users, dual users more often found e-cigarettes to look nice, and the variety of e-liquid flavors appealing $(p<0.05)$. Dual users reported more often than exclusive e-cigarette users that avoiding smoking restrictions and the novelty of e-cigarettes were reasons to vape $(p<0.05)$. For cigarettes, dual users found the flavor of tobacco and the variety of brands to be more attractive than exclusive e-cigarette users $(p<0.05)$. E-cigarette users found the adjustable settings and nicotine concentrations of e-cigarette more attractive than dual users $(p<0.05)$. Compared to dual users, e-cigarette users reported health benefits and e-cigarettes as an alternative for smoking more often as reasons for e-cigarette use $(p<0.05)$. In addition, e-cigarette users found the cigarette to be unattractive more often than dual users $(p<0.05)$. In particular, 
they found it unattractive how smokers smell after smoking a cigarette $(p<0.05)$. No differences were observed in unattractive product characteristics of the e-cigarette, such as the design, the e-liquid flavors, or the price.

\section{Differences in Socio-Cognitive Factors}

E-cigarette users had a more positive attitude towards e-cigarettes and had a more negative attitude towards smoking compared to dual users $(p<0.05)$ (see table 5.1). Compared to exclusive e-cigarette users, dual users felt more connected-their social ties with smokers were stronger-to other smokers and they more often had a partner, family, friends, and colleagues who smoked (Social influence ( $f$ ), $p<0.05$ ). Dual users had higher levels of deliberation about not smoking or vaping, and although they had a higher intention to quit vaping than exclusive e-cigarette users $(p<0.05)$, their self-efficacy to quit vaping and smoking was lower $(p<0.05)$. Dual users also perceive fewer risks related to smoking compared to e-cigarette users $(p<0.05)$. Significant differences were also found in information-seeking behavior, dual users less often used a Dutch Vape forum as a source of information than exclusive e-cigarette users $(p<0.05)$, and they would like to receive more information about e-liquids than exclusive e-cigarette users $(p<0.05)$. Dual users would find information independent if it was presented under the auspices of the national government $(p<0.05)$. Finally, exclusive e-cigarette users would find information more independent and reliable if researchers report no conflict of interest $(p<0.05)$.

Table 5.1 Significant differences between dual users and exclusive e-cigarette users.

\begin{tabular}{|c|c|c|}
\hline & $\begin{array}{l}\text { Dual Users } \\
(\mathrm{n}=80)\end{array}$ & $\begin{array}{l}\text { E-Cigarette } \\
\text { Users } \\
(n=636)\end{array}$ \\
\hline (1) Past and current smoking and vaping behavior & $\mathrm{n}=80$ & $\mathrm{n}=36$ \\
\hline $\begin{array}{l}\text { Quantity of tobacco cigarettes smoked in the past } \\
\text { (e-cigarette users) or currently (dual users) }\end{array}$ & $\begin{array}{l}\text { Current } \\
\text { smoking } \\
\text { quantity }{ }^{\mathrm{A}}\end{array}$ & $\begin{array}{l}\text { Past } \\
\text { smoking } \\
\text { quantity A }\end{array}$ \\
\hline$<1 / 2$ package $p$. day & $16.3 \%$ & $2.8 \%$ \\
\hline $1 / 2-1$ package $p$. day & $63.7 \%$ & $36.1 \%$ \\
\hline 1 package p. day & $13.8 \%$ & $22.2 \%$ \\
\hline$>1$ package p. day & $6.3 \%$ & $38.9 \%$ \\
\hline \multicolumn{3}{|l|}{ Lifetime status of tobacco smoking } \\
\hline$<100$ cigarettes in life & $6.30 \%$ & $0.00 \%$ \\
\hline$>100$ cigarettes in life & $93.70 \%$ & $100.00 \%$ \\
\hline \multicolumn{3}{|l|}{ Onset of tobacco smoking } \\
\hline$<6$ months & $1.3 \%$ & $2.8 \%$ \\
\hline $6-12$ months & $1.3 \%$ & $0.0 \%$ \\
\hline $1-5$ years & $8.8 \%$ & $0.0 \%$ \\
\hline $5-10$ years & $11.3 \%$ & $0.0 \%$ \\
\hline$>10$ years & $77.5 \%$ & $97.2 \%$ \\
\hline
\end{tabular}




\begin{tabular}{|c|c|c|}
\hline & $\begin{array}{l}\text { Dual Users } \\
(n=80)\end{array}$ & $\begin{array}{l}\text { E-Cigarette } \\
\text { Users } \\
(n=636)\end{array}$ \\
\hline \multicolumn{3}{|l|}{ Onset of vaping } \\
\hline$<6$ months & $35.0 \%$ & $13.9 \%$ \\
\hline 6-12 months & $20.0 \%$ & $16.7 \%$ \\
\hline $1-5$ years & $41.3 \%$ & $61.1 \%$ \\
\hline $5-10$ years & $3.8 \%$ & $8.3 \%$ \\
\hline (2) Product characteristics used & $\mathrm{n}=80$ & \\
\hline \multicolumn{3}{|l|}{ No significant differences were found } \\
\hline $\begin{array}{l}\text { (3) Attractiveness and reasons related to cigarettes and } \\
\text { e-cigarettes }\end{array}$ & $\mathrm{n}=80$ & $n=36$ \\
\hline \multicolumn{3}{|l|}{ Attractiveness of e-cigarettes } \\
\hline The product looks nice & $18.8 \%$ & $5.6 \%$ \\
\hline Due to all the different flavors & $46.3 \%$ & $25.0 \%$ \\
\hline $\begin{array}{l}\text { Because it is possible to alter the setting of the } \\
\text { E-cigarette to my wishes }\end{array}$ & $20.0 \%$ & $38.9 \%$ \\
\hline Because the nicotine level can be varied & $45.0 \%$ & $66.7 \%$ \\
\hline $\begin{array}{l}\text { Not applicable, I do not find the E-cigarette/vaper } \\
\text { attractive }\end{array}$ & $8.8 \%$ & $0 \%$ \\
\hline \multicolumn{3}{|l|}{ Attractive characteristics of cigarettes (yes\%) } \\
\hline The product looks nice & $7.5 \%$ & $0 \%$ \\
\hline Due to all the different flavors & $30.0 \%$ & $11.1 \%$ \\
\hline Because you can smoke different brands & $26.3 \%$ & $5.6 \%$ \\
\hline Not applicable, I do not find the cigarette attractive & $28.8 \%$ & $72.2 \%$ \\
\hline \multicolumn{3}{|l|}{ Unattractiveness of cigarettes } \\
\hline The price of the product & $35.0 \%$ & $58.3 \%$ \\
\hline Because you stink after you have smoked a cigarette & $43.8 \%$ & $66.7 \%$ \\
\hline \multicolumn{3}{|l|}{ Reasons for e-cigarette use } \\
\hline $\begin{array}{l}\text { For their health advantages: effects on health, fewer } \\
\text { ingredients than a cigarette. }\end{array}$ & $42.25 \%$ & $72.2 \%$ \\
\hline $\begin{array}{l}\text { As an alternative to cigarettes: it is like the smoking or } \\
\text { because of the throat hit }\end{array}$ & $28.8 \%$ & $50.0 \%$ \\
\hline $\begin{array}{l}\text { To get around the smoking ban (to be able to vape in } \\
\text { places where smoking is normally forbidden). }\end{array}$ & $22.5 \%$ & $5.6 \%$ \\
\hline $\begin{array}{l}\text { To try something new: out of curiosity about new } \\
\text { products, different flavors, different apparatus/designs, } \\
\text { for pleasure, as a hobby, or because it is cool/trendy/ } \\
\text { classy. }\end{array}$ & $11.3 \%$ & $0 \%$ \\
\hline
\end{tabular}




\begin{tabular}{lll}
\hline & $\begin{array}{l}\text { Dual Users } \\
(\mathrm{n}=80)\end{array}$ & $\begin{array}{l}\text { E-Cigarette } \\
\text { Users } \\
(\mathrm{n}=636)\end{array}$ \\
\hline $\begin{array}{ll}\text { (4) Socio-cognitive factors regarding cigarette use, } \\
\text { e-cigarette use, and not smoking or vaping }\end{array}$ & $\mathrm{n}=80$ & $\mathrm{n}=36$ \\
\hline Attitude towards e-cigarettes & $4.5(0.8)$ & $5.0(0.8)$ \\
Attitude towards smoking & $3.5(1.2)$ & $2.7(1.2)$ \\
Barrier: accessibility of e-cigarettes & $5.2(1.1)$ & $4.8(1.5)$ \\
Deliberation not using e-cigarettes and cigarettes & $4.5(1.4)$ & $3.9(1.3)$ \\
Independency of information: (e) & $50.0 \%$ & $72.2 \%$ \\
Independency of information: (h) & $18.8 \%$ & $5.6 \%$ \\
Information need: (j) & $7.9 \%$ & $0 \%$ \\
Information source used: not applicable & $6.3 \%$ & $0 \%$ \\
Information source used (h) & $6.3 \%$ & $22.2 \%$ \\
Intention to quit vaping A. & $3.8(2.0)$ & $2.9(1.8)$ \\
Intention to quit vaping B. & $3.6(2.4)$ & $2.3(1.8)$ \\
Reliability of information (e) & $51.3 \%$ & $75.0 \%$ \\
Risk perception of smoking (cognitive) A & $4.7(1.3)$ & $5.3(1.1)$ \\
Self-efficacy to not vape or smoke & $3.9(1.2)$ & $4.8(1.2)$ \\
Social Influence A & $4.2(1.7)$ & $3.2(1.6)$ \\
Social influence D & $33.8 \%$ & $13.9 \%$ \\
Social influence F & $3.6(1.1)$ & $4.1(1.1)$ \\
Social Ties with other smokers (n = 79) & $3.3(1.1)$ & $2.3(1.2)$ \\
\hline & & \\
\hline
\end{tabular}

Note: Data on are presented as means (SD) or percentages of dual users, and exclusive e-cigarette users. All factors presented here are significant. A complete overview of all included variables in the random forest can be found in Appendix 6. A Quantity of tobacco cigarettes smoked in the past or currently displays the current smoking behavior of dual users, and the past smoking behavior of exclusive e-cigarette users before they switched to exclusive e-cigarette use; Independency of information: (e) If the researchers themselves have no vested interest in the results; Independency of information: (h) If the research is under the auspices of the national government, if there is a governmental logo; Information need: (j) I would like more information about the e-liquids available; Information source used: Not applicable: I never search for information; Information source used: (h) Dutch Vape forum or Acvoda (Active for vaping); Intention to quit vaping A. Please indicate on a scale from 1 to 7 your intent to quit vaping in the next 6 months; Intention to quit vaping B. Please indicate which of the statements indicates your intention best; Reliability of information: (e) I find research reliable if the researchers have no conflict of interest to declare; Risk perception of smoking (cognitive) A: If I smoke, then my risk of developing some form of cancer during my lifetime is...; Social Influence A: Society thinks that you should not smoke E-cigarettes; Social influence D: Smoking status partner (\% of yes); Social Influence F: How many of your family, friends or colleagues use cigarettes? 


\section{Identifying Unique Factors that Discriminate Dual User from an Exclusive E-Cigarette User}

Random forest analysis on dual use versus e-cigarette use identified 7 of the 163 factors as contributing significantly to the prediction accuracy (FDR 5\%). Together, these seven factors allowed for $86.2 \%$ prediction accuracy. Figure 5.1 shows the 25 highest-ranking relevant distinguishing features, with the top seven significant factors after adjusting for multiple testing. The seven most relevant factors to distinguish a dual user from an exclusive e-cigarette user are (FDR $5 \%$ ): Social ties with other smokers, quantity of tobacco cigarettes smoked in the past (e-cigarette users) or currently (dual users), self-efficacy to not vape and smoke, unattractiveness of cigarettes, attitude towards e-cigarettes, barriers: accessibility of e-cigarettes, and intention to quit vaping (A) (see table 5.1 for significant differences between dual users and exclusive e-cigarette use).

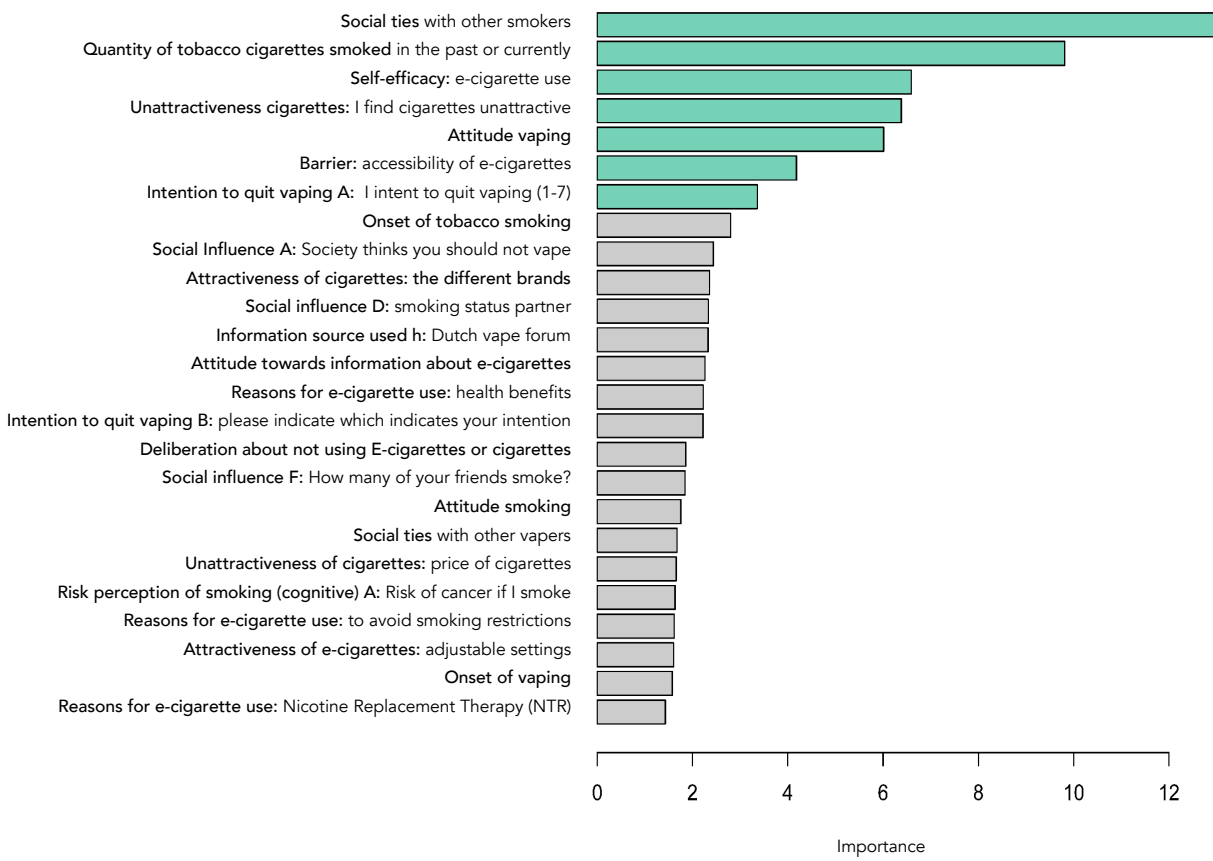

Figure 5.1. Top twenty-five factors to distinguish between dual users and e-cigarette users. Bar lengths indicate the variable importance factors, the seven significant (FDR 5\%) factors are shown in dark gray. 


\section{Discussion}

We used random forest-a machine learning algorithm—-to identify important and unique distinguishing features between dual users and exclusive e-cigarette users. Based on the random forest, adult, current dual users and adult, current exclusive e-cigarette users can be distinguished from each other with $86.2 \%$ accuracy based on three out of four included clusters of factors: Current and past smoking behavior, unattractiveness of cigarette product characteristics, and socio-cognitive factors regarding smoking, vaping, and not smoking and vaping. Similar to previous research, 9,23,24 our random forest analysis found no distinguishing features between dual users and exclusive e-cigarette users in product characteristics used.

First, regarding current and past smoking behavior, previous research found that dual users reduce the number of cigarettes smoked a day. ${ }^{25,45}$ Our findings also indicate that adult, current dual users $(n=80)$ currently smoked fewer cigarettes a day than e-cigarette users did in the past, when they were cigarette smokers $(n=36) .{ }^{25,45}$ Research found that the number of cigarettes smoked per day increased the likelihood of initiating e-cigarette use,, 22 the reduced level of current smoking quantity a day among dual users may hint at a transitory phase of switching completely to exclusive e-cigarette use. ${ }^{46}$. Similar to PATH ${ }^{47}$ studies in the US, longitudinal research in the Netherlands is needed to investigate transitory phases of smoking and vaping to increase our understanding of dual use and exclusive e-cigarette use.

Second, exclusive e-cigarette users found cigarettes more unattractive than dual users. This unattractive aspect of cigarettes was a distinguishing feature between dual users and exclusive e-cigarette users. Further research is necessary to understand if increasing the unattractiveness of cigarettes might facilitate smokers-including dual users-to switch to exclusive e-cigarette use. Additionally, similarly to earlier results, dual users found the variety of e-liquid flavors available an attractive characteristic of both e-cigarettes and cigarettes, which is similar to earlier results, and they more often than exclusive e-cigarette users vape to avoid smoking restrictions. ${ }^{19,25-29}$ Consequently, research is needed to gain insight into attractive aspects of e-cigarettes and unattractive aspects of cigarettes for smokers and dual users to identify factors that health communication can target. By targeting the identified distinguishing factors, health communication strategies can stress the pros of e-cigarettes and the cons of cigarettes for smokers and dual users. Furthermore, research into attractive and unattractive aspects of cigarettes and e-cigarettes is needed among never smokers and vapers to target preventive health communication strategies at vulnerable non-smokers and non-vapers. 19,24,30

Third, in contrast with previous research, ${ }^{23}$ our results show that various sociocognitive factors are important to distinguish a dual user from an exclusive 
e-cigarette user. Dual users experienced more social ties with other smokers than exclusive e-cigarette users, and contrary to dual users, exclusive e-cigarette users had higher levels of perceived self-efficacy to not smoke or vape..$^{30,34}$ In addition, dual users had a more negative attitude towards e-cigarettes than exclusive e-cigarette users, which is supported by previous research. ${ }^{24}$ Lastly, dual users, more often than exclusive e-cigarette users, had a partner who smoked. These factors could be targeted with health communication to aid smokers and dual users who want to switch to exclusive e-cigarette use or quit smoking.

Finally, the results from our random forest analysis provide insight into factors that had a unique contribution in distinguishing the dual users from exclusive e-cigarette users, which may have a practical implication for the improvement of health communication about smoking and vaping. Further research is needed to test effective communication strategies that target these factors to prevent the adverse health effects of dual use. The seven features provide a first insight into the most relevant features that health communication may be able to target to aid dual users who would like to switch to exclusive use in the future, or prevent dual use among exclusive users. Health communication strategies that stress the pros of e-cigarettes for cigarette smokers; that provide tools on how to cope with the pressure of a social environment to smoke cigarettes; and that provide tools on how to better cope with not smoking cigarettes to increase motivation to fully switch from cigarettes to e-cigarettes should be tested. Factors that can be targeted in health communication could focus on supporting smoking cessation among smokers and dual users by managing outcome expectancies of e-cigarette use compared to cigarette smoking, improving social ties of smokers and dual users with exclusive e-cigarette users, ${ }^{24,30,34}$ making cigarettes seem less attractive, ${ }^{48}$ strengthening positive attitudes towards e-cigarettes as a smoking cessation tool with inoculation messages and build resistance for a pro-smoking social environment of smokers and dual users, ${ }^{49}$ and providing guidance in the deliberation process of smoking cessation. ${ }^{50}$

\section{Limitations}

To ensure one-time smokers or exclusive e-cigarette users were excluded in our analysis, the subset of dual users and exclusive e-cigarette users was relatively small, but sufficient in size for classification by methods, such as random forest. Due to our small sample, further research is needed to investigate the generalizability of the features found in the current study. In addition, due to the cross-sectional study design, no causal conclusions can be drawn on the most relevant distinguishing features. Selection bias may have occurred, as an online panel was used, which include individuals who are motivated to fill in questionnaires. 


\section{Conclusions}

This study combined factors from four different research angles into a single machine learning analysis to identify the most relevant distinguishing features for discerning a dual user from an exclusive e-cigarette user. Our results demonstrate that it is a combination of features from three clusters that discern a dual user from an exclusive e-cigarette user: Current and past smoking behavior, the unattractiveness of cigarette product characteristics, and sociocognitive factors regarding smoking and vaping. This particular combination provides new and relevant information regarding the differences between dual users and e-cigarettes users that can be applied to develop improved health communication targeted to prevent adverse health effects related to dual use. 


\section{References}

1. Filippidis FT, Laverty AA, Gerovasili V, Vardavas Cl. Two-year trends and predictors of e-cigarette use in 27 European Union member states. Tob Control. 2017;26(1):98-104.

2. McMillen RC, Gottlieb MA, Shaefer RM, Winickoff JP, Klein JD. Trends in Electronic Cigarette Use Among U.S. Adults: Use is Increasing in Both Smokers and Nonsmokers. Nicotine Tob Res. 2015;17(10):1195-1202.

3. Cullen KA, Ambrose BK, Gentzke AS, et al. Notes from the Field: Use of Electronic Cigarettes and Any Tobacco Product Among Middle and High School Students - United States, 2011-2018. MMWR Morb Mortal Wkly Rep. 2018;67(45):1276-1277.

4. Miech R, Johnston L, O'Malley PM, Bachman JG, Patrick ME. Adolescent Vaping and Nicotine Use in 2017-2018 - U.S. National Estimates. N Engl J Med. 2019;380(2):192-193.

5. World Health Organization. Tobacco Free Initiative (TFI). Electronic cigarettes (ecigarettes) or electronic nicotine delivery systems 2015. http://www.who.int/ tobacco/communications/statements/eletronic_cigarettes/en/. Accessed July 12, 2017, 2016.

6. Glasser AM, Collins L, Pearson JL, et al. Overview of Electronic Nicotine Delivery Systems: A Systematic Review. Am J Prev Med. 2017;52(2):e33-e66.

7. Hajek P, Etter JF, Benowitz N, Eissenberg T, McRobbie H. Electronic cigarettes: review of use, content, safety, effects on smokers and potential for harm and benefit. Addiction. 2014;109(11):1801-1810.

8. Stratton K, Kwan L, Y., Eaton DL. Public health consequences of e-cigarettes. Washington, DC, United States: National Academies Press;2018. 9780309468343.

9. Smith DM, Gawron M, Balwicki L, et al. Exclusive versus dual use of tobacco and electronic cigarettes among adolescents in Poland, 2010-2016. Addict Behav. 2019;90:341-348.

10. Soneji S, Barrington-Trimis JL, Wills TA, et al. Association Between Initial Use of e-Cigarettes and Subsequent Cigarette Smoking Among Adolescents and Young Adults: A Systematic Review and Meta-analysis. JAMA Pediatr. 2017. doi:10.1001/jamapediatrics.2017.1488.

11. Staal YCM, Talhout R. Alternative tobacco products: harm reduction? . Bilthoven: National Institute for Public Health and the Environment;2016. 2016-0103.

12. Visser WF, Klerx WN, Cremers H, et al. The Health Risks of Electronic Cigarette Use to Bystanders. Int J Environ Res Public Health. 2019;16(9).

13. Borland R, Murray K, Gravely S, et al. A new classification system for describing concurrent use of nicotine vaping products alongside cigarettes (so-called 'dual use'): findings from the ITC-4 Country Smoking and Vaping wave 1 Survey. Addiction. 2019;114 Suppl 1:24-34. 
14. McRobbie H. Modelling the Population Health Effects of E-Cigarettes Use: Current Data Can Help Guide Future Policy Decisions. Nicotine Tob Res. 2017;19(2):131-132.

15. World Health Organization. Tobacco. Factsheet 2017. http://www.who.int/ mediacentre/factsheets/fs339/en/. Accessed November 30, 2018, 2018.

16. Goniewicz ML, Gawron M, Smith DM, et al. Exposure to Nicotine and Selected Toxicants in Cigarette Smokers Who Switched to Electronic Cigarettes: A Longitudinal Within-Subjects Observational Study. Nicotine Tob Res. 2017;19(2):160-167.

17. Levy DT, Borland R, Lindblom EN, et al. Potential deaths averted in USA by replacing cigarettes with e-cigarettes. Tob Control. 2018;27(1):18-25.

18. Levy DT, Borland R, Villanti AC, et al. The Application of a Decision-Theoretic Model to Estimate the Public Health Impact of Vaporized Nicotine Product Initiation in the United States. Nicotine Tob Res. 2017;19(2):149-159.

19. Romijnders K, van Osch L, de Vries H, Talhout R. Perceptions and Reasons Regarding E-Cigarette Use among Users and Non-Users: A Narrative Literature Review. Int J Environ Res Public Health. 2018;15(6).

20. Pacek LR, Wiley JL, McClernon FJ. A Conceptual Framework for Understanding Multiple Tobacco Product Use and the Impact of Regulatory Action. Nicotine Tob Res. 2019;21(3):268-277.

21. Farsalinos KE, Romagna G, Voudris V. Factors associated with dual use of tobacco and electronic cigarettes: A case control study. Int J Drug Policy. 2015;26(6):595-600.

22. English TM, Smith TB, Song X, Whitman MV. Barriers to electronic cigarette use. Public Health Nurs. 2018;35(5):363-368.

23. Adriaens K, Van Gucht D, Baeyens F. Differences between Dual Users and Switchers Center around Vaping Behavior and Its Experiences Rather than Beliefs and Attitudes. Int J Environ Res Public Health. 2017;15(1).

24. Ruther T, Wissen F, Linhardt A, et al. Electronic Cigarettes-Attitudes and Use in Germany. Nicotine Tob Res. 2016;18(5):660-669.

25. Lehmann K, Kuhn S, Reimer J. Electronic Cigarettes in Germany: Patterns of Use and Perceived Health Improvement. Eur Addict Res. 2017;23(3):136-147.

26. Laverty AA, Vardavas $\mathrm{Cl}$, Filippidis FT. Design and marketing features influencing choice of e-cigarettes and tobacco in the EU. Eur J Public Health. 2016;26(5):838-841.

27. Chen-Sankey JC, Kong G, Choi K. Perceived ease of flavored e-cigarette use and e-cigarette use progression among youth never tobacco users. PLoS One. 2019;14(2):e0212353.

28. Wills TA, Knight R, Sargent JD, et al. Longitudinal study of e-cigarette use and onset of cigarette smoking among high school students in Hawaii. Tob Control. 2017;26(1):34-39.

29. Hummel K, Hoving C, Nagelhout GE, et al. Prevalence and reasons for use of electronic cigarettes among smokers: Findings from the International Tobacco Control (ITC) Netherlands Survey. Int J Drug Policy. 2015;26(6):601-608. 
30. Schoren C, Hummel K, Vries H. Electronic cigarette use: comparing smokers, vapers, and dual users on characteristics and motivational factors. Tobacco Prevention \& Cessation. 2017;3(April). doi:10.18332/tpc/69392.

31. Wadsworth E, Neale J, McNeill A, Hitchman SC. How and Why Do Smokers Start Using E-Cigarettes? Qualitative Study of Vapers in London, UK. Int J Environ Res Public Health. 2016;13(7).

32. Shepherd R. Social determinants of food choice. Proc Nutr Soc. 1999;58(4):807-812.

33. Stafleu A, de Graaf C, Van Staveren WA, Burema J. Affective and cognitive determinants of intention to consume twenty foods that contribute to fat intake. Ecology of Food and Nutrition. 2001;40(3):193-214.

34. Pokhrel P, Herzog TA, Muranaka N, Regmi S, Fagan P. Contexts of cigarette and e-cigarette use among dual users: a qualitative study. BMC Public Health. 2015; 15:859.

35. THE EUROPEAN PARLIAMENT AND OF THE COUNCIL. Tobacco Products Directive 2014/04/EU. Vol DIRECTIVE 2014/40/EU. Brussels: THE EUROPEAN PARLIAMENT AND OF THE COUNCIL.; 2014:38.

36. de Raad van State. Tabaks- en rookwarenwet. In: de Raad van State, Volksgezondheid, Welzijn en Sport, eds. BWBR0004302/2019-11-17/0. Den Haag: de Raad van State, 2018.

37. Peters G-JY, Crutzen R. Confidence in constant progress: or how pragmatic nihilism encourages optimism through modesty. Health Psychology Review. 2017;11(2):140-144.

38. Peters GY, Crutzen R. Pragmatic nihilism: how a Theory of Nothing can help health psychology progress. Health Psychol Rev. 2017;11(2):103-121.

39. Flycatcher Internet Research B.V. [Have a discussion about research that will never be up for discussion.] https://www.flycatcher.eu/. Accessed August, 14, 2019.

40. Centraal Bureau voor Statistiek (CBS). [International Standard Classification of Education (ISCED)]. Heerlen: Centraal Bureau voor Statistiek (CBS);2018.

41. Heatherton TF, Kozlowski LT, Frecker RC, Fagerstrom KO. The Fagerstrom Test for Nicotine Dependence: a revision of the Fagerstrom Tolerance Questionnaire. British journal of addiction. 1991;86(9):1119-1127.

42. R: A language and environment for statistical computing [computer program]. Vienna, Austria: R Foundation for Statistical Computing; 2018.

43. Breiman L. Random forests. Machine Learning. 2001;45:5-32.

44. Benjamini Y, Hochberg Y. Controlling the False Discovery Rate: A Practical and Powerful Approach to Multiple Testing. Journal of the Royal Statistical Society Series B (Methodological). 1995;57(1):289-300.

45. Etter JF. Electronic cigarette: a longitudinal study of regular vapers. Nicotine Tob Res. 2017. doi:10.1093/ntr/ntx132.

46. Nardone N, Ko J, St Helen G, Benowitz NL. Nicotine intake, dependence, and characteristics of electronic cigarette and dual users. Tobacco Regulatory Science. 2019;5(1):27-35. 
47. PATH (Population Assessment of Tobacco and Health). Population Assessment of Tobacco and Health: Research Objectives. 2018. https://pathstudyinfo.nih. gov/UI/StudyOverviewMobile.aspx. Accessed October 2, 2019.

48. Drovandi A, Teague PA, Glass B, Malau-Aduli B. A systematic review of smoker and non-smoker perceptions of visually unappealing cigarette sticks. Tob Induc Dis. 2018;16(January):02.

49. Compton J, Jackson B, Dimmock JA. Persuading Others to Avoid Persuasion: Inoculation Theory and Resistant Health Attitudes. Front Psychol. 2016;7:122.

50. Stacey D, Kryworuchko J, Belkora J, et al. Coaching and guidance with patient decision aids: A review of theoretical and empirical evidence. BMC Med Inform Decis Mak. 2013;13 Suppl 2(2):S11. 
PART 2 



\section{CHAPTER 6}

\section{A deliberate choice? Exploring factors related to informed decision-making about childhood vaccination among acceptors, refusers, and partial acceptors}

Romijnders K

van Seventer SL

Scheltema M, et al.

A deliberate choice? Exploring factors related to informed decisionmaking about childhood vaccination among acceptors, refusers, and partial acceptors.

Vaccine. 2019;37(37):5637-5644. 


\section{Abstract}

In light of the decline in childhood vaccination coverage, the question rises concerning what factors play a role in informed decision-making about childhood vaccination. Insight into factors related to this decision helps us to support parents' informed decision-making about childhood vaccination. We conducted 12 semi-structured focus group interviews across the Netherlands based on the definition of informed decision-making: three with acceptors, three with refusers, and six with partial acceptors to ask about knowledge, attitudes, deliberation, and information needs. We performed a thematic analysis of the transcripts. Acceptors viewed the decision to participate in the National Immunization Program (NIP) as self-evident. Refusers and partial acceptors, however, reported extensively deliberating the pros and cons of accepting or refusing the NIP in much detail. Their answers indicated that their knowledge was not always evidence-based. In addition, refusers and partial acceptors perceived fewer risks of vaccine-preventable diseases (VPDs), more risks of side-effects of vaccines, less social support from their environment, and less trust in child welfare centers (CWCs) and information provided than acceptors. We observed distinct differences in factors related to decision-making about childhood vaccination between acceptors, refusers, and partial acceptors. Acceptors may perceive accepting childhood vaccinations as self-evident, refusers may rely mostly on anecdotal information rather than evidence-based information to weigh up the pros and cons of side-effects of vaccines and the VPDs, and partial acceptors may elaborately deliberate the pros and cons of each vaccine and VPD individually, which was time-consuming, and difficult. To strengthen and support decisionmaking among parents, more elaborate dialogues are needed between Child Vaccine Providers (CVPs) and parents. These discussions could also build trust between parents and CVPs, discuss the evidence-based advantages of childhood vaccinations, and decrease parents' susceptibility to anecdotal information and misperceptions about childhood vaccinations shared by parents. 


\section{Introduction}

Childhood vaccinations are very successful interventions to protect against vaccine-preventable diseases (VPDs). ${ }^{1-4}$ In the Netherlands, the National Immunization Program (NIP) offers vaccinations free of charge and on a voluntary basis. ${ }^{5}$ Nowadays within the NIP, vaccinations are offered against 12 childhood diseases (i.e., polio, diphtheria, tetanus, pertussis, rubella, measles, mumps, disease caused by Haemophilus influenzae type b, meningococcal ACWY disease, hepatitis $B$, pneumococcal disease and cervical cancer caused by human papillomavirus (HPV)). ${ }^{5}$ In recent years, vaccination coverage has declined in various countries, including the Netherlands (from 95.4\% in 2014 to $92.6 \%$ in 2018, for DTaP-IPV vaccination estimated for two-year-olds). 5,6 Due to this decline, the question arises of whether this is an informed decision and how their decision could be supported or strengthened.

In recent years, informed decision-making has gained more attention in the context of childhood vaccination. ${ }^{2}$ Often, research classifies decisions as informed when decision-makers have relevant knowledge about the subject and the decision reflects the attitudes of the decision-maker. ${ }^{7}$ In behavior theories, an informed decision is defined as informed when also the consequences are deliberated, and the pros and cons are considered in-depth. ${ }^{8}$ Lehmann, de Melker, Timmermans, Mollema ${ }^{2}$ quantified how many parents accepting and refusing vaccinations made an informed decision about accepting childhood vaccinations. They found that refusers made a more informed decision about childhood vaccination than acceptors. While refusers elaborately deliberated the decision, acceptors had more evidence-based knowledge about vaccinations. In addition to knowledge, values, and deliberation, research has revealed additional important factors related to the decision about accepting childhood vaccinations. For example, risk perception, positive beliefs about the effectiveness and safety of vaccines, anticipated regret about VPDs and side-effects, trust in the NIP and information about the NIP, decisional conflict, positive social environment towards accepting the NIP, and low perceived barriers, such as vaccinations being free of charge 2,8-15. Research has focused on decision-making about accepting vaccinations among parents 2,16,17, but insight into whether parents also consider other options, such as refusing or partially accepting vaccinations is lacking. This may yield important information on how to support parents in making an informed decision about childhood vaccinations, and how supporting informed decisionmaking may reduce decisional conflict and vaccine hesitancy, ${ }^{18-20}$ positively affect intention to accept childhood vaccinations, and thus, the vaccination coverage. ${ }^{21}$

Consequently, this qualitative study explores similarities and differences in factors related to decision-making about childhood vaccination among parents who accept (acceptors), refuse (refusers), or partially accept (partial acceptors) childhood vaccinations with regard to accepting, refusing, or partially accepting childhood vaccinations. We examined whether acceptors, refusers, and partial 
acceptors have similar knowledge and attitudes about childhood vaccinations, and how they evaluated the pros and cons of accepting, refusing, and partially accepting childhood vaccinations.

\section{Methods}

To explore differences in factors related to informed decision-making of acceptors, refusers, and partial acceptors, we set up three focus groups with acceptors, three with refusers, and six with partial acceptors (three with parents are delaying vaccinations and three with parents who are refusing some vaccinations. As no new themes emerged in the last of the three focus group sessions, it was deemed that saturation was reached. Eligibility was determined based on the age of their child (two years old, born in 2013 and 2014, see table 6.1). We chose to include the age of the child as an eligibility criterion to be able to classify parents of these children in the three groups: acceptors, refusers, and partial acceptors, based on their decision at the time of the focus groups about five vaccination moments (child is approximately two years old)). These five vaccinations moments were chosen to limit recall bias, and to make sure that parents made a conscious decision not to vaccinate, rather than through circumstances, such as sickness. Focus group discussions were chosen to stimulate an interactive discussion among peers. ${ }^{22,23}$ This study was approved by the Medical Ethics Committee of Zuyderland - Zuyd (16-N-84).

\section{Recruitment}

We invited 300 acceptors, 399 refusers, and 464 partial acceptors. Participants were randomly selected within each group from Praeventis, the individual vaccination database in the Netherlands of the RIVM. Possible participants received an invitation. Three large municipalities were selected from various parts of the Netherlands to promote a diverse selection of participants. The invitees received a letter of invitation containing the goal and procedure of the study. We did not differentiate between mothers and fathers, but only one parent from the same household could participate in a focus group. The parents could choose themselves which of the two would participate. Interested parents could register by following a link to an online registration form; a registration number was used to access the registration form. This number was checked for duplicates, so only one parent from the same household was included in the study. We asked about age, gender, level of education, availability, and contact information of parents. The final selection of participants for focus groups was based on the parents' availability and vaccination status of the child to ensure an open discussion among parents. Age, gender, and level of education were used to reduce selection bias. Education level was determined based on the Dutch version of the international standard classification of education (ISCED). ${ }^{24}$ Parents received an e-mail containing information on the date, time, and place of the focus group 
from the first author. All parents were also contacted by phone by the first author to ensure participation. Of the total of 1163 invited parents, we received 197 applications (109 (55\%) acceptors, 32 (16\%) refusers, 56 (29\%) partial acceptors). A complete overview of participant characteristics is reported in Appendix 8.

Table 6.1 Definitions of acceptors, refusers, and partial acceptors

\begin{tabular}{ll}
\hline Parental group & Definition \\
\hline Acceptors & Acceptors are parents (at least one of whom was born in the \\
& Netherlands) of children born in 2013 or 2014, who received all \\
& vaccinations scheduled according to the Dutch NIP. \\
Refusers & Refusers are parents (at least one of whom was born in the \\
& Netherlands) of children born in 2013 or 2014 who received none of \\
the vaccinations scheduled according to the Dutch NIP. & \\
Partial acceptors & \\
& Parents who partially accept childhood vaccinations are parents (at \\
& least one of whom was born in the Netherlands) who refuse or delay \\
& of the vaccines of children born in 2013 or 2014 . For example, some \\
& of DTaP-IPV-Hib-HBV a vaccines; or they did not receive four doses of \\
& DTaP-IPV-Hib-HBV a vaccines but did receive three doses of PCV a \\
vaccine; or their first DTaP-IPV-Hib-HBV a vaccine was delayed more \\
than four months.
\end{tabular}

Note: childhood vaccination status was determined by reported vaccination status for DTaP-IPV-Hib-HBV, PCV, MenC, BMR vaccination status in the Dutch Praeventis status for vaccination uptake reporting. ${ }^{a} D=$ Diphtheria, $\mathrm{HBV}=$ Hepatitis $B, \mathrm{Hib}=$ Hib disease, $M$ $=$ Measles, Men $C=$ Meningococcal disease type $C, B=$ Mumps, PCV = Pneumococcal disease, $\mathrm{IPV}=$ Polio, $\mathrm{R}=$ Rubella, $\mathrm{T}=$ Tetanus, $\mathrm{aP}=$ Whooping cough

\section{Procedure}

The focus group sessions were conducted between February 13, 2017 and March 2, 2017 at convenient locations in three large cities across the Netherlands. Written informed consent was obtained before the start of the session, and after participation the parents received a 30 euro incentive. The number of participants per focus group varied between two and eight but on average a focus group consisted of five parents, and a session lasted approximately two hours. A semi-structured protocol based on the definition of informed decisionmaking ${ }^{8}$ with open-ended questions was used to ensure minimal steering from the moderator and to allow participants to discuss all relevant subjects. ${ }^{25}$ All focus group sessions were audio recorded, and flipcharts were used so that participants could visualize the topics that had been discussed.

The topic list of this protocol was developed according to the definition of 
informed decision-making of van den Berg, Timmermans, ten Kate, van Vugt, van der Wal ${ }^{8}$ and previous research conducted by Lehmann, de Melker, Timmermans, Mollema ${ }^{2}$ to investigate decision-making. A pilot focus group session was conducted with colleagues to test the topic list, after which the topic list was revised. The revised and final topic list was used during all focus group sessions, but specific phrasings of questions were adapted to fit specific groups (Appendix 9).

The first author (K.A.G.J.R. a female, academic behavioral scientist) moderated all focus group sessions, but the observers varied between authors: SS, MS, and LM. The focus group session started with a general introduction, and an opening question asking about participants' knowledge of childhood vaccination, using a mind map to visualize the topics mentioned for participants. In the second part of the session, participants were asked about their attitude and positive and negative aspects towards accepting, refusing, and partially accepting childhood vaccination. Participants were asked to provide individual positive and negative aspects that might have influenced their decision, on Post-its. These were shared in the group after everybody had time to consider their answers. Deliberation and Information needs were explored by discussing to what extent participants considered all risks and benefits of accepting, refusing, or partially accepting childhood vaccinations, and their need and understanding of information. The semi-structured protocol with open-ended questions allowed participants to discuss additional aspects related to their decision-making with each other.

\section{Analysis}

All focus groups were audio recorded and anonymously transcribed using transcription software F4. ${ }^{26}$ All observers kept field notes, and these were used during the transcription of the focus group session and to add context to a transcript. For example, if one participant made a comment and another participant was vigorously shaking his or her head in disagreement, this was noted in the transcript, or during the mind map exercise; if a participant walked in late for a session, this was reported in the transcript.

The focus group transcripts were thematically analyzed using Nvivo $9^{23,27}$ to identify factors that appeared to be related to decision-making about childhood vaccination. The qualitative data analyses consisted of four phases. In the first phase, two observers (SS and MS) and the first author deduced relevant themes and subthemes from a random selection of the transcript of the first focus group (acceptors), and discussed and improved these with the first and last authors. ${ }^{2,8}$ Second, the observers SS and MS used these relevant themes and subthemes to develop a coding list. They then used this list to code another random selection of the transcript of the first focus group and explore possible additional relevant codes. After this, the first author and two observers discussed the code list, and the initial coding of a section of the first focus group transcript. Third, the two 
observers independently coded the entire transcript of the first focus group to look for additional codes, using the improved code list. The first author also coded this transcript to check for additional relevant codes. The coding list was discussed among the observers and the first author to resolve any differences and to add additional codes to create a final coding taxonomy. In the fourth and final phases, the final coding taxonomy was used to code the transcripts individually by KR, SS, and MS. The first author checked two additional transcripts of two other focus groups (refusers and partial acceptors) to ensure the coding taxonomy was used accordingly and checked for additional relevant codes; in this phase, no new codes were deemed necessary. ${ }^{28}$ Examples of the final coding taxonomy are: anticipated regret regarding infectious diseases, beliefs about the importance of herd immunity, beliefs about the competence of the immune system of their child, Child Welfare Center, source of information, knowledge, and trust in competence of the CVP.

\section{Results}

We set up three focus groups with acceptors $(n=19)$, three with refusers $(n=12)$, and six with partial acceptors $(n=24)$, of which three with parents delaying vaccinations and three with parents refusing some vaccinations. Since no clear differences were found between parents who delay some vaccinations and parents who reject some vaccinations, we discuss the findings of these parents as one group. Of the 55 participants, $75 \%$ were female and $25 \%$ were male, with an average age of 39 years $( \pm 5.7, \min =27, \max =58), 96 \%$ of the participants were highly educated (i.e. university education) (Appendix 9). Because of the explorative and qualitative nature of this study, the results are not intended to be generalized beyond the study population. ${ }^{29}$

\section{Knowledge about childhood vaccination}

When asked to talk about what they knew about childhood vaccination, most parents were able to mention some facts. For example, they shared facts about the NIP schedule, inclusion of combination vaccines in the NIP, the tasks of the CWCs, the high vaccination coverage in the Netherlands, low risk for susceptibility of VPDs in the Netherlands, differences in vaccination schedules between the Netherlands and other European countries, religious reasons parents may have to refuse childhood vaccinations, and the importance of herd immunity. While acceptors were able to report most evidence-based information about childhood vaccination during a mind mapping exercise, they expressed the most doubts about being well-informed when asked how informed they felt. Refusers and partial acceptors reported different information based on studies and anecdotal evidence acquired on, for example, vaccine-critical websites and social media. When asked about how informed they felt, they stated that they felt very informed (quote 1): 
My knowledge of vaccines and immunization is high... I think that some of these diseases are really good for the development of a child, as part of their natural development. I know that there are studies that show that the hand-eye coordination of a child improves after they got sick [from a VPD]. ... I really think that by experiencing diseases [VPDs] you'll be stronger later in life. (quote 1 - \#49_refuser)

Refusers mainly shared justifications based on knowledge that was discordant with scientific consensus, and rather referred to anecdotal evidence they acquired from vaccine-critical websites and social media (quote 2).

Herd immunity is based on a lie. Herd immunity doesn't exist! It's all got to do with hygiene, that's why all the VPDs have disappeared. (quote 2 \#49_refuser)

\section{Attitudes about childhood vaccination}

Parents shared their thoughts, both positive and negative, on childhood vaccination. The overall attitude of acceptors and partial acceptors was positive towards vaccinations (quote 3 ).

Vaccines are one of the best inventions ever! (quote 3 - \#37_partial acceptors)

Most acceptors mentioned that they did not just perceive individual benefits, but they also perceived aiding the herd immunity with childhood vaccinations as a great public benefit (quote 4).

The public benefit of vaccination is a really important aspect for me. (quote 4 - \#21_acceptor)

Acceptors were mostly negative towards refusing vaccinations, except for the vaccine against hepatitis $B$. Acceptors noted that they did not see the added benefit of the recently added hepatitis B vaccination (quote 5) (note: hepatitis $B$ vaccination was introduced in the Netherlands in 2011):

This is one vaccine that makes me wonder: 'do we really need it?' We didn't receive this vaccine growing up, but because there are risk groups, all our children have to receive Hepatitis B in a cocktail...? (quote 5-\#23_acceptor)

Partial acceptors consciously assessed the pros and cons of accepting or refusing each individual vaccination, and were therefore not outspokenly negative or positive. Refusers were mostly negative about the NIP and vaccinations. They discussed negative aspects about the Dutch NIP and vaccines, such as the perceived early start of vaccinations, the lack of possibility to discuss alternatives 
and doubts with people in their social environment or with CVPs, the rigidity of a standardized schedule, the lack of transparency of the NIP, combination vaccines, and the perceived mandatory nature of the NIP.

\section{Deliberation about childhood vaccination}

During the focus group sessions, parents were asked to discuss deliberating childhood vaccinations. Most acceptors reported not giving the pros and cons of childhood vaccinations much thought, but when asked about their perceived pros and cons, all were able to share theirs. This lack of deliberation was not perceived as negative, since acceptors viewed childhood vaccination not as a choice but as self-evident. They mentioned that there is not much thought needed to deliberate the pros of childhood vaccination (quote 6).

For us, childhood vaccination is really self-evident. It's not that I didn't think about alternatives, I knew you could decide to delay vaccines. But I considered it self-evident, why would the NIP exist if it wasn't good...? (quote 6-\#26_acceptor)

Compared to acceptors, refusers and partial acceptors did deliberate the pros and cons of childhood vaccinations. Refusers and partial acceptors deliberated the pros and cons of the VPDs versus side-effects of vaccines. They also consciously deliberated the pros and cons of accepting or refusing each individual vaccination. They mentioned that this was an elaborate, time-consuming, and difficult process. They explained it was difficult to find trustworthy information and that they did not feel supported in their decision-making. When asked how deliberate they perceived their decision, refusers and partial acceptors reported to have made a very deliberate choice. When asked how they had made a deliberate choice, parents explained (quote 7):

You look at the pros and cons for each disease, plus... I like statistics. So I look at the diseases and at the statistical risks of the disease. You read about vaccinations in general, those pros and cons you consider as well. We looked at each disease separately, what is the story behind the vaccine... then you make a decision. (quote 7 - \#51_refuser)

\section{Information need about childhood vaccination}

When asked about their information needs, parents stated that several of their questions remained unanswered. They reported concerns about contradictory information being available, which they find difficult to navigate. Most parents in this study mentioned that when they asked their CVPs about the contradicting information they received no or unsatisfactory answers, such as childhood vaccinations are safe. Most parents explained they wanted to know why vaccinations were safe or why vaccinations worked (quote 8): 
Childhood vaccination is really a diabolical dilemma... do we know what it does to you? What is going into my child? (quote 8 - \#6_acceptor)

Most parents agreed that the information provision about the NIP was currently inadequate (brochures and CVPs). They mentioned that the tone of voice of information about the NIP by CVPs is patronizing, which made parents feel that they were perceived as stupid and bad parents (quote 9).

We need to start open discussions and not just a one-way flow of information from the government or health professionals: 'you are just a stupid citizen and you should listen and follow our advice'. We ARE equal and we want an open dialogue. (quote 9-\#34_partial acceptor)

Refusers and partial accepters noted that information about symptoms and case fatality rates of the VPDs was lacking. They also reported that information about the consequences of their choice about childhood vaccinations, for example how they should act if their child shows symptoms of one of the VPDs, was not available. Acceptors and partial acceptors realized that their search for information about childhood immunization is influenced by their beliefs and that they will search for information that confirms their initial opinions.

\section{Additional factors related to decision-making about childhood vaccination \\ Risk perception: severity and susceptibility of VPDs and side-effects of vaccines}

Both the severity and susceptibility of VPDs and side-effects of vaccines were expressed as being influential in the decision to accept, refuse, or partially accept vaccines. Acceptors perceived the severity and susceptibility of the VPDs as great, which increased their anticipated regret should they not accept all childhood vaccinations. Unlike acceptors, partial acceptors and refusers perceived the risks of alleged side-effects of vaccines as great. For example, epilepsy, lactose intolerance, and an underdeveloped immune system were mentioned. They also mentioned other strategies to boost the immune system of their child (quote 10):

Delaying the NIP was a deliberate choice because I was breastfeeding my child. Her immune system would strengthen through me, through breastfeeding... (quote 10 - \#16 partial acceptor)

Neither refusers nor partial acceptors perceived all VPDs as being a risk. These parents mentioned that experiencing a disease would aid the development of their child (quote 1). Among refusers and partial acceptors, the severity and susceptibility of each VPD was debated separately (quote 11). 
It really depends on the type of disease [VPD]. I'm thinking, really... how likely is it he or she will get polio? The risk is so small, that's why I was comfortable with my decision to refuse this vaccine. (quote 11 -\#13_partial acceptor)

In the end, acceptors and partial acceptors described the anticipated regret of the risk of a VPD as being a decisive factor in their decision about childhood vaccination (quote 12):

You would just never forgive yourself if your child would get sick... that's why you vaccinate your child. The risk is too great. (quote 12 - \#39 partial acceptor)

\section{Norms in parents' social environment towards childhood vaccination}

The importance of norms in their social environment often recurred as a factor related to decision-making about childhood vaccination. Acceptors stated that their decision was confirmed by a strong social norm expressed by friends, parents, and the CWC, which reinforced their decision to accept vaccinations. Acceptors explained that they and society perceive the refusal of vaccination as being negative or the wrong choice, describing it as selfish. Refusers and partial acceptors felt criticized by the same social norm in society, and among friends and family for their decision (quote 13), since the majority of society perceived accepting childhood vaccination as self-evident (quote 6).

The debate makes me very uncomfortable... You enter a war zone as soon as you mention you refused the NIP, I didn't tell my family... I just didn't feel like starting a war with them (quote 13-\#11_refuser)

Refusers and partial acceptors stated that their social environment changed due to their choice; for example, they no longer had the same friends.

\section{Trust in information provision}

Due to the tone of voice of the information (brochure and information from CVPs) about the NIP, many participating parents experienced a lack of trust in this information (quote 14):

The information brochure of the NIP is presented so black and white, and blunt, that I start mistrusting it... (quote 14 - \#23_acceptor)

Lack of trust was related to one-sided information provided, and parents concluded that trustworthy information would discuss both pros and cons of childhood vaccination and would appeal to a variety of parents.

Trust and confidence in child vaccine providers Most participating parents lack confidence in the knowledge of CVPs at CWCs 
about childhood vaccinations and their skills to address their doubts about childhood vaccinations. When asked what they would like to change about the CWC, they all stated that they needed room for a dialogue in which parents and CVPs are equal, without a condescending tone of voice. In particular, the lack of time CVPs took to discuss childhood vaccinations was perceived as negative, and the tone of voice of the CVPs was experienced as haughty. Some refusers or partial acceptors even mentioned that the latter was a reason to refuse or partially accept vaccinations (quote 15).

I wanted to discuss childhood vaccination, but that was not possible... they just didn't want to discuss it with me. At the time, I was still trying to decide what to do; it was not my intention to refuse... (quote 15 - \#28_refuser)

\section{Discussion}

We explored whether Dutch parents made an informed decision about childhood vaccination and factors related to informed decision-making about accepting, refusing, or partially accepting childhood vaccination .Our qualitative study was based on the definition of informed decision-making ${ }^{8}$ and assessed factors associated with the ongoing assessment phase of parents' informed decision-making. ${ }^{17}$ Knowledge, attitudes, and deliberation differed among parents. Acceptors perceived accepting childhood vaccinations as selfevident, refusers relied mostly on anecdotal information rather than evidencebased information to weigh up the pros and cons of side-effects of vaccines and the VPDs, and partial acceptors described an elaborate, time-consuming, and difficult deliberation to weigh up the pros and cons of each vaccine and VPD individually. In line with previous research, 2,8,9,11-15,30-34 besides knowledge, attitudes, and deliberation, other factors were reported in relation to informed decision-making. For example, all participating parents mentioned their information needs about childhood vaccination in general and about vaccine safety, a need for a supportive social environment, and a strong social norm to vaccinate their children. While acceptors trusted the information provided, refusers and partial acceptors considered that there was a lack of open dialogue with CVPs, one-sided information provision about the NIP, and lack of trust in the CWC. While acceptors reported the severity and susceptibility about VPDs and anticipated regret about their child getting sick from a VPD when not vaccinating as factors related to decision-making, refusers and partial acceptors mentioned side-effects of vaccines.

Acceptors could recall more evidence-based information about the NIP than refusers and partial acceptors; they were negative about refusing childhood vaccinations and positive about the NIP. Although previous research indicates that acceptors tend to be uninformed, ${ }^{17}$ and acceptors in our study felt uninformed, we found that they were able to provide more evidence-based information than 
other parent groups. Acceptors strongly believed that childhood vaccination is an action that benefits not only their child (individual benefit), but also herd immunity (societal benefit) and they described a positive and strong social norm in place regarding this belief, which is confirmed by Brunson ${ }^{17}$. This strong social norm was also perceived by refusers and partial acceptors, but they perceived this norm as judgmental. ${ }^{35}$ Overall, acceptors did not perceive uptake of childhood vaccinations as a choice which needs much deliberation because they considered it as self-evident, and this finding is confirmed by previous research. 2,36

All participating parents mentioned inadequate information provision, stating that the mere response of 'vaccines are safe' is not satisfactory. Similar to refusers and partial acceptors, acceptors perceived this type of information provided by the CWC as condescending. This may also be why acceptors did not feel informed. Stimulating an open dialogue between parents and CVPs may increase parents' feeling of being informed ${ }^{30,35,37-39}$. The lack of discussion with CVPs, the perception that childhood vaccination is self-evident, and the patronizing tone of voice of CVPs may leave parents vulnerable for anti-vaccination messages about alleged risks and side-effects of childhood vaccination. ${ }^{30-34,39-41}$ As suggested by Benin, Wisler-Scher, Colson, Shapiro, Holmboe ${ }^{37}$, attitudes towards childhood vaccination are continuously developing and shifting. Therefore, it is important to strengthen existing positive attitudes about childhood vaccination and build resistance for future anti-vaccination messages, as well as to discuss the arguments and anecdotal evidence used on anti-vaccination websites. ${ }^{42}$

Refusers may base their arguments against vaccination mainly on anecdotal evidence and were negative about childhood vaccinations in general. They indicated that they had consciously deliberated the pros, but mostly the cons of participating in the NIP, and some mentioned that they did not know about alternative vaccination schedules at the time of decision-making. Compared to acceptors, refusers may believe that the risks of vaccine side-effects are more severe than the risks of VPDs, and that they do not trust the information about the NIP offered by CVPs. Refusers mostly preferred to acquire anecdotal evidence from vaccine-critical websites and social media platforms, such as Facebook@. They reported searching and gathering information supporting anti-vaccination arguments. ${ }^{43,44}$ In addition, using search engines to gather information about childhood vaccination leads to selection bias due to previously used search terms and the ranking of websites by search engines. ${ }^{45}$

Partial acceptors may elaborately deliberate the pros and cons of each vaccine and VPD individually, which resulted in a feeling of decisional conflict regarding the benefits and risks of vaccines versus the perceived benefits and risks of experiencing VPDs. Some parents lost their trust in the competence of CVPs when their questions were ignored, or when the CVPs were not able to answer their questions. Because their questions remained unanswered, their decisional conflict increased. ${ }^{17,18}$ This feeling of decisional conflict may lead parents to 
search for anti-vaccination arguments and diminishes the positive attitude of parents about childhood vaccination. In addition, partial acceptors described a lack of social support from friends, family, and CVPs with regard to their choice to partially accept childhood vaccinations. Research shows that decisional conflict and lack of discussion between parents and CVPs at the CWC influences the information seeking behavior of parents navigating anti-vaccination websites. ${ }^{39,41}$ In an open discussion among CVPs and parents, inoculation messages about childhood vaccination can strengthen existing positive attitudes and build resistance for anti-vaccination messages. ${ }^{42}$ These messages are similar to a vaccination, parents could be trained to resist attacks on their positive beliefs about childhood vaccination by practicing their response to anti-vaccination messages. ${ }^{42}$

Finally, many participants expressed the need for more information about childhood vaccination..$^{30-34}$ This information need was not met by the CVPs. Refusers and partial acceptors mentioned that they accessed vaccine-critical websites because their questions are ignored by CVPs. Furthermore, they view the current information provision as insufficient, and they distrust the information provision about the NIP. All groups agree that the tone of voice of CVPs at the CWC is condescending. The inadequate information provision and condescending tone of voice do not meet the information needs of parents, and our research confirms findings from Benin, Wisler-Scher, Colson, Shapiro, Holmboe ${ }^{37}$ indicating that this leads to a lack of trust among parents regarding CVPs and CWCs. Our results demonstrate that merely disseminating evidencebased knowledge does not lead to a trusting relationship between parents and the CVP. Research found that some CVPs find it difficult to discuss alternative vaccination decisions with parents. ${ }^{46,47}$ CVPs need to have knowledge about the NIP, time, and skills to discuss childhood vaccinations with all parents ${ }^{37}$. In particular, it is important to not exclude parents refusing or partially accepting childhood vaccination. In this way, evidence-based information can be exchanged, misperceptions and doubts can be addressed, positive attitudes can be strengthened, questions can be answered, and the various options for childhood vaccination can be discussed. To increase factual knowledge about childhood vaccination and facilitate discussion skills among CVPs to build trusting relationships with parents, the Dutch public health institute developed an e-learning tool, and funds were made available by the government to reduce time constraints to discuss childhood vaccination with parents in 2017-2018. ${ }^{48}$ The e-learning tool was adopted by over one thousand CVPs in 2017. ${ }^{9}$ While further research and monitoring is needed to evaluate the implementation, adoption, and effectiveness of this tool, these changes and measures may stimulate an open dialogue, increase informed decision-making, reduce decisional conflict, and increase trust between parents and CVP professionals. ${ }^{10,48,49}$ 


\section{Application and further research}

To gain more insight into which factors played a role in informed decisionmaking about childhood vaccination among acceptors, refusers, and partial acceptors, population surveys are necessary. The outcome of such quantification can be used to support informed decision-making on the part of parents about childhood vaccination.

Acceptors, refusers, and partial acceptors agree that the information provision is currently not sufficient. Refusers and partial acceptors would like more information on consequences of and susceptibility to VPDs and possible sideeffects of childhood vaccinations. Such information is a potential measure to counter anti-vaccination messages, and to increase informed decision-making about childhood vacations., 31,37,44,50 Betsch, Renkewitz, Haase ${ }^{43}$ showed that numeric information, in combination with narratives about the susceptibility to VPDs and side-effects of vaccines had the greatest impact on parents' risk perception towards childhood vaccination. Further research is necessary to test how a combination of numeric risk communication and narratives can inform parents about the low level of individual susceptibility of VPDs, which may have severe consequences; and the greater individual susceptibility of side-effects after a childhood vaccination, which are mild, pass quickly, and have no lasting effects. 3,34,38,39,41,43 The information on risk communication and narratives can be used in a communication approach of CVPs at the CWC to answer the questions of parents in detail and thus build a trustworthy relationship. In addition, our results show that while parents accepting childhood vaccinations are not interested in refusing or partially refusing childhood vaccinations, refusers and partial acceptors are highly interested in elaborate information about various vaccination options. Refusers appeared to be interested in hearing more about partially accepting childhood vaccination instead of refusing the NIP. Compared to refusing childhood vaccinations, there are more health benefits associated with partially accepting the NIP. Still, accepting all childhood vaccinations yields the most individual and public health benefits for children, so the possible adverse effects of informing parents - such as acceptors switching to refusers or partial acceptors - need to be prevented. Further research is necessary to investigate the individual and public health effect of informing parents about these options of childhood vaccinations.

\section{Strengths and limitations}

This study explored whether parents make an informed decision, and factors related to the decision about childhood vaccination (e.g. accepting, refusing, or partially accepting), by examining parents' knowledge, attitude, and deliberation, and additional factors concerning accepting, refusing, and partially accepting childhood vaccinations. There are several limitations in this study. ${ }^{22}$ Selection bias may have occurred. Respondents were asked to participate in a two-hour 
discussion, which may have attracted individuals more inclined to talk about childhood vaccination. In addition, $96 \%$ of the persons in our sample were highly educated, and this percentage is not a reflection of the Dutch population. We drew a randomly selected sample within each municipality, but mainly higher educated parents responded to our invitation. We suggest that further research consciously includes other segments of the population, and that differences between low and higher educated parents should be investigated. Because of the overrepresentation of higher educated parents, and the explorative and qualitative nature of this study, the results are not able to be generalized to Dutch parents. ${ }^{29}$

We asked parents to consider their decision in retrospect, thereby possibly introducing recall bias. However, children were not older than two years old and the last vaccinations for which parents had made a decision was no later than ten months prior to the focus group sessions. Even though the moderator followed rigorous training for focus groups, interviewer bias may be a factor. There was one moderator to standardize a possible bias, and the moderator took measures to remain as neutral as possible in dress, tone, and body language.

\section{Conclusion}

To conclude, our exploration of informed decision-making and factors related to decision-making about childhood vaccination identifies distinct differences in knowledge, attitudes, and deliberation of parents. The findings can facilitate informed decision-making among parents by promoting an open dialogue at the CWC, and improving the type and form of information presented. An open dialogue between parents and CVPs may increase deliberation among parents, strengthen positive attitudes, prevent misperceptions, and resolve decisional conflict. 


\section{References}

1. E.A. van Lier, P.J. Oomen, H. Giesbers, et al. Vaccine Coverage of NIP in the Netherlands. Bilthoven: National Instituut of Public Health and the Environment;2016.

2. Lehmann BA, de Melker HE, Timmermans DRM, Mollema L. Informed decision making in the context of childhood immunization. Patient Educ Couns. 2017;100(12):2339-2345.

3. Brewer NT, Chapman GB, Gibbons FX, et al. Meta-analysis of the relationship between risk perception and health behavior: the example of vaccination. Health Psychol. 2007;26(2):136-145.

4. World Health Organization. Immunization Coverage. Immunization, Vaccines and Biologicals 2018. http://www.who.int/en/news-room/fact-sheets/detail/ immunization-coverage. Accessed June, 26, 2018.

5. National Institute for Public Health and the Environment (RIVM). [National Immunization Program]. History 2018. http://www.rijksvaccinatieprogramma.nl/ Over_Rijksvaccinatieprogramma/Geschiedenis. Accessed June 19, 2018.

6. E.A. van Lier, Geraedts JLE, P.J. Oomen, et al. [Vaccine Coverage of NIP in the Netherlands]. Bilthoven: National Instituut of Public Health and the Environment;2017.

7. Michie S, Dormandy E, Marteau TM. Informed choice: understanding knowledge in the context of screening uptake. Patient Educ Couns. 2003;50(3):247-253.

8. van den Berg M, Timmermans DR, ten Kate LP, van Vugt JM, van der Wal G. Informed decision making in the context of prenatal screening. Patient Educ Couns. 2006;63(1-2):110-117.

9. E.A. van Lier, Geraedts JLE, P.J. Oomen, et al. [Vaccine Coverage of NIP in the Netherlands]. Bilthoven: National Institute for Public Health and the Environment;2018.

10. Corben P, Leask J. Vaccination hesitancy in the antenatal period: a crosssectional survey. BMC Public Health. 2018;18(1):566.

11. Baron J. Thinking and Deciding. 4th ed. Cambridge: Cambridge University Press; 2007.

12. Marteau TM, Dormandy E, Crockett R. Informed choice: why measuring behaviour is important. Arch Dis Child. 2005;90(5):546-547; author reply 546547.

13. Michie S, Dormandy E, Marteau TM. The multi-dimensional measure of informed choice: a validation study. Patient Educ Couns. 2002;48(1):87-91.

14. Harmsen IA, Ruiter RA, Paulussen TG, et al. Factors that influence vaccination decision-making by parents who visit an anthroposophical child welfare center: a focus group study. Advances in preventive medicine. 2012;2012.

15. Montano DE, Kasprzyk D. Theory of Reasoned Action, Theory of Planned Behavior, and the Integrated Behavioral Model. In: Glanz K, Rimer BK, Viswanath K, eds. Health Behavior and Health Education: Theory, Research and Practice. 4th ed. New Jersey: John Wiley \& Sons; 2008:67-96. 
16. Serpell L, Green J. Parental decision-making in childhood vaccination. Vaccine. 2006;24(19):4041-4046.

17. Brunson EK. How parents make decisions about their children's vaccinations. Vaccine. 2013;31(46):5466-5470.

18. Bedford $H$, Attwell K, Danchin $M$, et al. Vaccine hesitancy, refusal and access barriers: The need for clarity in terminology. Vaccine. 2018;36(44):6556-6558.

19. MacDonald N, Dube E, Butler R. Vaccine hesitancy terminology: A response to Bedford et al. Vaccine. 2019;37(30):3947-3948.

20. MacDonald NE, Hesitancy SWGoV. Vaccine hesitancy: Definition, scope and determinants. Vaccine. 2015;33(34):4161-4164.

21. Pot M, Paulussen TG, Ruiter RA, et al. Effectiveness of a Web-Based Tailored Intervention With Virtual Assistants Promoting the Acceptability of HPV Vaccination Among Mothers of Invited Girls: Randomized Controlled Trial. J Med Internet Res. 2017;19(9):e312.

22. Powell RA, Single HM. Focus groups. Int J Qual Health Care. 1996;8(5):499-504.

23. Evers J, de boer F. The qualitive interview: art and skill. the Hague: Eleven International Publishing; 2012.

24. Centraal Bureau voor Statistiek (CBS). [International Standard Classification of Education (ISCED)]. Heerlen: Centraal Bureau voor Statistiek (CBS);2018.

25. Dicicco-Bloom B, Crabtree BF. The qualitative research interview. Med Educ. 2006;40(4):314-321.

26. f4transkript [computer program]. Version 7. Marburg, Germany: audiotranskription; 2017.

27. NVivo qualitative data analysis Software [computer program]. Version version 9, 20102010.

28. Vaismoradi M, Turunen $\mathrm{H}$, Bondas T. Content analysis and thematic analysis: Implications for conducting a qualitative descriptive study. Nurs Health Sci. 2013;15(3):398-405.

29. Neale J, Miller P, West R. Reporting quantitative information in qualitative research: guidance for authors and reviewers. Addiction. 2014;109(2):175-176.

30. Betsch C, Renkewitz F, Betsch T, Ulshofer C. The influence of vaccine-critical websites on perceiving vaccination risks. J Health Psychol. 2010;15(3):446-455.

31. Downs JS, de Bruin WB, Fischhoff B. Parents' vaccination comprehension and decisions. Vaccine. 2008;26(12):1595-1607.

32. Schmidt AL, Zollo F, Scala A, Betsch C, Quattrociocchi W. Polarization of the vaccination debate on Facebook. Vaccine. 2018;36(25):3606-3612.

33. Haase $N$, Betsch $C$. Parents trust other parents: lay vaccination narratives on the Web may create doubt about vaccination safety. Med Decis Making. 2012;32(4):645.

34. Haase N, Betsch C, Renkewitz F. Source Credibility and the Biasing Effect of Narrative Information on the Perception of Vaccination Risks. J Health Commun. 2015;20(8):920-929.

35. Brunson EK. The impact of social networks on parents' vaccination decisions. Pediatrics. 2013;131(5):e1397-1404. 
36. Tickner S, Leman PJ, Woodcock A. 'It's just the normal thing to do': exploring parental decision-making about the 'five-in-one' vaccine. Vaccine. 2007;25(42):7399-7409.

37. Benin AL, Wisler-Scher DJ, Colson E, Shapiro ED, Holmboe ES. Qualitative analysis of mothers' decision-making about vaccines for infants: the importance of trust. Pediatrics. 2006;117(5):1532-1541.

38. Betsch C, Bohm R, Airhihenbuwa CO, et al. Improving Medical Decision Making and Health Promotion through Culture-Sensitive Health Communication: An Agenda for Science and Practice. Med Decis Making. 2016;36(7):811-833.

39. Betsch $C$, Sachse K. Debunking vaccination myths: strong risk negations can increase perceived vaccination risks. Health Psychol. 2013;32(2):146-155.

40. Betsch C, Sachse K. Dr. Jekyll or Mr. Hyde? (How) the Internet influences vaccination decisions: recent evidence and tentative guidelines for online vaccine communication. Vaccine. 2012;30(25):3723-3726.

41. Siegrist M, Cvetkovich G. Better negative than positive? Evidence of a bias for negative information about possible health dangers. Risk Anal. 2001;21(1):199206.

42. Compton J, Jackson B, Dimmock JA. Persuading Others to Avoid Persuasion: Inoculation Theory and Resistant Health Attitudes. Front Psychol. 2016;7:122.

43. Betsch C, Renkewitz F, Haase N. Effect of narrative reports about vaccine adverse events and bias-awareness disclaimers on vaccine decisions: a simulation of an online patient social network. Med Decis Making. 2013;33(1):14-25.

44. Glick M. Believing is seeing: Confirmation bias. J Am DentAssoc. 2017;148(3):131132.

45. Wolfe RM, Sharp LK. Vaccination or immunization? The impact of search terms on the internet. J Health Commun. 2005;10(6):537-551.

46. Harmsen IA, Ruiter RA, Kok G, et al. Child vaccine providers' experience with the National Immunisation Programme and their consults with parents. Bilthoven: RIVM; 2014.

47. Mollema L, Staal JM, van Steenbergen JE, Paulussen TG, de Melker HE. An exploratory qualitative assessment of factors influencing childhood vaccine providers' intention to recommend immunization in the Netherlands. BMC Public Health. 2012;12(1):128.

48. National Institute for Public Health and the Environment (RIVM). E-Learning: Backgrounds NIP. 2017. https://www.nspoh.nl/bij-en-nascholing/e-learningachtergronden-rijksvaccinatieprogramma/. Accessed June 28th, , 2018.

49. Geelen E, van Vliet H, de Hoogh P, Horstman K. Taming the fear of voice: Dilemmas in maintaining a high vaccination rate in the Netherlands. Soc Sci Med. 2016;153:12-19.

50. Weinstein ND. Why it won't happen to me: perceptions of risk factors and susceptibility. Health Psychol. 1984;3(5):431-457. 



\section{CHAPTER 7}

Deciding on childhood vaccination: differences in decisional conflict and determinants between parer s Mo accepted, refused, and partly accepted childhood ra cingation

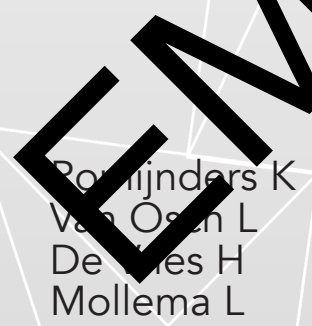

(2020). Deciding on childhood vaccination: differences in decisional conflict and determinants between parents who accepted, refused, and partially accepted childhood vaccination. (Submitted, 2020) 


\section{PART 3}





\section{CHAPTER 8}

Exploring differences in knowledge, attitude, and deliberation: an illustration of next to best eath decisions in the cases of hildobd vaccination and smoking ebavior

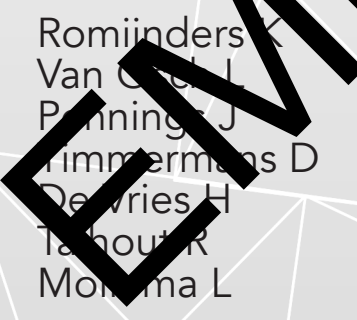

(2020). Exploring differences in knowledge, attitude, and deliberation: an illustration of next to best health decisions in the cases of childhood vaccination and smoking behavior. (Submitted, 2020) 


\section{CHAPTER 9}

General Discussion 

Every day we make decisions about our own health and the health of others, for example, when a parent makes a decision about childhood vaccination. When making health-related decisions, there can be different options to choose from. Public health professionals often inform the public about an option they recommend based on scientific evidence. However, this healthiest, recommended option might not be suitable for everyone, due to their personal values, priorities with regard to health, experiences, opinions, and the norms of their social environment. Consequently, in these cases people may choose options that match their individual values and goals but that are considered by public health professionals to be, for example, next to best. From a public health and scientific point of view, next to best health options are less harmful or less healthy than the unrecommended health option, but not less harmful or less healthy compared to the recommended health option. Another option people may choose is the unrecommended option, which is considered as being unhealthy by public health experts and science.

Not smoking, and accepting childhood vaccination are both choice options that are recommended by public health experts since they promote health. ${ }^{1-8}$ Whether people consider that the advantages of these recommended choice options outweigh those of alternative choice options depends on their values, preferences, experiences, and social environment.9-16 In this thesis we explored two examples of decisions we identified as a next to best health decision: e-cigarette use and partially accepting childhood vaccinations. To expand our understanding of these next to best health decisions, we had two aims. First, we aimed to examine determinants that influence the decision about smoking behavior and childhood vaccination, both qualitatively and quantitatively. Second, we examined the extent to which decisions regarding smoking behavior and childhood vaccination adhere to the criteria of informed decision-making. With the insights into the factors related to the decision and whether the decisions adhered to the criteria of informed decision-making, we are able to better facilitate and support decision-making about smoking behavior and childhood vaccination. In this thesis, we used the three criteria knowledge, attitude, and deliberation of informed decision-making of van den Berg, Timmermans, ten Kate, van Vugt, van der Wal ${ }^{17}$ to investigate how people made a decision about the recommended, unrecommended, and next to best health option. We defined a decision as being informed if the decision-maker has relevant evidence-based knowledge about the subject, has an attitude towards the subject that reflects his or her choice (i.e. the choice is value-consistent), and has deliberated all options. ${ }^{17-23}$ This definition of informed decision-making is based on a Rational Decision model, which reflects a rational style in decision-making with an emphasis on thorough and logical processing. ${ }^{24,25}$ It is important to investigate the criteria of informed decision-making because supporting informed decisionmaking may reduce decisional conflict, and reducing decisional conflict may support decision-making. ${ }^{26-28}$ With regard to smoking behavior, increasing informed decision-making about smoking cessation and lowering decisional 
conflict regarding smoking cessation may support smokers in their efforts to quit smoking. ${ }^{29}$ With regard to childhood vaccination, increasing informed decisionmaking and decreasing decisional conflict may reduce vaccine hesitancy ${ }^{30-32}$ and it may positively affect intention to accept childhood vaccinations, and therefore also positively affect the vaccination coverage. ${ }^{33}$ According to the Elaboration Likelihood Model ${ }^{34}$, people can make a decision through two types of routes: the central route or the peripheral route. ${ }^{34}$ To make an informed decision, it is important that people use the central route of processing. Central processing could lead to decisions that are less vulnerable to unobjective information, ${ }^{35,36}$ or decisional regret ${ }^{27}$ and result in a higher level of sticking to a healthy choice. ${ }^{34}$ With the studies described in this thesis, we aimed to increase our understanding of the next to best health decisions in order to improve health communication and support decision-making. Part 1 of this thesis provided an exploration of factors related to the decision about never-use, smoking, and e-cigarette use. Part 2 explored factors related to the decision about accepting, refusing, and partially accepting childhood vaccination, and decisional conflict experienced by parents with regard to their decision to accept, refuse, or partially accept childhood vaccinations. Part 3 operationalized the criteria of informed decisionmaking ${ }^{17}$ about smoking behavior and childhood vaccination. As such, it provides insights into the extent to which recommended, unrecommended, and next to best health decisions adhere to the criteria of an informed decision. To conclude this thesis, the current chapter summarizes the main findings and discusses the conclusions and implications of these findings for research, health communication, and policy.

\section{Main findings}

\section{Part 1 Exploring the decision about never-use, smoking, and e-cigarette use}

In part 1, we focused on determinants that are related to the decision regarding never-use, smoking, and e-cigarette use (first aim of this thesis). Our systematic narrative review of chapter 2 about reasons and perceptions regarding e-cigarettes among never-users, smokers, and e-cigarette users (i.e. both dual users of cigarettes and e-cigarettes, as well as exclusive e-cigarette users) showed that e-cigarette users perceived e-cigarettes as being less harmful than cigarettes. Different reasons and benefits were reported by never-users, smokers, dual users, and e-cigarette users. Reasons and benefits of e-cigarettes reported by never-users were the novelty of the product and its potential to aid their concentration. Smokers mentioned that it mimics the smoking routine, whereas dual users reported benefits of avoiding smoking restrictions. E-cigarette users reported benefits of increased athletic performance and that e-cigarettes are discrete to use. In addition to these reported individual benefits, several benefits were mentioned for the social environment of a user, such as that e-cigarette use 
is safer for bystanders and that there is less environmental pollution.

Chapter 3 described - through qualitative analysis - determinants reported by never-users, smokers, and e-cigarette users in relation to the decision concerning smoking behavior and e-cigarette use. Besides knowledge, attitudes, and deliberation, these were perception of risks and benefits of e-cigarettes compared to cigarettes, influence of the social environment concerning e-cigarette use, and trust in information about the risks and benefits of e-cigarettes from the government. Additionally, we found that e-cigarette users used user experiences (i.e. a vape forum) as their main source of information about e-cigarette use and they reported that switching from cigarettes to e-cigarettes was a deliberate decision. Results from the qualitative exploration of chapter 3 also revealed that e-cigarette users, compared to never-users and smokers, reported anecdotal information found on e-cigarette users fora, perceived few risks of e-cigarettes compared to cigarettes, reported a sense of community and support with and by other users. Never-users and smokers perceived e-cigarettes as being less harmful than cigarette smoking, which we also found in our narrative literature review (chapter 2).

A limitation of many studies looking at determinants is that they do not take into account the attractiveness of e-cigarette product characteristics. However, e-liquid flavors were reported to be an important reason to use e-cigarettes in chapter 2. Hence, the role of product characteristics and, in particular, e-liquid flavors regarding e-cigarette use was explored in depth in chapter 4 . Our results - from a quantitative analysis described in chapter 4 - demonstrated that menthol/mint and sweet e-liquid flavors were reported to be preferred by neverusers. Tobacco and menthol/mint e-liquid flavors were preferred by smokers and dual users, and sweet and fruit flavors were preferred by e-cigarette users compared to other flavor categories.

Finally, our exploration of differences - through quantitative analysis - between dual users and exclusive e-cigarette users in chapter 5 identified seven distinguishing features, namely: compared to exclusive e-cigarette users, dual users felt more connected with other smokers (i.e. their social ties with smokers were stronger), exclusive e-cigarette users smoked more in the past than dual users do in the present, self-efficacy to quit vaping and smoking was lower among dual users, e-cigarette users found the cigarette to be unattractive more often than dual users, e-cigarette users had more positive attitudes towards vaping than dual users, dual users perceived more barriers to accessing e-cigarettes, and finally, dual users had a higher intention to quit vaping than e-cigarette users.

\section{Part 2 Exploring the decision about childhood vaccination}

In part 2 we focused on factors related to the decision about accepting, refusing, and partially accepting childhood vaccinations (first aim of this thesis). Chapter 
6 of this dissertation explored - through a qualitative study - the decision regarding childhood vaccination among parents who accepted, refused, and partially accepted childhood vaccination. Our findings demonstrated that partial acceptors mentioned perceiving few risks of vaccine-preventable diseases (VPDs), risks of side effects of vaccines, low social support from their environment, low trust in Child Welfare Centers (CWCs), and information provided from these CWCs.

Chapter 7 described the results of a quantitative analysis on determinants and decisional conflict related to decision-making among acceptors, refusers, and partial acceptors. Overall, trust in the National Immunization Program (NIP) was high among acceptors but moderate among refusers and partial acceptors. Acceptors perceived the susceptibility of side effects of vaccines as being lower compared to the susceptibility of VPDs if you refuse (some) vaccines. Refusers and partial acceptors perceived the susceptibility of side effects of vaccines as being higher compared to the VPDs. While anticipated regret towards negative consequences of VPDs was high among acceptors when considering refusing childhood vaccinations, anticipated regret among refusers and partial acceptors with regard to potential side effects for the child was high when considering accepting vaccines. All parents reported a social norm favoring accepting childhood vaccinations. Partial acceptors experienced more barriers with regard to vaccination than refusers and acceptors. On the decisional conflict scale, acceptors scored highest on uninformed, refusers scored highest on unsupported, and partial acceptors scored highest on uncertainty.

\section{Part 3 Exploring knowledge, attitudes, and deliberation}

In chapter 8 we examined to what extent decisions about smoking behavior and childhood vaccination adhere to the criteria of informed decision-making (second goal of this thesis). Our results showed that never-users and acceptors both had relatively low levels of deliberation. In addition, our findings indicate that cognitive beliefs of refusers and partial acceptors are not in accordance with scientific evidence about childhood vaccination. Partial acceptors scored in-between refusers and acceptors on knowledge, scores on attitudes, and deliberation with regard to accepting, refusing, and partially accepting childhood vaccination. In contrast, vaccine refusers had deliberated their decision thoroughly, smokers were found to report low levels of deliberation. Smokers and e-cigarette users were most positive about not smoking or using e-cigarettes, and acceptors, refusers, and partial acceptors were most positive towards their own behavior. 


\section{Reflection on main findings}

\section{Exploring smoking behavior and childhood vaccination}

This thesis is structured around the exploration of the next to best health decisions regarding smoking behavior and childhood vaccinations. To expand our understanding of these next to best health decisions, we first reflect on the criteria of informed decision-making, such as knowledge and cognitive beliefs, attitudes, and deliberation and the extent to which these decisions about smoking behavior and childhood vaccination adhered to the criteria of informed decisionmaking. Second, we reflect on additional factors related to the decisions about smoking behavior and childhood vaccinations, such as perceived susceptibility and severity, trust in information, anticipated regret, social support, and selfefficacy.

\section{Knowledge and cognitive beliefs}

This thesis indicates that those who opted for the recommended option (i.e. never-users and vaccine acceptors) had higher levels of knowledge about smoking behavior and childhood vaccinations, respectively, than those choosing unrecommended and next to best health options (e.g. smokers, e-cigarette use, vaccine refusers and partial acceptors). Other studies also found that neverusers and vaccine acceptors had high levels of knowledge about smoking and childhood vaccinations, respectively. 5,37,38 With regard to the unrecommended option (i.e. smokers and vaccine refusers) and next to best choice (i.e. e-cigarette users and partial acceptors) option, our results demonstrated that although smokers and e-cigarette users, as well as refusers and partial acceptors, stated that they were familiar with the common health risks of smoking or refusing childhood vaccinations, respectively (chapters $3-8$ ), the level of evidencebased knowledge among those who chose the unrecommended and next to best health options was low. These findings are in line with studies reporting low levels of knowledge among smokers in the United States, ${ }^{38,39}$ Canada, the United Kingdom, and Australia. ${ }^{39}$ In addition, findings from a previous study among vaccine refusers and partial acceptors also showed low levels of knowledge among these groups. ${ }^{5}$ To the best of our knowledge, no such previous findings with regard to low or high levels of knowledge about e-cigarettes could be identified among e-cigarette users.

Even though our results showed low levels of evidence-based knowledge among those choosing the unrecommended and next to best options, chapter 3 and chapter 7 demonstrated that e-cigarette users, vaccine refusers, and partial acceptors felt very informed. Interestingly, no such findings could be identified in previous research. A possible explanation may be that e-cigarette users, vaccine refusers, and partial acceptors all reported extensively searching for information with regard to their decision. However, e-cigarette users, vaccine refusers, and partial acceptors - but not necessarily smokers - mainly shared 
justifications based on information that was discordant with scientific consensus in our qualitative studies (chapters 3 and 6), and these findings were confirmed in our quantitative studies (chapter 8 ). This information may lead to or stimulate cognitive beliefs - found in chapters 3, 6, and 8 - that are not in accordance with scientific evidence, which has been reported in previous literature. ${ }^{40-42}$ In addition, their information-seeking behavior, such as using non-scientific sources rather than searching for scientific information, may confirm their cognitive beliefs or decision. Examples of such non-scientific sources could be user experiences, vaccine-critical websites, or social media,43-50 where parents share experiences with childhood vaccinations., 91-56 This phenomenon of looking for information to confirm a decision taken is also called bolstering: the reinforcement of a chosen option over the alternatives by selective information-seeking and processing. Janis and Mann ${ }^{57}$ have suggested that bolstering may facilitate arriving at a decision or occur after a decision has been made. In the latter case, refusers or partial acceptors, for example, would look for information that reinforces their chosen option over accepting vaccinations, and will therefore for instance use vaccine-critical websites. ${ }^{58}$ Among smokers specifically, an explanation for low levels of evidence-based knowledge might be found in the cognitive dissonance theory of Festinger ${ }^{59}$. Their actions - smoking - may be in conflict with their scientifically correct knowledge about smoking behavior, causing cognitive dissonance. 9,60 This conflict between their smoking behavior and their knowledge of the health risks of smoking may lead them to rely on cognitive beliefs that are in line with their behavior and decision, which might be why they answer the knowledge statements incorrectly.

\section{Attitude}

We identified attitudes about all three health options among those who chose for the recommended, unrecommended, and next to best health options. Those who opted for the recommended health option were most positive towards their own decision, and not outspokenly negative or positive towards the next to best health option. Those who opted for the next to best health decisions reported most positive attitudes towards their own behavior. In addition, e-cigarette users were not outspokenly negative or positive towards not smoking and not using e-cigarettes (i.e. never-use), but outspokenly negative towards smoking (chapters 3, 4 and 8). Partial acceptors on the other hand were not outspokenly negative or positive towards accepting or refusing childhood vaccinations (chapters 6, and 8). Although positive attitudes among partial acceptors towards accepting childhood vaccination have been identified before, ${ }^{5}$ to the best of our knowledge no such findings could be identified about attitudes towards the unrecommended or next to best health options. The not outspoken negative or positive attitudes towards accepting, refusing, and partially accepting childhood vaccinations among parents who partially accepted childhood vaccinations may indicate an ambivalence with regard to their decision. ${ }^{61}$ In addition, with regard to those who chose the unrecommended option, our findings suggest that while vaccine refusers were very positive towards their own choice - which is in line with 
previous research ${ }^{5}$ - smokers were negative towards smoking. Previous research confirmed that smokers are often negative towards their own behavior, ${ }^{62}$ and findings of the ITC Netherlands National Report ${ }^{63}$ revealed that Dutch smokers had a negative opinion about their own behavior. A possible explanation is cognitive dissonance related to smoking. In this case their knowledge about the health consequences of smoking is in conflict with their behavior, causing negative attitudes and dissonance.., 60

\section{Deliberation}

Deliberation about smoking behavior and childhood vaccination was highest among those who opted for the next to best health option. Research previously identified high levels of consideration among partial acceptors and e-cigarette users. ${ }^{5,64}$

With regard to the next to best health option, e-cigarette users consciously deliberated initiation of e-cigarette use versus continuation of cigarette smoking by using knowledge acquired and by weighing the benefits of e-cigarette use and disadvantages of cigarette smoking (chapters 3 and 8). Partial acceptors deliberated accepting, refusing, and partially accepting childhood vaccinations (chapter 8). Our findings from chapters 6, 7, and 8 suggest that partial acceptors made a decision about each vaccine offered to them separately, and not an overall decision to partially accept childhood vaccinations. They - as well as vaccine refusers - described an elaborate, time-consuming, and complex deliberation process (chapter 6).

With regard to the recommended health option, never-users and vaccine acceptors reported giving their decision little thought. Vaccine acceptors specified this was not perceived as negative because they viewed their decision about childhood vaccination as self-evident. Since the current vaccination coverage is high (90\%), but is decreasing ${ }^{65}$, it could be argued that low levels of deliberation among parents accepting all the childhood vaccination is not a problem. ${ }^{65}$ However, parents who are not making a deliberate decision might be vulnerable for negative messages about their decision, ${ }^{9}$ and it is therefore important that they understand why they decided for the recommended option and deliberate this decision in order to build resilience. ${ }^{66}$ Deliberation about e-cigarette use was relatively low among smokers compared to levels of deliberation about childhood vaccinations among refusers. A possible explanation of low levels of deliberation among smokers about a less harmful alternative may be provided by their nicotine addiction, which may make it difficult for them to consider an alternative to smoking. ${ }^{67-69}$ 


\section{Exploring informed decision-making}

This thesis described the differences and similarities found in knowledge, attitude, and deliberation. Overall, those who opted for the recommended health option lacked deliberation about their decision. Those who opted for the unrecommended or next to best health options had low levels of knowledge. In addition, smokers did not deliberate much and were relatively negative with regard to their own behavior. With regard to the second goal of this thesis, the findings of chapters $2-6$, and 8 show that in our studies, the decisions about smoking behavior and childhood vaccination did not adhere to at least one of the criteria of the definition of an informed decision. Although similarities were found in the three criteria of informed decision-making for the recommended, unrecommended, and next to best health options, there are differences in the context of these exemplary cases.

With regard to the two different contexts in which these decisions are made, several aspects could be considered. Smoking is an addictive behavior, which may make it difficult to make an informed decision about smoking cessation or switching to e-cigarettes. ${ }^{67-69}$ In our studies too, smokers lacked evidence-based knowledge, had relatively negative attitudes towards their own behavior, had relatively low levels of deliberation regarding smoking, e-cigarette use, or not smoking or using e-cigarettes. Vaccination decisions were not characterized by addictive features. Another possible explanation of the lack of commonalities in these unrecommended decisions may be that smokers are confronted with the health consequences of smoking by health warnings, pictorial warnings, or stories about sick smokers on a daily basis, for example, when they buy a pack of cigarettes. ${ }^{70-73}$ Vaccine refusers, compared to smokers, are not often confronted with the possible health consequences of their decision about childhood vaccination due to the herd immunity realized by the high vaccination coverage. Furthermore, parents are invited to actively make a decision about childhood vaccination for their child through a letter of invitation and an information brochure. ${ }^{74,75}$ Although there is no invitation for never-users to actively decide about not initiating cigarettes or e-cigarettes, never-users and vaccine acceptors both had high levels of evidence-based knowledge, positive attitudes towards their own decision, and low levels of deliberation. The findings of our thesis suggest that although there is no invitation for never-users to deliberate their decision, similar factors, such as high levels of evidence-based knowledge, trust in evidence-based information, positive attitudes towards the recommended option, perceptions of high susceptibility and severity of consequences of the unrecommended and next to best health options, and positive social norms about the recommended options play a role in the decision about the recommended health option in general. Both never-users and vaccine acceptors might be vulnerable for negative messages about their decision, ${ }^{9}$ and it is therefore important that they understand why they decided on the recommended option and deliberate this decision in order to build resilience. ${ }^{66}$ The following section 
describes additional factors that may be related to informed decision-making.

\section{Additional factors related to decision-making about smoking behavior and childhood vaccination}

\section{Perceived susceptibility and severity}

Our findings and previous research ${ }^{6,76}$ suggest that for those who opted for the unrecommended or next to best health options, perceived susceptibility and severity were reported to be in relation to their decisions (chapters $2-7$ ), which is in line with previous research about the unrecommended option. ${ }^{43,44,46,66,76-119}$ With regard to the next to best health options, our findings suggest that partial acceptors, similar to vaccine refusers, do not perceive the susceptibility and severity of VPDs as being as high as the susceptibility and severity of side effects of vaccines. Previous studies have shown that the greater perceived susceptibility and severity of possible side effects versus the lower perceived susceptibility and severity of VPDs influenced decisions about accepting or refusing childhood vaccination. ${ }^{66,77-87}$ The perceived susceptibility and severity of side effects of vaccines and VPDs if a parent had partially accepted vaccines was not previously investigated. A possible explanation for the perceived higher risks of side effects versus the risks of a VPD among vaccine refusers and partial acceptors might be the cognitive beliefs of vaccine refusers and partial acceptors. ${ }^{51,120-122}$ For example, cognitive beliefs with regard to long-term side effects of vaccines, a belief that vaccines are no longer necessary because VPDs no longer occur in the Netherlands, or about the ineffectiveness of vaccines (chapter 8) may explain why some parents perceive the severity of side effects of vaccines to be greater. Additionally, a possible explanation for a moderate perceived severity of VPDs might be that partial acceptors - and to some extent refusers - perceive some VPDs as childhood diseases that are essential for the development of their child. ${ }^{85}$ Another explanation might be that parents see children experience the mild side effects of a vaccine more often than the severe consequences of a VPD and therefore, they perceive the susceptibility and severity as greater.

With regard to e-cigarette use as a next to best decision compared to smoking cessation or not initiating cigarettes or e-cigarettes, our results demonstrated that e-cigarette users perceived fewer risks of e-cigarettes than never-users and smokers (chapters 2, 3, and 4), which was also found in other research.43,44,46,88-111 An explanation of this low perception of harm of e-cigarettes among e-cigarette users may be due to the use of e-cigarettes itself. For example, e-cigarette users expected (before initiation) and experienced (after continuation of use) health benefits from e-cigarette use. It is possible that positive outcome expectancies and experiences lead to a low perception of harm. ${ }^{43,90,94,105,123-126}$ In addition, we found that while never-users and e-cigarette users reported the health risks associated with smoking as important (chapters 2 and 3), smokers are unrealistically optimistic about their own susceptibility to bad outcomes, which was supported by previous findings. ${ }^{67,127-129}$ This optimism bias may explain why 
these smokers did not (yet) switch to a less harmful alternative.

\section{Trust in information}

Trust in information about smoking behavior (in general) and childhood vaccination (i.e. information brochure ${ }^{74,75}$ ) provided by public health experts was higher among never-users and vaccine acceptors than among those who chose for the unrecommended or next to best health option (chapters 3, 4, 6, and 7), which was also found in previous studies on both subjects..$^{51,120,130-132}$

With regard to vaccine acceptors, in previous research trust was shown to be one of the decisive factors in the decision regarding accepting childhood vaccinations. ${ }^{51,86,121,133}$ In our studies, acceptors reported trusting the NIP and the information about the NIP (chapters 6 and 7), and this trust in information may explain why acceptors scored higher on evidence-based knowledge about childhood vaccination. A possible explanation for their trust in the NIP may be that because the NIP was developed by the government, it engenders an inherent sense of trust. ${ }^{134}$ Additionally, parents who accepted vaccines perceived childhood vaccination as being self-evident (chapter 6). According to previous research, it may be that because acceptors trust the NIP and the information about the NIP, they do not think this information needs much further deliberation ${ }^{51,86,121,133}$ which may in part explain why they scored high on feeling uninformed about childhood vaccination (chapter 7)..$^{79,81,135,136}$ However, they reported having made a conscious decision to accept all childhood vaccinations (chapters 6 and 8). It seems that because acceptors trust the NIP, in their opinion trust is the reason that they feel they made a conscious decision. ${ }^{51,66,87,120-122}$ The lower levels of trust found among refusers and partial acceptors versus acceptors may be related to scoring high on not feeling supported (chapter 7) in decisionmaking about childhood vaccinations. ${ }^{78,85,137}$ This may be because Child Vaccine Providers (CVPs) were reported to not have enough time or knowledge to answer questions (chapter 7), which was also identified in previous research 51,120,130,131, or because the tone of voice of the information provided by the government was perceived as condescending and untrustworthy (chapter 7). ${ }^{85,138-140}$

With regard to decisions about smoking behavior, we found that never-users, smokers, and e-cigarette users trusted information about smoking from the government or public health experts (chapter 3 ), which was in line with previous research. ${ }^{132}$ Possibly this is because the health risks of smoking were regarded as common knowledge and the information about consequences of smoking are widespread due to health warnings and pictorial warnings. ${ }^{70-73}$ E-cigarette users however distrusted information provided by public health experts about e-cigarettes; to the best of our knowledge, this was not investigated before. A possible explanation might be bolstering, which was explained above.

\section{Anticipated regret}

The role of anticipated regret in healthy behavior, such as exercising, 
practicing safe sex, eating healthily, and not using drugs, has previously been documented. 66,79,81,135,136,141-146 Anticipated regret seemed to be an important factor related to the decision about childhood vaccination, but was not mentioned in the qualitative study (chapter 3 ) in relation to decisions about smoking behavior. Therefore, measures of anticipated regret were not included in our questionnaire about smoking behavior.

Vaccine acceptors mentioned anticipated regret with regard to their child experiencing a VPD if they were to refuse vaccines for their child as an important consideration in their decision to accept childhood vaccinations (chapter 6). With regard to the next to best option, partial acceptors reported high levels of anticipated regret if they were to accept all childhood vaccinations and their child were to experience side effects due to a vaccine (chapter 7), and high levels of anticipated regret if they were to refuse all childhood vaccinations and their child were to experience a VPD. For some vaccines, partial acceptors may experience anticipated regret with regard to accepting this vaccine because they may consider the side effects of a vaccine to be more serious than their child experiencing a VPD. In the case of other vaccines, partial acceptors may experience anticipated regret if they were to refuse these vaccines because sometimes the side effects of the vaccine were not considered to be more serious than their child experiencing the disease.66,147 This assessment of the anticipated regret of regarding vaccines and VPDs may be made for each vaccine of the Dutch NIP, separately. In addition, possible anthroposophical convictions, such as a conviction that some VPDs are childhood diseases or some VPDs aid the development of child may also influence anticipated regret. ${ }^{56,66,85,86}$ This experienced anticipated regret in combination with perceived susceptibility and severity may explain why partial acceptors refuse some vaccines and accept others. ${ }^{85}$

\section{Social norms}

For both smoking behavior and childhood vaccinations, this thesis revealed strong social norms in place with regard to not smoking and not using e-cigarettes, and accepting childhood vaccination, which have been identified previously. 43,47,66,78,129,148-160 E-cigarette users, partial acceptors, and refusers specifically reported not feeling supported in their decision because they felt criticized by this strong positive social norm regarding accepting childhood vaccinations and not smoking or using e-cigarettes (chapters 3, 6 and 7), which was also found in studies conducted in the US. $52,53,87,152$

With regard to the next to best health options, e-cigarette users noted the importance of social support with regard to e-cigarette use (chapters 3 and 5). They described a sense of community among e-cigarette users, similar to for instance the sense of belongingness described by bikers (chapter 3). The importance of support when switching from cigarettes to e-cigarettes was also previously reported by e-cigarette users. ${ }^{148,150,161}$ Additionally, partial acceptors 
reported not feeling supported by their social environment or CVPs (chapters 6 and 7). One of the reasons they did not feel supported in their decision about childhood vaccination were barriers experienced, such as believing that the staff at the CWC did not acknowledge their questions about vaccinations (chapters 6 and 7$)$.

\section{Self-efficacy}

While practical barriers, such as conveniently located $\mathrm{CWCs}^{87}$ were previously found to be important in decision-making concerning childhood vaccination, ${ }^{162}$ our results indicate that parents perceived no practical barriers with regard to making an appointment at the CWC or the accessibility of a CWC (chapter 7). This might be because the NIP of the Netherlands is well organized. ${ }^{32,66,163}$ Partial acceptors did report difficulty when sorting through the information with regard to an alternative vaccination schedule. With regard to smoking behavior, research has shown that self-efficacy is an important factor in this decision. ${ }^{148,149,164}$ Schoren, Hummel and de Vries ${ }^{148}$ showed that e-cigarette users were most confident in their ability to not use e-cigarettes in particular situations compared to smokers and dual users, which was confirmed by the findings of our study described in chapter 5 . Chapter 5 showed that dual users were less confident in their ability to not use e-cigarettes or not smoke compared to e-cigarette users.

\section{E-cigarette product characteristics}

This thesis demonstrated that product characteristics seem to be important in the decision about e-cigarette use. Product characteristics of e-cigarettes were mentioned by never-users, smokers, dual users, and e-cigarette users as reasons to use e-cigarettes, and several characteristics, such as the availability of many e-liquid flavors, were mentioned as benefits (chapters 2 and 3). Indeed, the variety of flavor $43,90,91,93,95,97,100,103,165-167$ and the ability to alter technical specifications $90,119,168$ were previously found to be reasons for e-cigarette use. The attractiveness of several product characteristics was investigated in this thesis, and we found that all types of users (i.e. never-users, smokers, dual users, and exclusive e-cigarette users) found the availability of different e-liquid flavors to be the most attractive feature of e-cigarettes (chapter 4).

While concerns have been raised about potential initiation of e-cigarette use among never-users, ${ }^{169-171}$ the never-users in our study had a low intention to start vaping and more than two-thirds (68\%) of the never-users did not want to try any e-liquid flavor. Our findings suggest that although never-users found e-liquid flavors to be the most attractive aspect of e-cigarettes, attractiveness may not translate into an intention to try e-cigarettes among the never-users. Furthermore, two-thirds of the smokers reported interest in an e-liquid flavor other than tobacco. This may indicate that e-liquid flavors could support the decision of smokers to switch to vaping, ${ }^{172}$ for example by allowing the marketing of e-liquid flavors and other product characteristics that smokers find attractive. ${ }^{173}$ Different patterns of e-liquid flavors used by dual users and exclusive vapers were found. In line with 
previous research, ${ }^{91,174-178}$ both dual users and exclusive e-cigarette users mostly used tobacco- and mint-flavored e-cigarettes at initiation, but exclusive vapers currently used more fruit and sweet e-liquid flavors than dual users. This could be interpreted as vapers switching from tobacco to non-tobacco flavors over time, which is supported by a previous study. ${ }^{178}$ Because most adult exclusive vapers included in this study had been using e-cigarettes for one to five years, and most dual users reported vaping for only less than six months (appendix 7), it is possible that the dual users may switch to fruit or sweet e-liquid flavors in the future. The role of e-liquid flavors in supporting both the decision to switch towards e-cigarette use (for smokers) and to refrain from using e-cigarettes (for never-users) demonstrates the complexity of developing future regulations on e-liquid flavors.

\section{Methodological considerations}

To explore the decisions regarding smoking behavior and childhood vaccination, both qualitative and quantitative methods were used to provide a broad overview of factors that are important in these decisions. Additionally, this thesis was the first to compare findings of factors important in smoking behavior and childhood vaccination, and to discuss similarities and differences. Several methodological considerations were discussed in the individual chapters of this thesis. Here we will discuss the most important considerations, such as a lack of guidelines on what sufficient knowledge and deliberation means, what an informed decision actually is, response bias, and definitions of smokers and e-cigarette users.

With regard to how we measure knowledge, no consensus could be found in literature of informed decision-making with regard to a definition of knowledge. ${ }^{42,134}$ In this thesis, knowledge ${ }^{42}$ was defined as an evidence-based and justified belief based on scientific consensus and information. 5,75,160,179-181 Knowledge was assessed by asking whether a statement was considered 'true', 'false', or 'I don't know' and categorized according to the definition of informed decision-making ${ }^{17}$ into sufficient (i.e. correct answers) and insufficient (i.e. incorrect and 'I don't know' answers) using Abbott's blind guessing formula. Cognitive beliefs were also investigated. These beliefs were defined as a mental representation, or a conviction that something is true, ${ }^{182}$ and assessed by asking whether someone completely disagreed or agreed with a statement. If one's beliefs were in accordance with what experts consider to be true, the belief is equivalent to knowledge. ${ }^{134}$ According to previous research, people make a decision based on what they believe to be true - and not necessarily evidencebased knowledge - so it is not surprising that people answered the knowledge statements in accordance with what they believe. ${ }^{183-185}$ In addition, answering a question with 'I don't know' does not equal 'false', and thus the categorization of sufficient and insufficient knowledge does not cover whether people are aware what is true according to scientific evidence. Consequently, using the current 
definitions of informed decision-making ${ }^{17}$ it remains unclear whether people know what is correct according to scientific evidence, whether people are not aware of what is true according to scientific evidence, or whether they do not believe the scientific evidence. Hence, to gain more insight into these aspects, it may be relevant to combine awareness of what is true according to scientific evidence (i.e. knowledge) and relevant cognitive beliefs. The combination of two such measures would increase our understanding of which information participants use to make a decision, whether participants are informed but do not believe the information - which means providing them with scientific information will not increase their knowledge ${ }^{186-195}$ - or whether they are actually not informed or misinformed, which means they need additional information. ${ }^{42}$

With regard to knowledge, it is unclear when a decision is based on sufficient information as there are no guidelines on what people would need to know to qualify as sufficiently informed. ${ }^{17,42}$ While the definition of informed decisionmaking is very rigid and strict, it is not based on uniform standards of knowledge. A similar case could be made for levels of deliberation. In accordance with the definition of informed decision-making of van den Berg, Timmermans, ten Kate, van Vugt, van der Wal ${ }^{17}$, we used the midpoint of the scale to determine whether levels of deliberation were high or low. However, similar to knowledge, there are no guidelines on when a decision-maker deliberated a decision sufficiently. Moreover, according to the decision-maker, these levels of sufficient knowledge or deliberation may vary according to the subject, and the decision-maker may therefore favor a different decision style for each decision. ${ }^{134,196}$ Additionally, in the case of value-consistency in decision-making, attitudes are often used as a proxy for values in current studies but it is unclear whether attitudes are informative enough to be used as a proxy of values related to decision-making. ${ }^{197}$ Research is needed to investigate what people exactly would need to know (i.e. in terms of content), how much information people need (i.e. sufficient versus insufficient), how to measure knowledge, to what extent they need to deliberate to make a decision, or what makes the decision value-consistent. Research is also needed on how to balance the amount of information to make a decision and the information that is deemed relevant and necessary by the public in making a decision about smoking behavior and childhood vaccination.

Moreover, it is important to reflect further on the nature of what an informed decision is, as some questions have yet to be answered. Most definitions of informed decision-making suggest that individuals need to be informed and that the decision should reflect the decision-makers' values. ${ }^{18-22,27,198-202}$ The conceptualization of informed decision-making that we used is based on the definition of van den Berg et al. ${ }^{17}$ since they have added the process of deliberation of different choice options. Furthermore, these definitions dichotomize the decisions into informed or uninformed. ${ }^{17-22,27,198-202}$ However, previous research debated whether it is wise to dichotomize the decisions into an informed versus uninformed decision as this results in a crude distinction that does not reflect 
the variety in the levels of informed and uninformed decisions. ${ }^{17,134,203}$ This was one of the reasons that we did not dichotomize the decisions into informed or uninformed but investigated whether the decisions about smoking behavior and childhood vaccination adhered to one or more of the criteria of the definition of informed decision-making. Further research is needed to identify whether informed decision-making could also be regarded as a scale on which people can score differently. Second, should knowledge, value consistency, and deliberation all be equally important for defining and operationalizing informed decisionmaking? It is unclear whether these three criteria constitute the criteria or factors that make a decision informed, and if all three are necessary for a decision to be informed. Research is needed to investigate if other determinants may be important in supporting decision-making, which may depend on the type of decision and on the style of the decision-maker. In addition, deliberation could be considered to entail a process of considering and thinking about a variety of factors, including perceived susceptibility and severity, trust, anticipated regret, social support, and self-efficacy; the importance of these factors may differ per decision, situation, and person. Consequently, given this unclarity, it also remains unclear how to best facilitate informed decision-making, and more research is needed to explore this complex process.

Moreover, by asking respondents to consider their decision in retrospect, we may have introduced response bias. It is likely that scores on factors important in the decisions about smoking behavior and childhood vaccination at the time of conducting this study do not fully reflect the scores of the factors at the time of decision-making, opening up the possibility of cognitive dissonance. 59,204,205 Asking participants to consider a decision that has not yet been made was not possible in our studies because we wanted to compare the factors that played a role in the decisions for the recommended, unrecommended, and next to best decisions. These categories were made based on the behavior of participants, and thus we needed to wait until participants performed the behavior to make a categorization. Further research is needed to explore if scores or the importance of determinants of decision-making change during the decision-making process. For example, by setting up a cohort of soon-to-be parents to follow these parents through time and vaccination decisions.

With regard to the definitions of never-users, smokers, and e-cigarette users, there was no consensus in the literature about these definitions. The decision to not smoke or vape, to initiate smoking, start dual using cigarettes and e-cigarettes, or switching to e-cigarette use is dynamic, as people may change products over time, which means that different transitory phases can be determined. Our current studies were all cross-sectional, which is why we only offer a snapshot of the types of users and frequency of use among never-users, smokers, and e-cigarette users (i.e. both dual users of cigarettes and e-cigarettes, and exclusive e-cigarette users). Further research is needed to investigate how to best present the dynamic behaviors of never-use, smoking, dual use, 
and e-cigarette use in static definitions of use. Such research could build on the International Tobacco Control surveys, ${ }^{206,207}$ which use standardized survey measures to enable cross-country comparisons, ${ }^{207}$ so that the transitory phases of never-use, exclusive smoking, concurrent use of cigarettes and e-cigarettes, and exclusive e-cigarette use can be followed to investigate possible differences in tobacco product and e-cigarette use. Subsequently, a Delphi study - with experts in the field of e-cigarette use - could be asked to define characteristics of never-users, smokers, and e-cigarette users. ${ }^{208}$ These types of studies could be used to further specify definition of use, such as the classification system offered by Borland, Murray, Gravely, et al. ${ }^{209}$, and to identify additional features to distinguish exclusive smokers, dual users, and exclusive e-cigarette users.

\section{Recommendations for further research, health communication, and policy}

Based on the research presented in this thesis, several recommendations for further research, health communication and policy can be identified.

\section{Recommendations for further research}

Various recommendations for further research were discussed in the individual chapters of this thesis. Here we will highlight the need for research with regard to the next to best health option.

\section{Next to best health options}

In the Netherlands, the RIVM is responsible for providing the public with information about smoking behavior and childhood vaccination, for example through an information brochure and a website. ${ }^{74,75,180,181,210}$ Although not smoking or using e-cigarettes and accepting childhood vaccinations can be considered as most beneficial for public health, ${ }^{211-215}$ e-cigarette use or partially accepting childhood vaccination has potential individual and public health benefits compared to smoking or refusing all vaccines. . $3,7,8,122,211,216-221$ However, in itself, e-cigarette use and partially accepting childhood vaccinations are not beneficial for individual health nor without risks. ${ }^{214,222,223}$ Consequently, these options are not recommended from a public health perspective. People search for information that reinforces their chosen option or may facilitate arriving at the desired decision, ${ }^{57,58}$ and thus, it is important to provide evidence-based information about all options. Based on our results, we would recommend further research to investigate the effects of communicating about the recommended health options (e.g. not smoking or using e-cigarettes and accepting childhood vaccinations), the unrecommended option (e.g. smoking or refusing childhood vaccinations), and the next to best health options (e.g. e-cigarette use and partially accepting childhood vaccination). Such research - focused on for example childhood vaccination - could consist of testing the effect, appreciation, and acceptance 
of providing information on the recommended, unrecommended, and next to best health options on decision-making and intention to accept childhood vaccination in comparison to standard information (i.e. the information currently provided by RIVM). These insights into the effects of communicating about the recommended, unrecommended, and next to best health options could aid public health experts in determining the goals of health communication and the communication needs of the public.

\section{Recommendations for health communication}

Building on the recommendation to investigate the effects of communicating about the recommended health options, the unrecommended option, and the next to best health options, specific suggestions can be provided with regard to the communication techniques relevant to achieve the different goals. With regard to communicating about recommended and other options, it is important to articulate clearly which particular goals public health experts want to achieve. They may consider it their goal to provide scientific information without providing advice or decisional support. Another goal may be to facilitate informed decision-making even though the consequence of this may be that more people will choose for the unrecommended or next to best option rather than the recommended option, thereby increasing public health risks. An alternative goal may be to make sure that as many people as possible choose the recommended health option to increase public health gain. With the latter aim, several motivational techniques can be applied to steer the public in the desired and recommended direction. ${ }^{224,225}$ Rigorous testing of possible decisional effects of providing information on all options will allow public health experts and policy-makers to make an informed decision on possible adaptation of current communication efforts. The following section describes several techniques that can be used to support informed decision-making and techniques that may be used to promote uptake of the recommended health option. Here, we will focus on knowledge and cognitive beliefs, attitude, and deliberation.

\section{Knowledge, attitude, and deliberations}

Chapters 3 - 8 suggested that evidence-based knowledge about smoking behavior and childhood vaccination was low among those who opted for the unrecommended or next to best health options, that people have positive attitudes towards their own decision, indicating a high level of value consistency, and that those who opted for the recommended health option generally displayed low levels of deliberation.

A goal of health communication may be to provide scientific information without providing advice or decisional support. In order to do so, several channels could be used, such as circulating the information brochures about the NIP. ${ }^{225}$ In addition, websites could be used to provide information with more detail but layered in order to provide the extent of information desired by the audience. ${ }^{9,225-229}$. Such 
techniques facilitate the sharing of scientific information.

Another goal of health communication may be to facilitate informed decisionmaking. Several techniques could be used. One example could be the provision of an online decision aid to support informing decision-makers, reflecting on values that are important for the decision-maker, and stimulating the deliberation of choice options and information. ${ }^{29,136,230-235}$ In health decisions, decision aids proved successful in increasing knowledge compared to usual care, to improve judgements of the perceived susceptibility and severity that are in accordance with scientific evidence; they were also effective in choosing a health option that was in accordance with the decision-makers' values, indicating a high level of value consistency, and were effective in reducing scores of decisional conflict to levels that indicate informed decisions. ${ }^{234}$ To increase knowledge, it is important to provide risk information in a combination of numeric and narrative risk information and to incorporate the beliefs and values of the decisionmaker. ${ }^{13,203,236-238}$ An example of an evidence-based technique to increase knowledge is elaboration of information. ${ }^{225}$ Elaboration stimulates the decisionmaker to add meaning to the information that is processed, it consists of easy and understandable information, with direct instruction to accomplish the goal of the decision-maker. ${ }^{34,225,239}$ For example, smokers could be triggered about the negative health effects of smoking by being provided with messages that are personally relevant, such as explaining short-term instead of long-term health consequences. To further support informed decision-making, it is important to support decision-makers to clarify values and attitudes with regard to the health options. An example of such a technique is counseling. ${ }^{225}$ During counseling, examples of different choices and why people make these choices are provided, including scenarios or testimonials to describe the choice options. Decisionmakers are encouraged to prioritize values that are important to them or are offered different features of health options with personal balance scales. ${ }^{240} \mathrm{~A}$ technique to support deliberation about all health options could be providing guidance in deliberating and considering the health options available to decision-makers. ${ }^{241-243}$ This can be provided in a decision aid 15,135,136,233,244-246 for example, by providing an option for decision-makers to make a list of advantages or disadvantages, risks, benefits, goals, and values ranked in order of what is important to them. ${ }^{241,242}$ about all options.

A goal of health communication could also be to make sure that as many people as possible choose the recommended health option to increase public health gain. An example of motivational techniques to increase knowledge to promote the recommended health option among those who chose for the unrecommended option and the next to best health option is persuasive communication in the form of narratives. This can be used to make sure the perception of susceptibility and severity of decision-makers is in line with scientific evidence. Due to identification with the characters in a narrative and the vividness of the risk information described, imaginability of the health threats 
of the unrecommended health option is expected to increase, which in turn increases the likelihood of taking protective action. For example, in the case of childhood vaccination, the RIVM may use narratives to explain scientifically proven consequences of VPDs and vaccine side effects. ${ }^{6,12,75,180,247}$ These narratives may influence a parent to decide to accept childhood vaccinations, or they may potentially counter anti-vaccination messages and weaken negative beliefs because it easier to recall and understand the information about risks compared with providing scientific information. $6,10,13,25,51,55,248,249$ In addition, narratives are known to reduce defensive reacting or counterarguing to health messages. ${ }^{250,251}$ Consequently, it may prove useful to use a more contextualized approach to inform parents who have persistent cognitive beliefs not in accordance with scientific evidence about evidence-based information. One technique that could be used is attitude inoculation. ${ }^{252}$ Attitude inoculation messages work very similarly to a vaccination; decision-makers are trained to resist attacks on their positive attitudes towards the recommended health option by practicing their response to positive messages to the unrecommended or next to best health option. ${ }^{252}$ In a decision-aid, inoculation messages could be used to strengthen existing positive attitudes, weaken attitudes that are positive towards unrecommended health options, and build resistance for marketing of tobacco and e-cigarettes and anti-vaccination messages, respectively. ${ }^{172,252-255}$ Another strategy could be motivational interviewing. 225,256 Motivational interviewing pertains to an approach to enhance the internal motivation to switch to the recommended health option of a decision-maker based on their own arguments for change, 225,256 and has previously been shown to be effective in changing vaccine hesitancy in Canada by increasing deliberation about the decision to accept childhood vaccinations..$^{225,257}$

\section{Considerations for policy-makers}

With regard to policy, we can offer some recommendations concerning an informed public and the regulation of e-cigarettes.

\section{Informed decision-making}

If policy-makers want to foster informed choices among the public concerning health options, our research and research by others indicates that it is important to identify the best conditions for facilitating such rational and informed decisions. Most definitions of informed decision-making suggest that individuals need to be informed and that the decision should reflect the decision-makers' values, and are based on a rational decision model. 18-22,27,198-202 These definitions dichotomize the

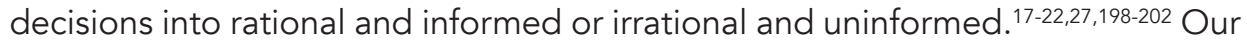
results suggest that most participants may not have made optimal, rational, and informed decisions about smoking behavior or childhood vaccinations according to the criteria of informed decision-making. On the one hand, it could be that these three criteria are not absolute in explaining informed decision-making. On the other hand, the results may imply that public health policies are needed 
to foster the identification of factors that facilitate informed decision-making among the general public, and to safeguard the public against factors that may hinder informed decision-making. ${ }^{194,258}$ In addition, it may not be preferable for the public to make rational and informed decisions in every case because it is cognitively tiring. Reconsideration and reorientation may be needed about what informed decisions are, which factors foster informed decision-making and which factors hinder it, and what or whether informed decision-making is desired.

\section{E-cigarette product characteristics}

The regulation of e-cigarettes in order to optimize public health benefits is challenging. Compared to cigarette smoking, e-cigarette use may reduce harm among smokers, ${ }^{259-262}$ but due to their toxic ingredients it is not a harmless product. 259,263 In addition, concerns have been raised that e-cigarette use may contribute to nicotine addiction and the renormalization of cigarette smoking in adolescent never-smokers. ${ }^{171,264-267}$ Consequently, from a public health perspective, the initiation of vaping by current non- and never-smokers and, thereby, exposure to potentially toxic ingredients should be prevented. ${ }^{267}$ Our findings showed that product characteristics may be an attractive aspect of e-cigarettes. However, the relation between product characteristics on the one hand, and how this may influence positive attitudes and an intention to start or switch to e-cigarettes on the other hand, remains unclear. The findings of chapter 4 indicate that e-liquid flavors are an attractive aspect of e-cigarettes for neverusers, smokers, and e-cigarette users. Therefore, more research is needed to investigate the relation between e-cigarette product characteristics, and attitude and intention concerning the next to best health option (i.e. e-cigarette use). Moreover, as e-cigarettes are marketed as an alternative to smoking, cessation research needs to monitor potential long-term side effects and when they occur, and whether usage of e-cigarettes are a real viable alternative for smoking cessation for certain groups. 


\section{References}

1. Acheson D. Public health in England: the report of the Committee of Inquiry into the Future Development of the Public Health Function. London: The Stationery Office; 1988.

2. World Health Organization. WHO REPORT ON THE GLOBAL TOBACCO EPIDEMIC, 2015. Geneva: World Health Organization;2015.

3. World Health Organization. Tobacco. Factsheet 2017. http://www.who.int/ mediacentre/factsheets/fs339/en/. Accessed November 30, 2018, 2018.

4. E.A. van Lier, P.J. Oomen, H. Giesbers, et al. Vaccine Coverage of NIP in the Netherlands. Bilthoven: National Instituut of Public Health and the Environment;2016.

5. Lehmann BA, de Melker HE, Timmermans DRM, Mollema L. Informed decision making in the context of childhood immunization. Patient Educ Couns. 2017; 100(12):2339-2345.

6. Brewer NT, Chapman GB, Gibbons FX, et al. Meta-analysis of the relationship between risk perception and health behavior: the example of vaccination. Health Psychol. 2007;26(2):136-145.

7. World Health Organization. Immunization Coverage. Immunization, Vaccines and Biologicals 2018. http://www.who.int/en/news-room/fact-sheets/detail/ immunization-coverage. Accessed June, 26, 2018.

8. World Health Organization. Ten Threats to Global Health in 2019. Vaccine Hesitancy 2019. https://www.who.int/emergencies/ten-threats-to-globalhealth-in-2019. Accessed 26th of February, 2019.

9. Betsch C, Renkewitz F, Betsch T, Ulshofer C. The influence of vaccine-critical websites on perceiving vaccination risks. J Health Psychol. 2010;15(3):446-455.

10. Betsch C, Renkewitz F, Haase N. Effect of narrative reports about vaccine adverse events and bias-awareness disclaimers on vaccine decisions: a simulation of an online patient social network. Med Decis Making. 2013;33(1):14-25.

11. Betsch C, Sachse K. Dr. Jekyll or Mr. Hyde? (How) the Internet influences vaccination decisions: recent evidence and tentative guidelines for online vaccine communication. Vaccine. 2012;30(25):3723-3726.

12. Betsch $C$, Sachse K. Debunking vaccination myths: strong risk negations can increase perceived vaccination risks. Health Psychol. 2013;32(2):146-155.

13. Betsch C, Ulshofer C, Renkewitz F, Betsch T. The influence of narrative v. statistical information on perceiving vaccination risks. Med Decis Making. 2011;31(5):742753.

14. Borland $\mathrm{R}$, Yong $\mathrm{HH}$, Balmford J, et al. Do risk-minimizing beliefs about smoking inhibit quitting? Findings from the International Tobacco Control (ITC) FourCountry Survey. Prev Med. 2009;49(2-3):219-223.

15. Betsch C,WickerS. E-healthuse, vaccination knowledgeand perception ofown risk: Drivers of vaccination uptake in medical students. Vaccine. 2012;30(6):1143-1148.

16. Ahmed S, Bryant L, Hewison J. 'Balance' is in the eye of the beholder: providing information to support informed choices in antenatal screening via Antenatal Screening Web Resource. Health Expect. 2007;10(4):309-320. 
17. van den Berg M, Timmermans DR, ten Kate LP, van Vugt JM, van der Wal G. Informed decision making in the context of prenatal screening. Patient Educ Couns. 2006;63(1-2):110-117.

18. Bekker H. Genetic screening: facilitating informed choices. In: Cooper DN, Thomas N, eds. Encyclopaedia of the Human Genome2001:926-930.

19. Bekker HL, Hewison J, Thornton JG. Applying decision analysis to facilitate informed decision making about prenatal diagnosis for Down syndrome: a randomised controlled trial. Prenat Diagn. 2004;24(4):265-275.

20. Green JM, Hewison J, Bekker HL, Bryant LD, Cuckle HS. Psychosocial aspects of genetic screening of pregnant women and newborns: a systematic review. NIHR Health Technology Assessment programme: Executive Summaries: NIHR Journals Library; 2004.

21. Kohut RJ, Dewey D, Love EJ. Women's knowledge of prenatal ultrasound and informed choice. J Genet Couns. 2002;11(4):265-276.

22. Rimer BK, Briss PA, Zeller PK, Chan ECY, Woolf SH. Informed decision making: What is its role in cancer screening? Cancer. 2004;101(5 SUPPL.):1214-1228.

23. Tepper AM, Kaslow FW. Informed decision-making capacity: a patient's ability to participate in treatment determinations. Law Psychol Rev. 1981;6:49-67.

24. Simon HA. A behavioral model of rational choice. The quarterly journal of economics. 1955;69(1):99-118.

25. Baron J. Thinking and Deciding. 4th ed. Cambridge: Cambridge University Press; 2007.

26. Pot M. Improving HPV vaccination Acceptability by a web-based tailored intervetion [dissertation]. Amsterdam: Work and Social Psychology, Maastricht University; 2018.

27. O'Connor AM. Validation of a decisional conflict scale. Med Decis Making. 1995;15(1):25-30.

28. O'Connor A. user Manual - Decisional Conflict Scale. 1993 [updated 2010].

29. BinDhim NF,McGeechanK, TrevenaL.SmartphoneSmoking CessationApplication (SSC App) trial: a multicountry double-blind automated randomised controlled trial of a smoking cessation decision-aid 'app'. BMJ Open. 2018;8(1):e017105.

30. Bedford $H$, Attwell $K$, Danchin $M$, et al. Vaccine hesitancy, refusal and access barriers: The need for clarity in terminology. Vaccine. 2018;36(44):6556-6558.

31. MacDonald N, Dube E, Butler R. Vaccine hesitancy terminology: A response to Bedford et al. Vaccine. 2019;37(30):3947-3948.

32. MacDonald NE, Hesitancy SWGoV. Vaccine hesitancy: Definition, scope and determinants. Vaccine. 2015;33(34):4161-4164.

33. Pot M, Paulussen TG, Ruiter RA, et al. Effectiveness of a Web-Based Tailored Intervention With Virtual Assistants Promoting the Acceptability of HPV Vaccination Among Mothers of Invited Girls: Randomized Controlled Trial. J Med Internet Res. 2017;19(9):e312.

34. Petty RR, Barden J, Wheeler SC. The Elaboration Likelihood Model of Pursuasion: Developing health promotions for sustained behavioral change. In: Diclimente RJ, Crosby RA, Kegler M, eds. Emerging theories in health promotion practice and research. $2^{\text {nd }}$ ed. San Francisco: Jossey-Bass; 2009:185-214. 
35. Pajor EM, Eggers SM, Curfs KCJ, Oenema A, de Vries H. Why do Dutch people use dietary supplements? Exploring the role of socio-cognitive and psychosocial determinants. Appetite. 2017;114:161-168.

36. Pajor EM. DIETARY SUPPLEMENT USE: Reasons, decisions, and health communication [Doctoral Thesis]. Maastricht: CAPHRI - Promoting Health \& Personalised Care Health promotion, Maastricht University; 2019.

37. Yang J, Hammond D, Driezen P, Fong GT, Jiang Y. Health knowledge and perception of risks among Chinese smokers and non-smokers: findings from the Wave 1 ITC China Survey. Tob Control. 2010;19 Suppl 2:118-23.

38. Klesges RC, Somes G, Pascale RW, et al. Knowledge and beliefs regarding the consequences of cigarette smoking and their relationships to smoking status in a biracial sample. Health Psychol. 1988;7(5):387-401.

39. Siahpush M, McNeill A, Hammond D, Fong GT. Socioeconomic and country variations in knowledge of health risks of tobacco smoking and toxic constituents of smoke: results from the 2002 International Tobacco Control (ITC) Four Country Survey. Tob Control. 2006;15 Suppl 3:iii65-70.

40. Koski K, Holst J. Exploring Vaccine Hesitancy Through an Artist-Scientist Collaboration : Visualizing Vaccine-Critical Parents' Health Beliefs. J Bioeth Inq. 2017;14(3):411-426.

41. Dube E, Farrands A, Lemaitre $T$, et al. Overview of knowledge, attitudes, beliefs, vaccine hesitancy and vaccine acceptance among mothers of infants in Quebec, Canada. Human vaccines \& immunotherapeutics. 2019;15(1):113-120.

42. Hunt DP. The concept of knowledge and how to measure it. Journal of intellectual capital. 2003;4(1):100-113.

43. Coleman BN, Johnson SE, Tessman GK, etal. "It's not smoke. It's nottar. It's not 4000 chemicals. Case closed": Exploring attitudes, beliefs, and perceived social norms of e-cigarette use among adult users. Drug Alcohol Depend. 2016;159:80-85.

44. Pepper JK, Emery SL, Ribisl KM, Rini CM, Brewer NT. How risky is it to use e-cigarettes? Smokers' beliefs about their health risks from using novel and traditional tobacco products. J Behav Med. 2015;38(2):318-326.

45. Rohde JA, Noar SM, Horvitz C, et al. The Role of Knowledge and Risk Beliefs in AdolescentE-CigaretteUse:APilotStudy. IntJEnvironResPublicHealth.2018;15(4).

46. Tan AS, Lee CJ, Bigman CA. Comparison of beliefs about e-cigarettes' harms and benefits among never users and ever users of e-cigarettes. Drug Alcohol Depend. 2016;158:67-75.

47. Chiou L, Tucker C, National Bureau of Economic R. Fake news and advertising on social media : a study of the anti-vaccination movement. Cambridge, Mass.: National Bureau of Economic Research; 2018: http://www.library.yorku.ca/e/ resolver/id/287744606.

48. Fernandez-Luque L, Bau T. Health and social media: perfect storm of information. Healthcare informatics research. 2015;21(2):67-73.

49. Mollema L, Harmsen IA, Broekhuizen E, et al. Disease detection or public opinion reflection? Content analysis of tweets, other social media, and online newspapers during the measles outbreak in The Netherlands in 2013. J Med Internet Res. 2015;17(5):e128. 
50. Betsch C. Social media targeting of health messages. A promising approach for research and practice. Human vaccines \& immunotherapeutics. 2014;10(9):26362637.

51. Benin AL, Wisler-Scher DJ, Colson E, Shapiro ED, Holmboe ES. Qualitative analysis of mothers' decision-making about vaccines for infants: the importance of trust. Pediatrics. 2006;117(5):1532-1541.

52. Brunson EK. How parents make decisions about their children's vaccinations. Vaccine. 2013;31(46):5466-5470.

53. Brunson EK. The impact of social networks on parents' vaccination decisions. Pediatrics. 2013;131(5):e1397-1404.

54. Brunson EK. Identifying Parents Who Are Amenable to Pro-Vaccination Conversations. Glob Pediatr Health. 2015;2:2333794X15616332.

55. Glick M. Believing is seeing: Confirmation bias. J Am DentAssoc. 2017;148(3):131132.

56. Harmsen IA, Doorman GG, Mollema L, et al. Parental information-seeking behaviour in childhood vaccinations. BMC Public Health. 2013;13(1):1219.

57. Janis IL, Mann L. Decision making: A psychological analysis of conflict, choice, and commitment. Free Press; 1977.

58. Mann L, Janis IL, Chaplin R. Effects of anticipation of forthcoming information on predecisional processes. Journal of Personality and Social Psychology. 1969;11(1):10-16.

59. Festinger L. A theory of cognitive dissonance. Stanford, Ca.: Stanford University Press; 1962.

60. Fotuhi O, Fong GT, Zanna MP, et al. Patterns of cognitive dissonance-reducing beliefs among smokers: a longitudinal analysis from the International Tobacco Control (ITC) Four Country Survey. Tob Control. 2013;22(1):52-58.

61. van Harreveld F, Nohlen HU, Schneider IK. The ABC of Ambivalence : Affective, Behavioral, and Cognitive Consequences of Attitudinal Conflict. Advances in Experimental Scoial Psychology. 2015;52:285-324.

62. Jenks RJ. Attitudes and perceptions toward smoking: smokers' views of themselves and other smokers. J Soc Psychol. 1994;134(3):355-361.

63. The International Tobacco Control Policy Evaluation Project. ITC Netherlands National Report. ZonMw, ASCoR, Maastricht University, University of Waterloo, The International Tobacco Control Policy Evaluation Project,;2015.

64. Wadsworth E, Neale J, McNeill A, Hitchman SC. How and Why Do Smokers Start Using E-Cigarettes? Qualitative Study of Vapers in London, UK. Int J Environ Res Public Health. 2016;13(7).

65. E.A. van Lier, P.J. Oomen, H. Giesbers, et al. Vaccine Coverage of NIP in the Netherlands 2018. Bilthoven: National Institute for Public Health and the Environment;2019.

66. Harmsen IA, Ruiter R, Paulussen T, et al. Development of a monitoring system to evaluate the acceptance of childhood vaccination. Bilthoven: RIVM; 2014.

67. Gray RJ, Hoek J, Edwards R. A qualitative analysis of 'informed choice' among young adult smokers. Tob Control. 2016;25(1):46-51. 
68. Hoek J, Ball J, Gray R, Tautolo ES. Smoking as an 'informed choice': implications for endgame strategies. Tob Control. 2017;26(6):669-673.

69. Leventhal H, Glynn K, Fleming R. Is the smoking decision an 'informed choice'? Effect of smoking risk factors on smoking beliefs. JAMA. 1987;257(24):3373-3376.

70. van Mourik DA, Candel M, Nagelhout GE, et al. How the New European Union's (Pictorial) Tobacco Health Warnings Influence Quit Attempts and Smoking Cessation: Findings from the 2016-2017 International Tobacco Control (ITC) Netherlands Surveys. Int J Environ Res Public Health. 2019;16(21).

71. Borland $\mathrm{R}$, Yong $\mathrm{HH}$, Wilson $\mathrm{N}$, et al. How reactions to cigarette packet health warnings influence quitting: findings from the ITC Four-Country survey. Addiction. 2009;104(4):669-675.

72. Thrasher JF, Swayampakala K, Borland R, et al. Influences of Self-Efficacy, Response Efficacy, and Reactance on Responses to Cigarette Health Warnings: A Longitudinal Study of Adult Smokers in Australia and Canada. Health Commun. 2016;31(12):1517-1526.

73. Yong HH, Borland R, Hammond D, et al. Smokers' reactions to the new larger health warning labels on plain cigarette packs in Australia: findings from the ITC Australia project. Tob Control. 2016;25(2):181-187.

74. E.A. van Lier, Geraedts JLE, P.J. Oomen, et al. [Vaccine Coverage of NIP in the Netherlands]. Bilthoven: National Institute for Public Health and the Environment;2018.

75. National Institute for Public Health and the Environment (RIVM). [National Immunization Program]. History 2018. http://www.rijksvaccinatieprogramma.nl/ Over_Rijksvaccinatieprogramma/Geschiedenis. Accessed June 19, 2018.

76. Czoli CD, Fong GT, Mays D, Hammond D. How do consumers perceive differences in risk across nicotine products? A review of relative risk perceptions across smokeless tobacco, e-cigarettes, nicotine replacement therapy and combustible cigarettes. Tob Control. 2017;26(e1):e49-e58.

77. Jarmolowicz DP, Reed DD, Francisco AJ, et al. Modeling effects of risk and social distance on vaccination choice. J Exp Anal Behav. 2018;110(1):39-53.

78. Tickner S, Leman PJ, Woodcock A. 'It's just the normal thing to do': exploring parental decision-making about the 'five-in-one' vaccine. Vaccine. 2007;25(42):7399-7409.

79. Paulussen TG, Hoekstra F, Lanting Cl, Buijs GB, Hirasing RA. Determinants of Dutch parents' decisions to vaccinate their child. Vaccine. 2006;24(5):644-651.

80. Bostrom A. Vaccine risk communication: Lessons from risk perception, decision making and environmental risk communication research. Risk. 1997;8:173.

81. Wroe AL, Turner N, Salkovskis PM. Understanding and predicting parental decisions about early childhood immunizations. Health Psychol. 2004;23(1):3341.

82. Dube E, MacDonald NE. Managing the risks of vaccine hesitancy and refusals. Lancet Infect Dis. 2016;16(5):518-519.

83. Karafillakis $E$, Larson $H J$, consortium A. The benefit of the doubt or doubts over benefits? A systematic literature review of perceived risks of vaccines in European populations. Vaccine. 2017;35(37):4840-4850. 
84. Harmsen IA, Lambooij MS, Ruiter RA, et al. Psychosocial determinants of parents' intention to vaccinate their newborn child against hepatitis B. Vaccine. 2012;30(32):4771-4777.

85. Harmsen IA, Mollema L, Ruiter RA, et al. Why parents refuse childhood vaccination: a qualitative study using online focus groups. BMC Public Health. 2013;13(1):1183.

86. Harmsen IA, Ruiter RA, Paulussen TG, et al. Factors that influence vaccination decision-making by parents who visit an anthroposophical child welfare center: a focus group study. Advances in preventive medicine. 2012;2012.

87. Larson HJ, Jarrett C, Eckersberger E, Smith DM, Paterson P. Understanding vaccine hesitancy around vaccines and vaccination from a global perspective: a systematic review of published literature, 2007-2012. Vaccine. 2014;32(19):21502159.

88. Anand V, McGinty KL, O'Brien K, et al. E-cigarette Use and Beliefs Among Urban Public High School Students in North Carolina. J Adolesc Health. 2015;57(1):4651.

89. Bauhoff S, Montero A, Scharf D. Perceptions of e-cigarettes: a comparison of adult smokers and non-smokers in a Mechanical Turk sample. The American journal of drug and alcohol abuse. 2017;43(3):311-323.

90. Baweja R, Curci KM, Yingst J, et al. Views of Experienced Electronic Cigarette Users. Addict Res Theory. 2016;24(1):80-88.

91. Berg CJ. Preferred flavors and reasons for e-cigarette use and discontinued use among never, current, and former smokers. Int J Public Health. 2016;61(2):225236.

92. Biener L, Song E, Sutfin EL, Spangler J, Wolfson M. Electronic Cigarette Trial and Use among Young Adults: Reasons for Trial and Cessation of Vaping. Int J Environ Res Public Health. 2015;12(12):16019-16026.

93. Bold KW, Kong G, Cavallo DA, Camenga DR, Krishnan-Sarin S. Reasons for Trying E-cigarettes and Risk of Continued Use. Pediatrics. 2016;138(3).

94. Chaffee BW, Gansky SA, Halpern-Felsher B, et al. Conditional risk assessment of adolescents' electronic cigarette perceptions. Am J Health Behav. 2015;39(3):421-432.

95. Cheney MK, Gowin M, Wann TF. Electronic Cigarette Use in Straight-to-Work Young Adults. Am J Health Behav. 2016;40(2):268-279.

96. Gowin M, Cheney MK, Wann TF. Knowledge and Beliefs About E-Cigarettes in Straight-to-Work Young Adults. Nicotine Tob Res. 2017;19(2):208-214.

97. Hilton S, Weishaar H, Sweeting H, Trevisan F, Katikireddi SV. E-cigarettes, a safer alternative for teenagers? A UK focus group study of teenagers' views. BMJ Open. 2016;6(11):e013271.

98. Kahr MK, Padgett S, Shope CD, et al. A qualitative assessment of the perceived risks of electronic cigarette and hookah use in pregnancy. BMC Public Health. 2015;15(1):1273.

99. Kim H, Davis AH, Dohack JL, Clark PI. E-Cigarettes Use Behavior and Experience of Adults: Qualitative Research Findings to Inform E-Cigarette Use Measure Development. Nicotine Tob Res. 2017;19(2):190-196. 
100. Kistler CE, Crutchfield TM, Sutfin EL, et al. Consumers' Preferences for Electronic Nicotine Delivery System Product Features: A Structured Content Analysis. Int J Environ Res Public Health. 2017;14(6):07.

101. Li J, Bullen C, Newcombe R, Walker N, Walton D. The use and acceptability of electronic cigarettes among New Zealand smokers. $N$ Z Med J. 2013;126(1375):48-57.

102. Mark KS, Farquhar B, Chisolm MS, Coleman-Cowger VH, Terplan M. Knowledge, Attitudes, and Practice of Electronic Cigarette Use Among Pregnant Women. $J$ Addict Med. 2015;9(4):266-272.

103. Patel D, Davis KC, Cox S, et al. Reasons for current E-cigarette use among U.S. adults. Prev Med. 2016;93:14-20.

104. Pineiro B, Correa JB, Simmons VN, et al. Gender differences in use and expectancies of e-cigarettes: Online survey results. Addict Behav. 2016;52:91-97.

105. Rass O, Pacek LR, Johnson PS, Johnson MW. Characterizing use patterns and perceptions of relative harm in dual users of electronic and tobacco cigarettes. Exp Clin Psychopharmacol. 2015;23(6):494-503.

106. Saddleson ML, Kozlowski LT, Giovino GA, et al. Enjoyment and other reasons for electronic cigarette use: Results from college students in New York. Addict Behav. 2016;54:33-39.

107. Sherratt FC, Marcus MW, Robinson J, Newson L, Field JK. Electronic cigarette use and risk perception in a Stop Smoking Service in England. Addiction Research \& Theory. 2015;23(4):336-342.

108. Sherratt FC, Newson L, Marcus MW, Field JK, Robinson J. Perceptions towards electronic cigarettes for smoking cessation among Stop Smoking Service users. Br J Health Psychol. 2016;21(2):421-433.

109. Trumbo CW, Harper R. Use and perception of electronic cigarettes among college students. J Am Coll Health. 2013;61(3):149-155.

110. Zhu SH, Gamst A, Lee M, et al. The use and perception of electronic cigarettes and snus among the U.S. population. PLoS One. 2013;8(10):e79332.

111. Wackowski OA, Bover Manderski MT, Delnevo CD. Smokers' sources of e-cigarette awareness and risk information. Prev Med Rep. 2015;2:906-910.

112. Ambrose BK, Rostron BL, Johnson SE, et al. Perceptions of the relative harm of cigarettes and e-cigarettes among U.S. youth. Am J Prev Med. 2014;47(2 Suppl 1):S53-60.

113. Amrock SM, Lee L, Weitzman M. Perceptions of e-Cigarettes and Noncigarette Tobacco Products Among US Youth. Pediatrics. 2016;138(5).

114. Amrock SM, Zakhar J, Zhou S, Weitzman M. Perception of e-cigarette harm and its correlationwithuseamongU.S. adolescents. Nicotine TobRes.2015;17(3):330-336.

115. Camenga DR, Fiellin LE, Pendergrass T, et al. Adolescents' perceptions of flavored tobacco products, including E-cigarettes: A qualitative study to inform FDA tobacco education efforts through videogames. Addict Behav. 2018;82:189-194.

116. Cooper M, Case KR, Loukas A, Creamer MR, Perry CL. E-cigarette Dual Users, Exclusive Users and Perceptions of Tobacco Products. Am J Health Behav. 2016;40(1):108-116. 
117. Maloney EK, Cappella JN. Does Vaping in E-Cigarette Advertisements Affect Tobacco Smoking Urge, Intentions, and Perceptions in Daily, Intermittent, and Former Smokers? Health Commun. 2016;31(1):129-138.

118. Pokhrel P, Fagan P, Kehl L, Herzog TA. Receptivity to e-cigarette marketing, harm perceptions, and e-cigarette use. Am J Health Behav. 2015;39(1):121-131.

119. Simmons VN, Quinn GP, Harrell PT, et al. E-cigarette use in adults: a qualitative study of users' perceptions and future use intentions. Addict Res Theory. 2016;24(4):313-321.

120. Chen NT. Predicting Vaccination Intention and Benefit and Risk Perceptions: The Incorporation of Affect, Trust, and Television Influence in a Dual-Mode Model. Risk Anal. 2015;35(7):1268-1280.

121. GlanzJM, WagnerNM, NarwaneyKJ, etal.Amixedmethodsstudyofparentalvaccine decision making and parent-provider trust. Acad Pediatr. 2013;13(5):481-488.

122. World Health Organization. Vaccination and trust: how concerns arise and the role of communciation in mitigating crisis. UN City, Marmorvej 51 DK-2100 Copenhagen, Denmark: WHO Regional Office for Europe;2017.

123. Pokhrel P, Herzog TA, Muranaka N, Fagan P. Young adult e-cigarette users' reasons for liking and not liking e-cigarettes: A qualitative study. Psychol Health. 2015;30(12):1450-1469.

124. McQueen A, Tower S, Sumner W. Interviews with "vapers": implications for future research with electronic cigarettes. Nicotine Tob Res. 2011;13(9):860-867.

125. Wills TA, Knight R, Williams RJ, Pagano I, Sargent JD. Risk factors for exclusive e-cigarette use and dual e-cigarette use and tobacco use in adolescents. Pediatrics. 2015;135(1):e43-51.

126. White J, Li J, Newcombe R, Walton D. Tripling use of electronic cigarettes among New Zealand adolescents between 2012 and 2014. J Adolesc Health. 2015;56(5):522-528.

127. Weinstein ND, Marcus SE, Moser RP. Smokers' unrealistic optimism about their risk. Tob Control. 2005;14(1):55-59.

128. McMaster C, Lee C. Cognitive dissonance in tobacco smokers. Addict Behav. $1991 ; 16(5): 349-353$.

129. Lucherini M, Rooke C, Amos A. "They're thinking, well it's not as bad, I probably won't get addicted to that. But it's still got the nicotine in it, so...": Maturity, Control, and Socializing: Negotiating Identities in Relation to Smoking and Vaping-A Qualitative Study of Young Adults in Scotland. Nicotine Tob Res. 2019;21(1):81-87.

130. Haase N, Betsch C. Parents trust other parents: lay vaccination narratives on the Web may create doubt about vaccination safety. Med Decis Making. 2012;32(4):645.

131. Siegrist M, Cvetkovich G. Perception of hazards: the role of social trust and knowledge. Risk Anal. 2000;20(5):713-719.

132. Vereen RN, Westmaas JL, Bontemps-Jones J, Jackson K, Alcaraz KI. Trust of Information about Tobacco and E-Cigarettes from Health Professionals versus Tobacco or Electronic Cigarette Companies: Differences by Subgroups and Implications for Tobacco Messaging. Health Commun. 2020;35(1):89-95. 
133. Peretti-Watel P, Ward JK, Vergelys C, et al. 'I Think I Made The Right Decision ... I Hope I'm Not Wrong'. Vaccine hesitancy, commitment and trust among parents of young children. Sociol Health Illn. 2019;41(6):1192-1206.

134. Douma LN. Colorectal Cancer Screening: Yes or No? Insights into public opinion and the individual decision-making process [Doctoral]. Amsterdam: Faculteit der Geneeskunde, Vrije Universiteit Amsterdam; 2019.

135. Shourie S, Jackson C, Cheater FM, et al. A cluster randomised controlled trial of a web based decision aid to support parents' decisions about their child's Measles Mumps and Rubella (MMR) vaccination. Vaccine. 2013;31(50):6003-6010.

136. Connolly T, Reb J. Toward interactive, Internet-based decision aid for vaccination decisions: better information alone is not enough. Vaccine. 2012;30(25):38133818.

137. Brown KF, Kroll JS, Hudson MJ, et al. Factors underlying parental decisions about combination childhood vaccinations including MMR: a systematic review. Vaccine. 2010;28(26):4235-4248.

138. Mollema L, Staal JM, van Steenbergen JE, Paulussen TG, de Melker HE. An exploratory qualitative assessment of factors influencing childhood vaccine providers' intention to recommend immunization in the Netherlands. BMC Public Health. 2012;12(1):128.

139. Mollema L, Wijers N, Hahne SJ, et al. Participation in and attitude towards the national immunization program in the Netherlands: data from population-based questionnaires. BMC Public Health. 2012;12:57.

140. Geelen E, van Vliet H, de Hoogh P, Horstman K. Taming the fear of voice: Dilemmas in maintaining a high vaccination rate in the Netherlands. Soc Sci Med. 2016;153:12-19.

141. Abraham C, Sheeran P. Deciding to exercise: the role of anticipated regret. Br J Health Psychol. 2004;9(Pt 2):269-278.

142. van der Pligt J, Richard R. Changing adolescents' sexual behaviour: perceived risk, self-efficacy and anticipated regret. Patient Educ Couns. 1994;23(3):187196.

143. Richard R, van der Pligt J, de Vries NK. Anticipated affect and behavioral choice. Basic and Applied Social Psychology. 1996;18(2):111-129.

144. Leder S, Florack A, Keller J. Self-regulation and protective health behaviour: how regulatory focus and anticipated regret are related to vaccination decisions. Psychol Health. 2015;30(2):165-188.

145.Ziarnowski KL, Brewer NT, Weber B. Present choices, future outcomes: anticipated regret and HPV vaccination. Prev Med. 2009;48(5):411-414.

146. Wroe $A L$, Clements CJ. Feeling bad about immunising children. Aust N Z J Public Health. 2005;29(6):584.

147. Hamama-Raz Y, Ginossar-David E, Ben-Ezra M. Parental regret regarding children's vaccines-The correlation between anticipated regret, altruism, coping strategies and attitudes toward vaccines. Isr J Health Policy Res. 2016;5:55.

148. Schoren C, Hummel K, Vries H. Electronic cigarette use: comparing smokers, vapers, and dual users on characteristics and motivational factors. Tobacco Prevention \& Cessation. 2017;3(April). doi:10.18332/tpc/69392. 
149. De Vries H, Mudde AN, Dijkstra A, Willemsen MC. Differential beliefs, perceived social influences, and self-efficacy expectations among smokers in various motivational phases. Prev Med. 1998;27(5 Pt 1):681-689.

150. East KA, Hitchman SC, McNeill A, Thrasher JF, Hammond D. Social norms towards smoking and vaping and associations with product use among youth in England, Canada, and the US. Drug Alcohol Depend. 2019;205:107635.

151. Hummel K, Willemsen MC, de Vries H, Monshouwer K, Nagelhout GE. Social Acceptance of Smoking Restrictions During 10 Years of Policy Implementation, Reversal, and Reenactment in the Netherlands: Findings From a National Population Survey. Nicotine Tob Res. 2017;19(2):231-238.

152. Gorukanti A, Delucchi K, Ling P, Fisher-Travis R, Halpern-Felsher B. Adolescents' attitudes towards e-cigarette ingredients, safety, addictive properties, social norms, and regulation. Prev Med. 2017;94:65-71.

153. Lazuras L, Chatzipolychroni E, Rodafinos A, Eiser JR. Social cognitive predictors of smoking cessation intentions among smoker employees: the roles of anticipated regret and social norms. Addict Behav. 2012;37(3):339-341.

154. Peters RJ, Jr., Meshack A, Lin MT, Hill M, Abughosh S. The social norms and beliefs of teenage male electronic cigarette use. J Ethn Subst Abuse. 2013;12(4):300-307.

155. Waters EA, Mueller-Luckey G, Levault K, Jenkins WD. Perceived Harms and Social Norms in the Use of Electronic Cigarettes and Smokeless Tobacco. J Health Commun. 2017;22(6):497-505.

156. Bruine de Bruin W, Parker AM, Galesic M, Vardavas R. Reports of social circles' and own vaccination behavior: A national longitudinal survey. Health Psychol. 2019;38(11):975-983.

157. Fadda M, Allam A, Schulz PJ. Arguments and sources on Italian online forums on childhood vaccinations: Results of a content analysis. Vaccine. 2015;33(51):71527159.

158. Goldstein S, MacDonald NE, Guirguis S, Hesitancy SWGoV. Health communication and vaccine hesitancy. Vaccine. 2015;33(34):4212-4214.

159. Bozzola E, Spina G, Russo R, et al. Mandatory vaccinations in European countries, undocumented information, false news and the impact on vaccination uptake: the position of the Italian pediatric society. Ital J Pediatr. 2018;44(1):67.

160. Romijnders K, van Seventer SL, Scheltema M, et al. A deliberate choice? Exploring factors related to informed decision-making about childhood vaccination among acceptors, refusers, and partial acceptors. Vaccine. 2019;37(37):5637-5644.

161. Colditz JB, Welling J, Smith NA, James AE, Primack BA. World Vaping Day: Contextualizing Vaping Culture in Online Social Media Using a Mixed Methods Approach2017.

162. Marta F, Elisa G, Luisa R, etal. Validation of a scale to measure parental psychological empowerment in the vaccination decision. J Public Health Res. 2017;6(2):955.

163. F.A. Q, Mollema L, van Vliet JA, De Melker H, van Lier EA. Geen relatie tussen veranderingen in organisatorische aspecten met betrekking tot vaccineren binnen de jeugdgezondheidszorg en ontwikkeling in aantal gevaccineerden 2013-2017. Bilthoven: RIVM;2018. 
164. Pokhrel P, Herzog TA, Muranaka N, Regmi S, Fagan P. Contexts of cigarette and e-cigarette use among dual users: a qualitative study. BMC Public Health. 2015; 15:859.

165. Amato MS, Boyle RG, Levy D. How to define e-cigarette prevalence? Finding clues in the use frequency distribution. Tob Control. 2016;25(e1):e24-29.

166. Pepper JK, Ribisl KM, Emery SL, Brewer NT. Reasons for starting and stopping electronic cigarette use. Int J Environ Res Public Health. 2014;11(10):1034510361.

167. Rutten LJ, Blake KD, Agunwamba AA, et al. Use of E-Cigarettes Among Current Smokers: Associations Among Reasons for Use, Quit Intentions, and Current Tobacco Use. Nicotine Tob Res. 2015;17(10):1228-1234.

168. McKeganey N, Dickson T. Why Don't More Smokers Switch to Using E-Cigarettes: The Views of Confirmed Smokers. Int J Environ Res Public Health. 2017;14(6):16.

169. Cullen KA, Ambrose BK, Gentzke AS, et al. Notes from the Field: Use of Electronic Cigarettes and Any Tobacco Product Among Middle and High School Students United States,2011-2018. MMWRMorb MortalWklyRep.2018;67(45):1276-1277.

170. Miech R, Johnston L, O'Malley PM, Bachman JG, Patrick ME. Adolescent Vaping and Nicotine Use in 2017-2018 - U.S. National Estimates. N Engl J Med. 2019;380(2):192-193.

171. McMillen RC, Gottlieb MA, Shaefer RM, Winickoff JP, Klein JD. Trends in Electronic Cigarette Use Among U.S. Adults: Use is Increasing in Both Smokers and Nonsmokers. Nicotine Tob Res. 2015;17(10):1195-1202.

172. Buu A, Hu YH, Piper ME, Lin HC. The association between e-cigarette use characteristics and combustible cigarette consumption and dependence symptoms: Results from a national longitudinal study. Addict Behav. 2018;84:6974.

173. Diamantopoulou E, Barbouni A, Merakou K, Lagiou A, Farsalinos K. Patterns of e-cigarette use, biochemically verified smoking status and self-reported changes in health status of a random sample of vapeshops customers in Greece. Intern Emerg Med. 2019;14(6):843-851.

174. Schneller LM, Bansal-Travers M, Goniewicz ML, et al. Use of flavored electronic cigarette refill liquids among adults and youth in the US-Results from Wave 2 of the Population Assessment of Tobacco and Health Study (2014-2015). PLoS One. 2018;13(8):e0202744.

175. O'Connor RJ, Fix BV, McNeill A, et al. Characteristics of nicotine vaping products used by participants in the 2016 ITC Four Country Smoking and Vaping Survey. Addiction. 2019;114 Suppl 1(Suppl 1):15-23.

176. Amaro H, Blake SM, Morrill AC, et al. HIV prevention community planning: challenges and opportunities for data-informed decision-making. AIDS Behav. 2005;9(2 Suppl):S9-27.

177. Harrell MB, Weaver SR, Loukas A, et al. Flavored e-cigarette use: Characterizing youth, young adult, and adult users. Prev Med Rep. 2017;5:33-40.

178. Russell C, McKeganey N, Dickson T, Nides M. Changing patterns of first e-cigarette flavor used and current flavors used by 20,836 adult frequent e-cigarette users in the USA. Harm Reduct J. 2018;15(1):33. 
179. Romijnders K, van Osch L, de Vries H, Talhout R. A Deliberate Choice? Exploring the Decision to Switch from Cigarettes to E-Cigarettes. Int J Environ Res Public Health. 2019;16(4).

180. National institute for Public Health and the Environment (RIVM). [Tobacco]. 2018. https://www.rivm.nl/tabak. Accessed June 19, 2019.

181. National Institute for Public Health and the Environment (RIVM). Tobacco and Drugs. 2019. https://www.rivm.nl/rivm/kennis-en-kunde/expertisevelden/tabaken-drugs. Accessed October 28, 2019.

182. Merriam-Webster.com. "Belief". Merriam-Webster [Dictionary]. 2019. https:// www.merriam-webster.com/dictionary/belief. Accessed November 3, 2019.

183. Fabrigar LR, Petty RE, Smith SM, Crites SL, Jr. Understanding knowledge effects on attitude-behavior consistency: the role of relevance, complexity, and amount of knowledge. J Pers Soc Psychol. 2006;90(4):556-577.

184. Krosnick JA, Boninger DS, Chuang YC, Berent MK, et a. Attitude strength: One construct or many related constructs? Journal of Personality and Social Psychology. 1993;65(6):1132-1151.

185. Rosenstock IM. The health belief model and preventive health behavior. [S.I.]: [s.n.]; 1974.

186. Andreas G, Tilmann B. Modelling option and strategy choices with connectionist networks. Judgment and Decision Making. 2008;3(NA):215-228.

187. Beach LR, Mitchell TR. Image theory: Principles, goals, and plans in decision making. Acta Psychologica. 1987;66(3):201-220.

188. Fischhoff B. Assessing adolescent decision-making competence. Developmental Review. 2008;28(1):12-28.

189. Montgomery $\mathrm{H}$. The search for a dominance structure in decision making: Examining the evidence. In: Klein GA, Orasanu JE, Calderwood RE, Zsambok C, eds. Decision making in action: Models methods: Ablex Publishing; 1989:182188.

190. Svenson O. Values, Affect, and Processes in Human Decision Making: A differentiation and consolidation theory perspective. In: Schneider SL, Shanteau $\mathrm{J}$, eds. Emerging Perspectives on Judment and Decision research. Cambrigde: Cambridge University Press; 2003:287-326.

191. Champion VL, Skinner CS. The Health Belief Model. In: Glanz K, Rimer BK, Viswanath K, eds. Health Behavior and Health Education: Theory, Research and Practice. 4th ed. New Jersey: John Wiley \& Sons; 2008:45-66.

192. Montano DE, Kasprzyk D. Theory of Reasoned Action, Theory of Planned Behavior, and the Integrated Behavioral Model. In: Glanz K, Rimer BK, Viswanath $\mathrm{K}$, eds. Health Behavior and Health Education: Theory, Research and Practice. 4th ed. New Jersey: John Wiley \& Sons; 2008:67-96.

193. Norman P, Boer H, Seydel ER. Protection motivation theory. In: Conner M, Normal $P$, eds. Predicting health behaviour: RESEARCH AND PRACTICE WITH SOCIAL COGNITION MODELS. Vol 81. 2nd ed. Maidenhead, Berkshire: Open University Press; 2005:81-126.

194. Horstman K. Kanttekeningen bij de moraal van 'meer bewegen'. Huisarts en Wetenschap. 2011;2011(2):103-105. 
195. Kasten S, van Osch L, Candel M, de Vries H. The influence of pre-motivational factors on behavior via motivational factors: a test of the I-Change model. BMC Psychol. 2019;7(1):7.

196. Levin IP, Huneke ME, Jasper JD. Information Processing at Successive Stages of Decision Making: Need for Cognition and Inclusion-Exclusion Effects. Organ Behav Hum Decis Process. 2000;82(2):171-193.

197. Boer D, Fischer R. How and when do personal values guide our attitudes and sociality? Explaining cross-cultural variability in attitude-value linkages. Psychol Bull. 2013;139(5):1113-1147.

198. Summers AM. Informed choice in prenatal screening. Can Fam Physician. 1994;40:1688-1691, 1694-1687.

199. Marteau TM, Dormandy E, Michie S. A measure of informed choice. Health Expect. 2001;4(2):99-108.

200. Briss P, Rimer B, Reilley B, et al. Promoting informed decisions about cancer screening in communities and healthcare systems. American Journal of Preventive Medicine. 2004;26(1):67-80.

201. Michie S, Dormandy E, Marteau TM. The multi-dimensional measure of informed choice: a validation study. Patient Educ Couns. 2002;48(1):87-91.

202. Michie S, Dormandy E, Marteau TM. Informed choice: understanding knowledge in the context of screening uptake. Patient Educ Couns. 2003;50(3):247-253.

203. Timmermans D. [What motivates the decision-maker? The meaning of a deliberate and informed decision for public health and prevention] VU medisch centrum 2013.

204. Polit DF, Beck CT. Chapter 13: Data collection in Quantitative research. Nursing research : generating and assessing evidence for nursing practice. Ninth edition. ed. Philadelphia: Wolters Kluwer Health; 2017:293-327.

205. Baron J, Hershey JC. Outcome bias in decision evaluation. J Pers Soc Psychol. 1988;54(4):569-579.

206. Thompson ME, Fong GT, Hammond D, et al. Methods of the International Tobacco Control (ITC) Four Country Survey. Tob Control. 2006;15 Suppl 3:iii12-18.

207. Fong GT, Cummings KM, Borland R, et al. The conceptual framework of the International Tobacco Control (ITC) Policy Evaluation Project. Tob Control. 2006;15 Suppl 3:iii3-11.

208. Polit DF, Beck CT. Chapter 11: Specific Types of Quantitative Research. Nursing research : generating and assessing evidence for nursing practice. Ninth edition. ed. Philadelphia: Wolters Kluwer Health; 2017:257-272.

209. Borland R, Murray K, Gravely S, et al. A new classification system for describing concurrent use of nicotine vaping products alongside cigarettes (so-called 'dual use'): findings from the ITC-4 Country Smoking and Vaping wave 1 Survey. Addiction. 2019;114 Suppl 1:24-34.

210. National Institute for Public Health and the Environment (RIVM). E-Learning: Backgrounds NIP. 2017. https://www.nspoh.nl/bij-en-nascholing/e-learningachtergronden-rijksvaccinatieprogramma/. Accessed June 28th, , 2018.

211. Jackson ML. Challenges in comparing the safety of different vaccination schedules. Vaccine. 2013;31(17):2126-2129. 
212. Kings College London. All evidence shows that e-cigarettes have potential to reduce the harms caused by smoking. 2015. http://www.kcl.ac.uk/ioppn/news/ records/2015/August/ecigarettes.aspx. Accessed March 30, 2017, 2017.

213. Maziak W. Harm reduction at the crossroads: the case of e-cigarettes. Am J Prev Med. 2014;47(4):505-507.

214. Visser W, Geraets L, Klerx W, et al. The health risks of using e-cigarettes. Bilthoven, the Netherlands: National Institute for Public Health and the Environment (RIVM);2015.

215. Visser WF, Klerx WN, Cremers H, et al. The Health Risks of Electronic Cigarette Use to Bystanders. Int J Environ Res Public Health. 2019;16(9).

216. Saada A, Lieu TA, Morain SR, Zikmund-Fisher BJ, Wittenberg E. Parents' choices and rationales for alternative vaccination schedules: a qualitative study. Clin Pediatr (Phila). 2015;54(3):236-243.

217. Nadeau JA, Bednarczyk RA, Masawi MR, et al. Vaccinating my way--use of alternativevaccinationschedulesinNewYorkState. JPediatr.2015;166(1):151-156.

218. World Health Organization. Tobacco Questions for Surveys. Atlanta, GA: Centers for Disease Control and Prevention;2011.

219. World Health Organization. Tobacco Free Initiative (TFI). Electronic cigarettes (ecigarettes) or electronic nicotine delivery systems 2015. http://www.who.int/ tobacco/communications/statements/eletronic_cigarettes/en/. Accessed July $12,2017,2016$.

220. World Health Organization. Immunization Coverage. 2017. http://www.who.int/ mediacentre/factsheets/fs378/en/. Accessed June 19, 2017.

221. World Health Organization. Addressing Vaccine Hesitancy. 2018. https://www. who.int/immunization/programmes_systems/vaccine_hesitancy/en/. Accessed June 14, 2019.

222. Feemster KA, Offit P. Delaying vaccination is not a safer choice. JAMA Pediatr. 2013;167(12):1097-1098.

223. Glanz JM, Newcomer SR, Narwaney KJ, et al. A population-based cohort study of undervaccination in 8 managed care organizations across the United States. JAMA Pediatr. 2013;167(3):274-281.

224. Thaler RH, Sunstein CR. Nudge : improving decisions about health, wealth, and happiness. Revised and expanded edition. ed. New York: Penguin Books; 2009.

225. Bartholomew Eldredge LK. Intervention Mapping Step 3: Program Design. Planning health promotion programs : an intervention mapping approach. Fourth edition. ed. San Francisco, CA: Jossey-Bass \& Pfeiffer Imprints, Wiley; 2016:345-434.

226. Deng Z, Liu S. Understanding consumer health information-seeking behavior from the perspective of the risk perception attitude framework and social support in mobile social media websites. Int J Med Inform. 2017;105:98-109.

227. Grant L, Hausman BL, Cashion M, et al. Vaccination persuasion online: a qualitative study of two provaccine and two vaccine-skeptical websites. J Med Internet Res. 2015;17(5):e133. 
228. Reinwand DA, Crutzen R, Kienhuis AS, Talhout R, de Vries H. Website Use and Effects of Online Information About Tobacco Additives Among the Dutch General Population: A Randomized Controlled Trial. J Med Internet Res. 2017;19(3):e60.

229. Lazard AJ, Byron MJ, Vu H, et al. Website Designs for Communicating About Chemicals in Cigarette Smoke. Health Commun. 2019;34(3):333-342.

230. Jackson C, Cheater F, Peacock R, Leask J, Trevena L. Evaluating a web-based MMR decision aid to support informed decision-making by UK parents: A before-and-after feasibility study. Health Education Journal. 2010;69(1):74-83.

231. Moyo F, Archibald E, Slyer JT. Effectiveness of decision aids for smoking cessation in adults: a quantitative systematic review. JBI Database System Rev Implement Rep. 2018;16(9):1791-1822.

232. Warner DO, LeBlanc A, Kadimpati S, et al. Decision Aid for Cigarette Smokers Scheduled for Elective Surgery. Anesthesiology. 2015;123(1):18-28.

233. Willemsen MC, Wiebing $M$, van Emst A, Zeeman G. Helping smokers to decide on the use of efficacious smoking cessation methods: a randomized controlled trial of a decision aid. Addiction. 2006;101(3):441-449.

234. Stacey D, Legare F, Lewis K, et al. Decision aids for people facing health treatment or screening decisions. Cochrane Database Syst Rev. 2017;4:CD001431.

235. O'Connor AM, Bennett CL, Stacey D, et al. Decision aids for people facing health treatment or screening decisions. Cochrane Database Syst Rev. 2009(3):CD001431.

236. Ubel PA, Smith DM, Zikmund-Fisher BJ, et al. Testing whether decision aids introduce cognitive biases: results of a randomized trial. Patient Educ Couns. 2010;80(2):158-163.

237. Wilson EA, Wolf MS. Working memory and the design of health materials: a cognitive factors perspective. Patient Educ Couns. 2009;74(3):318-322.

238. Morgan MG, Fischhoff B, Bostrom A, Atman CJ. Risk communication: A mental models approach. Cambridge University Press; 2002.

239. Feldman-Stewart D, O'Brien MA, Clayman ML, et al. Providing Information about options. In:VolkR, Llewellyn-ThomasH, eds.2012UpdateofthelnternationalPatient Decision Aids Standards (IPDAS) Collaboration's Background Document 2012.

240. Pignone $M$, Fagerlin A, Abhyankar $P$, et al. Clarifying and Expressing Values. In: Volk R, Llewellyn-Thomas H, eds. 2012 Update of the International Patient Decision Aids Standards (IPDAS) Collaboration's Background Document 2012.

241. Stacey D, Belkora J, Clay K, et al. Coaching and Guidance in Deliberation and Communication. In: Volk R, Llewellin EW, eds. 2012 Update of the International Patient Decision Aids Standrs (IPDAS) Collaboration's Background Document2012.

242. Stacey D, Kryworuchko J, Belkora J, et al. Coaching and guidance with patient decision aids: A review of theoretical and empirical evidence. BMC Med Inform Decis Mak. 2013;13 Suppl 2:S11.

243. Stacey D, Murray MA, Legare F, et al. Decision coaching to support shared decision making: a framework, evidence, and implications for nursing practice, education, and policy. Worldviews Evid Based Nurs. 2008;5(1):25-35. 
244. Tubeuf S, Edlin R, Shourie S, et al. Cost effectiveness of a web-based decision aid for parents deciding about MMR vaccination: a three-arm cluster randomised controlled trial in primary care. Br J Gen Pract. 2014;64(625):e493-499.

245. WallaceC, LeaskJ, TrevenaLJ.Effects ofawebbased decisionaidonparentalattitudes to MMR vaccination: a before and after study. BMJ. 2006;332(7534):146-149.

246. Do HP, Tran BX, Le Pham Q, et al. Which eHealth interventions are most effective for smoking cessation? A systematic review. Patient Prefer Adherence. 2018; 12:2065-2084.

247. Haase N, Betsch C, Renkewitz F. Source Credibility and the Biasing Effect of Narrative Information on the Perception of Vaccination Risks. J Health Commun. 2015;20(8):920-929.

248. Gianfredi V, Moretti M, Lopalco PL. Countering vaccine hesitancy through immunization information systems, a narrative review. Human vaccines \& immunotherapeutics. 2019;15(11):2508-2526.

249. Weinstein ND. Why it won't happen to me: perceptions of risk factors and susceptibility. Health Psychol. 1984;3(5):431-457.

250. de Wit JB, Das E, Vet R. What works best: objective statistics or a personal testimonial? An assessment of the persuasive effects of different types of message evidence on risk perception. Health Psychol. 2008;27(1):110-115.

251. Hinyard LJ, Kreuter MW. Using narrative communication as a tool for health behavior change: a conceptual, theoretical, and empirical overview. Health Educ Behav. 2007;34(5):777-792.

252. Compton J, Jackson B, Dimmock JA. Persuading Others to Avoid Persuasion: Inoculation Theory and Resistant Health Attitudes. Front Psychol. 2016;7:122.

253. Chen JC. Flavored E-cigarette Use and Cigarette Smoking Reduction and Cessation-A Large National Study among Young Adult Smokers. Subst Use Misuse. 2018;53(12):2017-2031.

254. Chen-Sankey JC, Kong G, Choi K. Perceived ease of flavored e-cigarette use and e-cigarette use progression among youth never tobacco users. PLoS One. 2019;14(2):e0212353.

255. Villanti AC, Johnson AL, Ambrose BK, et al. Flavored Tobacco Product Use in Youth and Adults: Findings From the First Wave of the PATH Study (2013-2014). Am J Prev Med. 2017;53(2):139-151.

256. Miller WR, Rollnick S. Motivational interviewing : helping people change. 3rd ed. ed. New York, NY: Guilford Press; 2013.

257. Gagneur A, Gosselin V, Dube E. Motivational interviewing: A promising tool to address vaccine hesitancy. Vaccine. 2018;36(44):6553-6555.

258. Horstman K. Een kwestie van betekenissen. Tijdschrift voor gezondheidswetenschappen. 2016;94(8):281-282.

259. Prochaska JJ. The public health consequences of e-cigarettes: a review by the National Academies of Sciences. A call for more research, a need for regulatory action. Addiction. 2019;114(4):587-589.

260. Chen J, Bullen C, Dirks K. A Comparative Health Risk Assessment of Electronic Cigarettes and Conventional Cigarettes. Int J Environ Res Public Health. 2017;14(4). 
261. Goniewicz ML, Gawron M, Smith DM, et al. Exposure to Nicotine and Selected Toxicants in Cigarette Smokers Who Switched to Electronic Cigarettes: A Longitudinal Within-Subjects Observational Study. Nicotine Tob Res. 2017; 19(2):160-167.

262. Levy DT, Borland R, Lindblom EN, et al. Potential deaths averted in USA by replacing cigarettes with e-cigarettes. Tob Control. 2018;27(1):18-25.

263. Stratton K, Kwan L, Y., Eaton DL. Public health consequences of e-cigarettes. Washington, DC, United States: National Academies Press;2018.9780309468343.

264. Kinouani S, Pereira E, Tzourio C. Electronic Cigarette Use in Students and Its Relation with Tobacco-Smoking: A Cross-Sectional Analysis of the i-Share Study. Int J Environ Res Public Health. 2017;14(11):1345.

265. Liu X, Lugo A, Davoli E, et al. Electronic cigarettes in Italy: a tool for harm reduction or a gateway to smoking tobacco? Tob Control. 2019.

266. Soneji S, Barrington-Trimis JL, Wills TA, et al. Association Between Initial Use of e-Cigarettes and Subsequent Cigarette Smoking Among Adolescents and Young Adults: A Systematic Review and Meta-analysis. JAMA Pediatr. 2017. doi:10.1001/jamapediatrics.2017.1488.

267. McRobbie H. Modelling the Population Health Effects of E-Cigarettes Use: Current Data Can Help Guide Future Policy Decisions. Nicotine Tob Res. 2017;19(2):131-132. 

Valorization Addendum 


\section{Valorization Addendum}

The main aim of this thesis was to explore two examples of decisions we identified as a next to best health decision. When making health-related decisions, there can be different options to choose from. For instance, a parent can decide to accept, refuse, or partially accept childhood vaccinations; or a smoker can decide to quit smoking or switch from smoking regular cigarettes to electronic cigarettes (e-cigarettes). Public health professionals often inform individuals only about a recommended option, i.e. the option that is scientifically proven to be the healthiest. For example, they provide a brochure in order to inform parents about vaccinating their children according to the schedule of the National Immunization Program (NIP). ${ }^{1,2}$ However, this recommended option might not be suitable for all individuals due to different personal values, priorities with regard to health, previous experiences, opinions, and the norms of their social environment. Consequently, in these cases people may prefer to choose options that match their individual values and goals; yet, these options may be considered by public health professionals as, for example, 'next to best'. Next to best health options are - from a public health and scientific point of view - less harmful or healthier than the unrecommended health option, but less preferred than the recommended option. Another option people may choose is the unrecommended option, which is considered as being unhealthy by public health experts and science.

To expand our understanding of these next to best health decisions, we had two aims. First, we examined determinants influencing the decision about smoking behavior and childhood vaccination, both qualitatively and quantitatively. Second, we examined the extent to which decisions regarding smoking behavior and childhood vaccination adhere to the criteria of informed decision-making. The results may facilitate and support communication programs that incorporate decision-making about smoking behavior and childhood vaccination.

\section{Relevance of research into next to best health decisions}

\section{E-cigarette use}

In recent years a shift from recommended to next to best health options could be noticed. In the case of e-cigarettes, research has demonstrated that since their introduction in 2003, the appeal of e-cigarettes has increased rapidly. ${ }^{3-9}$ The number of people who smoke in the Netherlands is decreasing. ${ }^{10,11}$ In $2017,23 \%$ of the adult Dutch population smoked cigarettes. ${ }^{11}$ Of these $23 \%, 75 \%$ smoke daily. Three percent of Dutch adults use an e-cigarette. Ten percent of the current smokers sometimes use an e-cigarette, and daily smokers (12\%) use an e-cigarette more often compared to non-daily smokers (4\%). However, decision-making about e-cigarette use is largely uninvestigated, it is unclear how people make a decision about smoking and vaping behavior. In this thesis these decisions were investigated in order to provide information for health communication aimed to 
support these decisions. The current chapter will provide information how the findings of this thesis might be used for health communication strategies aimed to support decisions about smoking and vaping behavior.

\section{Partially accepting childhood vaccination}

For childhood vaccination a decrease in the vaccination coverage and an increase in the unrecommended and next to best health option was found in previous years. Of all Dutch two-year-olds born in $20143.6 \%$ did not receive any vaccines according to the NIP and $5.2 \%$ received or delayed some vaccines, and of Dutch two-year-olds born in 2015 4.6\% did not receive any vaccines according to the NIP and $5.2 \%$ received or delayed some vaccines. ${ }^{12}$ However, the vaccination coverage does not provide insight into whether parents have questions or doubts regarding their decision or how parents made a decision about childhood vaccination. For example, parents who accept all childhood vaccinations, may still have doubts about their decision or even experience regret. ${ }^{13-15}$ Or parents who refused childhood vaccination may have based this decision on fear of sideeffects their child may experience due to a vaccine. Because little is known about the doubts and regret parents may face with regard to accepting, refusing, and partially accepting childhood vaccination it is important to investigate decisionmaking. The current chapter will provide information about how the findings of this thesis might be used for health communication strategies aimed at supporting parents with decision-making about childhood vaccination.

\section{Activities as a result from this thesis}

\section{Further steps for health communication}

With regard to the next to best health option, further research is needed. Although recommended health options can be considered as most beneficial for public health, 6,16-19 next to best health options have potential individual and public health benefits compared to unrecommended health options. ${ }^{16,20-30}$ However, in itself, next to best health options are not the most beneficial for individual health nor without risks., 31,32 Consequently, these options are not recommended from a public health perspective.

Even though an option may not be recommended by public health experts, people search for information that reinforces their chosen option or may facilitate arriving at their desired decision, 33,34 and thus, it is important to provide evidence-based information about all options. Based on our results, we recommended further research to investigate the effects of communicating about the recommended health options, the unrecommended option, and the next to best health options. The current findings have instigated several efforts targeting the communication about childhood vaccination. Efforts have been made to investigate the effects of communicating about the recommended, unrecommended, and next to best health options on decision-making. In particular, the effect of communicating about these options on the intention to towards accepting or refusing the 
recommend health option and on decisional conflict experienced. Insights generated from these studies will further aid public health experts and policy makers in determining the goals of health communication. In addition, the results of such a experimental study may generate input for the communication effort of the RIVM. For example, the brochure presented to parents may be adapted as a result of this study. ${ }^{1,2,35-37}$

\section{Considerations for the RIVM}

The RIVM is currently responsible for informing parents about the National Immunization Program. For this purpose, they use a standard brochure that all new parents receive after the birth of their child. ${ }^{1,2,35-37}$ With an experimental design researchers from the RIVM want to investigate what the effects are of communicating about accepting (i.e. the recommended health option), refusing (the unrecommended health option), and partially accepting (i.e. the next to best health option) versus solely communicating about accepting childhood vaccination, on two primary outcomes: decisional conflict $^{38}$ related to the decision about childhood vaccination and intention towards childhood vaccination. The results of this study will inform policy makers about further steps needed in communication strategies.

\section{Considerations for policy makers and health professionals}

The results of this thesis and the experimental study may prove useful for policy makers. Policy makers may have different goals with providing information with regard to various health behaviors. ${ }^{39}$ If policy makers opt for providing scientific information without steering, they may want to facilitate informed decisionmaking, which may lead to more people choosing the unrecommended health option. On the other hand, if policy makers and health professionals do not include information about alternative health options - and thus neglect other options that may be considered - and only inform the public about the recommended health option, the public may search for information about alternative health options on informal channels. Not providing information about unrecommended or next to best health options, may thus facilitate biased information processing among the public and decrease trust in public health experts due to a lack of transparency. The experimental study may thus generate insight for policy makers. For example, if experienced conflict is reduced and the intention to accept the recommended health option remains the same or increases, then communicating about all three health options does not harm public health, then supporting decision-making may be a possible goal of communication. However, if intention to accept the recommended health option is reduced due to communicating about all three health options, then communicating about all three health options may not be desired and persuasion may be a goal of communication.

The results of this thesis may furthermore prove useful for health professionals. Health professionals, such as GPs and general practice-based nurse specialists, 
may be able to play an important role in the decision-making process about switching from cigarettes to e-cigarettes. Similarly, Child Vaccine Providers (CVPs) at the Child Welfare Centers (CWCs) may be important to assist in decisionmaking about childhood vaccination. With insight into factors that can support the decision-making process, health professionals may be able to exchange evidence-based information, address misperceptions and doubts, strengthen positive attitudes, answer questions, and discuss the various choice options.

\section{Dissemination of results}

This thesis resulted in several publications in scientific journals. These describe decision-making factors with regard to two relevant public health behaviors and provide implications for health communication. Our results about e-cigarette use and childhood vaccination generated media attention. For example, several news items were published by the RIVM, and a major Dutch newspaper. We discussed our findings at international and national conferences, and we were invited to speak at Yale University, the Virginia Common Wealth University at Richmond, and the Gillings School of Global Public Health in Chapel Hill. Policy makers, including the Dutch Secretary of Health, showed great interest in our results during multiple meetings. For example, policy makers were advised about a survey related to the attractiveness of e-cigarettes and we spoke about the decision-making of parents who refuse or partially accept childhood vaccination with the Dutch Secretary of Health. In addition, our results about the attractiveness of e-cigarettes were used by the Dutch secretary of health to strengthen his argument to ban the sales of non-tobacco e-liquid flavors and expand existing smoking bans to include e-cigarette use. ${ }^{40}$ These measures are part of the national prevention agreement that aims to achieve a smoke free generation in $2040 .{ }^{40}$ Results of our studies were also used in the yearly surveillance report of the Dutch National Immunization program, this led to multiple publications. ${ }^{1,12}$ Every year, surveillance and scientific developments are presented in a report of the National Immunization Program, in 2018 and 2019 our results were used to describe the scientific developments related to decision-making about childhood vaccination. 


\section{References}

1. E.A. van Lier, Geraedts JLE, P.J. Oomen, et al. [Vaccine Coverage of NIP in the Netherlands]. Bilthoven: National Institute for Public Health and the Environment;2018.

2. National Institute for Public Health and the Environment (RIVM). [National Immunization Program]. History 2018. http://www.rijksvaccinatieprogramma.nl/ Over_Rijksvaccinatieprogramma/Geschiedenis. Accessed June 19, 2018.

3. Pepper JK, Brewer NT. Electronic nicotine delivery system (electronic cigarette) awareness, use, reactions and beliefs: a systematic review. Tob Control. 2014;23(5):375-384.

4. Grana R, Benowitz N, Glantz SA. E-cigarettes: a scientific review. Circulation. 2014;129(19):1972-1986.

5. Hajek P, Etter JF, Benowitz N, Eissenberg T, McRobbie H. Electronic cigarettes: review of use, content, safety, effects on smokers and potential for harm and benefit. Addiction. 2014;109(11):1801-1810.

6. Visser W, Geraets L, Klerx W, et al. The health risks of using e-cigarettes. Bilthoven, the Netherlands: National Institute for Public Health and the Environment (RIVM);2015.

7. Xu Y, Guo Y, Liu K, Liu Z, Wang X. E-Cigarette Awareness, Use, and Harm Perception among Adults: A Meta-Analysis of Observational Studies. PLoS One. 2016;11(11):e0165938.

8. Glasser AM, Collins L, Pearson JL, et al. Overview of Electronic Nicotine Delivery Systems: A Systematic Review. Am J Prev Med. 2017;52(2):e33-e66.

9. King BA, Alam S, Promoff G, Arrazola R, Dube SR. Awareness and ever-use of electronic cigarettes among U.S. adults, 2010-2011. Nicotine Tob Res. 2013;15(9):1623-1627.

10. Centraal Bureau voor Statistiek (CBS). Gezondheid belangrijkste reden om te stoppen met roken. 2017. https://www.cbs.nl/nl-nl/nieuws/2017/44/ gezondheid-belangrijkste-reden-om-te-stoppen-met-roken.

11. Springvloet $L$, Bommele J, Willemsen M, van Laar M. KERNCIJFERS ROKEN 2017. Utrecht Trimbos-instituut;2018.

12. E.A. van Lier, P.J. Oomen, H. Giesbers, et al. Vaccine Coverage of NIP in the Netherlands 2018. Bilthoven: National Institute for Public Health and the Environment;2019.

13. Harmsen IA, Mollema L, Ruiter RA, et al. Why parents refuse childhood vaccination: a qualitative study using online focus groups. BMC Public Health. 2013;13(1):1183.

14. Bedford $H$, Attwell $K$, Danchin $M$, et al. Vaccine hesitancy, refusal and access barriers: The need for clarity in terminology. Vaccine. 2018;36(44):6556-6558.

15. MacDonald NE, Hesitancy SWGoV. Vaccine hesitancy: Definition, scope and determinants. Vaccine. 2015;33(34):4161-4164.

16. Jackson ML. Challenges in comparing the safety of different vaccination schedules. Vaccine. 2013;31(17):2126-2129. 
17. Kings College London. All evidence shows that e-cigarettes have potential to reduce the harms caused by smoking. 2015. http://www.kcl.ac.uk/ioppn/news/ records/2015/August/ecigarettes.aspx. Accessed March 30, 2017, 2017.

18. Maziak W. Harm reduction at the crossroads: the case of e-cigarettes. Am J Prev Med. 2014;47(4):505-507.

19. Visser WF, Klerx WN, Cremers H, et al. The Health Risks of Electronic Cigarette Use to Bystanders. Int J Environ Res Public Health. 2019;16(9).

20. Saada A, Lieu TA, Morain SR, Zikmund-Fisher BJ, Wittenberg E. Parents' choices and rationales for alternative vaccination schedules: a qualitative study. Clin Pediatr (Phila). 2015;54(3):236-243.

21. Nadeau JA, Bednarczyk RA, Masawi MR, et al. Vaccinating my way--use of alternative vaccination schedules in New York State. J Pediatr. 2015;166(1):151156.

22. World Health Organization. Tobacco Questions for Surveys. Atlanta, GA: Centers for Disease Control and Prevention;2011.

23. World Health Organization. Tobacco Free Initiative (TFI). Electronic cigarettes (ecigarettes) or electronic nicotine delivery systems 2015. http://www.who.int/ tobacco/communications/statements/eletronic_cigarettes/en/. Accessed July 12, 2017, 2016.

24. World Health Organization. WHO REPORT ON THE GLOBAL TOBACCO EPIDEMIC, 2015. Geneva: World Health Organization;2015.

25. World Health Organization. Tobacco. Factsheet 2017. http://www.who.int/ mediacentre/factsheets/fs339/en/. Accessed November 30, 2018, 2018.

26. World Health Organization. Immunization Coverage. 2017. http://www.who.int/ mediacentre/factsheets/fs378/en/. Accessed June 19, 2017.

27. World Health Organization. Vaccination and trust: how concerns arise and the role of communciation in mitigating crisis. UN City, Marmorvej 51 DK-2100 Copenhagen, Denmark: WHO Regional Office for Europe;2017.

28. World Health Organization. Immunization Coverage. Immunization, Vaccines and Biologicals 2018. http://www.who.int/en/news-room/fact-sheets/detail/ immunization-coverage. Accessed June, 26, 2018.

29. World Health Organization. Addressing Vaccine Hesitancy. 2018. https://www. who.int/immunization/programmes_systems/vaccine_hesitancy/en/. Accessed June 14, 2019.

30. World Health Organization. Ten Threats to Global Health in 2019. Vaccine Hesitancy 2019. https://www.who.int/emergencies/ten-threats-to-globalhealth-in-2019. Accessed 26th of February, 2019.

31. Feemster KA, Offit P. Delaying vaccination is not a safer choice. JAMA Pediatr. 2013;167(12):1097-1098.

32. Glanz JM, Newcomer SR, Narwaney KJ, et al. A population-based cohort study of undervaccination in 8 managed care organizations across the United States. JAMA Pediatr. 2013;167(3):274-281.

33. Janis IL, Mann L. Decision making: A psychological analysis of conflict, choice, and commitment. Free Press; 1977. 
34. Mann L, Janis IL, Chaplin R. Effects of anticipation of forthcoming information on predecisional processes. Journal of Personality and Social Psychology. 1969;11(1):10-16.

35. National Institute for Public Health and the Environment (RIVM). E-Learning: Backgrounds NIP. 2017. https://www.nspoh.nl/bij-en-nascholing/e-learningachtergronden-rijksvaccinatieprogramma/. Accessed June 28th, , 2018.

36. National institute for Public Health and the Environment (RIVM). [Tobacco]. 2018. https://www.rivm.nl/tabak. Accessed June 19, 2019.

37. National Institute for Public Health and the Environment (RIVM). Tobacco and Drugs. 2019. https://www.rivm.nl/rivm/kennis-en-kunde/expertisevelden/tabaken-drugs. Accessed October 28, 2019.

38. O'Connor AM. Validation of a decisional conflict scale. Med Decis Making. 1995;15(1):25-30.

39. Timmermans D. [What motivates the decision-maker? The meaning of a deliberate and informed decision for public health and prevention] VU medisch centrum 2013.

40. the Dutch Secretary of Health. Progress national prevention agreement. Den haag: Ministtry of Health, Well-being and Sports;2020. 


Summary 


\section{Summary}

Health-related decisions often involve a variety of options. Public health professionals often inform the public about an option they recommend based on scientific evidence. However, this healthiest, recommended option might not be suitable for everyone due to their personal values, priorities with regards to health, previous experiences, opinions, and the norms of their social environment. Consequently, in these cases people may choose options that match their individual values and goals but are considered by public health professionals as, for example, 'next to best'. Next to best health options are - from a public health and scientific point of view - less harmful or less healthy than the unrecommended health option, but not less harmful or less healthy compared to the recommended health option. Another option people may choose is the unrecommended option, which is considered as unhealthy by public health experts and science.

In this thesis we explored two examples of decisions in which an increase in the next to best health decision (i.e. e-cigarette use and partially accepting childhood vaccinations) was observed. To expand our understanding of these next to best health decisions, the aim of this thesis was twofold. The two aims were related to improving our understanding of the next to best health decisions in the context of smoking behavior and childhood vaccination. First, this thesis aimed to explore which socio-cognitive factors, such as perceived susceptibility and severity, trust, anticipated regret, social support, and self-efficacy, are related to the decisions regarding smoking behavior and childhood vaccination. With this in mind, we conducted qualitative and quantitative studies to explore and determine sociocognitive factors related to the decisions regarding e-cigarette use among neverusers, smokers, dual users, and exclusive e-cigarette users, as well as decisions concerning childhood vaccination among parents who choose to accept, refuse or partially vaccinate their child. Second, this thesis investigated whether the decisions with regard to smoking behavior and childhood vaccinations adhered to the criteria of informed decision-making. To this end, we explored differences in knowledge, attitude, and deliberation, as well as decisional conflict of those who opted for the recommended, the unrecommended, and the next to best health options. It is important to investigate the criteria for informed decisionmaking because supporting informed decision-making may reduce decisional conflict and support decision-making in general.

\section{Part I Exploring factors related to decision-making about smoking behavior}

In the first part of the thesis, Chapters 2 - 5 focus on smoking behavior. Chapter 2 describes a narrative systematic review of perceptions and reasons for e-cigarette use. Results indicate that e-cigarette users perceive e-cigarettes as being less harmful than cigarettes. In addition, reasons for and benefits of 
e-cigarette use reported by never-users were the novelty of the product and that it can aid concentration. Smokers mentioned that it mimics the smoking routine, whereas dual users reported benefits of avoiding smoking restrictions and the practicality of e-cigarettes. E-cigarette users reported benefits of increased athletic performance and that e-cigarettes can be used discretely.

Chapter 3 presents results from a qualitative focus group study into factors that play a role in the decision regarding e-cigarette use. Socio-cognitive factors, such as knowledge, perceived risks of e-cigarettes compared to cigarettes, trust in information, attitudes, and social norms about e-cigarette use, and deliberation were reported to be of influence in decisions related to smoking behavior and e-cigarette use.

Chapters 4 and 5 describe the results of a quantitative questionnaire into product characteristics of e-cigarettes and socio-cognitive factors related to the decision concerning smoking behavior. Results indicate that of all product characteristics investigated in chapter 4 (e.g. amendable nicotine levels or adjustable settings of e-cigarettes), e-liquid flavors were reported to be the most attractive aspect of e-cigarettes by all user groups. For example, menthol/mint and sweet e-liquid flavors were preferred by never-users, tobacco and menthol/mint e-liquid flavors were preferred by smokers and dual users, and sweet and fruit flavors were preferred by e-cigarette users compared to other flavor categories. In addition, dual users - dual use of tobacco cigarettes and e-cigarettes - and exclusive e-cigarette users - exclusive use of e-cigarettes - are two distinct e-cigarette user groups.

Chapter 5 presents our quantitative exploration of distinguishing features between these groups, and results indicate that seven features are important to distinguish a dual user from an exclusive e-cigarette user with $86 \%$ certainty: (1) compared to exclusive e-cigarette users, dual users felt more connected to other smokers; (2) the quantity of tobacco cigarettes smoked in the past was higher among exclusive e-cigarette users than the quantity smoked currently by dual users; (3) self-efficacy to quit vaping and smoking was lower among dual users; (4) e-cigarette users found the cigarette unattractive more often than dual users did; (5) e-cigarette users had more positive attitudes towards vaping than dual users; (6) dual users perceived more barriers to accessing e-cigarettes; and (7) dual users had a stronger intention to quit vaping than e-cigarette users (chapter 5). The findings from part I expand our knowledge of factors related to the decision about the next to best health decision: e-cigarette use.

\section{Part II Exploring factors related to decision-making about childhood vaccination}

In part II, chapters $6-7$ focus on childhood vaccination. Chapter 6 presents results from a qualitative focus group study into factors that play a role in the 
decision regarding childhood vaccination. Results indicate that several sociocognitive factors play a role in the decision to either accept, refuse, or partially accept childhood vaccinations, such as knowledge, perceived susceptibility and severity, trust in information, attitudes, anticipated regret, social norms, and deliberation.

Chapter 6 shows that partial acceptors perceived fewer risks of vaccinepreventable diseases (VPDs), more risks of side-effects of vaccines, less social support from their environment, and less trust in child welfare centers (CWCs) and information provided by the CWCs than acceptors. Partial acceptors reported having made a deliberate decision, and described this process of deliberation as elaborate, time-consuming, and difficult. Acceptors and refusers indicated that they had not given much thought to partially accepting childhood vaccination, (chapters 6 and 7).

Chapter 7 presents the results of a quantitative survey investigating factors related to the decision concerning childhood vaccination. Results demonstrate that acceptors perceived the susceptibility of side-effects of vaccines as lower compared to the susceptibility of VPDs if (some) vaccines are refused. Refusers and partial acceptors perceived the susceptibility of side-effects of vaccines to be higher compared to that of the VPDs. While anticipated regret towards negative consequences of VPDs was high among acceptors when considering refusing childhood vaccinations, anticipated regret among refusers and partial acceptors with regard to potential side-effects for the child was high when considering accepting vaccines. All parents reported a social norm favoring accepting childhood vaccinations. Trust in the National Immunization Program (NIP) was high among acceptors but moderate among refusers and partial acceptors. Partial acceptors experienced more barriers with regard to vaccination than refusers and acceptors. With regard to decisional conflict, on the decisional conflict scale, acceptors scored highest on uninformed, refusers scored highest on unsupported, and partial acceptors scored highest on uncertainty. The findings of part II expand our knowledge of factors related to the decision about the next to best health decision: partially accepted childhood vaccinations.

\section{Part III Decision-making}

In part III, chapter 8 presents the results of two quantitative surveys investigating smoking behavior and childhood vaccination. The aim of these studies was to investigate whether the decisions about smoking behavior and childhood vaccination adhered to criteria - knowledge, attitudes, and deliberation - of informed decision-making. The results indicate that overall, decisions about smoking behavior and childhood vaccination did not adhere to at least one of the criteria of informed decision-making. Those who opted for the recommended health option (i.e. never-users and acceptors) had relatively low levels of deliberation about their decision or the alternative health options. In addition, cognitive beliefs of smokers, e-cigarette users, refusers, and partial 
acceptors did not correspond with scientific evidence. Those who chose the next to best health option reported levels of knowledge, attitudes, and deliberation in-between those who chose the recommended and unrecommended health option. Whereas vaccine refusers had deliberated their decision thoroughly, smokers were found to report low levels of deliberation and were negative with regard to their own behavior. Those who chose for the next to best health decision were not outspokenly negative towards the recommended health option but e-cigarette users were outspokenly negative towards smoking.

In the general discussion in chapter 9, it is observed that further research is needed to investigate how to communicate about next to best health options, such as e-cigarette use and partially accepting childhood vaccination. Although not smoking or not using e-cigarettes and accepting childhood vaccinations can be considered as most beneficial for public health, e-cigarette use or partially accepting childhood vaccination has potential individual and public health benefits compared to smoking or refusing all vaccines. However, e-cigarette use and partially accepting childhood vaccinations are not beneficial for individual health or without risks. Consequently, these options are not recommended from a public health perspective. Based on our results, we would recommend further research to investigate the effects of communicating about the recommended health options (e.g. not smoking or not using e-cigarettes, and accepting childhood vaccinations), the unrecommended option (e.g. smoking or refusing childhood vaccinations), and the next to best health options (e.g. e-cigarette use and partially accepting childhood vaccination). Such research could test the effect, appreciation, and acceptability of providing information on all health options on decision-making and intention to accept the recommended option in comparison to standard information. With regard to communicating about best and other options, it is important to articulate clearly which particular goals public health experts want to achieve. They may consider it their goal to provide scientific information without providing advice or decisional support. Another goal may be to facilitate informed decision-making even though the consequence of this may be that more people will choose the unrecommended or next to best option rather than the recommended option, thereby increasing public health risks. Alternatively, public health experts may choose to take a more directive approach to get as many people as possible to choose the recommended health option to increase public health gain. With this aim, several motivational techniques can be applied to steer the public in the desired and recommended direction. Rigorous testing of possible decisional effects of providing information on all options will allow public health experts and policy makers to make an informed decision on possible adaptation of current communication efforts. 

Samenvatting 


\section{Samenvatting}

Keuzes met betrekking tot gezondheid omvatten vaak verschillende opties. Vanuit het perspectief van volksgezondheid wordt het publiek geïnformeerd door experts over een optie die wordt aanbevolen op basis van wetenschappelijk bewijs. De gezondste, aanbevolen optie is mogelijk niet voor iedereen geschikt bijvoorbeeld vanwege persoonlijke waarden of prioriteiten met betrekking tot gezondheid. Ook kunnen eerdere ervaringen, meningen en de sociale omgeving een rol spelen. Daardoor kunnen mensen in deze gevallen opties kiezen die beter passen bij hun individuele waarden en doelen, maar die vanuit volksgezondheid worden beschouwd als een één na beste keuze. Één na beste keuzes zijn - vanuit het oogpunt van volksgezondheid en wetenschap - minder schadelijk of minder ongezond dan de niet-aanbevolen optie voor gezondheid, maar schadelijker of minder gezond vergeleken met de aanbevolen gezondheidsoptie. Een andere optie die mensen kunnen kiezen is de niet-aanbevolen optie, die door deskundigen op het gebied van de volksgezondheid en de wetenschap als ongezond wordt beschouwd.

In dit proefschrift heb ik twee voorbeelden onderzocht van gezondheid gerelateerde keuzes waarbij in de laatste jaren een toename van de één na beste keuze (dat wil zeggen het gebruik van e-sigaretten (ook wel dampen genoemd) en het gedeeltelijk accepteren van vaccinaties voor kinderen) werd waargenomen in Nederland. Om ons begrip over de één na beste keuzes te vergroten is dit proefschrift geschreven. Het doel beschreven in dit proefschrift is daarbij tweeledig. Ten eerste was het doel te onderzoeken welke sociaalcognitieve factoren verband houden met de keuze rondom rookgedrag en vaccineren van kinderen. Denk hierbij aan de perceptie met betrekking tot de kans en ernst van bijvoorbeeld infectieziekten, het vertrouwen in informatie over de e-sigaret, verwachte spijt over het weigeren van vaccinaties, sociale steun en zelfeffectiviteit. Met dit in gedachten hebben wij kwalitatieve en kwantitatieve onderzoeken uitgevoerd om sociaal-cognitieve factoren te onderzoeken en te bepalen of deze factoren een rol spelen bij de keuzes over het gebruik van e-sigaretten bij niet-gebruikers, rokers, exclusieve e-sigaretgebruikers, en 'dual users' (dit zijn gebruikers die zowel tabakssigaretten als e-sigaretten gebruiken) en exclusieve e-sigaretgebruikers. Een vergelijkbaar onderzoek heb ik uitgevoerd met betrekking tot keuzes over vaccinatie van kinderen onder ouders die het Rijksvaccinatieprogramma volgen, die alle vaccinaties weigeren of die gedeeltelijk vaccineren. Ten tweede onderzochten wij in dit proefschrift of de keuzes rondom rookgedrag en vaccinaties voor kinderen voldeden aan de criteria van geïnformeerde besluitvorming. Daartoe heb ik de verschillen in kennis, houding en deliberatie onderzocht, evenals twijfels onder ouders die het Rijksvaccinatieprogramma volgen, die alle vaccinaties weigeren of die gedeeltelijk vaccineren. Het is belangrijk om de criteria voor geïnformeerde besluitvorming te onderzoeken omdat het ondersteunen van geïnformeerde besluitvorming twijfels kan verminderen en de kwaliteit van besluitvorming kan verbeteren. 


\section{Deel I Onderzoek naar factoren gerelateerd aan de keuze rondom rookgedrag}

In het eerste deel van dit proefschrift gaan de hoofdstukken 2-5 in op rookgedrag. Hoofdstuk 2 beschrijft een systematische review van percepties ten opzichte van de e-sigaret en redenen voor het gebruik van e-sigaretten. De resultaten geven aan dat e-sigaretgebruikers de e-sigaret als minder schadelijk beschouwden dan sigaretten. Niet-gebruikers gaven aan dat 'de nieuwigheid van het product' en 'de verwachting dat het de concentratie kan bevorderen' voordelen zijn van het gebruik van e-sigaretten. Rokers gaven aan dat de e-sigaret de rookroutine nabootst, terwijl 'dual users' voordelen rapporteerden zoals het vermijden van rookbeperkingen en het gemak van e-sigaretten. E-sigaret gebruikers meldden voordelen van verbeterde atletische prestaties en dat e-sigaretten discreet kunnen worden gebruikt.

Hoofdstuk 3 presenteert resultaten van een kwalitatieve focusgroep studie naar factoren die een rol kunnen spelen bij de beslissing over het gebruik van e-sigaretten. De resultaten laten zien dat sociaal cognitieve factoren van invloed zijn bij keuzes rondom rookgedrag en het gebruik van e-sigaretten. Hierbij valt te denken aan kennis, de perceptie van de kans en ernst van e-sigaretten in vergelijking met sigaretten, vertrouwen in informatie over de e-sigaret, houding en sociale normen over het gebruik van e-sigaretten, en deliberatie.

Hoofdstukken 4 en 5 beschrijven de resultaten van een kwantitatieve vragenlijst naar productkenmerken van e-sigaretten en sociaal cognitieve factoren gerelateerd aan de keuzes rondom rookgedrag. De resultaten geven aan dat van alle productkenmerken die in hoofdstuk 4 zijn onderzocht (bijvoorbeeld het kunnen aanpassen van nicotinegehalten of aanpasbare instellingen van e-sigaretten), de variatie aan smaken van e-vloeistoffen voor de e-sigaret door zowel niet-gebruikers als gebruikers als het meest aantrekkelijke aspect van e-sigaretten werd bevonden. Zo gaven niet-gebruikers de voorkeur aan menthol/ munt en zoete e-vloeistof smaken in vergelijking met andere smaakcategorieën. Rokers en 'dual users' gaven de voorkeur aan tabak en menthol/munt e-vloeistof smaken in vergelijking met andere smaakcategorieën. E-sigaretgebruikers gaven de voorkeur aan zoete smaken en fruitsmaken in vergelijking met andere smaakcategorieën. Bovendien laten de resultaten zien dat dual- en exclusieve e-sigaretgebruikers verschillende smaakvoorkeuren hadden met betrekking tot e-vloeistoffen terwijl beide gebruikersgroepen van e-sigaretten zijn.

Hoofdstuk 5 presenteert de kwantitatieve verkenning van onderscheidende kenmerken tussen de twee e-sigaretgebruikersgroepen. De resultaten geven aan dat zeven kenmerken belangrijk zijn om met $86 \%$ zekerheid een 'dual user' te onderscheiden van een exclusieve e-sigaretgebruiker:

1) Vergeleken met exclusieve e-sigaretgebruikers, voelden 'dual users' zich meer verbonden met andere rokers; 
2) De hoeveelheid tabak sigaretten die in het verleden werd gerookt is hoger onder exclusieve e-sigaretgebruikers dan de hoeveelheid die momenteel werd gerookt door 'dual users';

3) De eigen-effectiviteit om te stoppen met 'dampen' en roken was lager bij 'dual users';

4) Exclusieve e-sigaretgebruikers vonden de sigaret vaker onaantrekkelijk dan 'dual users';

5) E-sigaretgebruikers hadden een positievere houding ten opzichte van 'dampen' dan 'dual users';

6) 'Dual users' zagen meer belemmeringen rondom de verkrijgbaarheid van e-sigaretten;

7) 'Dual users' hadden een sterkere intentie om te stoppen met 'dampen' dan exclusieve e-sigaretgebruikers (hoofdstuk 5).

De bevindingen van deel I vergroten de kennis over factoren die een mogelijke rol spelen bij de keuze rondom een één na beste keuze: het gebruik van de e-sigaret.

\section{Deel II Onderzoek naar factoren gerelateerd aan de keuze rondom vaccinaties voor kinderen}

In deel II gaan de hoofdstukken 6 - 7 in op de keuze van ouders rondom vaccinaties van kinderen. Hoofdstuk 6 presenteert resultaten van een kwalitatieve focusgroep studie naar factoren die een rol spelen bij de keuze rondom vaccinatie voor kinderen. De resultaten geven aan dat verschillende sociaalcognitieve factoren mogelijk een rol spelen bij de keuze om vaccinaties voor kinderen al dan niet te accepteren, te weigeren of gedeeltelijk te accepteren. Het gaat daarbij om de aspecten kennis, de perceptie van de kans en ernst van infectieziekten en bijwerkingen, vertrouwen in informatie, houding, verwachte spijt, sociale normen en deliberatie.

Hoofdstuk 6 laat zien dat ouders die hun kind gedeeltelijk vaccineren een lage perceptie hebben van de risico's rondom de infectieziekten en een hoge perceptie van de risico's rondom de bijwerkingen van vaccins. Ook ervaren zij weinig sociale steun vanuit hun omgeving met betrekking tot de keuze over vaccineren en rapporteren zij weinig vertrouwen te hebben in de (informatie van de) consultatiebureaus. Ouders die hun kind gedeeltelijk vaccineren meldden een weloverwogen keuze te hebben genomen en beschreven het deliberatieproces als uitgebreid, tijdrovend en moeilijk. Ouders die het Rijksvaccinatieprogramma wel of helemaal niet volgen gaven aan niet veel aandacht te hebben besteed aan de optie om hun kind gedeeltelijk te vaccineren van kinderen (hoofdstukken 6 en 7).

Hoofdstuk 7 presenteert de resultaten van een kwantitatieve studie naar factoren die verband houden met de keuze rondom vaccinatie voor kinderen. 
De resultaten tonen aan dat ouders die het Rijksvaccinatieprogramma volgen de kans op bijwerkingen van vaccins als lager inschatten dan de kans op het krijgen van een infectieziekte als zij (sommige) vaccins zouden weigeren. Ouders die vaccins weigeren of sommige vaccins accepteren gaven aan dat de kans op bijwerkingen door een vaccinatie hoger is dan de kans voor het kind om een infectieziekte op te lopen. Ouders die het Rijksvaccinatieprogramma volgen verwachtten een hogere mate van spijt met betrekking tot de negatieve gevolgen van infectieziekten als gevolg van het weigeren van vaccinaties. Ter vergelijking, ouders die alle vaccinaties weigeren of ouders die gedeeltelijk vaccineren verwachten een hogere mate van spijt met betrekking tot de mogelijke bijwerkingen voor het kind van vaccins als gevolg van het volgen van het Rijksvaccinatieprogramma. Alle ouders rapporteerden een positieve sociale norm die uitgaat van het zijn van een voorstander inzake het accepteren van vaccinaties voor kinderen. Het vertrouwen in het Rijksvaccinatieprogramma was hoog bij ouders die dit programma volgen, maar matig bij ouders die alle vaccinaties weigeren of gedeeltelijk vaccineren. Ouders die gedeeltelijk vaccineren ondervonden meer belemmeringen op het gebied van het maken van een keuze rondom vaccineren dan ouders die alle vaccinaties weigeren of accepteren. Wat betreft twijfels met betrekking tot de keuze, rapporteerden ouders die alle vaccinaties accepteren zich niet geïnformeerd te voelen. Ouders die alle vaccinaties weigeren gaven aan onvoldoende ondersteuning te ontvangen van hun omgeving. Ouders die gedeeltelijk vaccineren gaven aan onzeker te zijn over de keuze. De bevindingen van deel II geven inzicht in de factoren die verband houden met de één na beste keuze: het gedeeltelijk (laten) vaccineren van kinderen.

\section{Deel III Besluitvorming}

In deel III - hoofdstuk 8 - worden de resultaten gepresenteerd van twee kwantitatieve studies naar rookgedrag en vaccinatie voor kinderen. Het doel van deze studies is om te onderzoeken of de keuzes rondom rookgedrag en vaccinatie voor kinderen voldoen aan criteria (voldoende kennis en deliberatie en een positieve houding t.a.v. het eigen gedrag) van geïnformeerde besluitvorming. De resultaten laten zien dat beslissingen over rookgedrag en vaccinatie bij kinderen in het algemeen niet voldeden aan ten minste één van de criteria voor geïnformeerde besluitvorming.

Participanten die kozen voor de aanbevolen gezondheidsoptie (dat wil zeggen niet-gebruikers en ouders die het Rijksvaccinatieprogramma volgen) rapporteerden relatief weinig deliberatie rondom de gemaakte keuze en/of de alternatieve keuzeopties.

De overtuigingen van participanten die gekozen hebben voor de niet aanbevolen en één na beste keuze kwamen niet overeen met het wetenschappelijk bewijs (hoofdstuk 3, 6 en 8). Deze overtuigingen zijn een mogelijke verklaring waarom 
deze participanten niet voldeden aan het criterium van 'voldoende kennis'. Participanten die voor de één na beste keuze optie kozen rapporteerden niveaus van kennis, houding en deliberatie die vallen tussen participanten die voor de aanbevolen en de niet-aanbevolen gezondheidsoptie kozen. Terwijl vaccinweigeraars hun keuze grondig hebben overwogen en positief waren over de gemaakte keuze, rapporteerden rokers een lage deliberatie en waren rokers negatief over hun eigen gedrag. Participanten die kozen voor de één na beste keuze waren niet uitgesproken negatief tegenover de aanbevolen gezondheidsoptie, maar opvallend was dat de e-sigaretgebruikers uitgesproken negatief waren over roken (dat wil zeggen de niet-aanbevolen optie).

Met betrekking tot participanten die voor de niet-aanbevolen optie gekozen hebben laten de resultaten zien dat vaccinweigeraars hun keuze grondig hadden overwogen en positief waren over de gemaakte keuze, terwijl rokers een lage deliberatie blijken te melden en dat rokers negatief waren over hun eigen gedrag.

\section{Algemene discussie}

In de algemene discussie in hoofdstuk 9 wordt opgemerkt dat verder onderzoek nodig is om te onderzoeken hoe men het beste kan communiceren over 'één na beste keuzes', zoals e-sigarettengebruik en gedeeltelijk vaccineren. Hoewel niet roken of niet 'dampen' en het volgen van het Rijksvaccinatieprogramma als het meest gunstig voor de volksgezondheid kan worden beschouwd, heeft e-sigaretgebruik of gedeeltelijk vaccineren potentiële individuele en volksgezondheidsvoordelen in vergelijking met traditioneel roken of het weigeren van alle vaccins. E-sigaretgebruik en gedeeltelijk vaccineren zijn niet per se gunstig voor de individuele gezondheid of zonder risico. Daarom worden deze één na beste keuzes niet aanbevolen vanuit het perspectief van de volksgezondheid. Dergelijk onderzoek zou het effect, de waardering en de aanvaardbaarheid kunnen testen van het verstrekken van informatie over alle gezondheidsopties rondom de besluitvorming. Ook is het dan mogelijk om de intentie om de aanbevolen optie te accepteren of te weigeren te testen bij het communiceren over alle drie de opties in vergelijking met de intentie om de aanbevolen optie te accepteren of te weigeren bij standaardinformatie.

Wat betreft het communiceren over de aanbevolen en andere opties, is het belangrijk om duidelijk te verwoorden welke specifieke doelen volksgezondheidsdeskundigen willen bereiken. Zij kunnen het als hun doel beschouwen om wetenschappelijke informatie te verstrekken zonder advies of beslissingsondersteuning. Een ander doel kan zijn om geïnformeerde besluitvorming te ondersteunen, hoewel het gevolg hiervan kan zijn dat meer mensen de niet-aanbevolen of één na beste keuze optie zullen kiezen in plaats van de aanbevolen optie, waardoor de risico's voor de volksgezondheid toenemen. Als alternatief kunnen deskundigen kiezen om een meer sturende benadering te 
volgen om zoveel mogelijk mensen de aanbevolen gezondheidsoptie te laten kiezen en de winst voor de volksgezondheid te vergroten. Met dit doel kunnen verschillende motivatietechnieken (persuasieve technieken) worden toegepast om het publiek in de gewenste richting te sturen. Volksgezondheidsdeskundigen en beleidsmakers kunnen op basis van de doorslaggegeven effecten van communiceren over alle drie de opties, een weloverwogen keuze maken over het aanpassen en het doel van de huidige communicatiestrategieën. 



\section{Curriculum Vitae}





\section{Curriculum Vitae}

Kim Romijnders was born on January 14, 1992 in Nijmegen, the Netherlands. After graduating high school (A-level, focus on science, health, technology, and Latin) in 2010, she started with the bachelor European Public Health at Maastricht University in Maastricht. After receiving her bachelor's degree, Kim continued with her masters Global Health and Health Education and Promotion in 2013.

During the period of 2013 - 2015, Kim worked as a research assistant at the University of Texas at Houston, USA. Here she was responsible for research and the project administration of two projects and, one quantitative survey and one qualitative program evaluation. She investigated the mental health of LGTBQ youth and the sexual health of men who have sex with men. Upon her return, she started an elective of human rights and trade at Thammasat University in Bangkok, Thailand. She finished both masters in 2015.

In the beginning of 2016, Kim started with her PhD project titled: risk communication about alternative health strategies at the Department of Health Education and Health Promotion at the Faculty of Health, Medicine and Life Sciences of Maastricht University (UM), and the Centre of Health Protection, at the Dutch National Institute for Public Health and the Environment (RIVM) in the Netherlands. She completed her PhD project under the supervision of Dr. Ir. Liesbeth Mollema (RIVM), Dr. Liesbeth van Osch (UM), Dr. Reinskje Talhout (RIVM), and Prof. Dr. Hein de Vries (UM). During her PhD project, she carried out several studies investigating the decisions about smoking behavior and childhood vaccinations. The results of these studies are described in this thesis. Currently, she researches the impact on daily life of a hypothetical HIV cure among people living with HIV and people at risk for HIV at the University Medical Center in Utrecht. 

Publication list 


\section{Publications in this thesis}

Romijnders KAGJ, van Osch L, de Vries H, Talhout R. Perceptions and Reasons Regarding E-Cigarette Use among Users and Never-users: A Narrative Literature Review. Int J Environ Res Public Health. 2018;15(6).

Romijnders KAGJ, van Osch L, de Vries H, Talhout R. A Deliberate Choice? Exploring the Decision to Switch from Cigarettes to E-Cigarettes. Int J Environ Res Public Health. 2019;16(4).

Romijnders KAGJ, van Seventer SL, Scheltema M, van Osch L, de Vries H, Mollema L. A deliberate choice? Exploring factors related to informed decision-making about childhood vaccination among acceptors, refusers, and partial acceptors. Vaccine. 2019;37:5637-44.

Romijnders KAGJ, Pennings JLA, van Osch L, de Vries H, Talhout R. A Combination of Factors Related to Smoking Behavior, Attractive Product Characteristics, and Socio-Cognitive Factors are Important to Distinguish a Dual User from an Exclusive E-Cigarette User. Int J Environ Res Public Health. 2019;16(21).

Romijnders KAGJ, Krusemann EJ, Boesveldt S, De Graaf C, De Vries H, Talhout $\mathrm{R}$. The relation between flavors as a product characteristic and determinants of decision-making about e-cigarette use. Int J Environ Res Public Health. 2019;16(23).

Romijnders KAGJ, Timmermans, D, Pennings, JLA, de Vries, H, van Osch, L, Talhout, R, and Mollema, L. Exploring differences in knowledge, attitude, and deliberation of the healthiest, unhealthiest, and alternative options: an illustration based on childhood vaccination and (non) smoking or vaping (Submitted, 2020).

Romijnders KAGJ, Osch, L, de Vries, H, and Mollema, L. Deciding on childhood vaccination: differences in decisional conflict and socio-cognitive factors between parents who accepted, refused, and partially accepted childhood vaccination. (Submitted, 2020) 


\section{Additional Publications}

Romijnders KAGJ, Nyoni JE, Ross MW, et al. Lubricant use and condom use during anal sex in men who have sex with men in Tanzania. Int J STD AIDS. 2016;27(14):1289-1302.

Romijnders KAGJ, Wilkerson JM, Crutzen R, et al. Strengthening Social Ties to Increase Confidence and Self-Esteem Among Sexual and Gender Minority Youth. Health Promot Pract. 2017;18(3):341-347.

Wilkerson JM, Schick VR, Romijnders KAGJ, et al. Social Support, Depression, Self-Esteem, and Coping Among LGBTQ Adolescents Participating in Hatch Youth. Health Promot Pract. 2017;18(3):358-365.

Wilkerson JM, Lawler SM, Romijnders KAGJ, et al. Exploratory Analyses of Risk Behaviors Among GLBT Youth Attending a Drop-In Center. Health Educ Behav. 2018;45(2):217-228.

King, B, Morphett, K, O'Connor, R, Fielding, K, Gartner, C, Romijnders, KAGJ, Talhout R, and Borland R. "it's all the other stuff!" How smokers understand "chemicals" in cigarettes and cigarette smoke. (submitted, 2019). 

Acknowledgements 
And now, the end is near...

Mijn dankwoord begin ik door mijn promotor, Hein, te danken. Het was mij meteen duidelijk dat jij vol zit met ideeën, dat jij overal kansen ziet en met passie over onderzoek praat. Jouw enthousiasme voor gezondheid, gedrag en onderzoek waren een inspiratie voor mij als onderzoeker. Naast onderzoek waren er altijd verhalen over laser gamen, fotografie, stijldansen of wijn om te bespreken. Ik heb veel van je geleerd en wil je dan ook bedanken voor het bieden van deze uitdaging.

Mijn drie copromotoren wil ik bedanken voor alle inspiratie tijdens dit proces. Ik heb een enorme bewondering voor jullie en het is mij dierbaar dat jullie mij gemotiveerd hebben om te groeien als onderzoeker. Dit proefschrift was er niet geweest zonder de passie die jullie over konden brengen op mij.

Reinskje, met jouw enthousiasme en open houding ben jij gedurende deze vier jaar iemand geweest waar ik altijd bij terecht kon met mijn wetenschappelijke problemen. Ik heb enorm genoten van onze samenwerking. Ik bewonder jouw aanpak van problemen en enorme passie voor het werk. Jij hebt mij altijd aangemoedigd om problemen die wij tegenkwamen op een andere manier te benaderen. Jij hebt mij geleerd om te kijken hoe ik met mijn onderzoek impact kon maken. Dank voor alle steun, of het nu ging om het plannen van een reis naar universiteiten in de VS of een presentatie voor de Staatssecretaris. Ik ben jou erg dankbaar voor alle kansen.

Liesbeth van Osch, dankzij jouw ontzettend geduldige en zorgzame persoonlijkheid heb ik gedurende deze vier jaar op jou kunnen steunen. Hoewel ik in het begin moest wennen aan de vraag "Enne?", zijn wij geen enkel overleg begonnen zonder dat jij aan mij vroeg hoe het met mij ging. Ik heb jou leren kennen als een doordachte, oprechte, bescheiden en vooral zorgzame vrouw. Op deze manier heb jij mij ook altijd begeleid, waar ik je enorm voor wil bedanken. Bedankt voor het altijd met mij meedenken en mij altijd te voorzien van een gedegen plan van aanpak.

Liesbeth Mollema, met jouw energie, hartelijkheid en openheid heb ik deze vier jaar altijd het gevoel gehad dat je voor mij klaar stond als ik jou nodig had. Jij wist mij altijd op een pragmatische wijze richting te geven in het zoeken naar oplossingen. Ik heb al mijn ideeën met jou uit kunnen pluizen en ik kon met al mijn vragen bij jou terecht. Dit zijn slechts enkele redenen waarom ik heb genoten van onze samenwerking. Ik heb een enorme bewondering voor jouw doorzettingsvermogen, compassie en sterke werkethiek. Jij laat je door niets uit het veld slaan en staat altijd voor iedereen klaar. Ik keek altijd uit naar onze overlegmomenten en vond het leuk om elkaar beter te leren kennen. Ik heb het altijd erg gewaardeerd dat jij aangaf dat ik goed bezig was, daarom wil ik jou in het bijzonder bedanken voor alle aanmoediging en steun. 
Zonder deelnemers heb je natuurlijk geen resultaten, dus ook de deelnemers van alle studies, hartelijk dank! Graag wil ik ook mijn leescommissie bedanken. Ik ben jullie erg dankbaar voor het lezen van mijn proefschrift. Dank voor de secretariële steun Janet, Irene, Ilse, Kim, Denise, Patricia en Daisy. Organisatorisch was het mij niet gelukt om te werken met drie afdelingen zonder jullie. Dank voor het geduld, doorschakelen en beantwoorden van al mijn vragen. Ook dank aan mijn coauteurs. Jeroen Pennings bedankt voor alle statistische expertise die je altijd paraat hebt en zo snel wilde delen. Ook wil ik Danielle Timmermans bedanken. Door jouw advies kon ik geïnformeerde keuzes maken tijdens mijn promotietraject.

Graag wil ik alle collega's bedanken bij het RIVM voor de gezelligheid, koffiemomenten en afdelingsuitjes. Vanaf mijn eerste dag heb ik mij bijzonder welkom gevoeld, dank voor de gastvrijheid! In het bijzonder wil ik een aantal mensen bedanken. Erna ik wil jou bedanken voor de constante bron van enthousiasme de afgelopen jaren. Ik ben erg dankbaar voor de herinneringen die wij gemaakt hebben de afgelopen drie jaar, waarvan Peru natuurlijk de mooiste is. Victoria, jij bent de meest georganiseerde persoon die ik heb leren kennen. Dank dat je altijd tijd hebt gemaakt om koffie samen te drinken en voor het luisteren naar de nodige frustraties. Ik hoop dat jij altijd jouw energie in het leven zal behouden. Gina dank voor de oprechtheid en zorgzaamheid waarmee jij altijd naar ons allemaal luistert. Astrid dank voor de vrolijkheid waarmee jij altijd het kantoor binnen komt. Vic, Gina, Astrid en Charlotte, ik wil jullie speciaal bedanken voor de leuke weekendjes weg. Coen, dank voor alle keren dat jij geluisterd hebt. Lieve GZB-aio's, ik wil jullie vooral bedanken dat ik de mijlpalen met jullie kon vieren en de frustraties met jullie kon delen. Jullie hebben veel gezelligheid toegevoegd aan deze vier jaar. Stella, Laura, Alessandro \& Christy I also want to thank you for providing the much-needed distractions from work: coffee, tea, lunches, and walks. Ook wil ik de Mannenliefde groep (Tom, Linda, Sander, Joram, Thomas, Marion, Birthe en Amber) bedanken voor mijn introductie in gezelligheid met collega's! Super bedankt voor alle goede gesprekken tijdens en na werktijd. Mijn voormalige studenten Marlieke, Yvette, Stephne en Manon wil ik ook bedanken. Mijn werk is er beter op geworden omdat ik op jullie kon vertrouwen. De vaste lunchgroep wil ik danken voor de gezelligheid tijdens de vele lunches: Jan, Jantine, Anne, Jeroen, Hedwig en Yvonne. Collega's bij GVO, dank voor het altijd warme onthaal in Maastricht. I would also like to thank Suchitra Krishnan-Sarin, Tom Eissenberg, and Noel Brewer for providing me with the opportunity to visit and learn from you. Gerjo Kok, Rik Crutzen, Mike Ross, and Mike Wilkerson, my passion for research got a kick-start because of you. Thank you for showing me what research entails.

Lieve vrienden en familie, nu richt ik mij tot jullie. Als mijn belangrijkste bron van inspiratie, energie en support wil ik jullie danken. Voor de mooie momenten, de steun, het begrip, de belangstelling en de aanmoediging. Aan iedereen die ik niet persoonlijk benoem, wil ik zeggen dat ik jullie niet vergeten ben. 
Charlotte, wat een reis is het geweest lieverd: Portugal, Nice, Dublin, Champagne, DC, San Francisco, New Haven en Richmond. Jij hebt mij vanaf dag één gesteund. Ik ben zo trost op wat jij allemaal bereikt en hoe jij het telkens weer allemaal voor elkaar krijgt. Jij was mijn steun en balans tijdens deze vier jaar, de eerste om te bellen toen ik mijn thesis ingeleverd had en als paranimf sta je naast mij wanneer ik deze mag verdedigen. Ik hoop dat je weet hoeveel jouw vriendschap voor mij betekent.

Lieve Henk, Mirian, Liza en Floor dank dat ik mij altijd welkom voel bij jullie en dat jullie altijd voor ons klaar staan.

Liefste dames, wat ben ik ontzettend dankbaar voor onze vriendschap. Liefste Marieke jij bent de meest zorgzame en onbaatzuchtige vriendin die ik mij maar kan wensen. Samen met Patrick sta jij altijd voor ons allemaal klaar. Jij denkt eerst aan een ander en dan aan jezelf. Jij hebt altijd naar mijn frustraties en mijlpalen geluisterd en er mede voor gezorgd dat ik meer bij de mijlpalen stil stond dan bij de frustraties. Liefste Judith, jij bent degene die altijd kalm blijft. Jouw eerlijkheid en relativeringsvermogen zijn altijd de welkome balans in onze (groeps)gesprekken. Ik heb veel bewondering voor hoe jij altijd optimistisch bent en blijft doorzetten. Met Steven en jou erbij zijn de discussies altijd net dát beetje leuker! Liefste Lies, al meer dan 15 jaar behoor jij tot mijn inner circle. Jij geeft mij altijd dat duwtje wat ik nodig heb om te bereiken wat ik wil. Jij bent loyaal, bevlogen en hebt een super wilskracht. Ik ben enorm trots op jou en alles wat je bereikt, maar ik ben vooral trots op hoe jij vecht voor wat jouw lief is. Jij staat altijd voor mij klaar en gaat voor ons allemaal door het vuur. Jij bent geen vriendin, maar familie. Ik ben enorm trots dat jij met mijn verdediging naast mij staat als mijn paranimf. By bringing Alex back as the ultimate souvenir from San Francisco and raising a puppy you add to our family and I wouldn't have it any other way. - Lieverds jullie hebben mijn wereld vergroot. Ik hoop dat wij herinneringen met elkaar blijven maken!

Voor de altijd lieve woorden wil ik opa en oma bedanken, 'I did it my way'. Jullie hebben vanaf mijn eerste dag voor mij klaar gestaan, ik ben en zal jullie nooit vergeten. Lieve mam en pap, dank voor de onbaatzuchtigheid waarmee jullie alles voor Britt en mij hebben gedaan. Ik zie het en waardeer het meer dan dat ik uit kan drukken. Dank dat jullie mij (zowel letter als figuurlijk) opvangen als ik val en mij uit blijven dagen. Dank dat jullie mij opgevoed hebben om in mijzelf te geloven en te weten dat ik het kan! Vooral bedankt dat jullie mij opgevoed hebben tot een nieuwsgierige, eigenwijze, loyale en warme doorzetter. Dank dat jullie mij de onderzoeker hebben gemaakt die ik vandaag de dag ben. Ik houd van jullie. Lieve Britt, mijn eerste herinnering is er een van jou! Jij bent het beste verjaardagscadeau dat ik ooit gehad heb. Blijf altijd wie je bent! Ik ben ontzettend trots op je. Je bent aanhoudend en ontwapend tegelijkertijd. I love you to the moon and back! 
Lieve Niels, wat ben ik vooral dankbaar voor jou in mijn leven. Dank dat ik altijd mijn PhD perikelen bij jou kwijt kon. Jij staat altijd voor mij klaar, bent geduldig, liefdevol en zorgzaam. Wat kan ik er veel van leren hoe jij je kunt herpakken en hoe positief jij in het leven staat! Ik wil je bedanken dat jij alles leuker maakt en dat jij mij een veilige thuishaven geeft zodat ik kan dromen. Jij bent mijn ultieme geïnformeerde keuze. Ik houd van jou.

Als ik dan terugblik op de afgelopen jaren en kijk wat ik nu heb bereikt, dan had ik het niet op deze manier kunnen doen, er zo mijn eigen draai aan kunnen geven, zonder jullie allen.

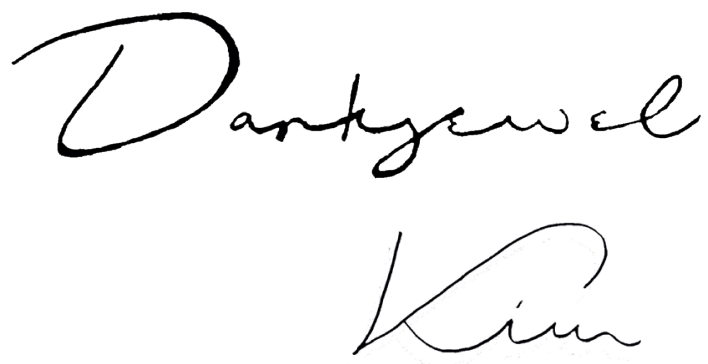



Appendices 


\title{
Appendix 1 Search Strategy for OvidMedline ${ }^{\circledR}$
}

\author{
Chapter 2 \\ Perceptions and Reasons Regarding E-Cigarette Use among Users and Non-Users: \\ A Narrative Literature Review

\begin{tabular}{lll}
\hline Data Source & Provider/Interface & Ovid \\
& Database & Medline ${ }^{\circledR}$ \\
& Date searched & $09-02-2016$ \\
& Database update & $09-02-2017$ \\
& Search developer(s) & Wim ten Have \& Kim Romijnders \\
Limiters & English only? (default is & y \\
\& other & "y") & \\
information & Date restrictions & 1950-present
\end{tabular}

Note: an asterisk is used as a wildcard symbol to broad the search by including words that start with the letters before the asterisk.

\section{Search Strategy}

1 (electr* adj (cigar* or nicotine)).tw. (803)

2 ((electronic or electrically) adj3 (cigar* or nicotine)).tw. (852)

3 (e-cig* or ecig* or e-cigarette* or ecigarette* or e-nicotine* or enicotine*).tw. (846)

4 electronic cigarettes/(439)

51 or 2 or 3 or $4(1316)$

6 (initiation or motivation* or motives or reason* or attitude* or belief* or expectan* or understanding or knowledge or reactions or awareness or perception* or opinion or views or debate* or discussion* or image or popularity or desirab* or demand).ti. (409599)

7 ((frequency adj5 ("use" or usage)) or (real-world adj5 ("use" or usage))).tw. (12469)

8 (("use" or usage) and (frequency or prevalence or among or change* or emerg* or factors or associations or trends or traditional or conventional or locations)).ti. (31844)

9 motivation/or perception/or awareness/or attitude/or attitude to health/or public opinion/or consensus/or focus groups/or social desirability/or consumer behavior/ (252874)

10 (internet or social media or Facebook or Twitter or YouTube).ti. or internet/ or social media/(59745)

115 and ( 6 or 7 or 8 or 9 or 10) (300)

12 (vaping or behavio? $r^{\star}$ ).ti. or (smoking sensation or smoking characteristics or sensation seeking).tw. or sensation/ or smoking/px or electronic cigarettes/px (247982)

135 and $12(135)$

table continues 


\section{Search Strategy}

14 harm reduction.ti. or harm reduction.ot. or harm reduction/ (2185)

155 and 14 (68)

16 (relative harm or product harm or cessation).ti. or (relative harm or product harm or cessation).ot. (11395)

17 smoking cessation/ or "tobacco use cessation"/ or health behavior/ or risk reduction behavior/ or treatment outcome/ (768920)

18 (effect or effects or efficacy or effectiv* or benefit or evidence* or consequences or impact or success* or public support or comparison or compared or control policies or strateg* or cochrane or foundation).ti. (2501872)

195 and (16 or 17$)$ and 18 (58)

20 (marketing or advertis* or commercials or communicating or communicat*).ti. (60382)

21 marketing/ or commerce/ or communication/ or exp advertising as topic/ or advertisements.pt. (102541)

225 and (20 or 21) (131)

23 (policy or policies or strateg* or public health or legislat* or regulat* or guideline* or government* or ban or bans or taxes or tax or taxation*).ti. (635686)

24 health policy/ or public policy/ or public health/ or social control policies/ or social control, formal/ or government regulation/ or legislation, medical/ or smoke-free policy/ or air pollution, indoor/lj or workplace/lj or restaurants/lj or smoking/lj or taxes/ or health promotion/ (235485)

25 (guideline or legislation).pt. (15644)

265 and (23 or 24 or 25) (274)

27 (effect or effects or efficacy or effectiv* or benefit or evidence* or consequences or impact or success* or public support or comparison).ti. (2373199)

$28 \quad 26$ and $27(24)$

29 (tobacco product*.ti. or tobacco products/) and (harm*.ti. or harm*.ot. or harm reduction/) (72)

3011 or 13 or 15 or 19 or 22 or 28 or $29(605)$

31 (english or dutch).lg. (20815326)

3230 and 31 (591)

33 (letter or comment or news).pt. (1342230)

3432 not 33 (505)

35 remove duplicates from 34 (498) 


\section{Appendix 2 Decision tree of Exclusion criteria in hierarchical order.}

\section{Chapter 2}

Perceptions and Reasons Regarding E-Cigarette Use among Users and Non-Users: A Narrative Literature Review

\section{\#1 not e-cigarette}

Does the article describe a subject which Does the article describe tobacco, smoking is not the electronic cigarette (e-cigarette), or alternative tobacco products without vaping/vapor? often "e-cigarette/vaping" mentioning the e-cigarette?

etc. is not mentioned in the title?

Does the article describe a subject which is Does the article describe a subject which is Yes? EXCLUDED based on exclusion criterion, \#1.

No? Move on to exclusion criterion \#2.

\section{\#2 toxicology and vaping behavior}

Does the article discuss the chemical composition of alternative tobacco products (e-cigarettes are thus clearly mention (otherwise excluded at \#1)?

Does the article describe the physiological response to e-cigarette use?

Does the article describe toxicological effects of e-cigarette use?

Does the article describe the use of nonhuman subjects? psychopharmacological properties, chemical characteristics, also testing for toxicity or safety, toxicological properties pharmacological attributes of nicotine, components of e-liquids (Gas

Chromatography-Mass Spectrometry analyses),

mention aerosol, air quality,

Topography,

Effectiveness (not in relation to harm reduction) of nicotine delivery

Safety/risks of an e-cigarette (use),

or ingredients,

burden of disease or

innovations regarding e-cigarettes?

health as an outcome,

nicotine health risks,

lung disease,

cancer,

mental illness,

blood levels

nicotine intake,

cravings (not as a subjective reasons

given for e-cigarette use, but tested

(e.g., experimental setting)

comorbidity/relation with disease/

mental

dependency (i.e., drug/alcohol use in

combination with e-cigarette use)

Yes? EXCLUDED based on exclusion criterion \#2.

No? Move on to exclusion criterion \#3. 


\section{\#3 opinion article}

Does the title or abstract revolve around or For example, feelings about the e-cigarette phrased in a way an opinion or stands with debate, or opinions about the e-cigarette regard to the e-cigarette? or titles that suggests an opinion towards the e-cigarette, or analyzing debates/ opinions? Usually, the title is framed as a question (e.g., "E-cigarettes: a nicotine gateway?")

Yes? EXCLUDED based on exclusion criterion \#3

No? Move on to exclusion criterion \#4

\section{\#4 market or marketing}

Does the article describe the market of alternative tobacco products (specifically mentioning e-cigarettes)?

Does the article describe marketing/ advertising of alternative tobacco products (specifically mentioning e-cigarettes)?

Examples
Not related to participants describing awareness of e-cigarettes as a result of marketing strategies

\author{
Market trends, \\ Sale points of e-cigarettes, \\ Retail, \\ Types of e-cigarettes on the market, \\ The increase in sales of e-cigarettes \\ The role of advertising on use
}

Yes? EXCLUDED based on exclusion criterion \#4.

No? move on to exclusion criterion \#5.

\section{\#5 harm reduction}

Is the article about harm reduction/ smoking cessation?

\section{EXCEPTION: But Not Perceptions Of Study Participants Regarding Perceptions Of Harm Or Perceived Effectiveness As Smoking Cessation.}

Other than participants describing the use of an e-cigarette as a form of harm perceptions or as a reason why the use the e-cigarette?

Does the article discuss smoking cessation, . with the e-cigarette as a tool

Measured effectiveness as smoking cessation aid

Evaluated the intention to quit smoking using e-cigarettes

Does the article discuss the public health debate surround the e-cigarette?

Yes? EXCLUDED based on exclusion criterion 5\#

No? move on to exclusion criterion \#6 
\#6 e-cigarette regulation

Does the article revolve around policy work/regulation/tobacco control/policy recommendations?
Asking for policy change,

Describes policy change with regard to the e-cigarette,

The e-cigarette as a form of harm reduction policy (other than users describing perceptions of harm), The e-cigarette in relation to tobacco control?

Yes? EXCLUDED based on exclusion criterion \#6

No? move on to exclusion criterion \#7

\section{\#7 subjective reports}

Does the article describe the use of the e-cigarette by as rehabilitation?

Does the article describe the use of e-cigarettes in institutionalized participants (not stop smoking services)

Does the article describe patterns of awareness?

Does the article describe patterns of use?
The use of e-cigarettes in out-patient centers,

Psychiatric clinics etc.

How to use the e-cigarette?

Opinion on use other than users' opinions themselves

No subjective reports of perceptions or reasons provided

Only description of awareness and patterns of use.

Alternative use for other drugs, such as marijuana.

Yes? EXCLUDED based on exclusion criterion \#7

No? move on to exclusion criterion \#8

\section{\#8 gateway effect}

Does the article describe the uptake of e-cigarettes or e-cigarettes as a gateway to other tobacco/drug products by individuals?

Does the article describe the risk factors leading to uptake of e-cigarettes without describing subjective reports of perceptions and reasons?

Yes? EXCLUDED based on exclusion criterion \#8

No? move on to exclusion criterion \#9

\section{\#9 not an article}

Is it not an article, but newspaper dissertations, narratives, commentaries, gray literature, and editorials were excluded etc.?

Yes, fill in "NO", and as exclusion criterion \#9

No? move on to exclusion criterion \#10

No? Fill in "MAYBE, appropriate for inclusion" (End of exclusion criteria screening, continue for full text)
EXCEPTION: Not the perception of participants that e-cigarettes are a gateway drug

EXCEPTION: Not if risk factors are the perceptions \& reasons provided by subjective reports of participants 


\section{\#10 conflict of interest}

Is there a conflict of interest?

Financial relationship questionable

Related to the tobacco industry

\section{\#11 age restriction apply}

Does the article include samples with unclear age restrictions?

Does the article include a sample with overlap of adults and adolescents

The article mentions age restriction for grades, however, not specific for age. If the grade falls well within the age restriction of $<18$, that age restriction do not apply. If students can be 18 or 19. Age restriction apply

- Age 15 to 19 years old

. 17 to 21 years old

- Etc. 


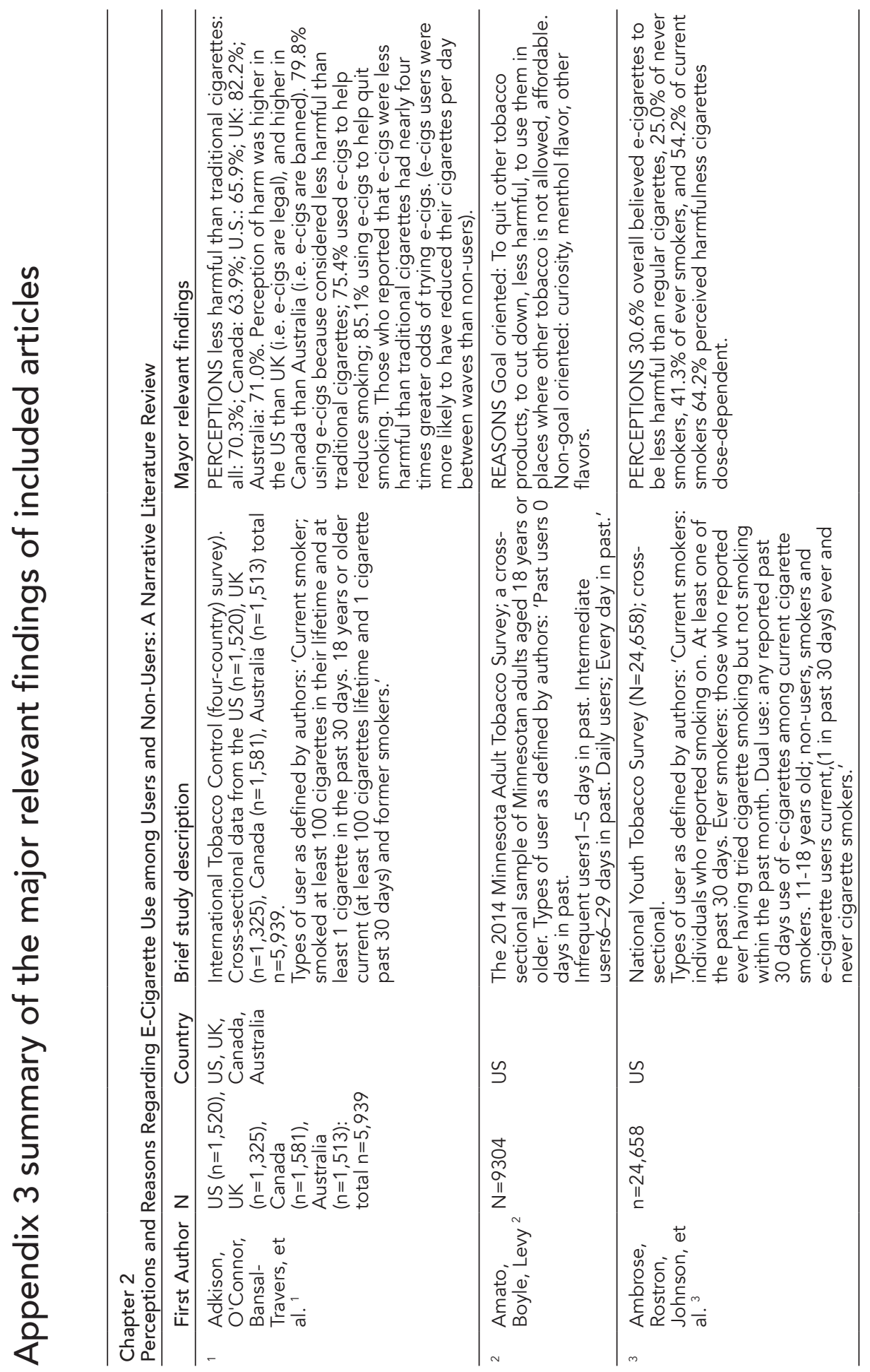




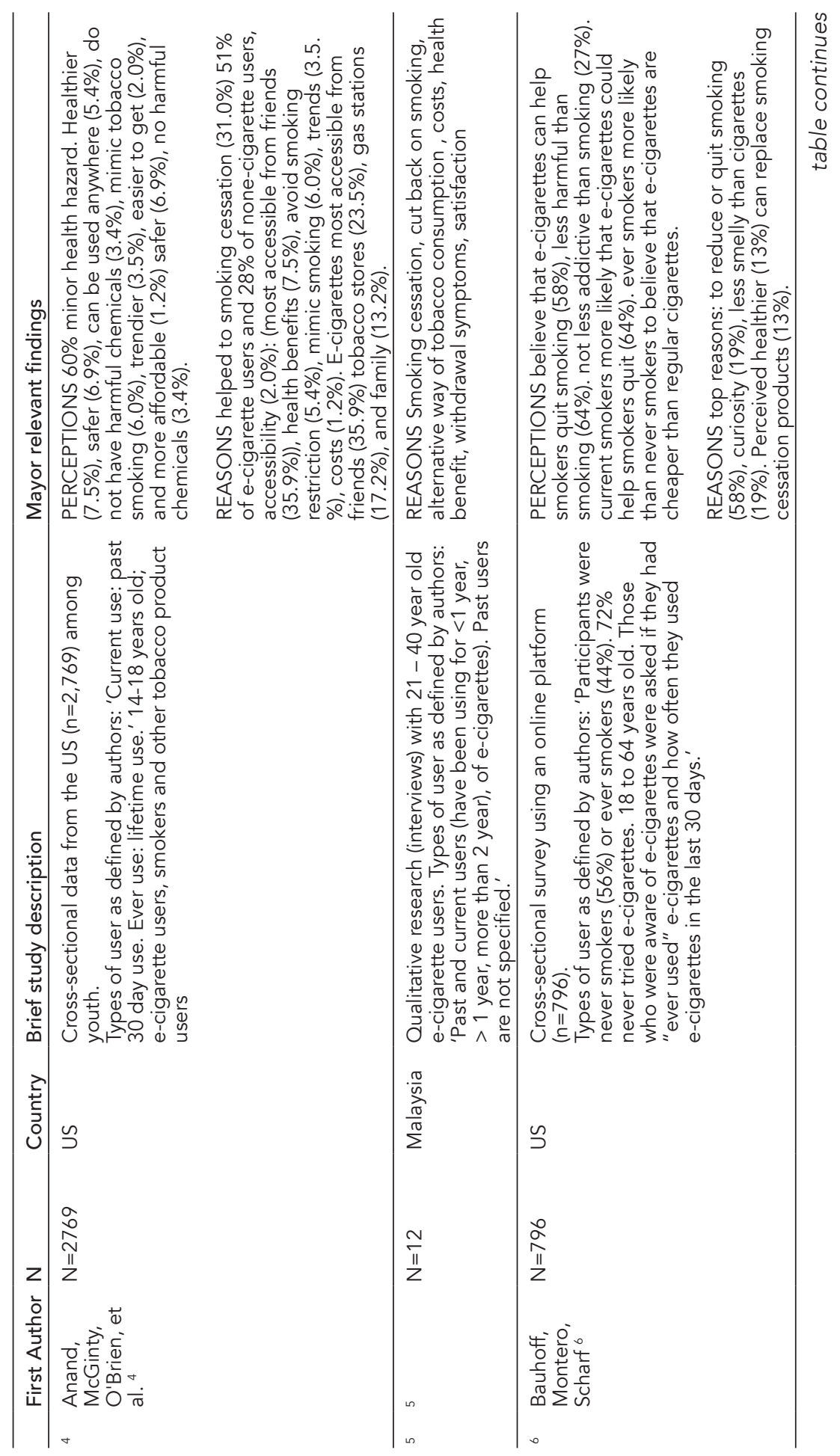




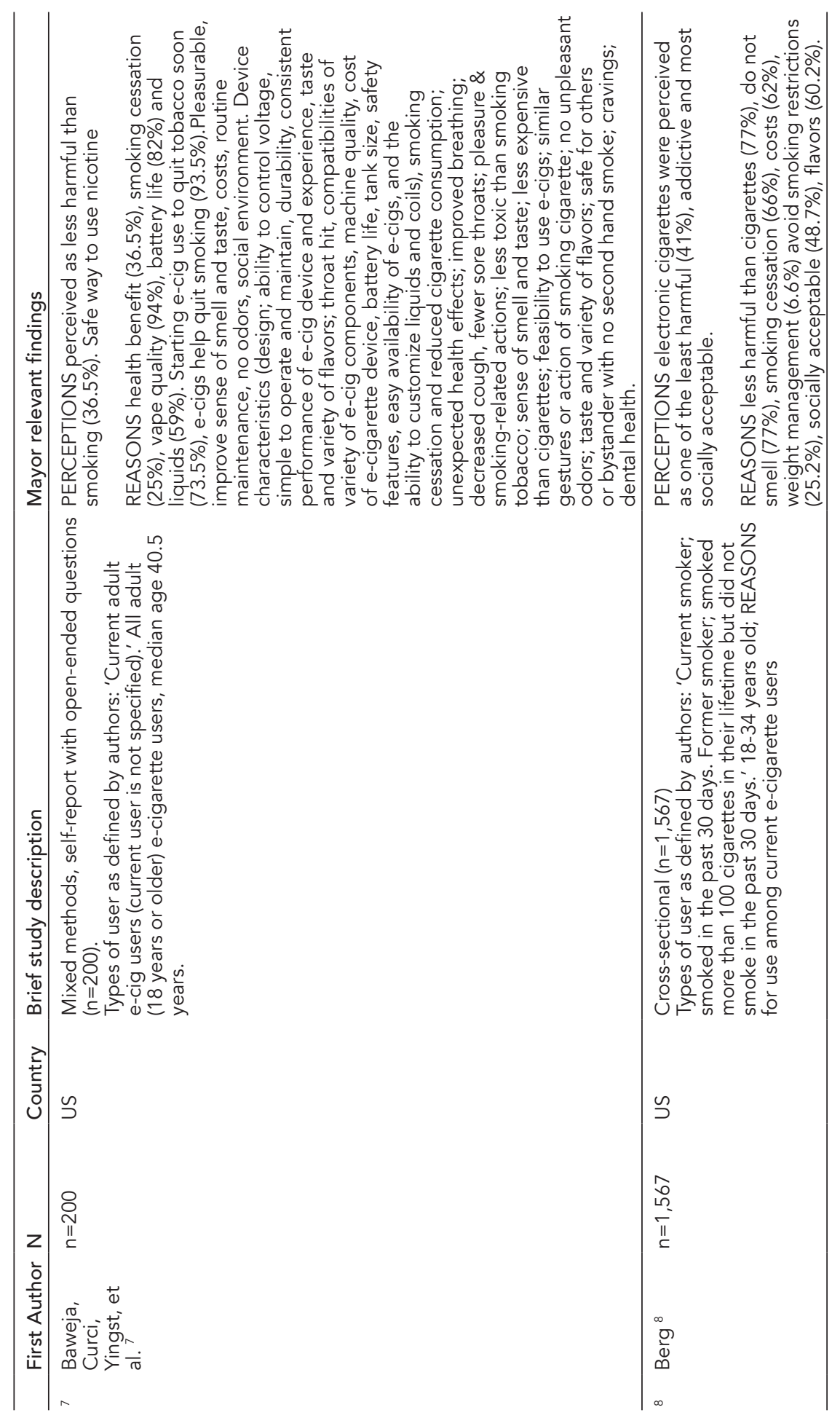




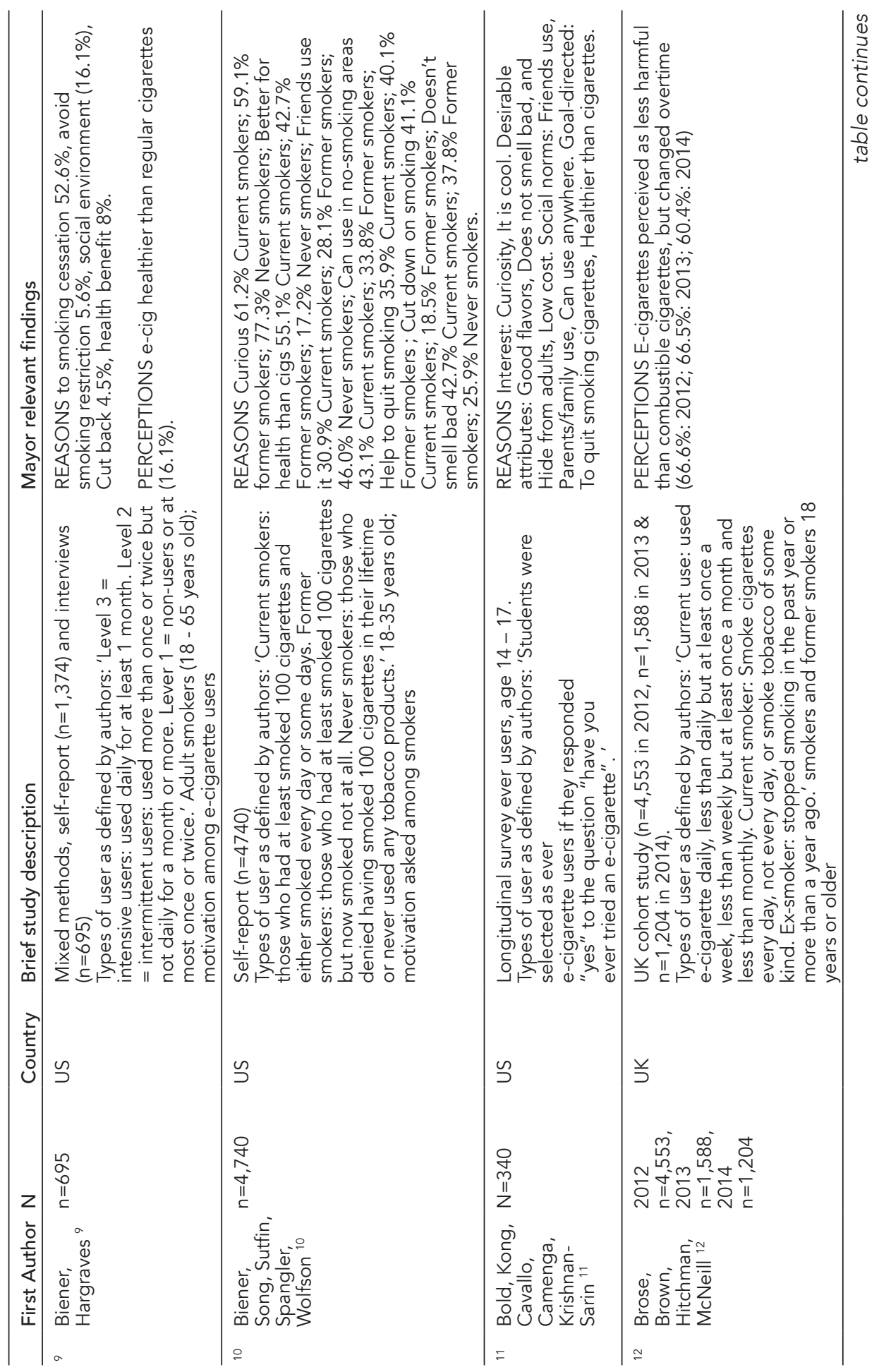




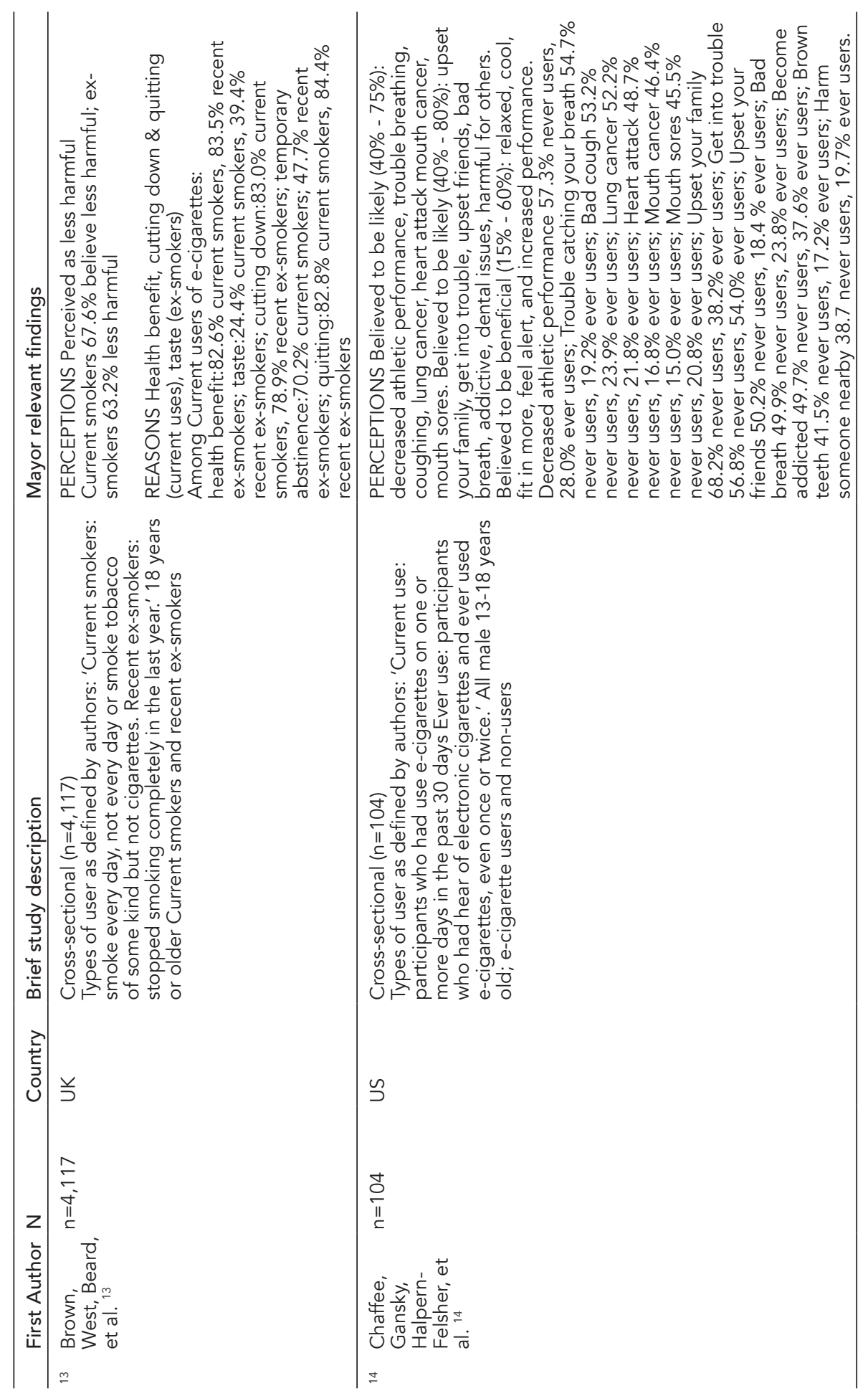




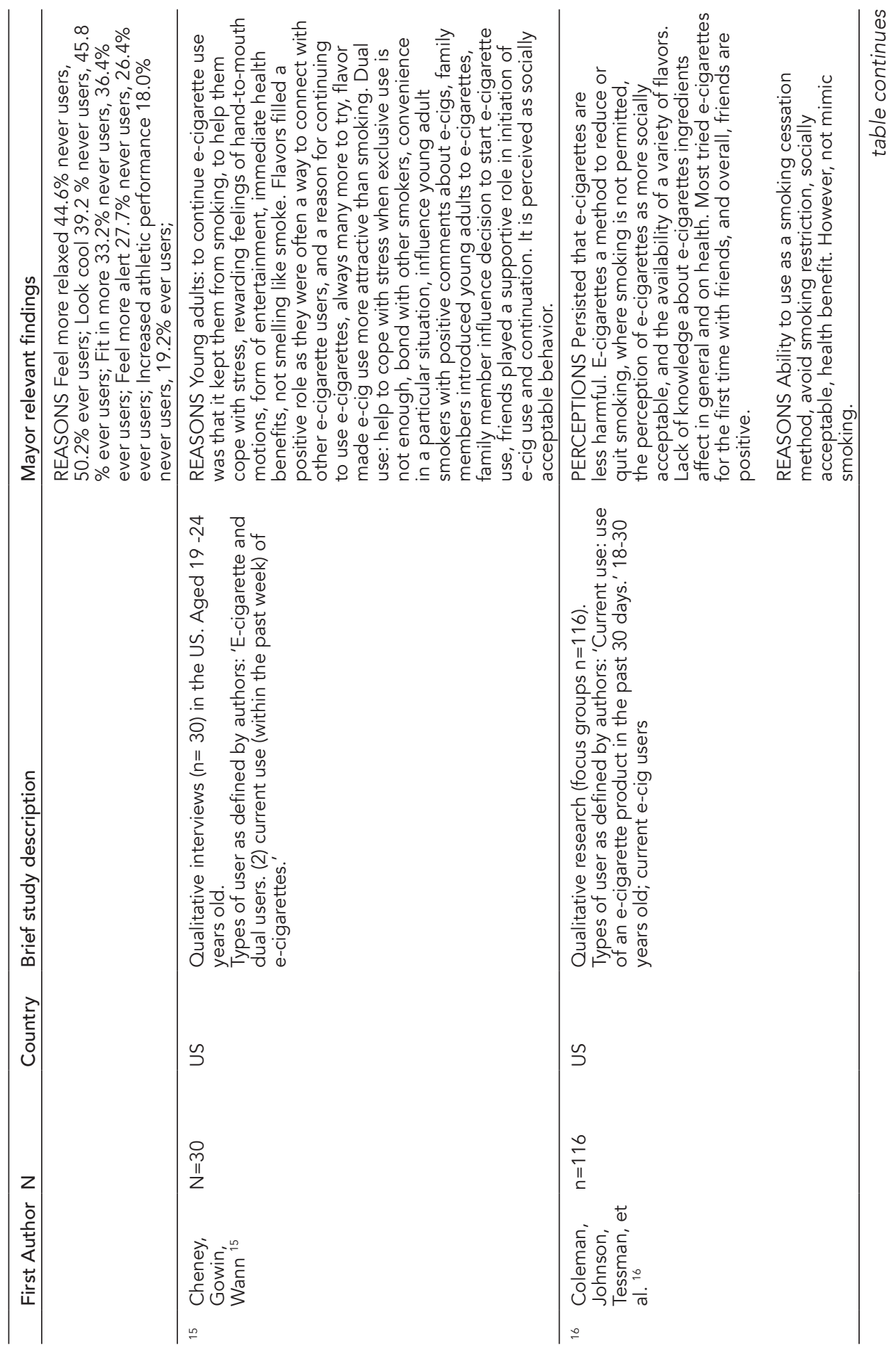




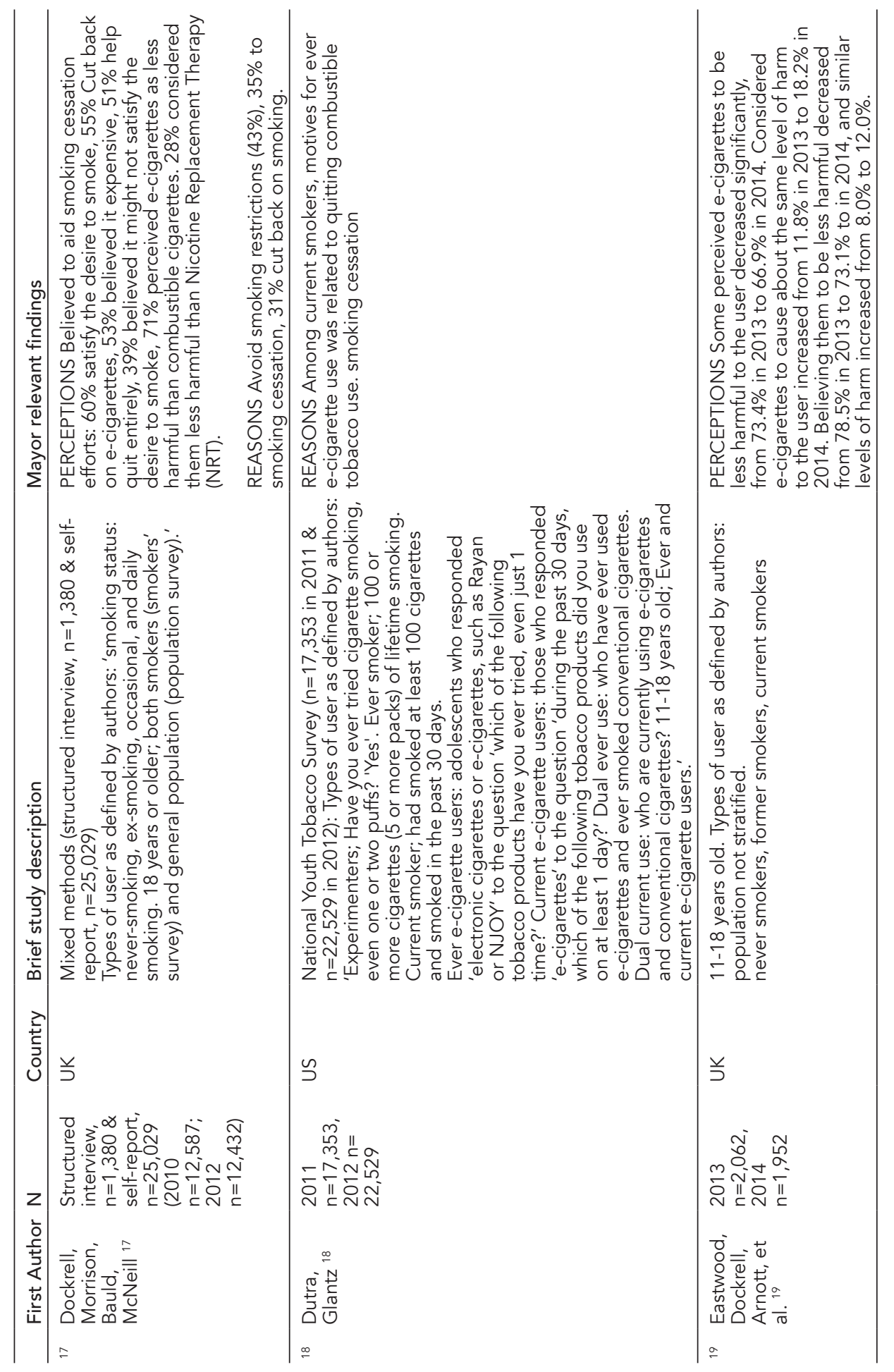




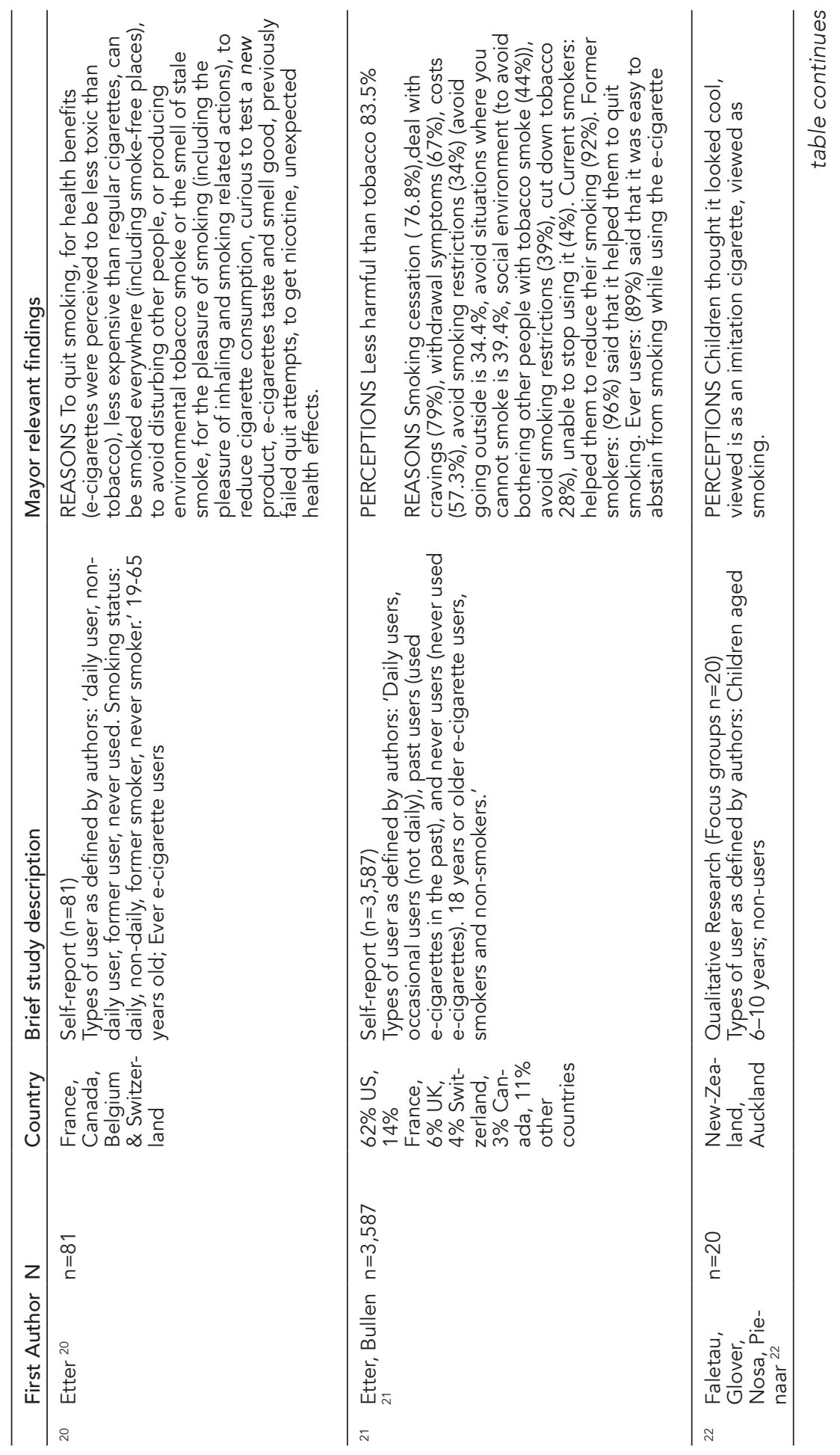




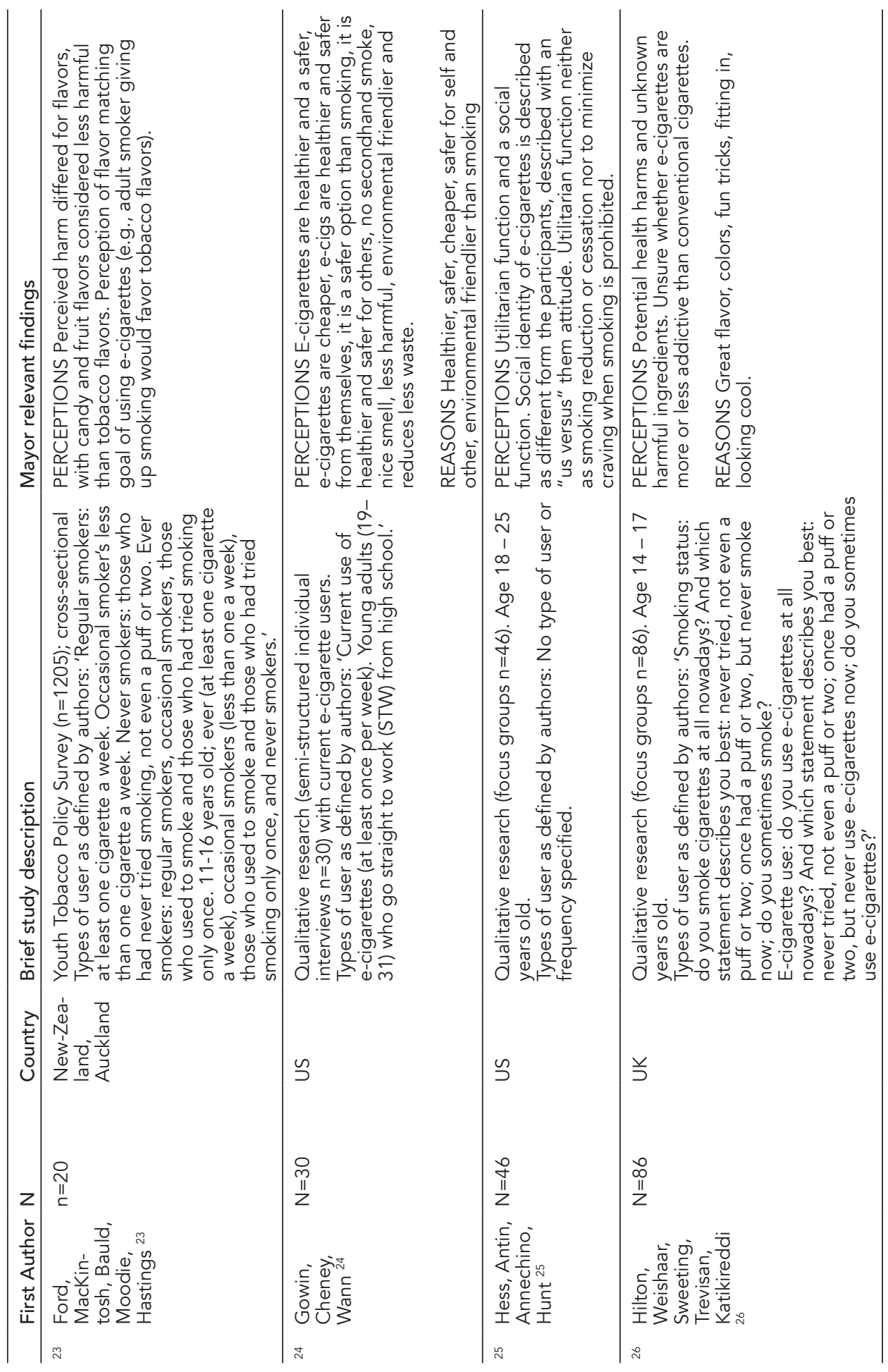




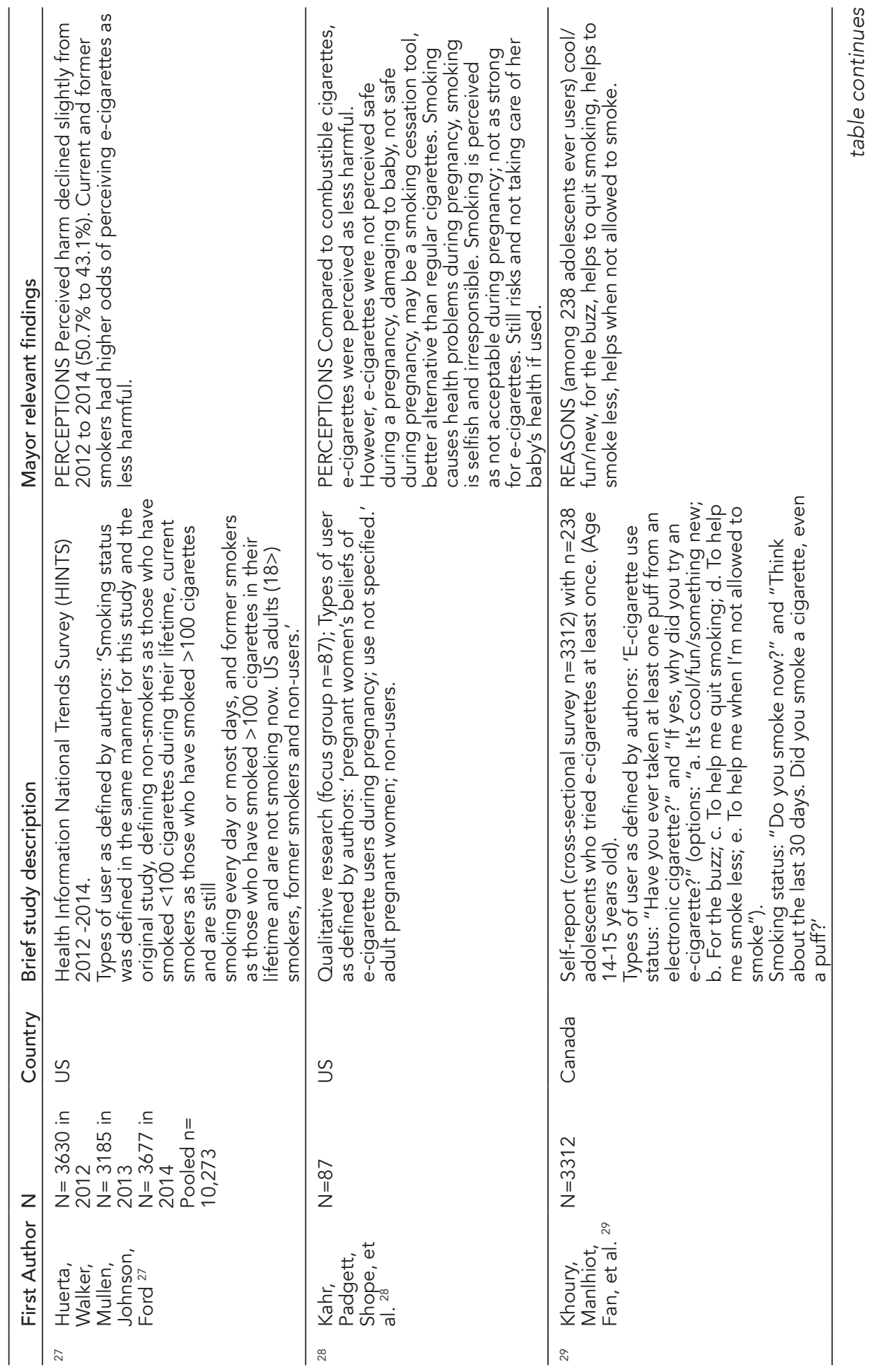




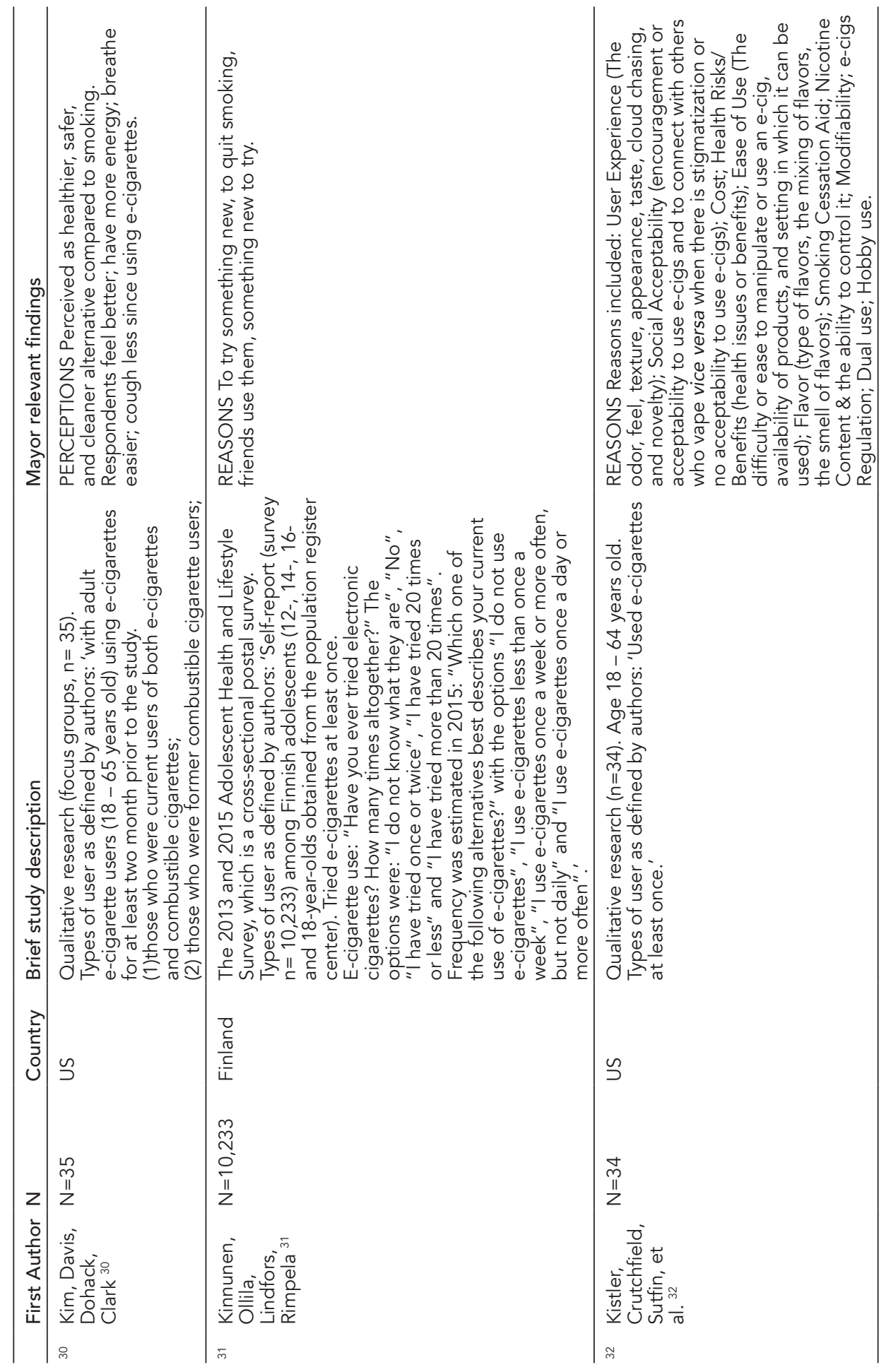




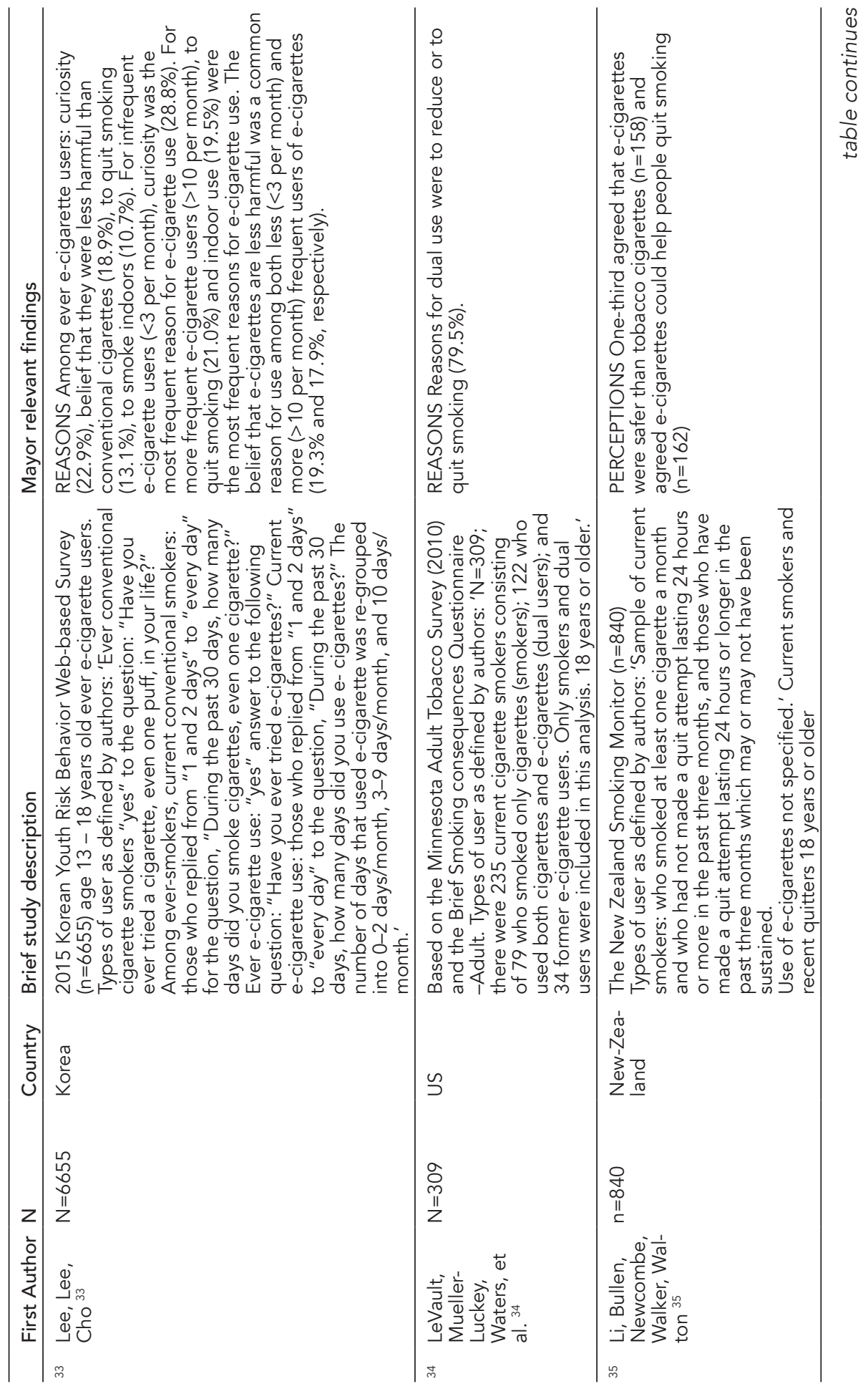




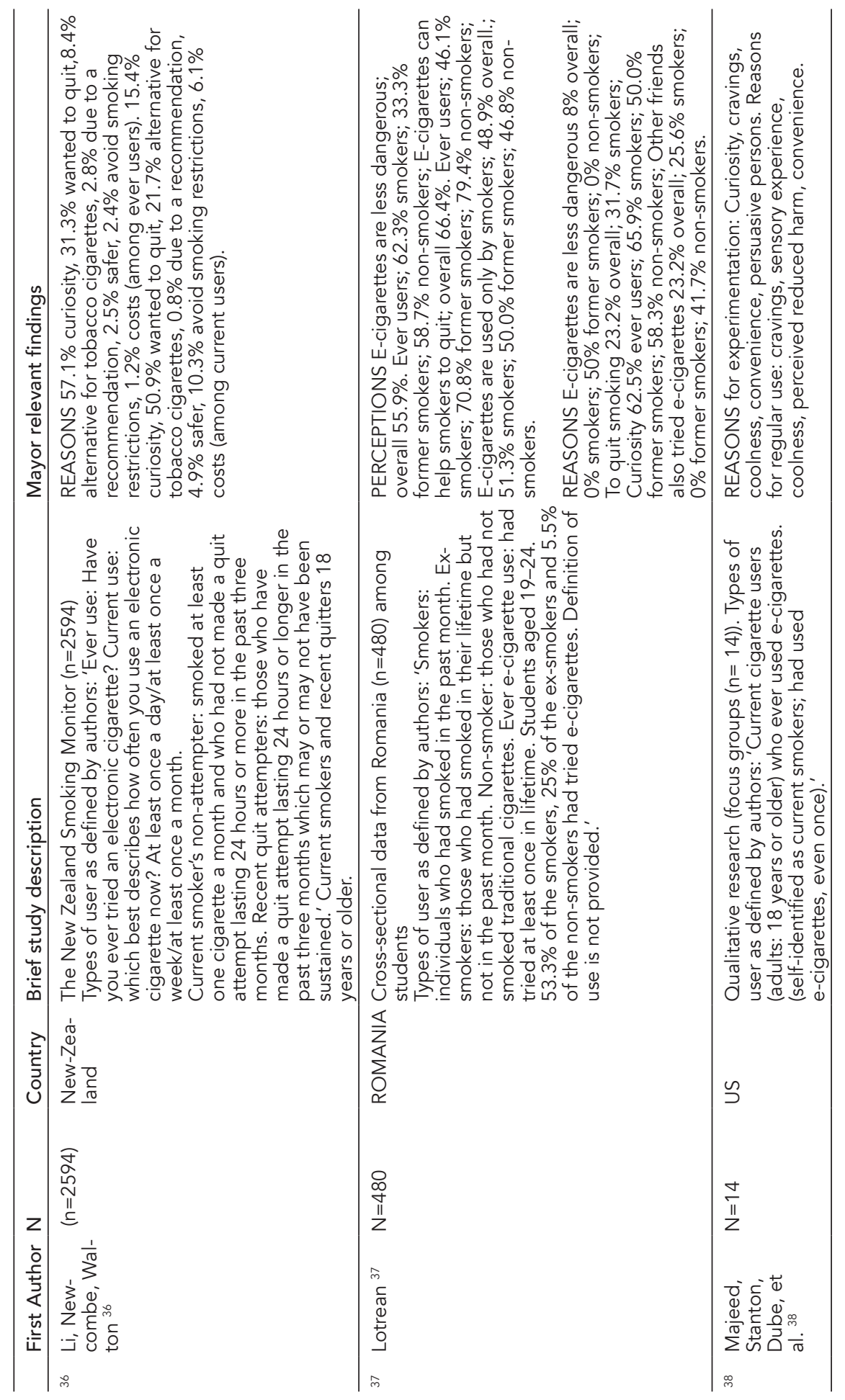




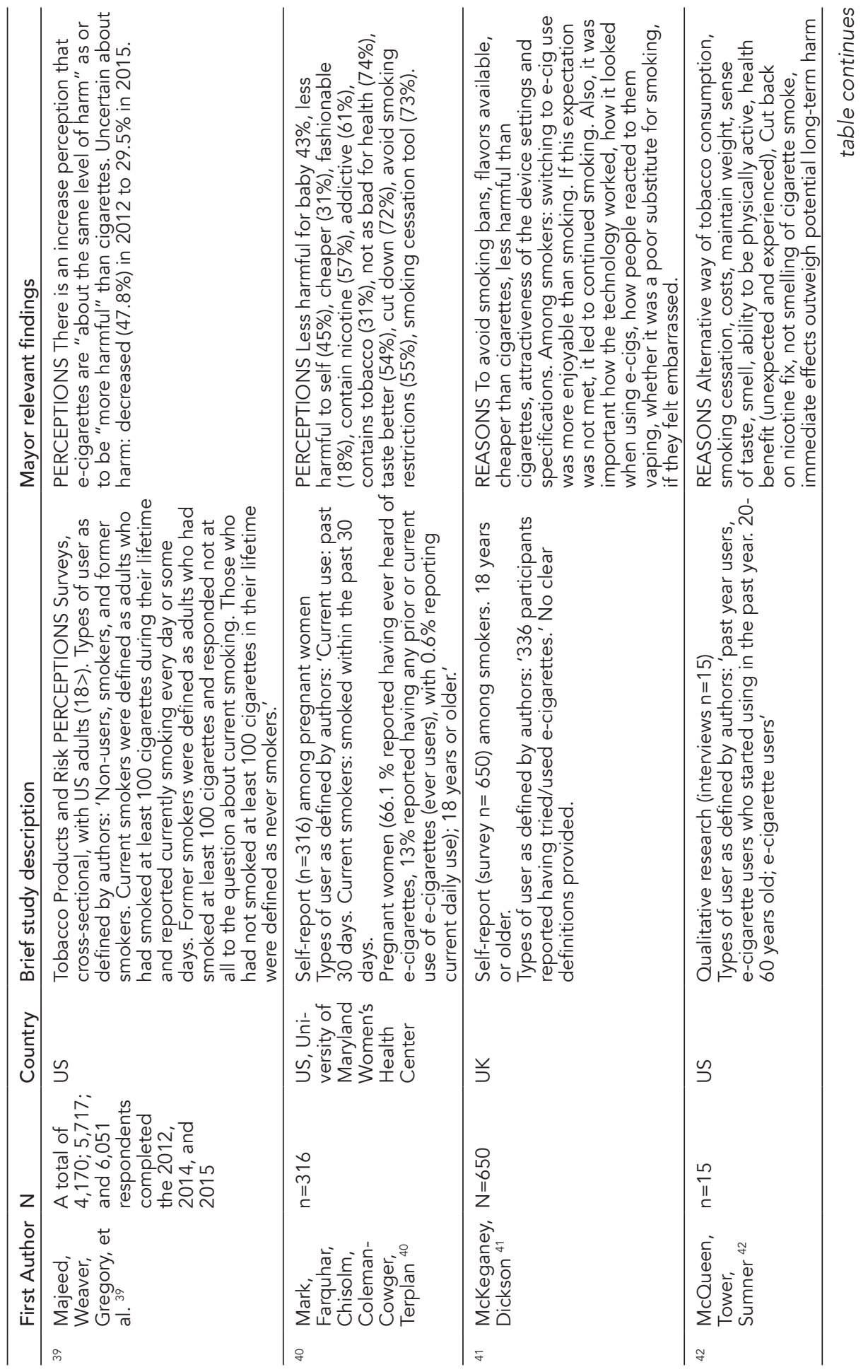




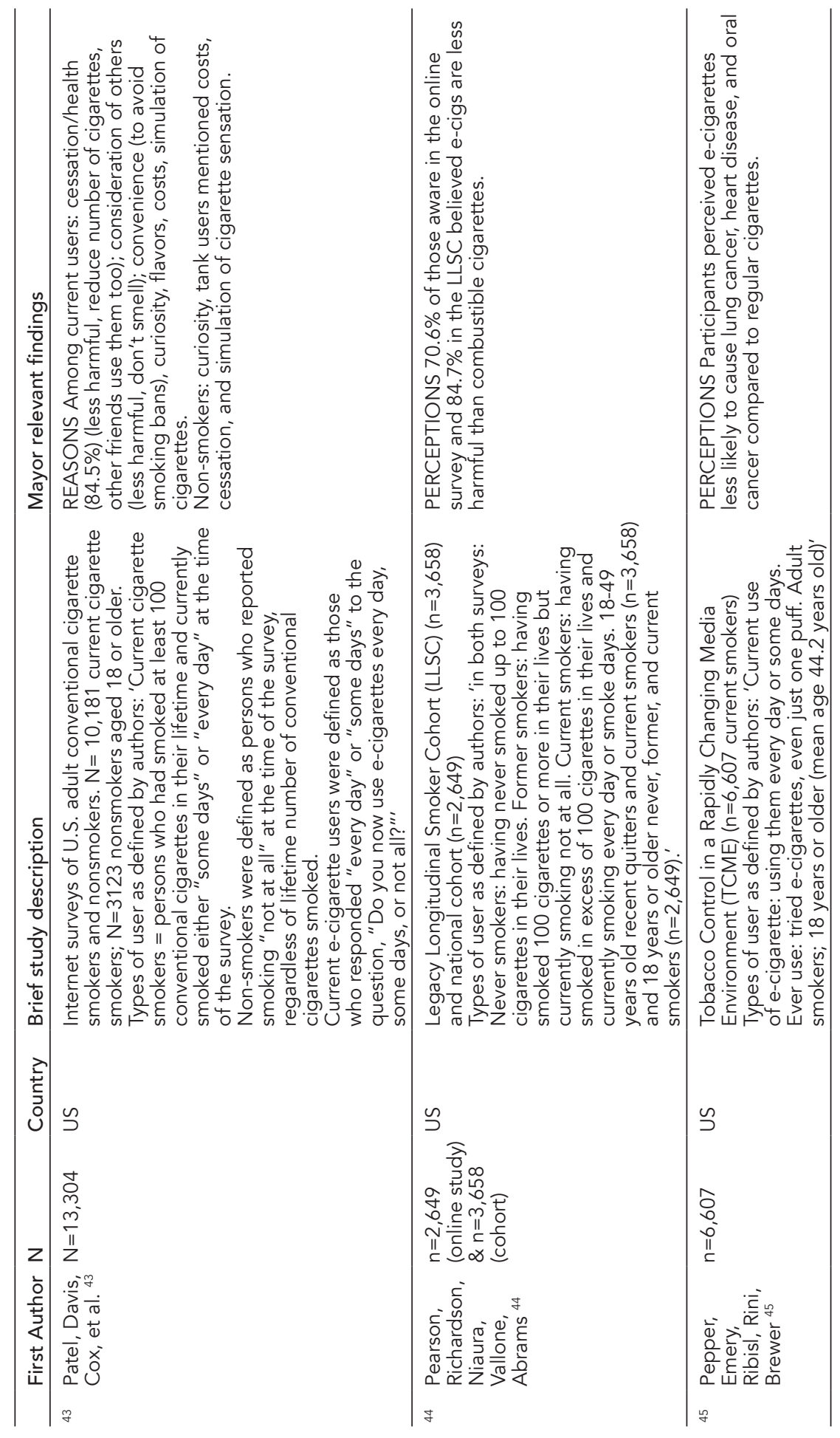




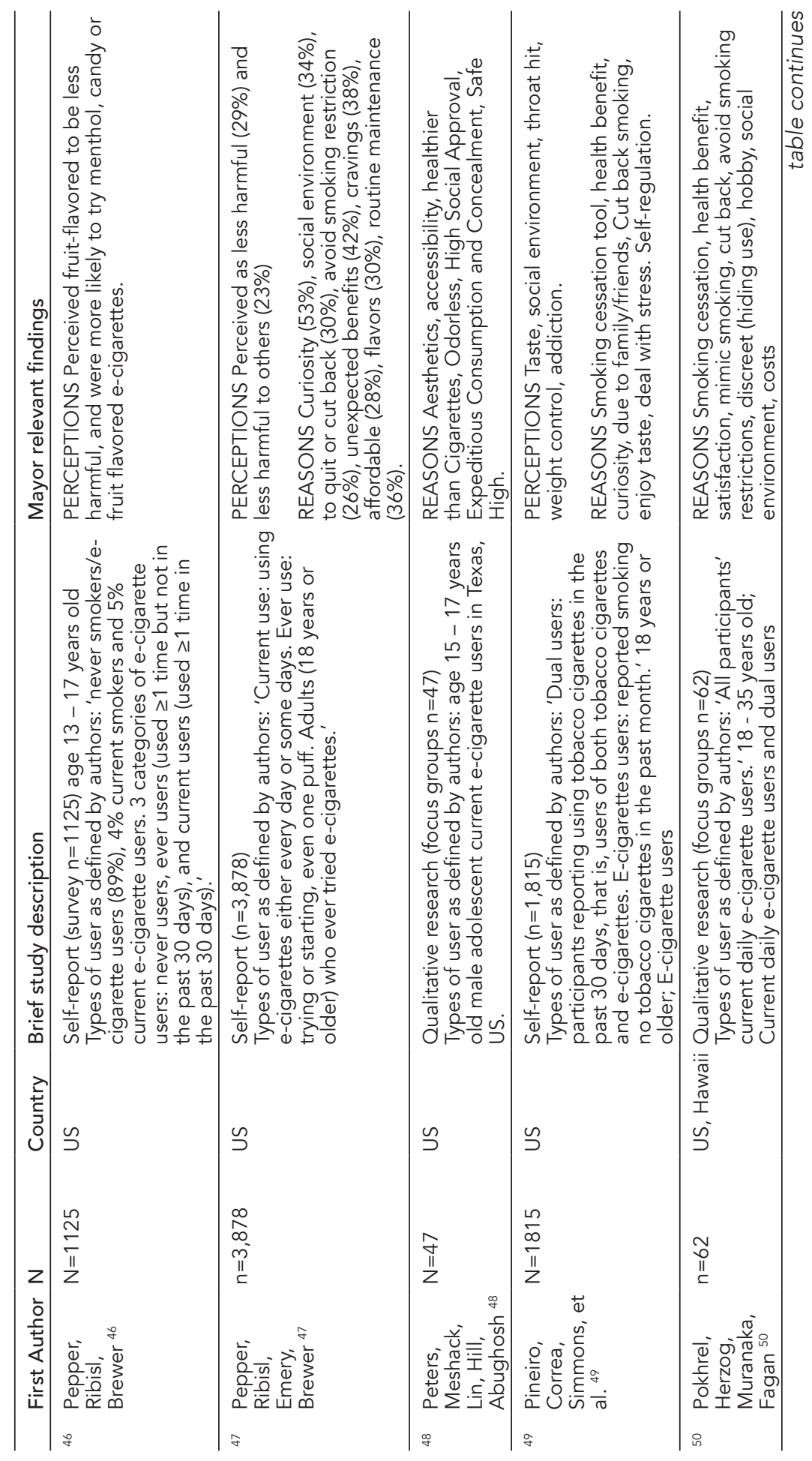




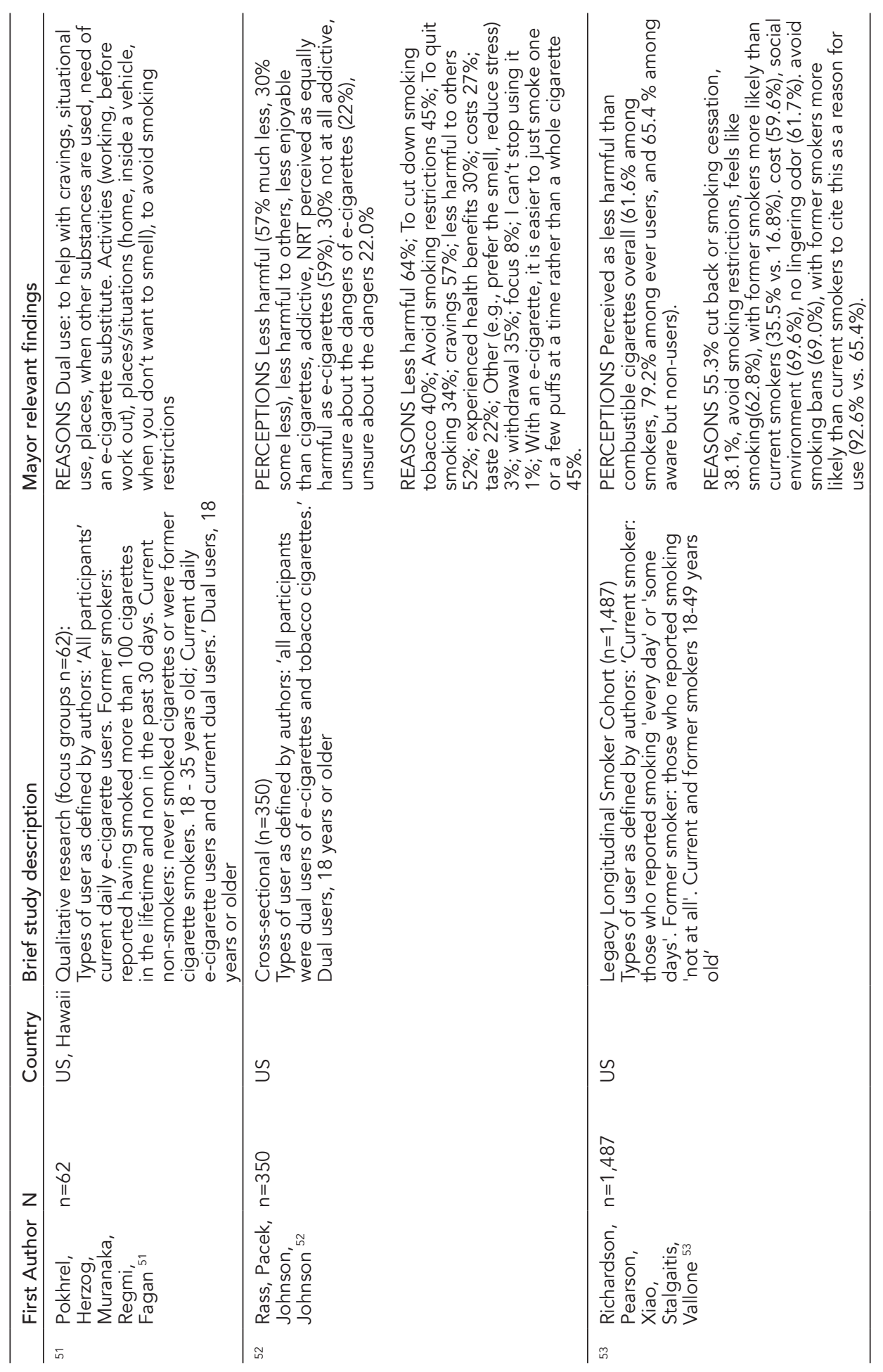




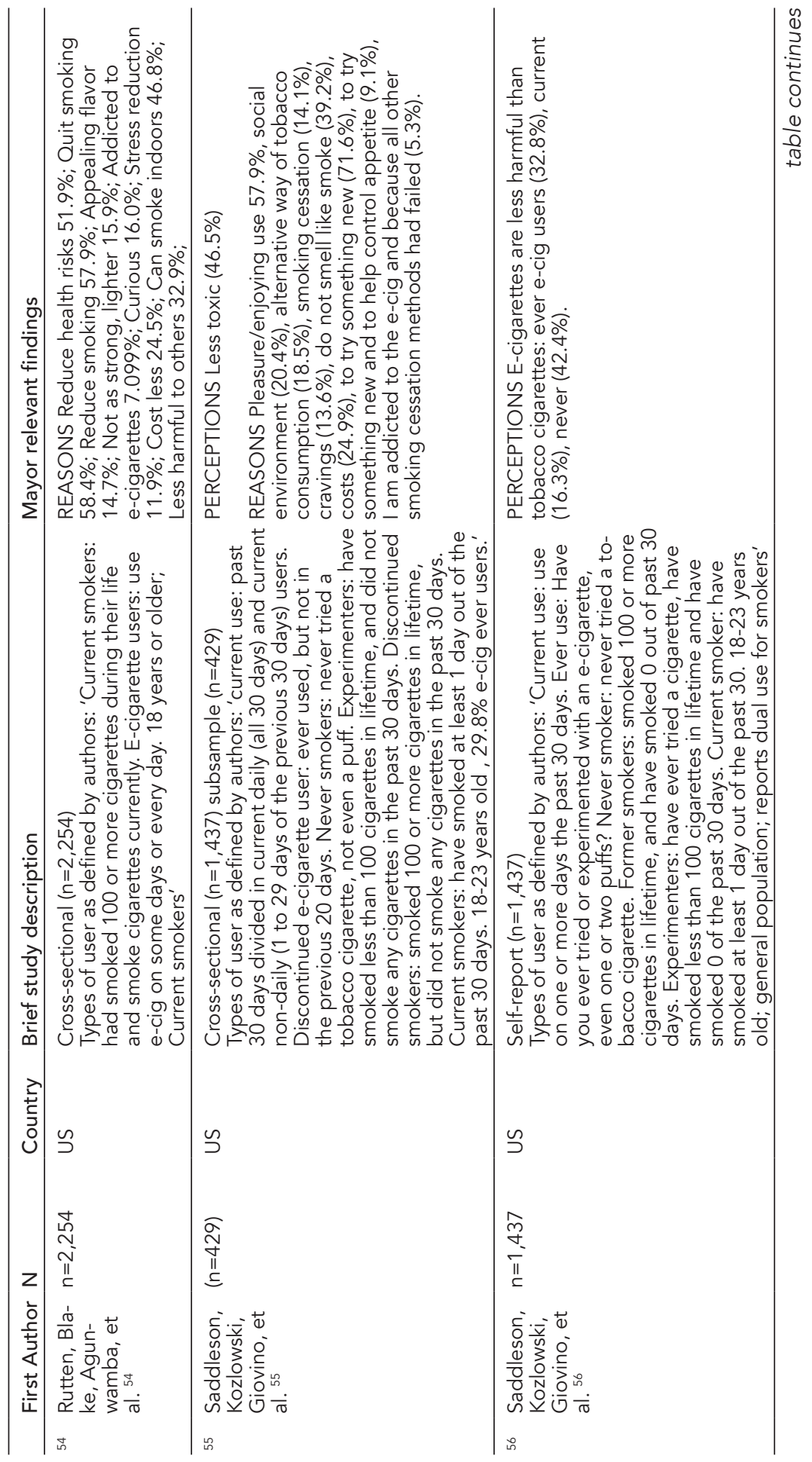




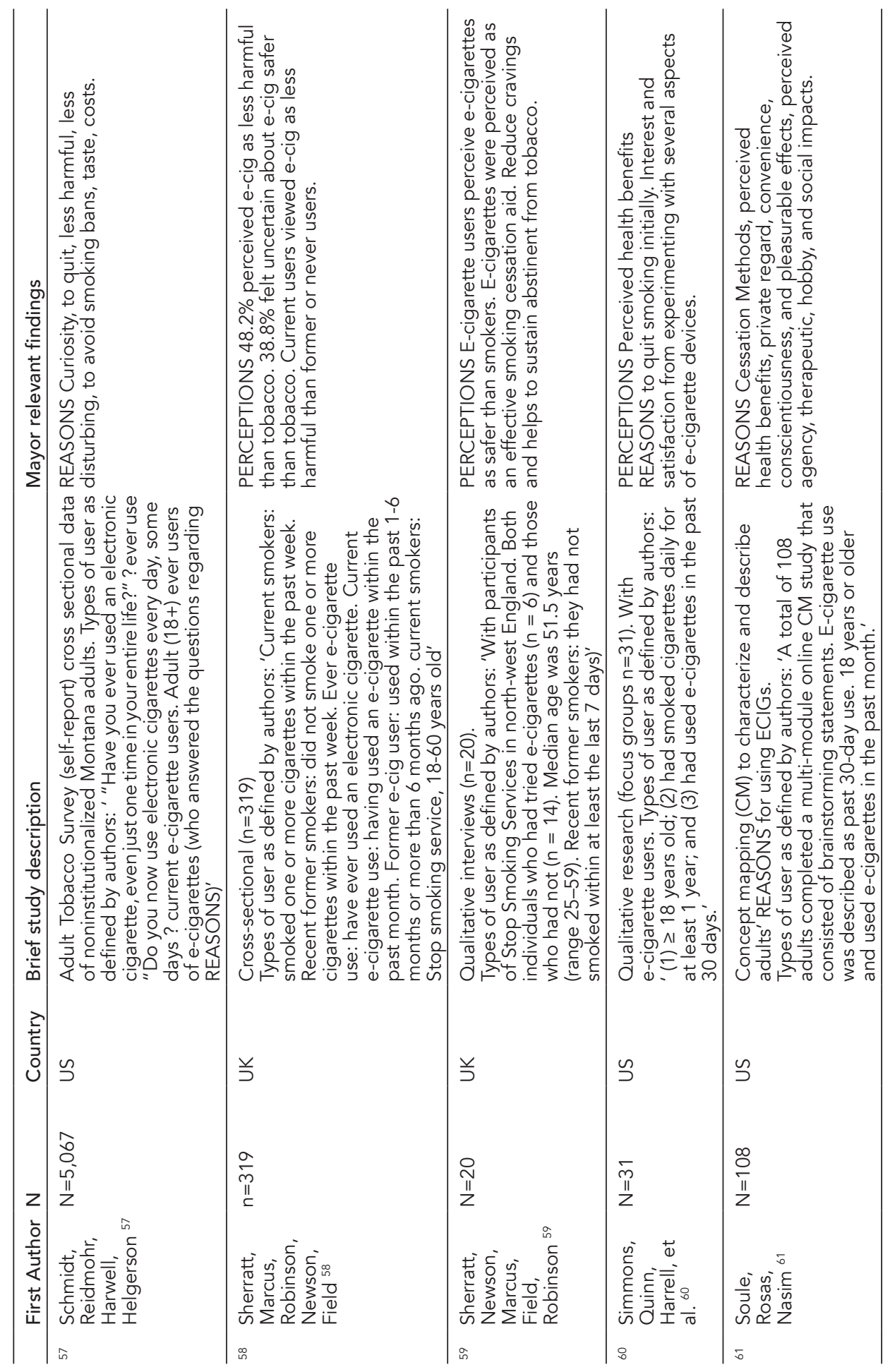




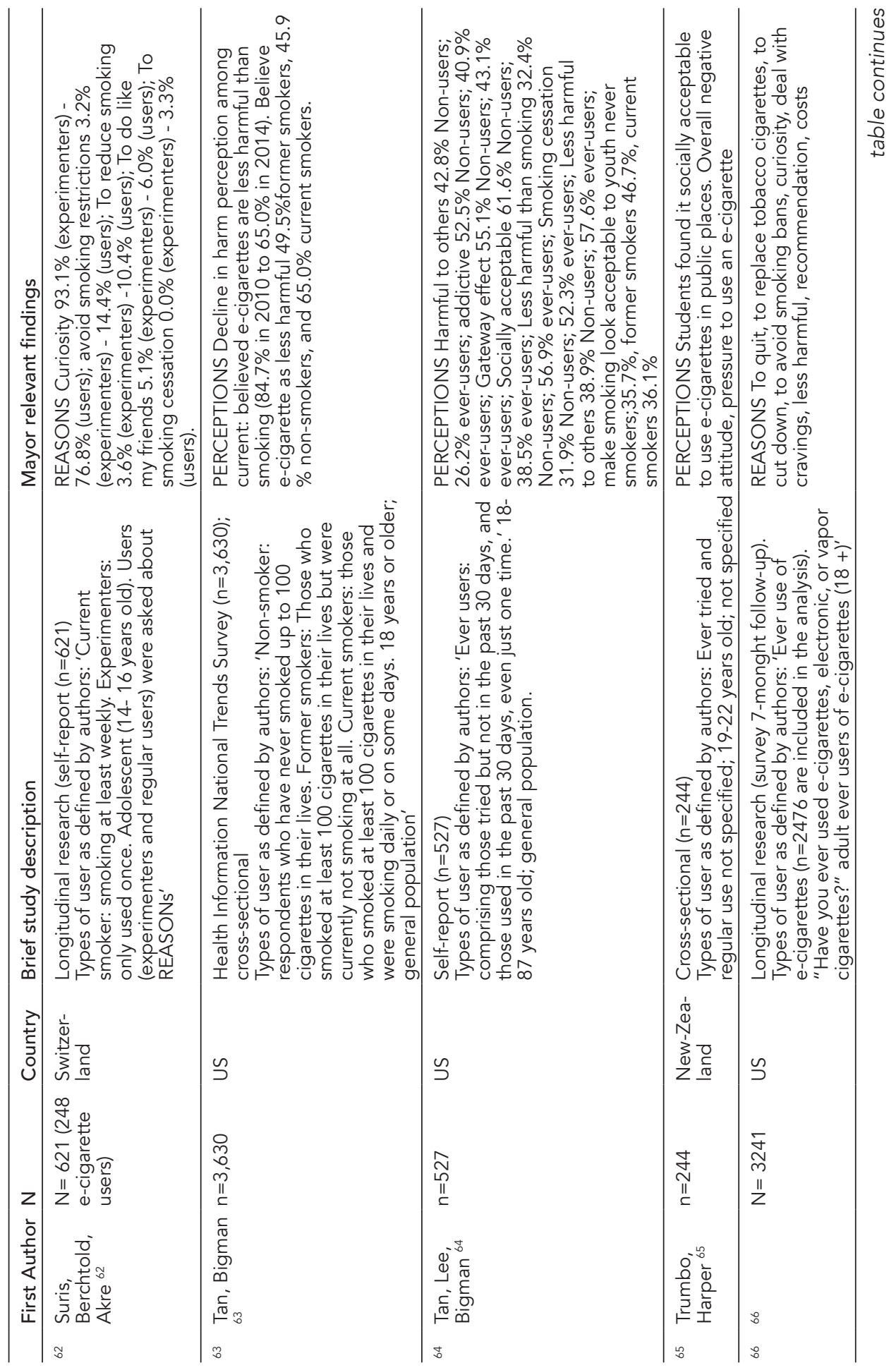




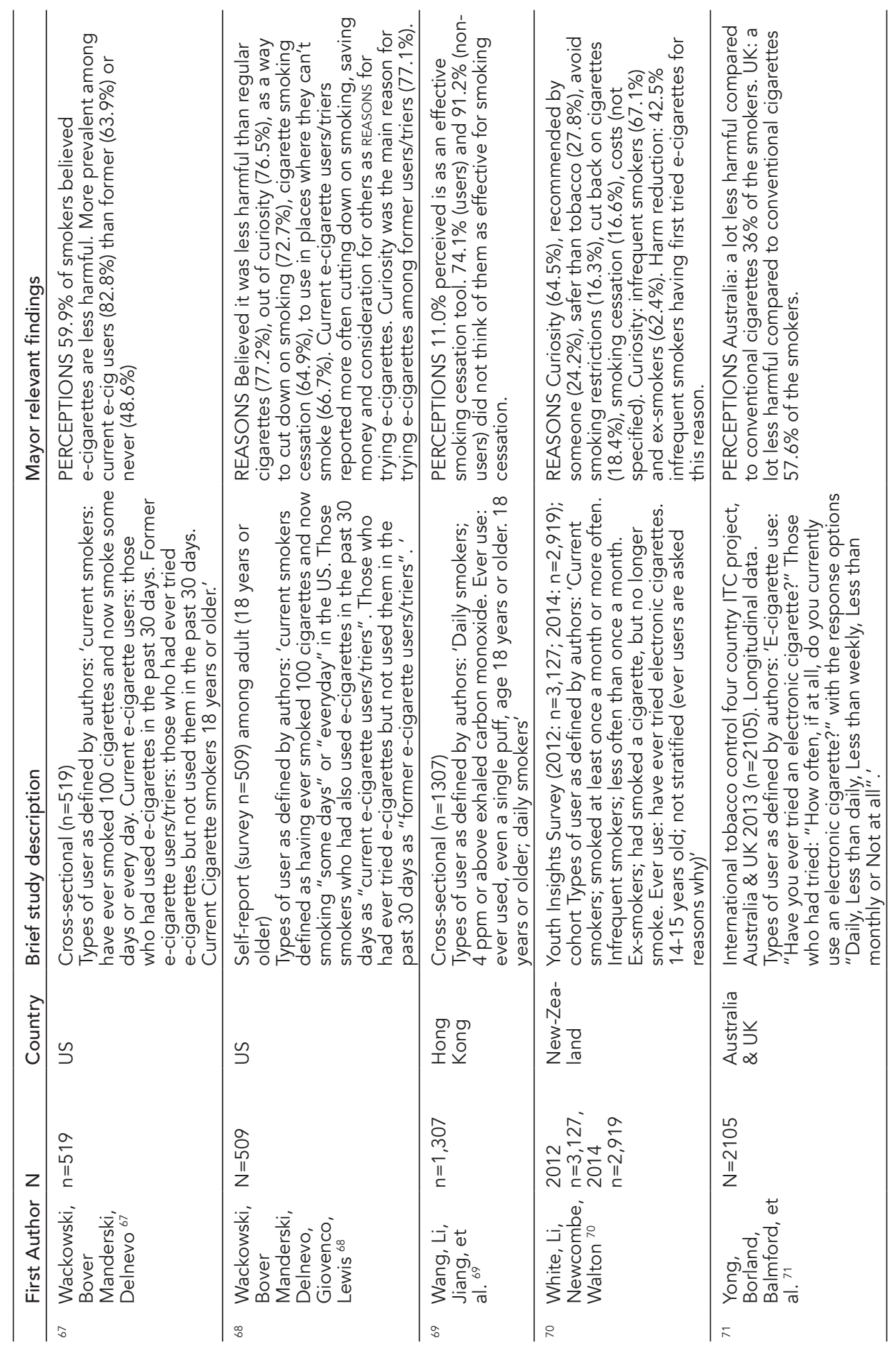




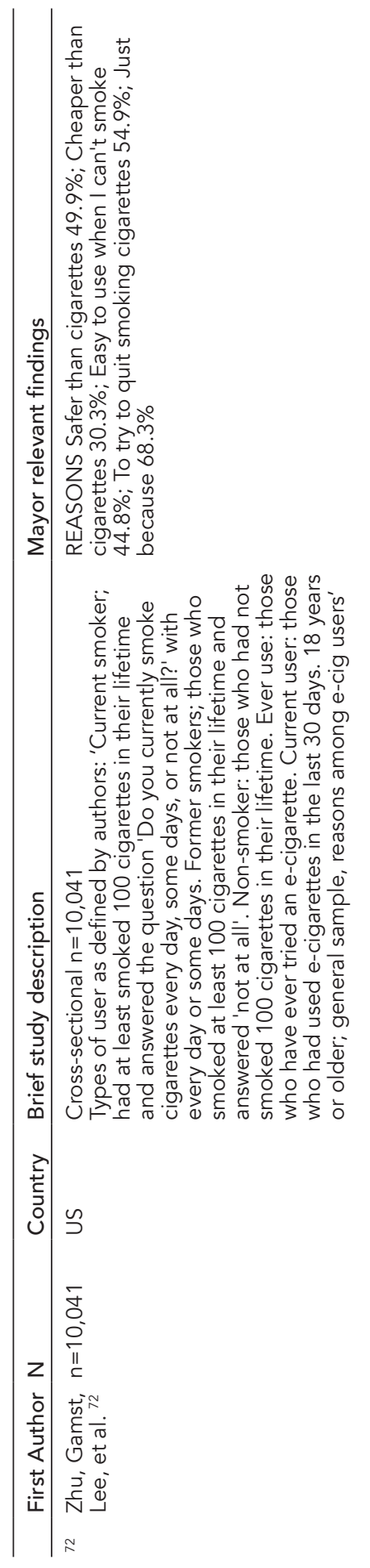




\section{References}

1. Adkison SE, O'Connor RJ, Bansal-Travers M, et al. Electronic nicotine delivery systems: international tobacco control four-country survey. Am J Prev Med. 2013;44(3):207-215.

2. Amato MS, Boyle RG, Levy D. How to define e-cigarette prevalence? Finding clues in the use frequency distribution. Tob Control. 2016;25(e1):e24-29.

3. Ambrose BK, Rostron BL, Johnson SE, et al. Perceptions of the relative harm of cigarettes and e-cigarettes among U.S. youth. Am J Prev Med. 2014;47(2 Suppl 1):S53-60.

4. Anand V, McGinty KL, O'Brien K, et al. E-cigarette Use and Beliefs Among Urban Public High School Students in North Carolina. JAdolesc Health. 2015;57(1):46-51.

5. Aziz Ur R, Mohamad MHN, Jamshed S. Safety and effectiveness of electronic cigarette as vapers perspective: A qualitative approach. International Medical Journal. 2015;22(5):362-366.

6. Bauhoff S, Montero A, Scharf D. Perceptions of e-cigarettes: a comparison of adult smokers and non-smokers in a Mechanical Turk sample. The American journal of drug and alcohol abuse. 2017;43(3):311-323.

7. Baweja R, Curci KM, Yingst J, et al. Views of Experienced Electronic Cigarette Users. Addict Res Theory. 2016;24(1):80-88.

8. Berg CJ. Preferred flavors and reasons for e-cigarette use and discontinued use among never, current, and formersmokers. Int J Public Health.2016;61(2):225-236.

9. Biener L, Hargraves JL. A longitudinal study of electronic cigarette use among a population-based sample of adult smokers: association with smoking cessation and motivation to quit. Nicotine Tob Res. 2015;17(2):127-133.

10. Biener L, Song E, Sutfin EL, Spangler J, Wolfson M. Electronic Cigarette Trial and Use among Young Adults: Reasons for Trial and Cessation of Vaping. Int J Environ Res Public Health. 2015;12(12):16019-16026.

11. Bold KW, Kong G, Cavallo DA, Camenga DR, Krishnan-Sarin S. Reasons for Trying E-cigarettes and Risk of Continued Use. Pediatrics. 2016;138(3).

12. Brose LS, Brown J, Hitchman SC, McNeill A. Perceived relative harm of electronic cigarettes over time and impact on subsequent use. A survey with 1-year and 2-year follow-ups. Drug Alcohol Depend. 2015;157:106-111.

13. Brown J, West R, Beard E, et al. Prevalence and characteristics of e-cigarette users in Great Britain: Findings from a general population survey of smokers. Addict Behav. 2014;39(6):1120-1125.

14. Chaffee BW, Gansky SA, Halpern-Felsher B, et al. Conditional risk assessment of adolescents' electronic cigarette perceptions. Am J Health Behav. 2015;39(3):421-432.

15. Cheney MK, Gowin M, Wann TF. Electronic Cigarette Use in Straight-to-Work Young Adults. Am J Health Behav. 2016;40(2):268-279.

16. Coleman BN, Johnson SE, Tessman GK, et al. "It's not smoke. It's not tar. It's not 4000 chemicals. Case closed": Exploring attitudes, beliefs, and perceived social norms of e-cigarette use among adult users. Drug Alcohol Depend. 2016;159:80-85. 
17. Dockrell M, Morrison R, Bauld L, McNeill A. E-cigarettes: prevalence and attitudes in Great Britain. Nicotine Tob Res. 2013;15(10):1737-1744.

18. Dutra LM, Glantz SA. Electronic cigarettes and conventional cigarette use among U.S. adolescents: a cross-sectional study. JAMA Pediatr. 2014;168(7):610-617.

19. Eastwood B, Dockrell MJ, Arnott D, et al. Electronic cigarette use in young people in Great Britain 2013-2014. Public Health. 2015;129(9):1150-1156.

20. Etter JF. Electronic cigarettes: a survey of users. BMC Public Health. 2010;10:231.

21. Etter JF, Bullen C. Electronic cigarette: users profile, utilization, satisfaction and perceived efficacy. Addiction. 2011;106(11):2017-2028.

22. Faletau J, Glover M, Nosa V, Pienaar F. Looks like smoking, is it smoking?: children's perceptions of cigarette-like nicotine delivery systems, smoking and cessation. Harm Reduct J. 2013;10:30.

23. Ford A, MacKintosh AM, Bauld L, Moodie C, Hastings G. Adolescents' responses to the promotion and flavouring of e-cigarettes. Int $\mathrm{J}$ Public Health. 2016;61(2):215-224.

24. Gowin M, Cheney MK, Wann TF. Knowledge and Beliefs About E-Cigarettes in Straight-to-Work Young Adults. Nicotine Tob Res. 2017;19(2):208-214.

25. Hess CA, Antin TM, Annechino R, Hunt G. Perceptions of E-Cigarettes among Black Youth in California. Int J Environ Res Public Health. 2017;14(1):11.

26. Hilton S, Weishaar H, Sweeting H, Trevisan F, Katikireddi SV. E-cigarettes, a safer alternative for teenagers? A UK focus group study of teenagers' views. BMJ Open. 2016;6(11):e013271.

27. Huerta TR, Walker DM, Mullen D, Johnson TJ, Ford EW. Trends in E-Cigarette Awareness and Perceived Harmfulness in the U.S. Am J Prev Med. 2017;52(3):339346.

28. Kahr MK, Padgett $S$, Shope CD, et al. A qualitative assessment of the perceived risks of electronic cigarette and hookah use in pregnancy. BMC Public Health. 2015;15(1):1273.

29. Khoury M, Manlhiot C, Fan CS, et al. Reported electronic cigarette use among adolescents in the Niagara region of Ontario. CMAJ. 2016;188(11):794-800.

30. Kim H, Davis AH, Dohack JL, Clark PI. E-Cigarettes Use Behavior and Experience of Adults: Qualitative Research Findings to Inform E-Cigarette Use Measure Development. Nicotine Tob Res. 2017;19(2):190-196.

31. Kinnunen JM, Ollila H, Lindfors PL, Rimpela AH. Changes in Electronic Cigarette Use from 2013 to 2015 and Reasons for Use among Finnish Adolescents. Int J Environ Res Public Health. 2016;13(11):09.

32. Kistler CE, Crutchfield TM, Sutfin EL, et al. Consumers' Preferences for Electronic Nicotine Delivery System Product Features: A Structured Content Analysis. Int J Environ Res Public Health. 2017;14(6):07.

33. Lee JA, Lee S, Cho HJ. The Relation between Frequency of E-Cigarette Use and Frequency and Intensity of Cigarette Smoking among South Korean Adolescents. Int J Environ Res Public Health. 2017;14(3):14.

34. LeVault K, Mueller-Luckey G, Waters EA, et al. E-cigarettes: Who's using them and why? The Journal of family practice. 2016;65(6):390-397. 
35. Li J, Bullen C, Newcombe R, Walker N, Walton D. The use and acceptability of electronic cigarettes among New Zealand smokers. N Z Med J. 2013;126(1375):48-57.

36. Li J, Newcombe R, Walton D. The prevalence, correlates and reasons for using electronic cigarettes among New Zealand adults. Addict Behav. 2015;45:245251.

37. Lotrean LM. Use of electronic cigarettes among Romanian university students: a cross-sectional study. BMC Public Health. 2015;15:358.

38. Majeed BA, Stanton CA, Dube SR, et al. Electronic Cigarette Use among Current Smokers: A Pilot Qualitative Study. Health behavior and policy review. 2016;3(6):590-596.

39. Majeed BA, Weaver SR, Gregory KR, et al. Changing Perceptions of Harm of E-Cigarettes Among U.S. Adults, 2012-2015. Am J Prev Med. 2017;52(3):331338.

40. Mark KS, Farquhar B, Chisolm MS, Coleman-Cowger VH, Terplan M. Knowledge, Attitudes, and Practice of Electronic Cigarette Use Among Pregnant Women. J Addict Med. 2015;9(4):266-272.

41. McKeganey N, Dickson T. Why Don't More Smokers Switch to Using E-Cigarettes: The Views of Confirmed Smokers. Int J Environ Res Public Health. 2017;14(6):16.

42. McQueen A, Tower S, Sumner W. Interviews with "vapers": implications for future research with electronic cigarettes. Nicotine Tob Res. 2011;13(9):860-867.

43. Patel D, Davis KC, Cox S, et al. Reasons for current E-cigarette use among U.S. adults. Prev Med. 2016;93:14-20.

44. Pearson JL, Richardson A, Niaura RS, Vallone DM, Abrams DB. e-Cigarette awareness, use, and harm perceptions in US adults. Am J Public Health. 2012;102(9):1758-1766.

45. Pepper JK, Emery SL, Ribisl KM, Rini CM, Brewer NT. How risky is it to use e-cigarettes? Smokers' beliefs about their health risks from using novel and traditional tobacco products. J Behav Med. 2015;38(2):318-326.

46. Pepper JK, Ribisl KM, Brewer NT. Adolescents' interest in trying flavoured e-cigarettes. Tob Control. 2016;25(Suppl 2):ii62-ii66.

47. Pepper JK, Ribisl KM, Emery SL, Brewer NT. Reasons for starting and stopping electronic cigarette use. Int J Environ Res Public Health. 2014;11(10):1034510361.

48. Peters RJ, Jr., Meshack A, Lin MT, Hill M, Abughosh S. The social norms and beliefs of teenage male electronic cigarette use. J Ethn Subst Abuse. 2013;12(4):300-307.

49. Pineiro B, Correa JB, Simmons VN, et al. Gender differences in use and expectancies of e-cigarettes: Online survey results. Addict Behav. 2016;52:91-97.

50. Pokhrel P, Herzog TA, Muranaka N, Fagan P. Young adult e-cigarette users' reasons for liking and not liking e-cigarettes: A qualitative study. Psychol Health. 2015;30(12):1450-1469.

51. Pokhrel P, Herzog TA, Muranaka N, Regmi S, Fagan P. Contexts of cigarette and e-cigarette use among dual users: a qualitative study. BMC Public Health. 2015;15:859. 
52. Rass O, Pacek LR, Johnson PS, Johnson MW. Characterizing use patterns and perceptions of relative harm in dual users of electronic and tobacco cigarettes. Exp Clin Psychopharmacol. 2015;23(6):494-503.

53. Richardson A, Pearson J, Xiao H, Stalgaitis C, Vallone D. Prevalence, harm perceptions, and reasons for using noncombustible tobacco products among current and former smokers. Am J Public Health. 2014;104(8):1437-1444.

54. Rutten LJ, Blake KD, Agunwamba AA, et al. Use of E-Cigarettes Among Current Smokers: Associations Among Reasons for Use, Quit Intentions, and Current Tobacco Use. Nicotine Tob Res. 2015;17(10):1228-1234.

55. Saddleson ML, Kozlowski LT, Giovino GA, et al. Enjoyment and other reasons for electronic cigarette use: Results from college students in New York. Addict Behav. 2016;54:33-39.

56. Saddleson ML, Kozlowski LT, Giovino GA, et al. Risky behaviors, e-cigarette use and susceptibility of use among college students. Drug Alcohol Depend. 2015;149:25-30.

57. Schmidt L, Reidmohr A, Harwell TS, Helgerson SD. Prevalence and reasons for initiating use of electronic cigarettes among adults in Montana, 2013. Prev Chronic Dis. 2014;11:E204.

58. Sherratt FC, Marcus MW, Robinson J, Newson L, Field JK. Electronic cigarette use and risk perception in a Stop Smoking Service in England. Addiction Research \& Theory. 2015;23(4):336-342.

59. Sherratt FC, Newson L, Marcus MW, Field JK, Robinson J. Perceptions towards electronic cigarettes for smoking cessation among Stop Smoking Service users. Br J Health Psychol. 2016;21(2):421-433.

60. Simmons VN, Quinn GP, Harrell PT, et al. E-cigarette use in adults: a qualitative study of users' perceptions and future use intentions. Addict Res Theory. 2016;24(4):313-321.

61. Soule EK, Rosas SR, Nasim A. Reasons for electronic cigarette use beyond cigarette smoking cessation: A concept mapping approach. Addict Behav. 2016;56:41-50.

62. Suris JC, Berchtold A, Akre C. Reasons to use e-cigarettes and associations with other substances among adolescents in Switzerland. Drug Alcohol Depend. 2015;153:140-144.

63. Tan AS, Bigman CA. E-cigarette awareness and perceived harmfulness: prevalence and associations with smoking-cessation outcomes. Am J Prev Med. 2014;47(2):141-149.

64. Tan AS, Lee CJ, Bigman CA. Comparison of beliefs about e-cigarettes' harms and benefits among never users and ever users of e-cigarettes. Drug Alcohol Depend. 2016;158:67-75.

65. Trumbo CW, Harper R. Use and perception of electronic cigarettes among college students. J Am Coll Health. 2013;61(3):149-155.

66. Vickerman KA, Carpenter KM, Altman T, Nash CM, Zbikowski SM. Use of electronic cigarettes among state tobacco cessation quitline callers. Nicotine Tob Res. 2013;15(10):1787-1791. 
67. Wackowski OA, Bover Manderski MT, Delnevo CD. Smokers' sources of e-cigarette awareness and risk information. Prev Med Rep. 2015;2:906-910.

68. Wackowski OA, Bover Manderski MT, Delnevo CD, Giovenco DP, Lewis MJ. Smokers' Early E-cigarette Experiences, Reasons for Use, and Use Intentions. Tob Regul Sci. 2016;2(2):133-145.

69. Wang MP, Li WH, Jiang N, et al. E-Cigarette Awareness, Perceptions and Use among Community-Recruited Smokers in Hong Kong. PLoS One. 2015;10(10):e0141683.

70. White J, Li J, Newcombe R, Walton D. Tripling use of electronic cigarettes among New Zealand adolescents between 2012 and 2014. J Adolesc Health. 2015;56(5):522-528.

71. Yong $\mathrm{HH}$, Borland R, Balmford J, et al. Prevalence and Correlates of the Belief That Electronic Cigarettes are a Lot Less Harmful Than Conventional Cigarettes Under the Different Regulatory Environments of Australia and the United Kingdom. Nicotine Tob Res. 2017;19(2):258-263.

72. Zhu SH, Gamst A, Lee M, et al. The use and perception of electronic cigarettes and snus among the U.S. population. PLoS One. 2013;8(10):e79332. 


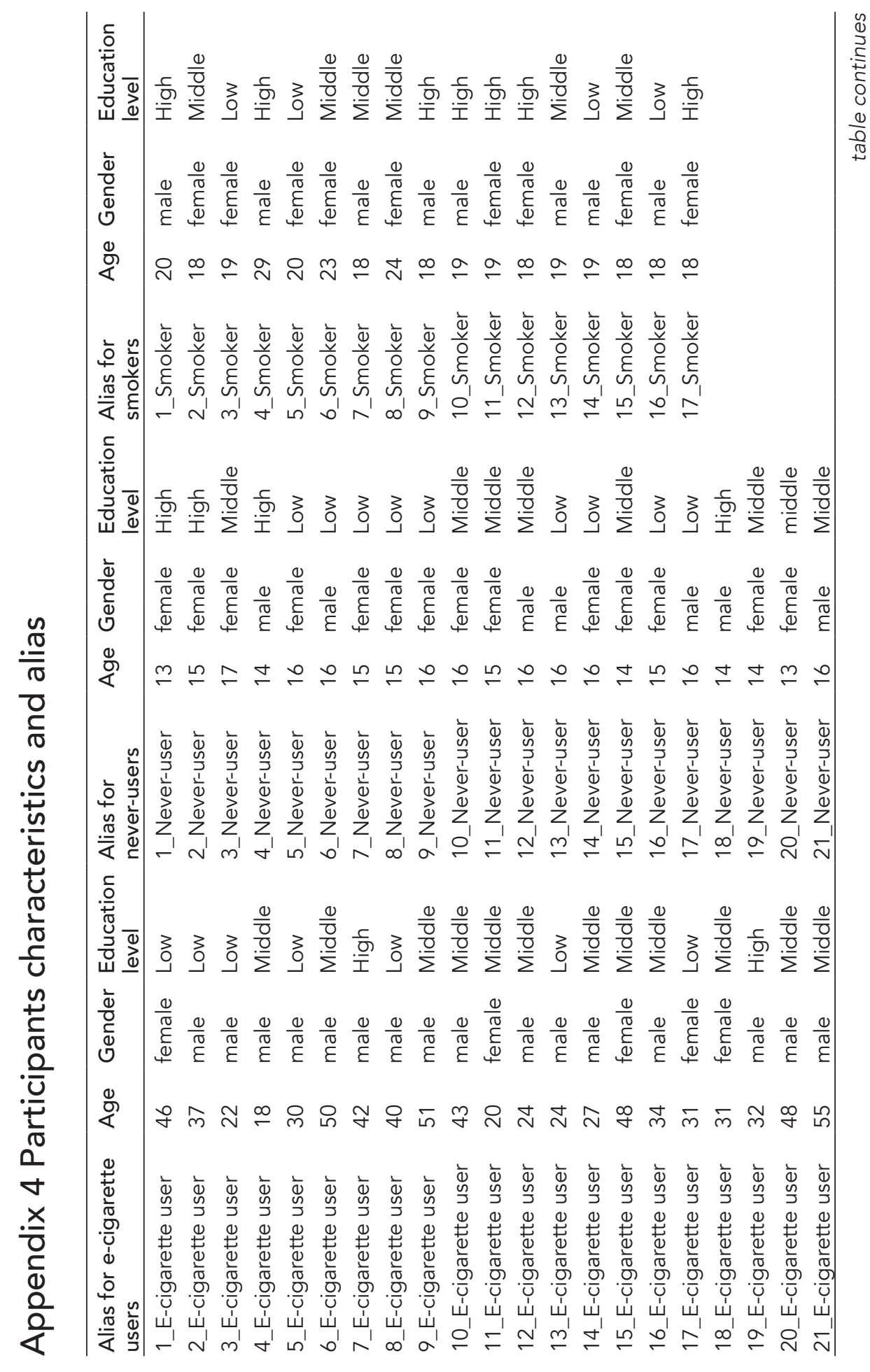




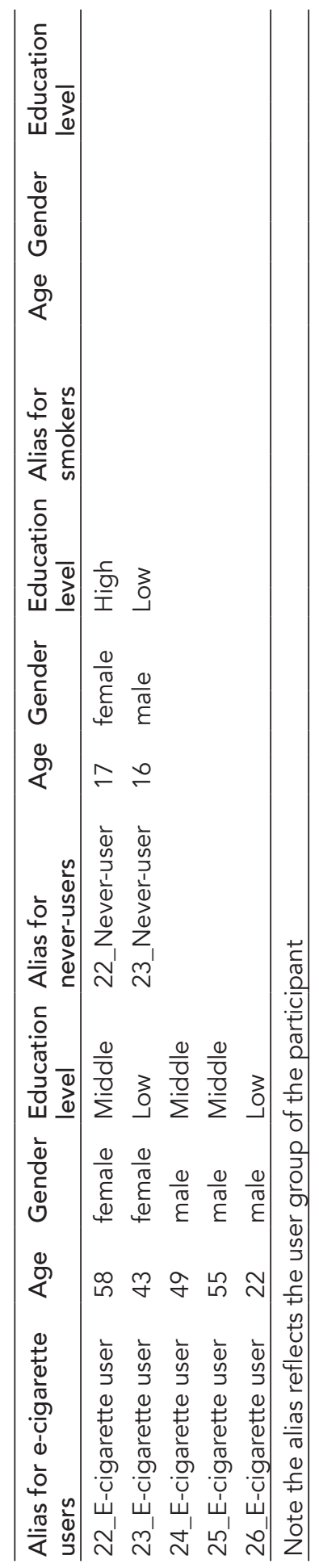




\title{
Appendix 5 Topic guide: exploring decision making process of e-cigarette use initiation
}

\author{
Chapter 3 \\ A Deliberate Choice? Exploring the Decision to Switch from Cigarettes to \\ E-Cigarettes
}

Note: All participants have to sign an informed consent before the start of the introduction.

Introduction by interviewer

Welcome! My name is ... and this is ..., who will be helping me with the discussion today. I work for ... and I my research is about....

Today we are discussing e-cigarettes. Your opinion as user/smoker/non-user is very important. We would like to talk to you about e-cigarettes and this discussion will take approximately two hours, with a break. At the end of our discussion we have time for general questions about e-cigarettes.

We would like to stress that there are no correct or wrong answers. Today is all about your experiences and your ideas. We will be hearing a lot of different ideas and experiences, so I would like to ask you to respect each other. Please listen carefully to each other and please let each other finish speaking.

This group discussion will be audio recorded. - Turn on audio recording- All personal information will be made anonymous, and please remember that your participation is voluntary. This means that you can leave at all times, you do not have to explain yourself.

Are there any remaining questions before we start?

Introduction participants

Please introduce yourself shortly. Do you use e-cigarettes exclusively? Or do you also use cigarettes or something else? What do you enjoy doing?

Make name tags

\section{General prompts}

What do you mean?

Can you tell me more about that?

What comes to mind?

Can you explain that to me?

. Is there anything else that you can think of? 
Topic guide: exploring decision making process of e-cigarette use initiation

Knowledge about e-cigarettes

What do you know about e-cigarettes?

Prompts

Risks, batteries, taxes, different

e-cigarettes, costs, health benefits

Attitude

What did you think when you used it?

What do you think of e-cigarettes?

Prompts

How does it feel? Do you compare

it to cigarette smoking? What do

you think of the action of using

e-cigarettes?

\section{Deliberation}

Did you ever try an e-cigarette?

When did you try an e-cigarette?

How did you consider e-cigarette use?

Who played a role in your decision?

What played a role in your decision?

How difficult was it to make a decision?

Prompts Did you consider using something else, like an NRT? Did you ask for advice? Did you go to a shop? Are you happy with your decision? Would you do it differently? What would have made it easier for you to make a decision about e-cigarette use?

[use these prompts to link to next topic]

\section{Information need}

What information is important to make a decision about e-cigarette use?

Where did you look for information about e-cigarettes?

Prompts

Which information was important to you? Which source was important to you? How do you know how to trust information? Which information do you still miss?

\section{Closing}

Is there anything we did not cover today that you find important related to e-cigarettes?

Do you have any questions left?

Note: due to the semi-structured protocol these questions are examples and may vary slightly in each focus group in both style and order. 


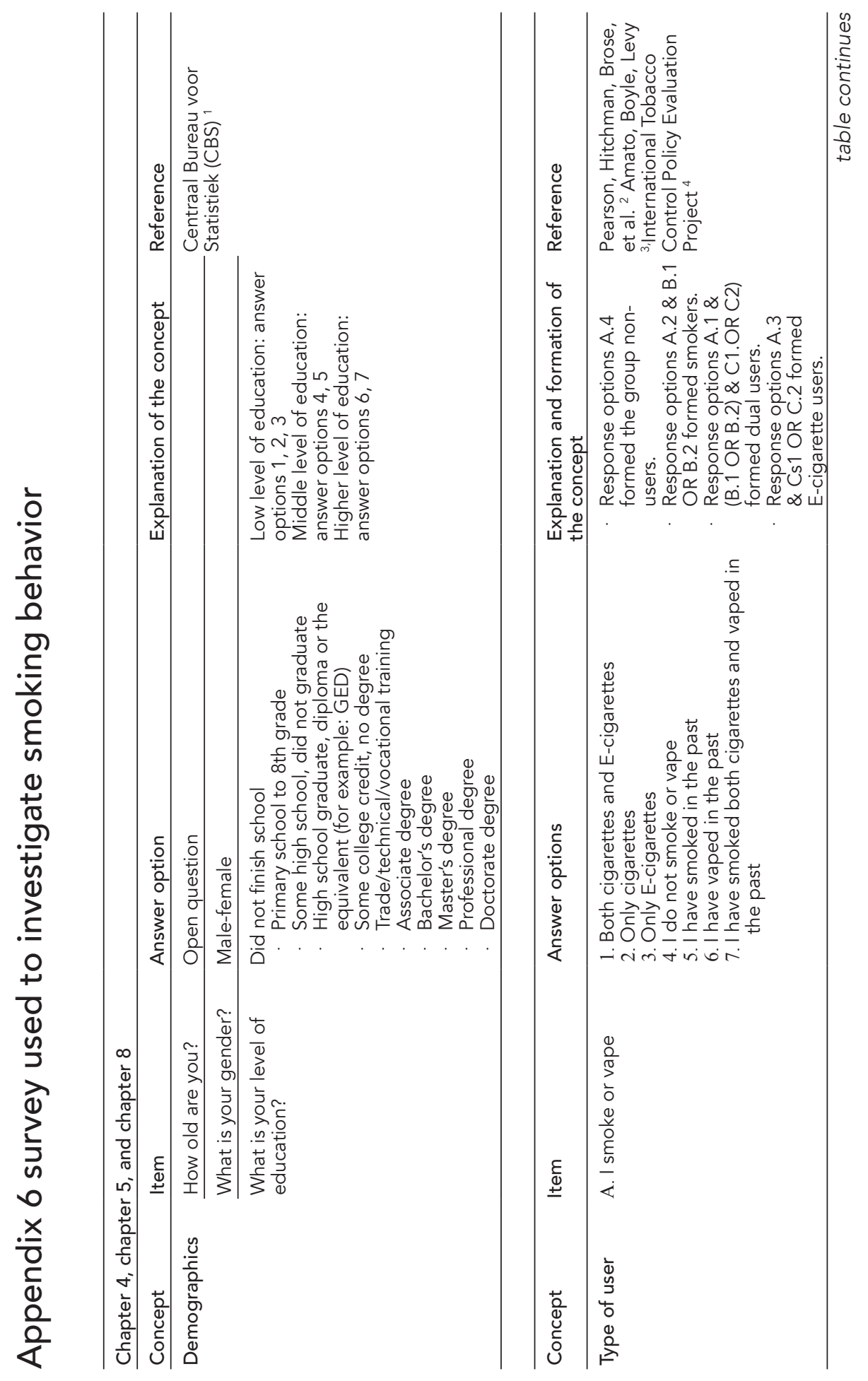




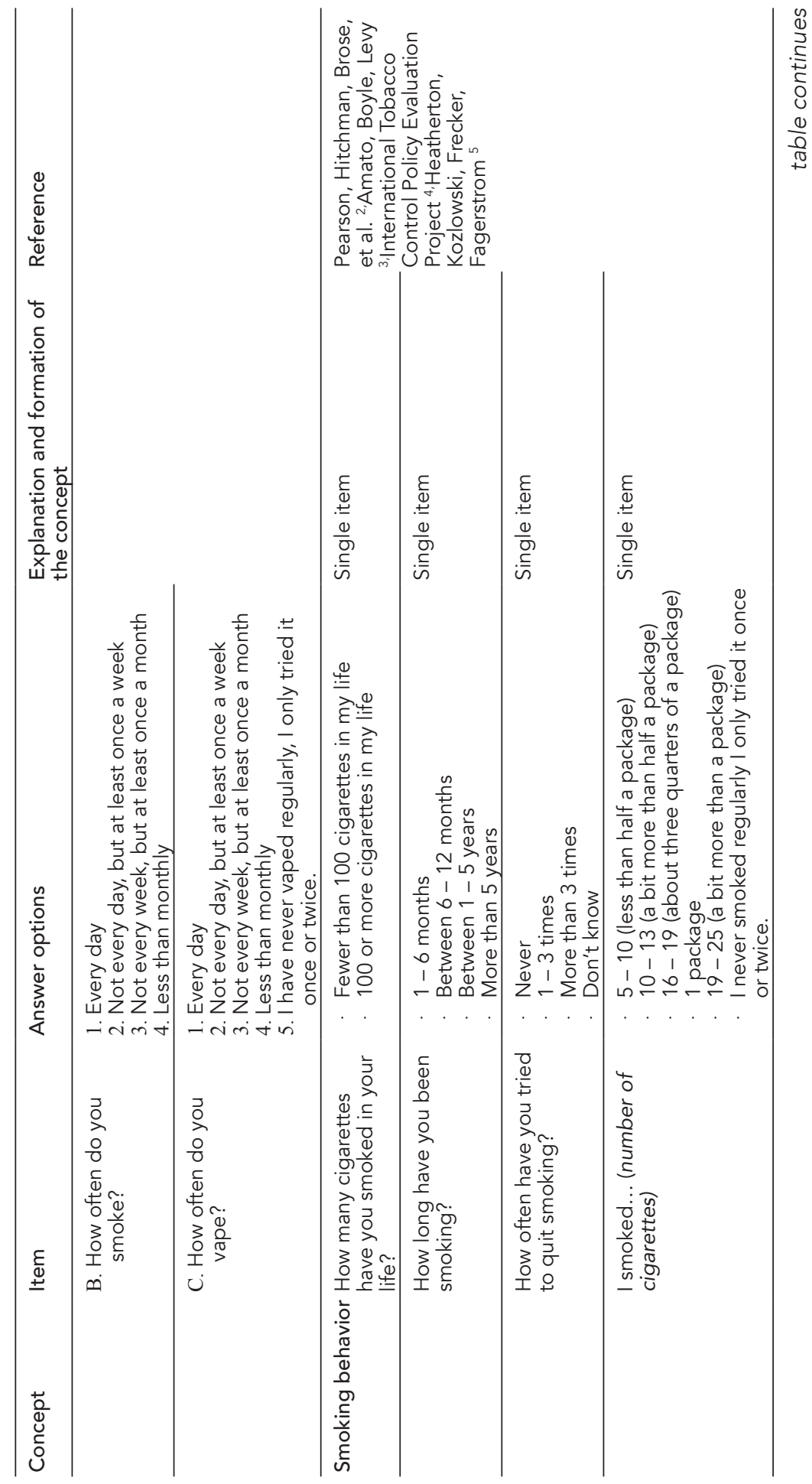




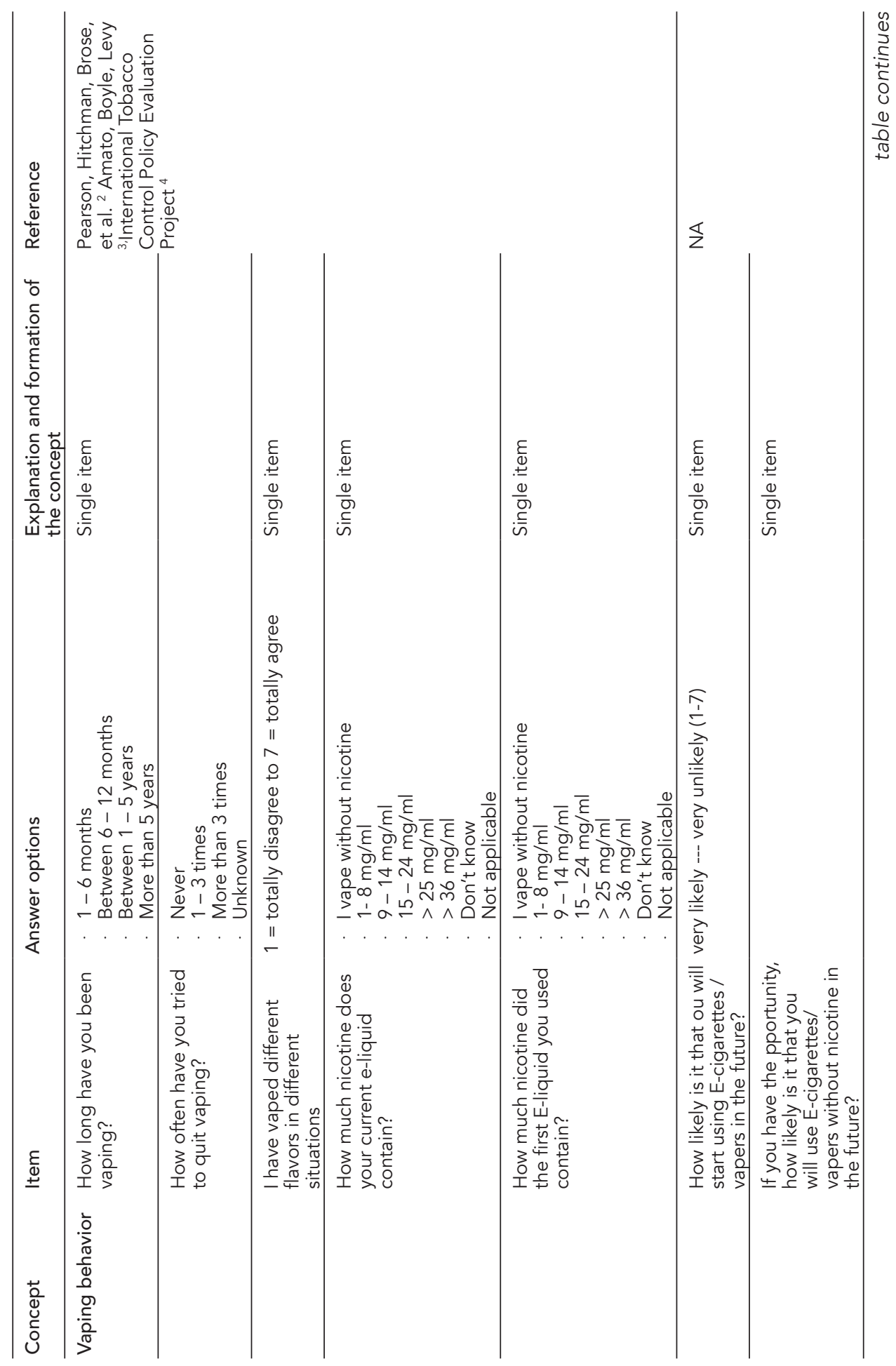




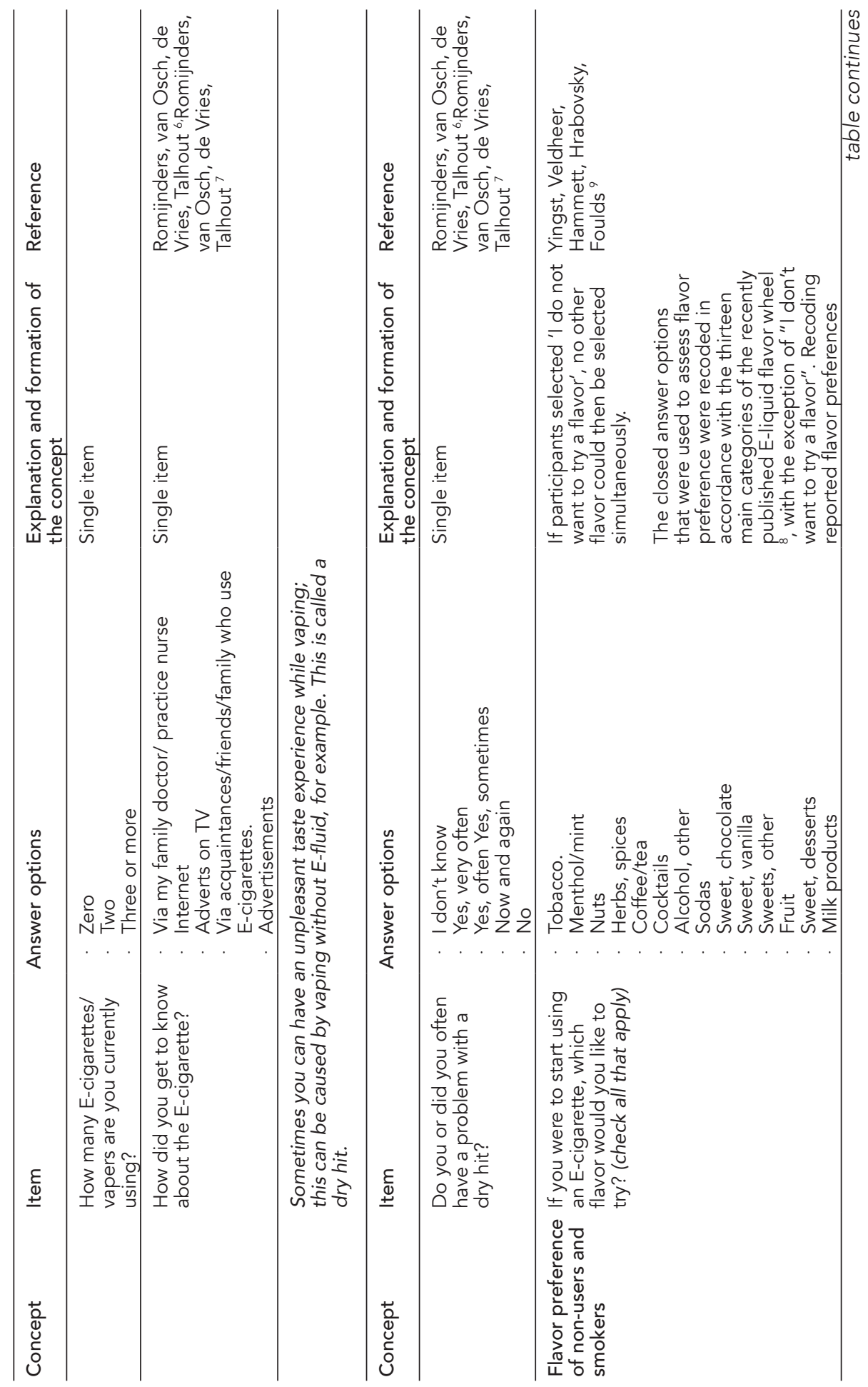




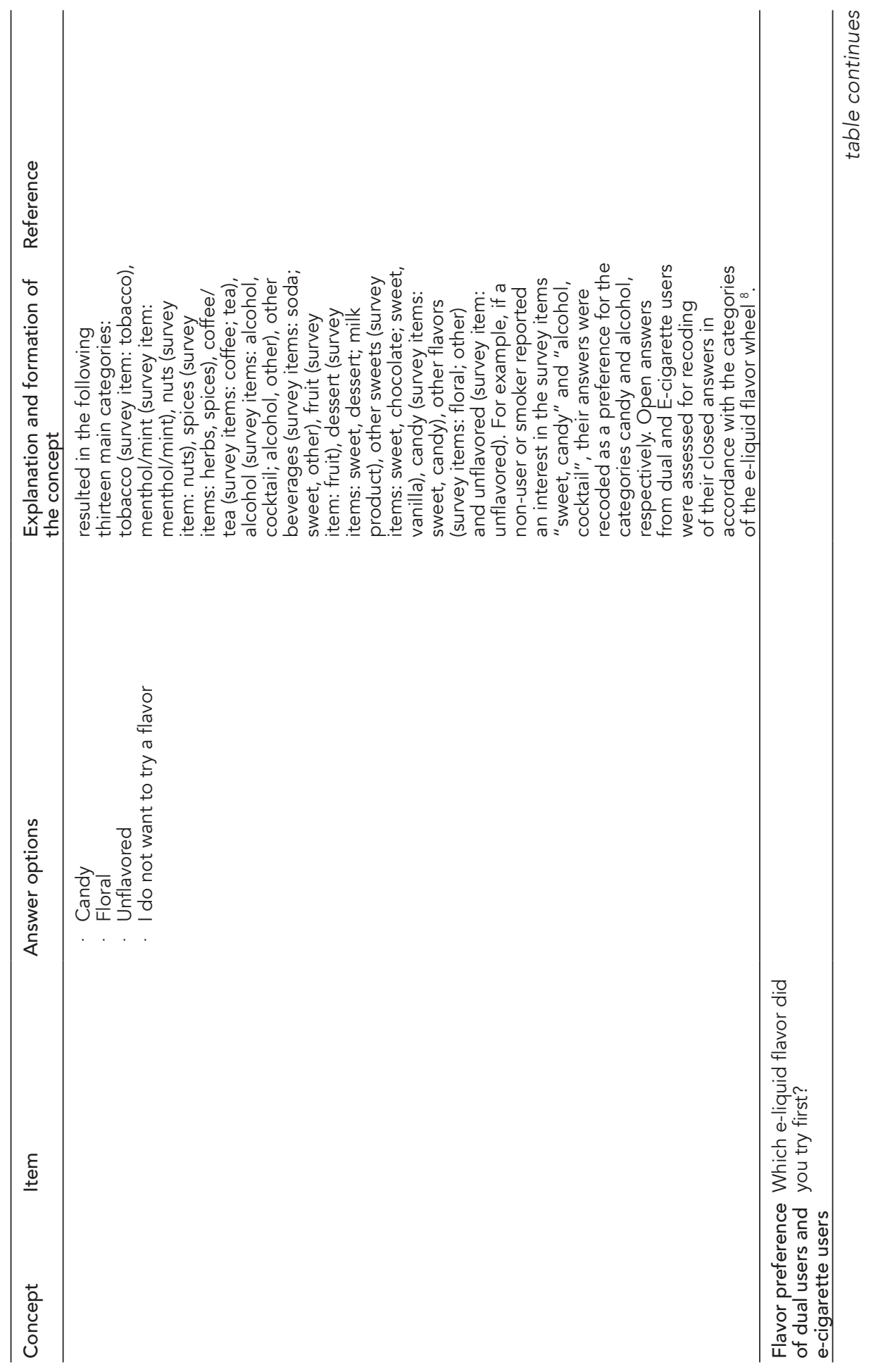




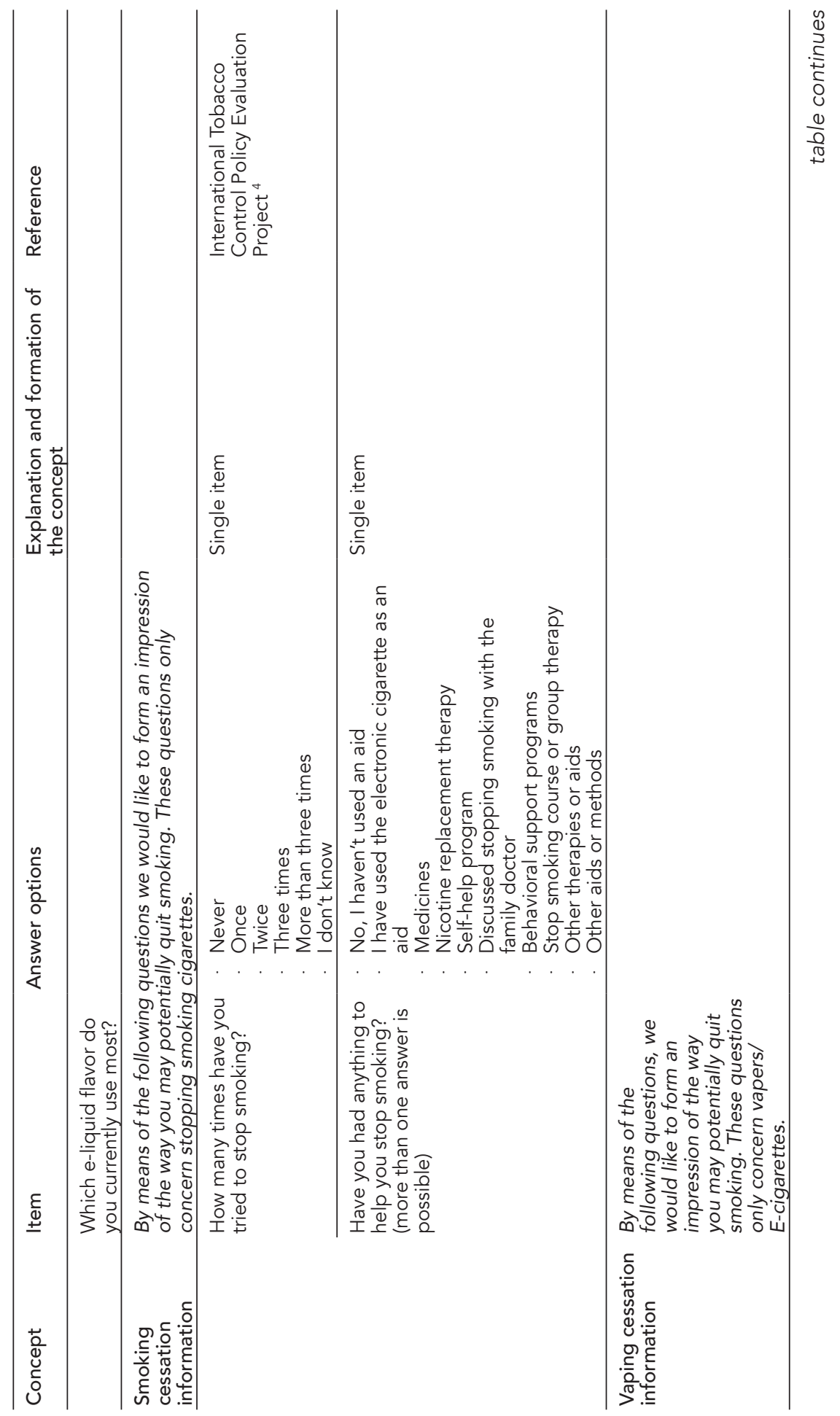




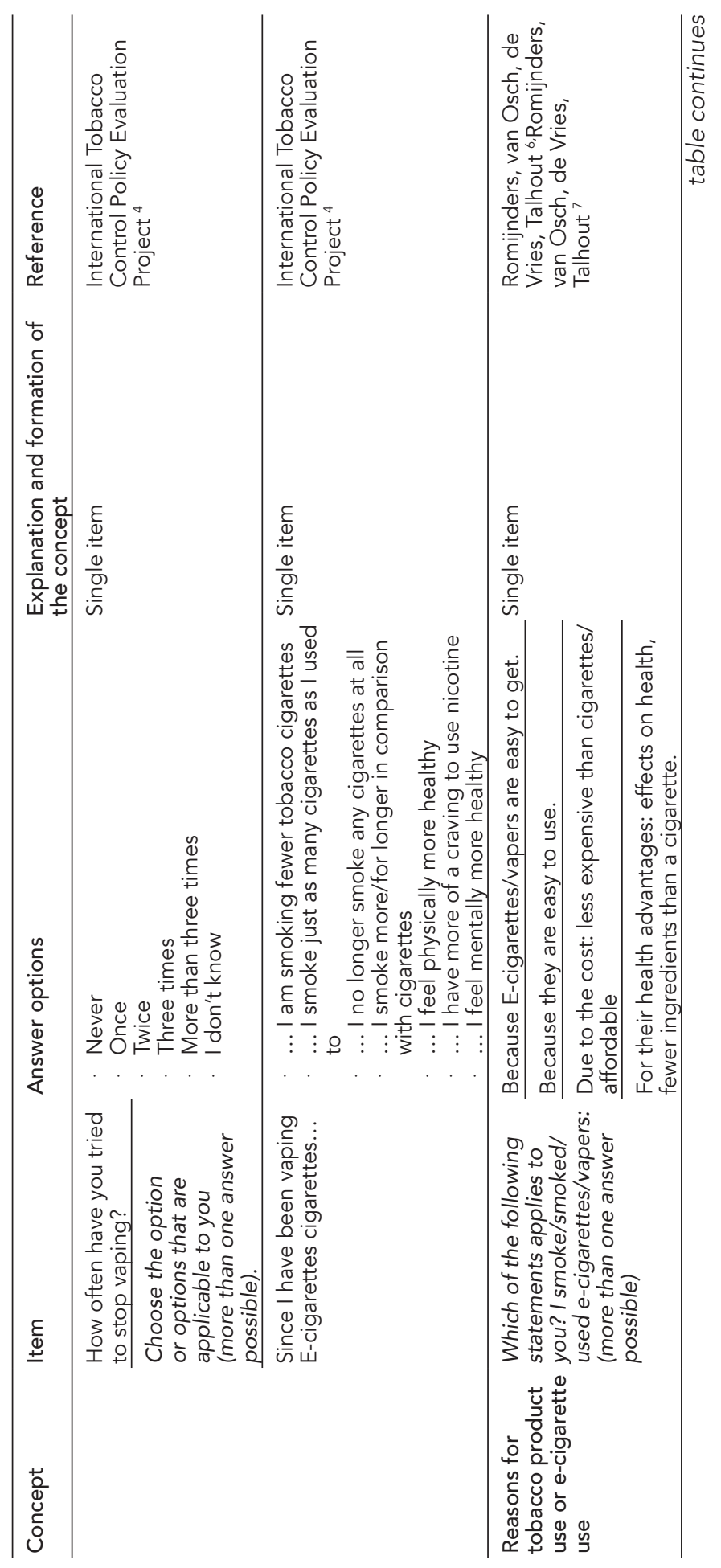




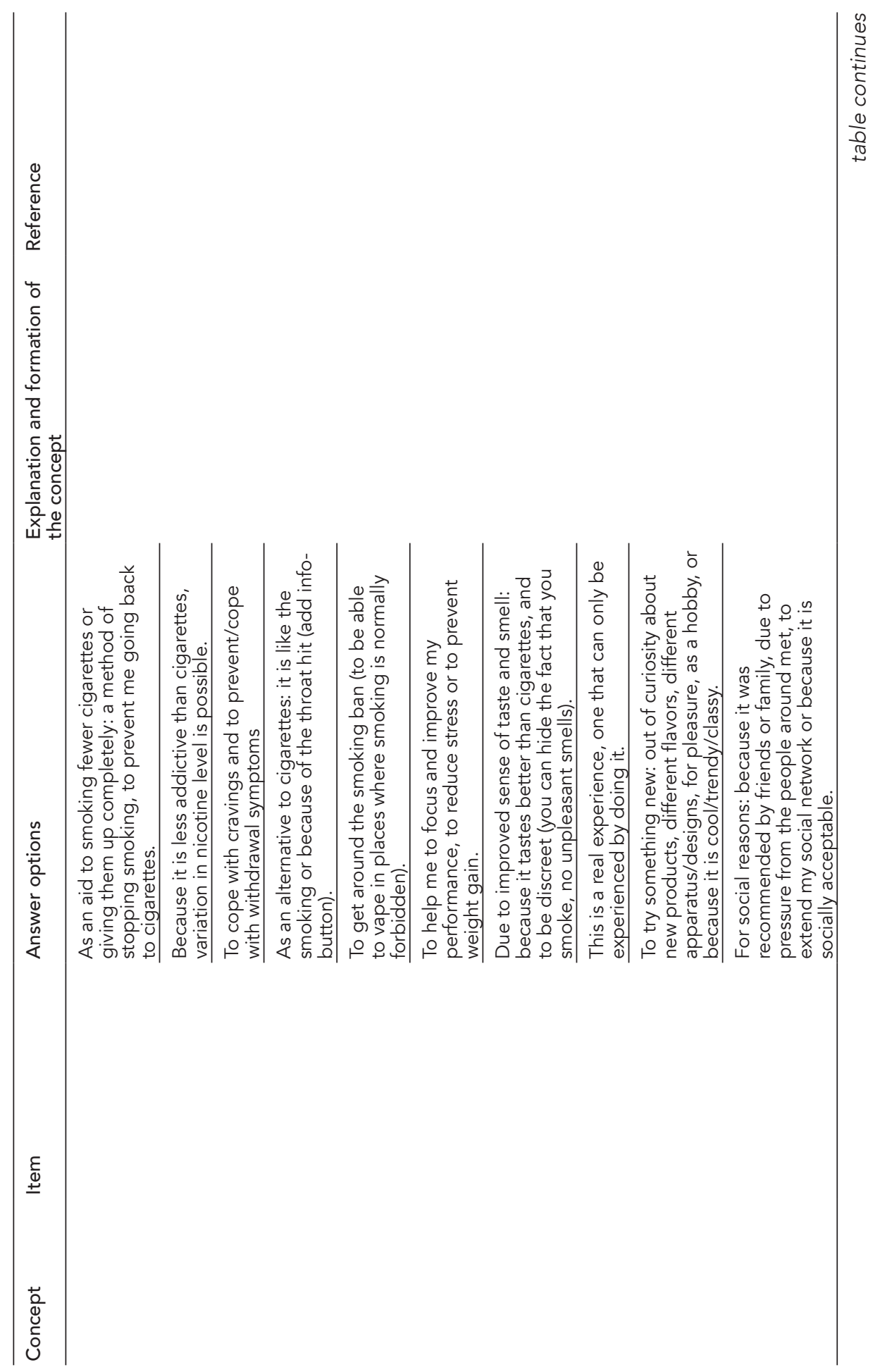




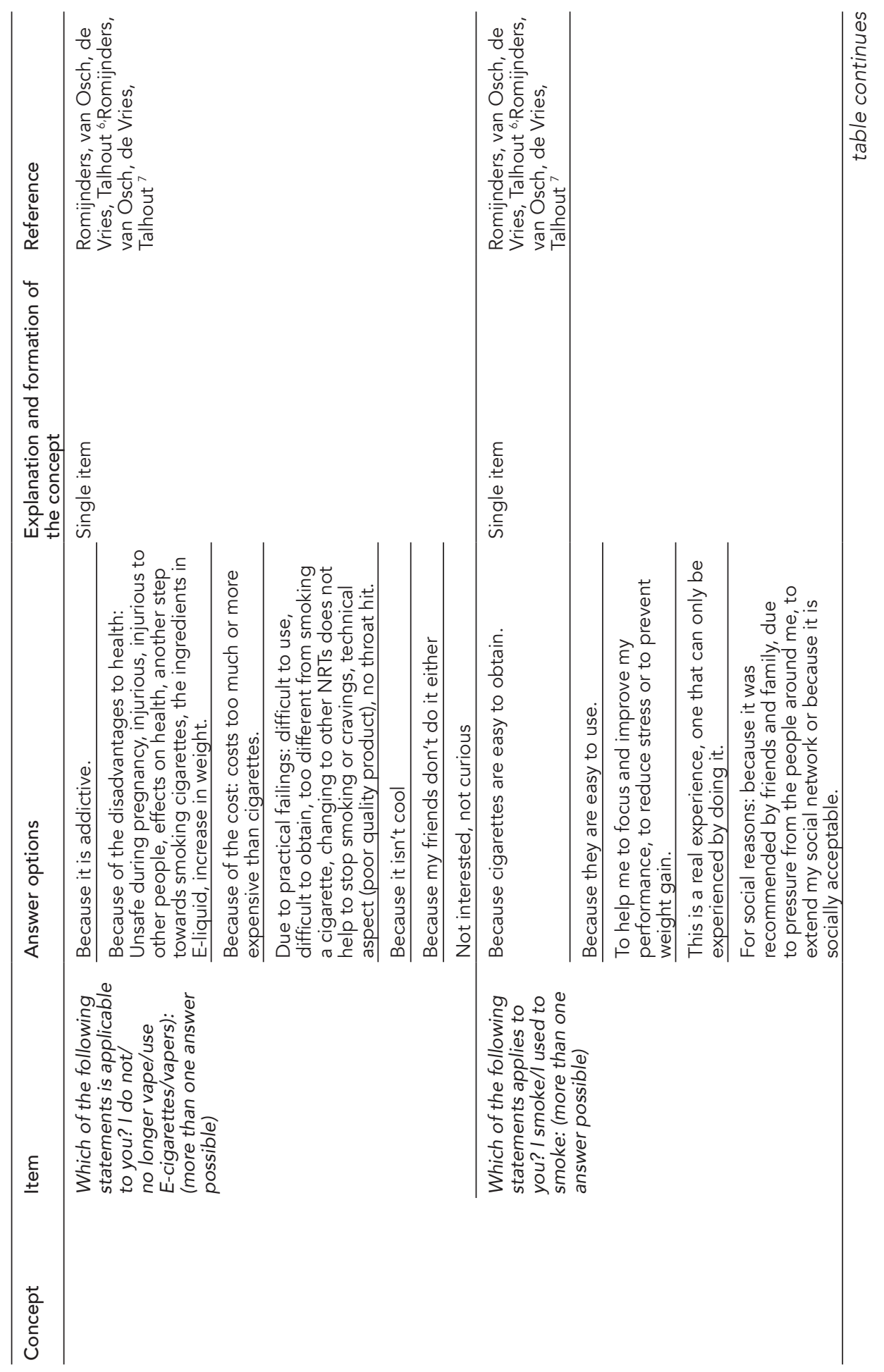




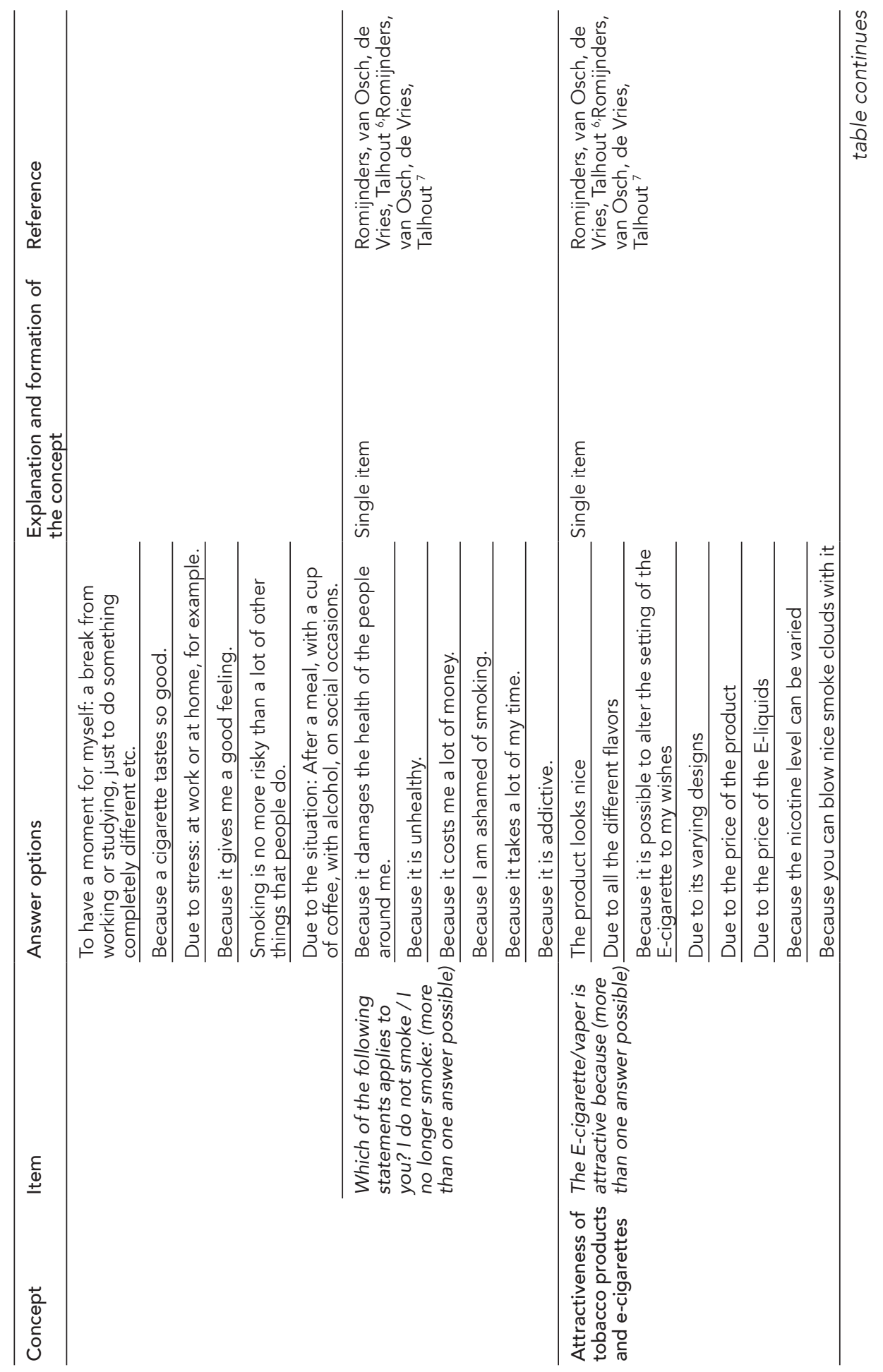




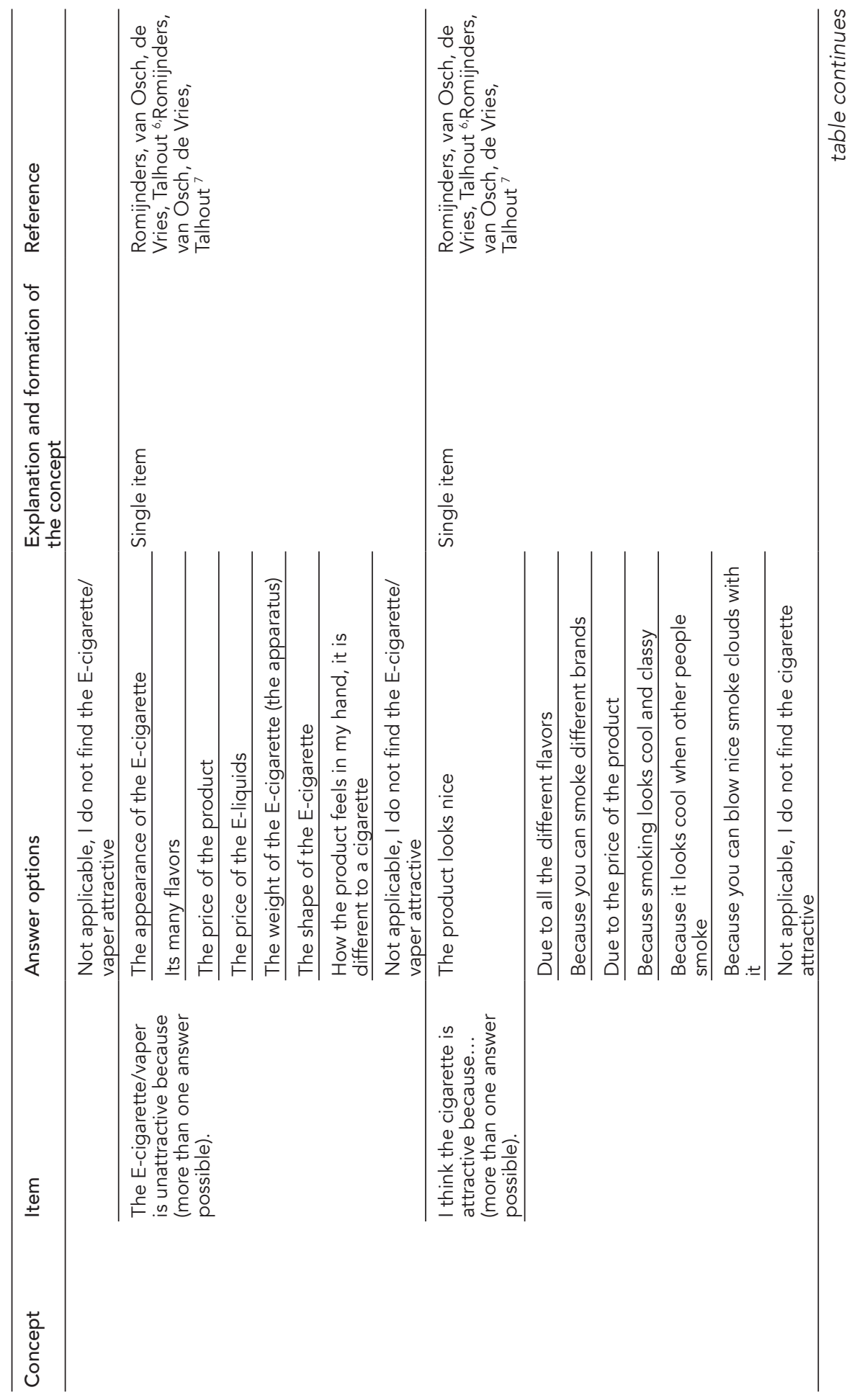



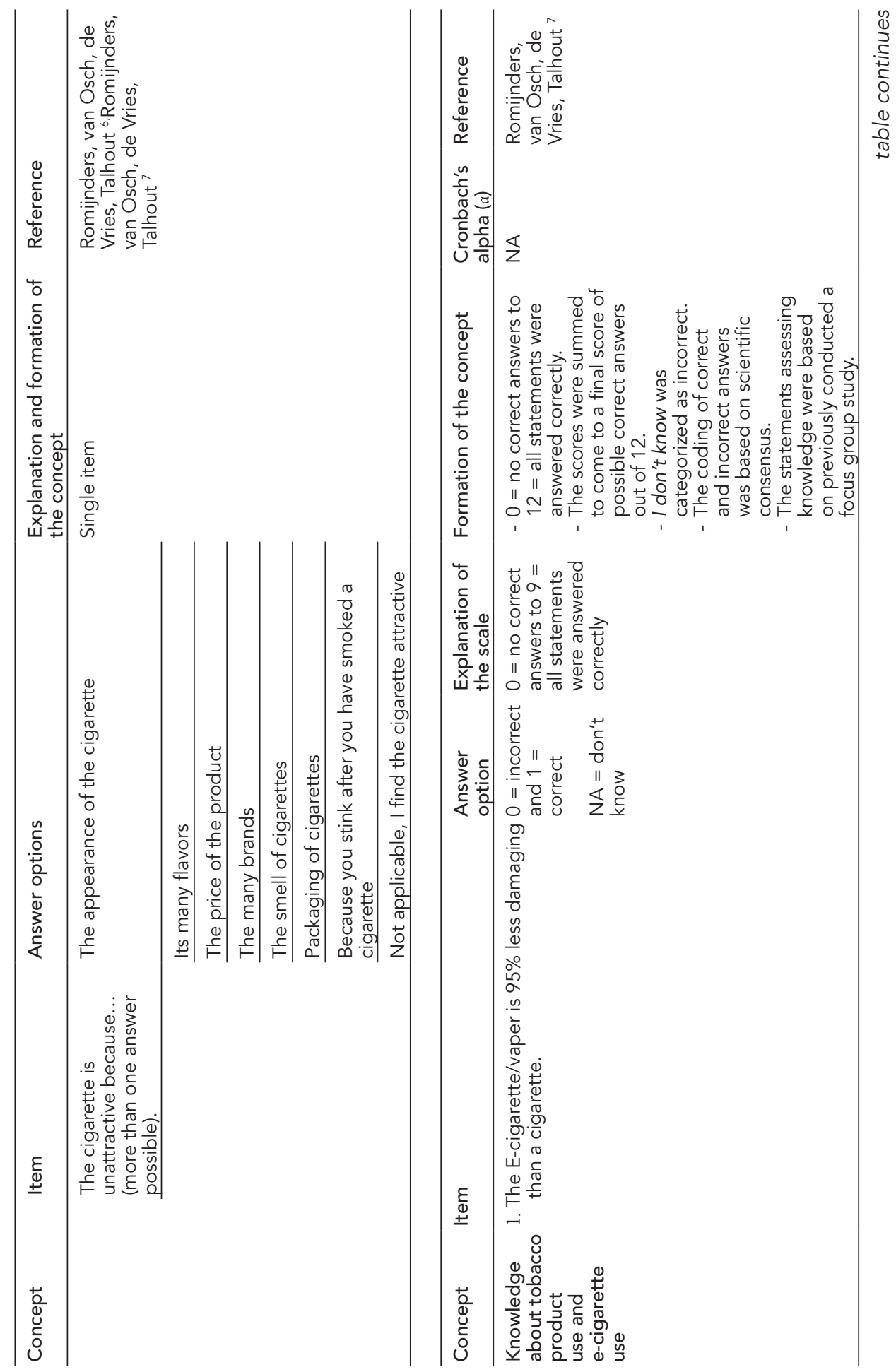


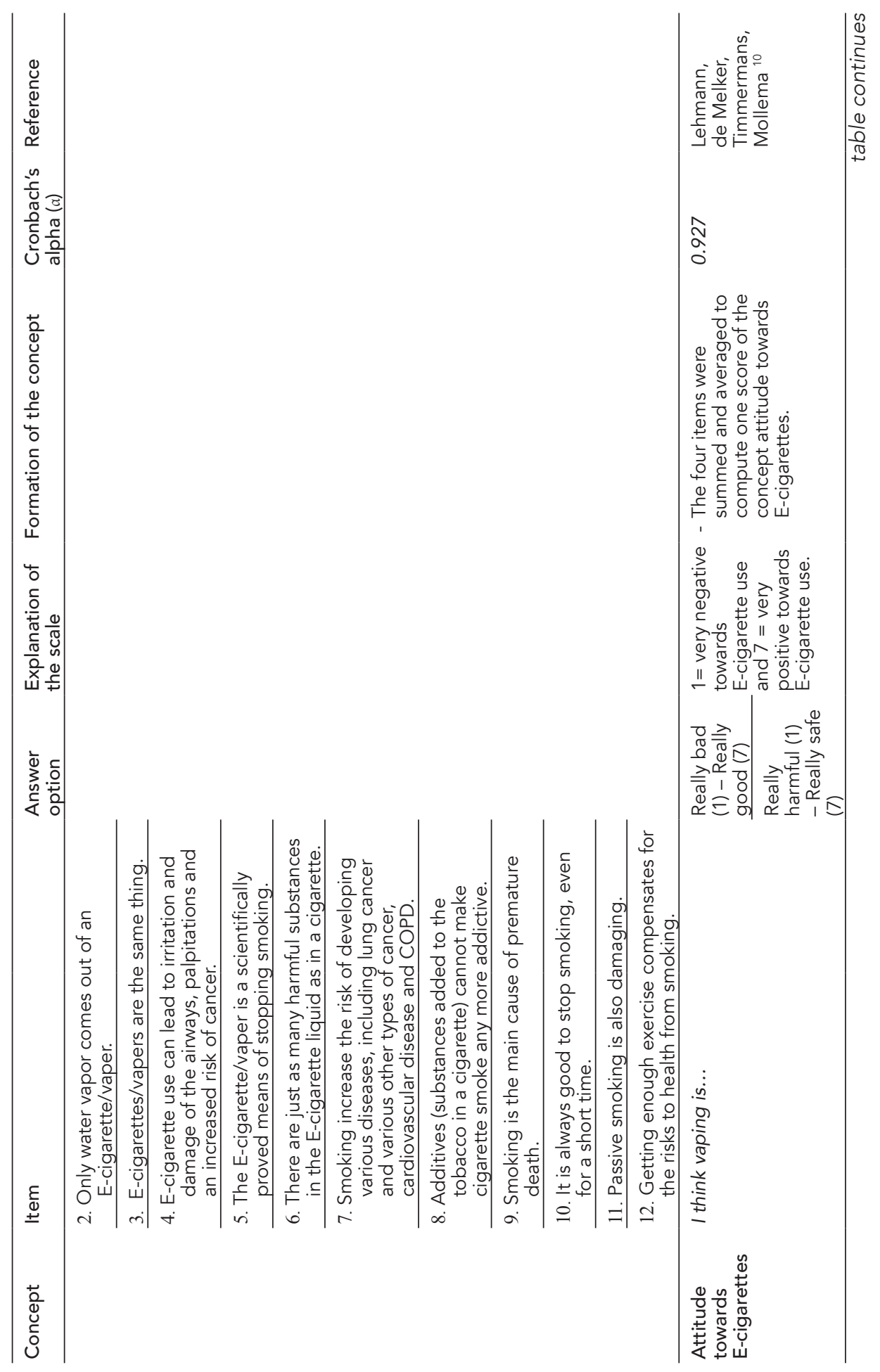




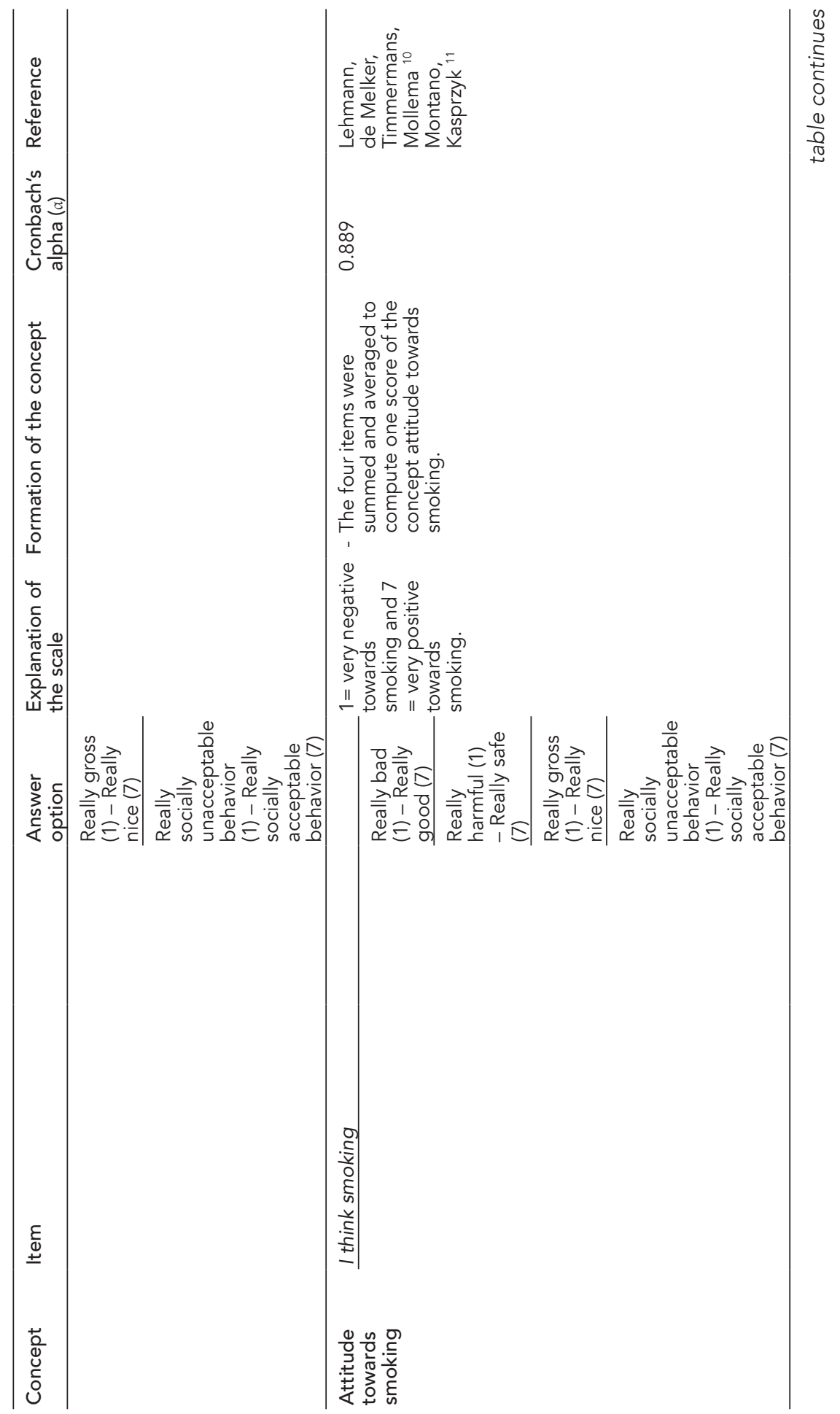




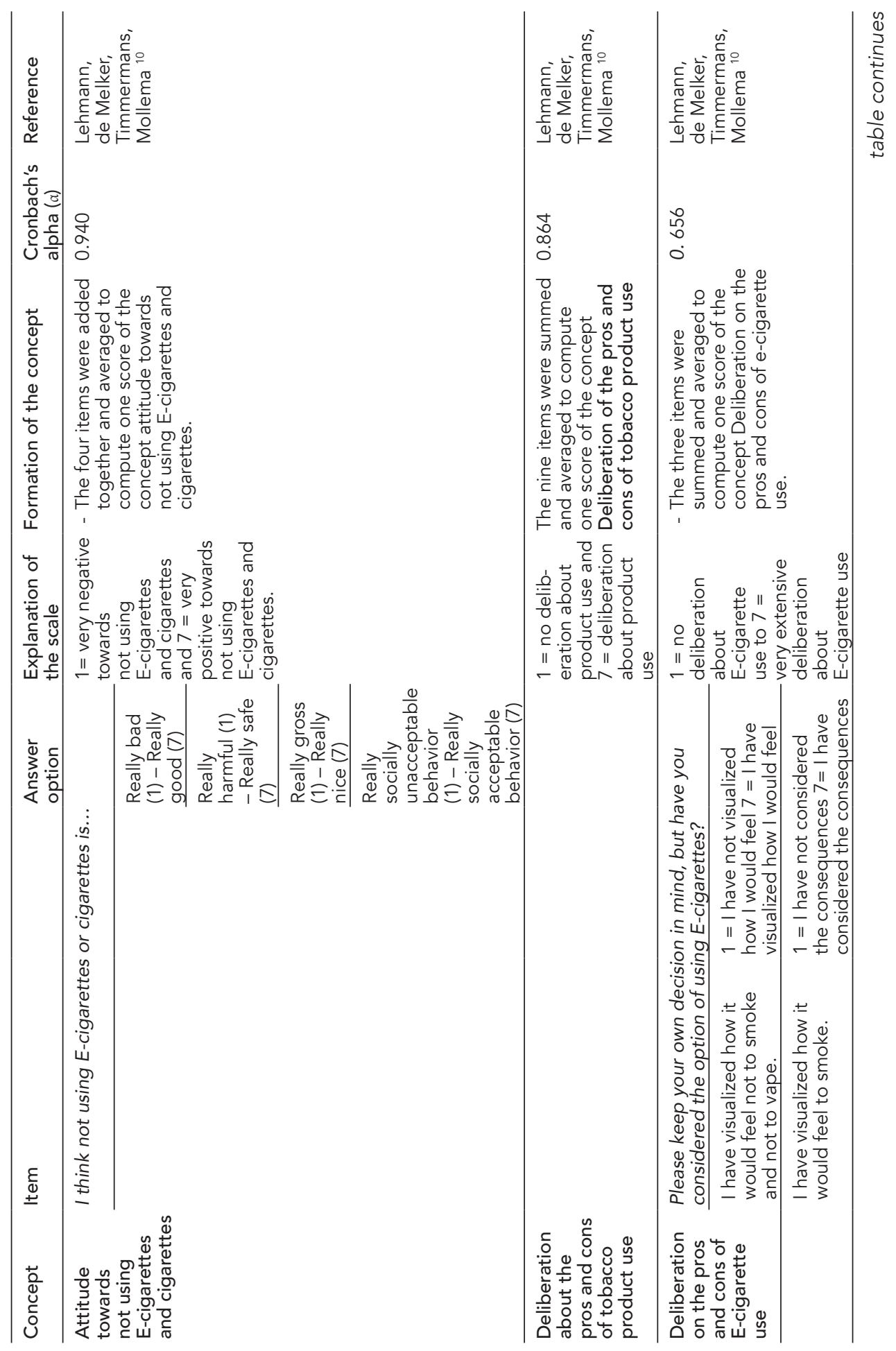




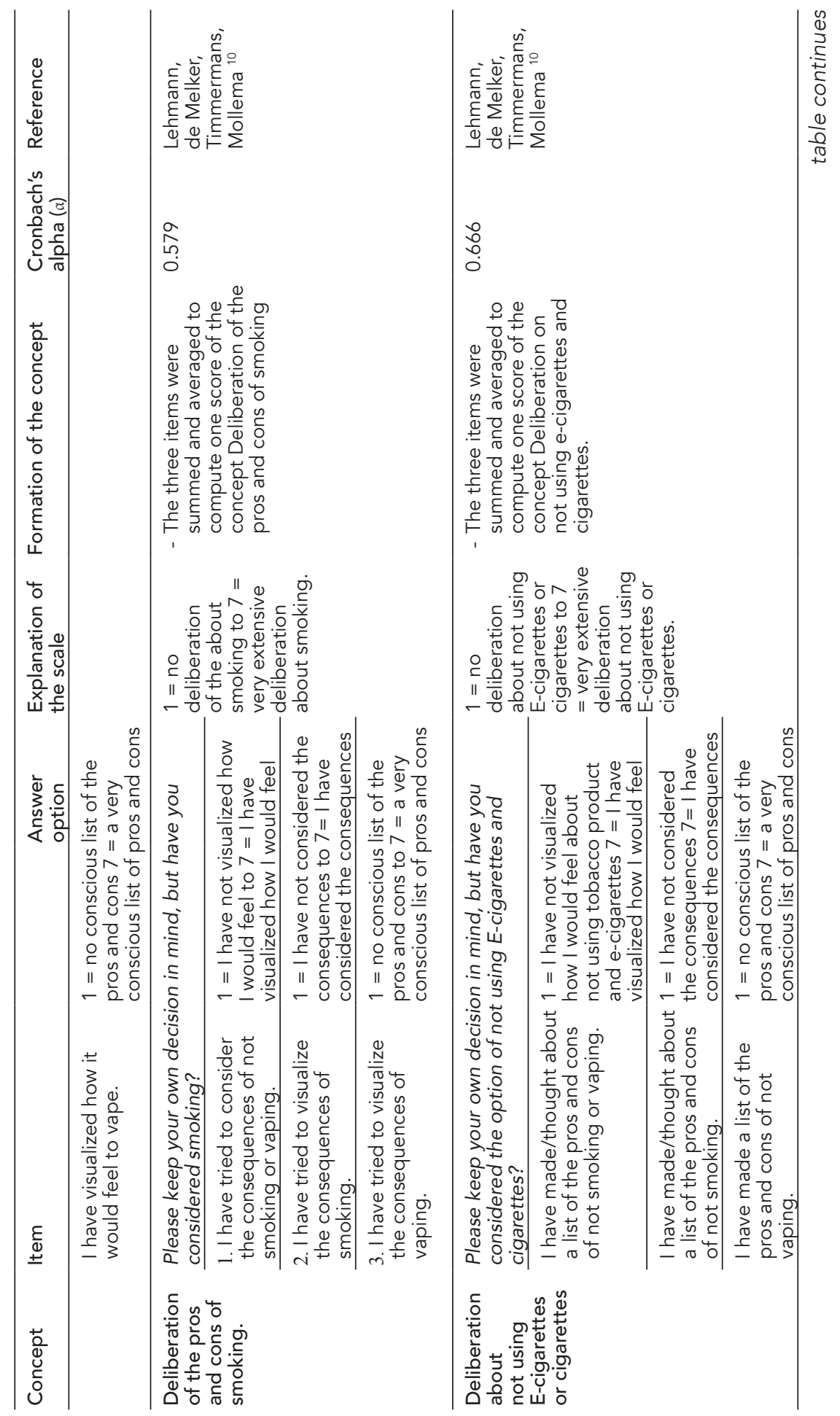




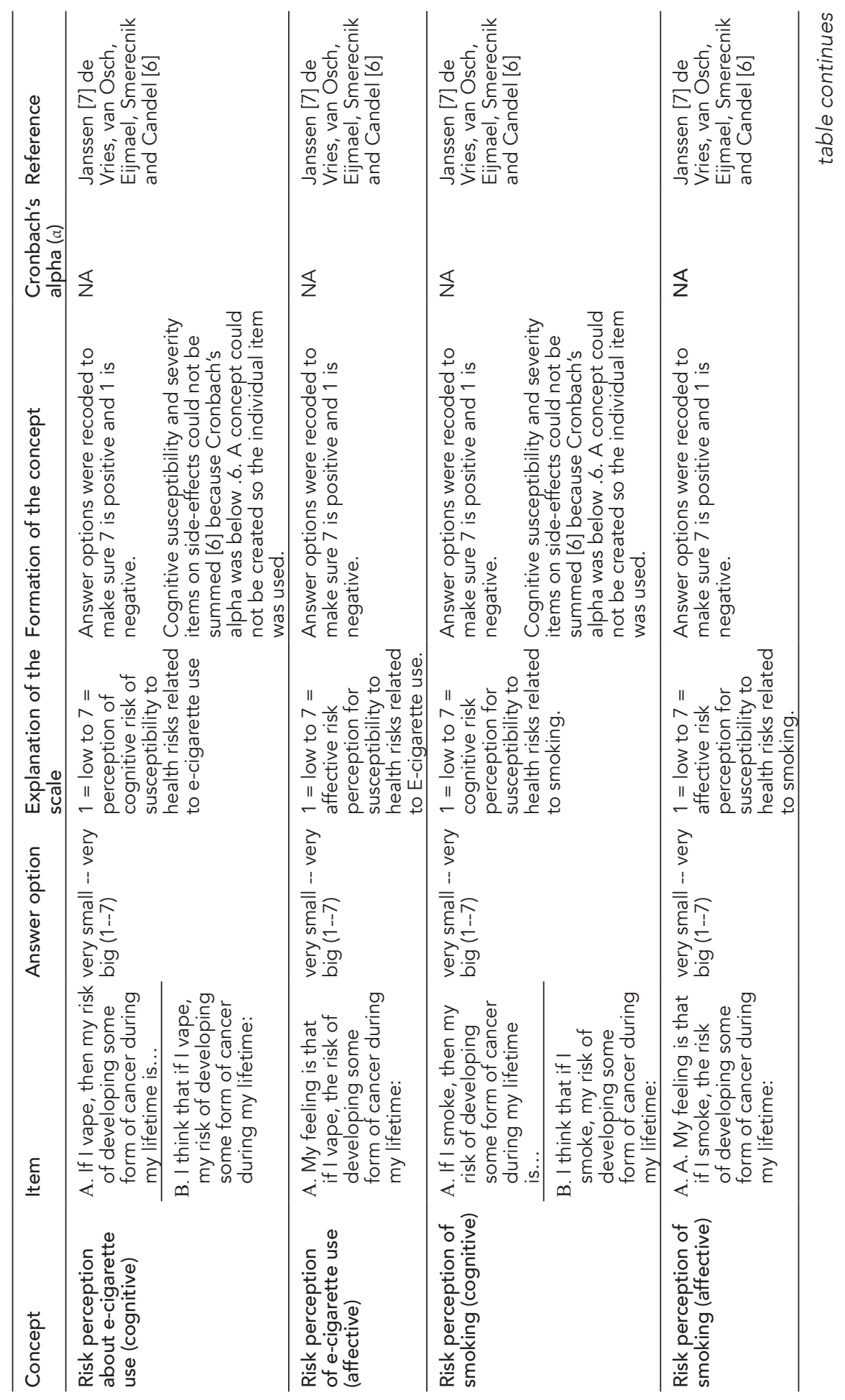




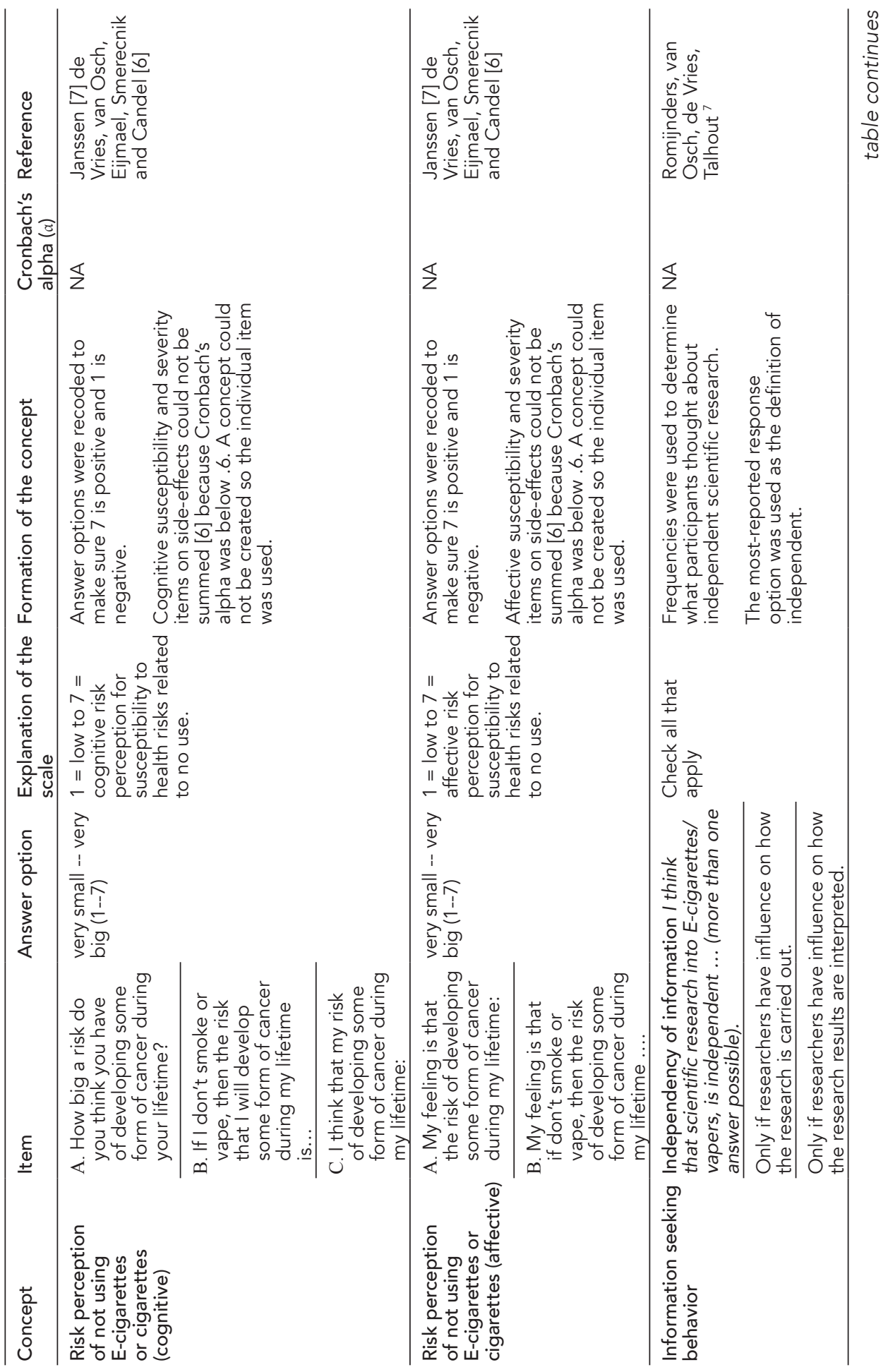




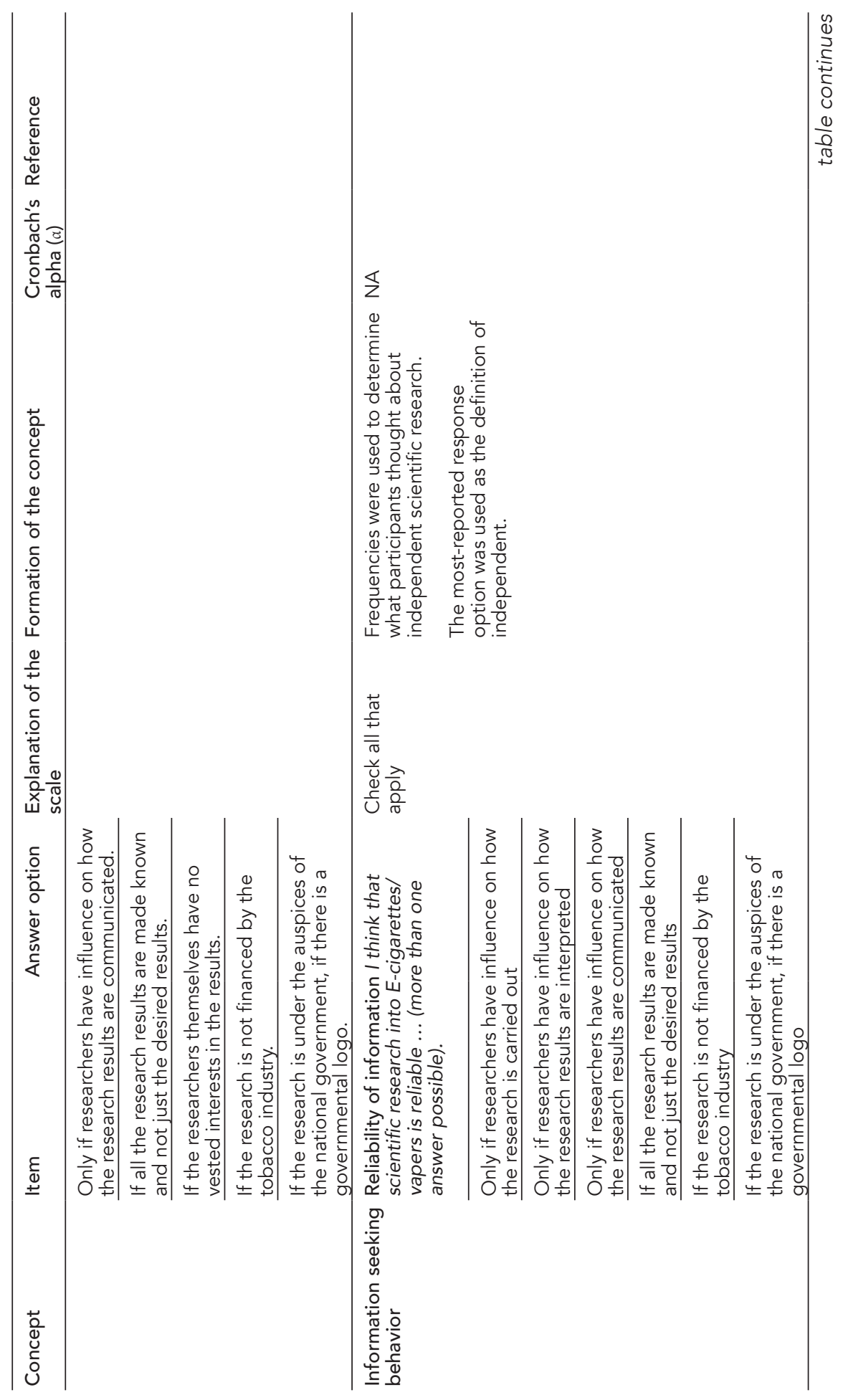




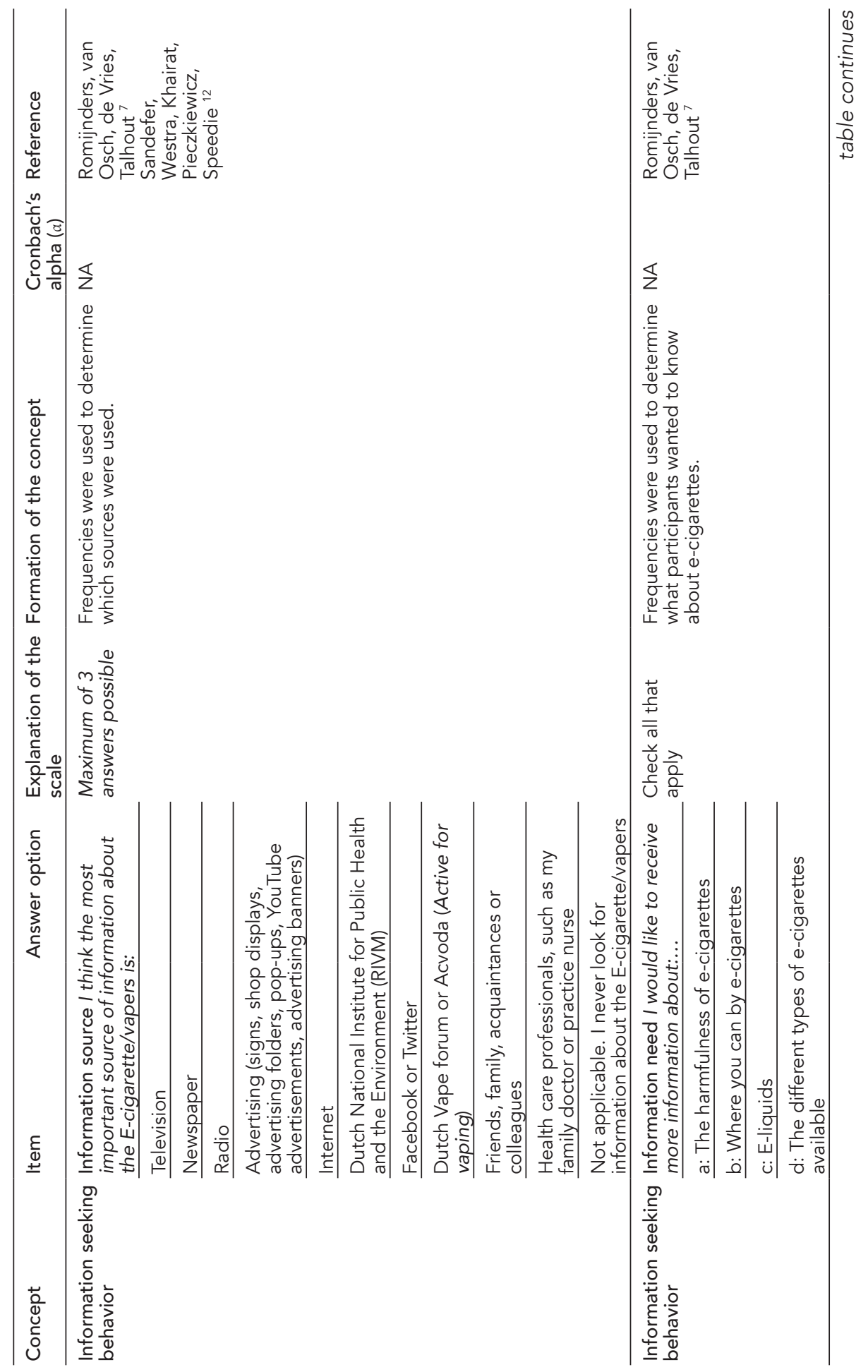




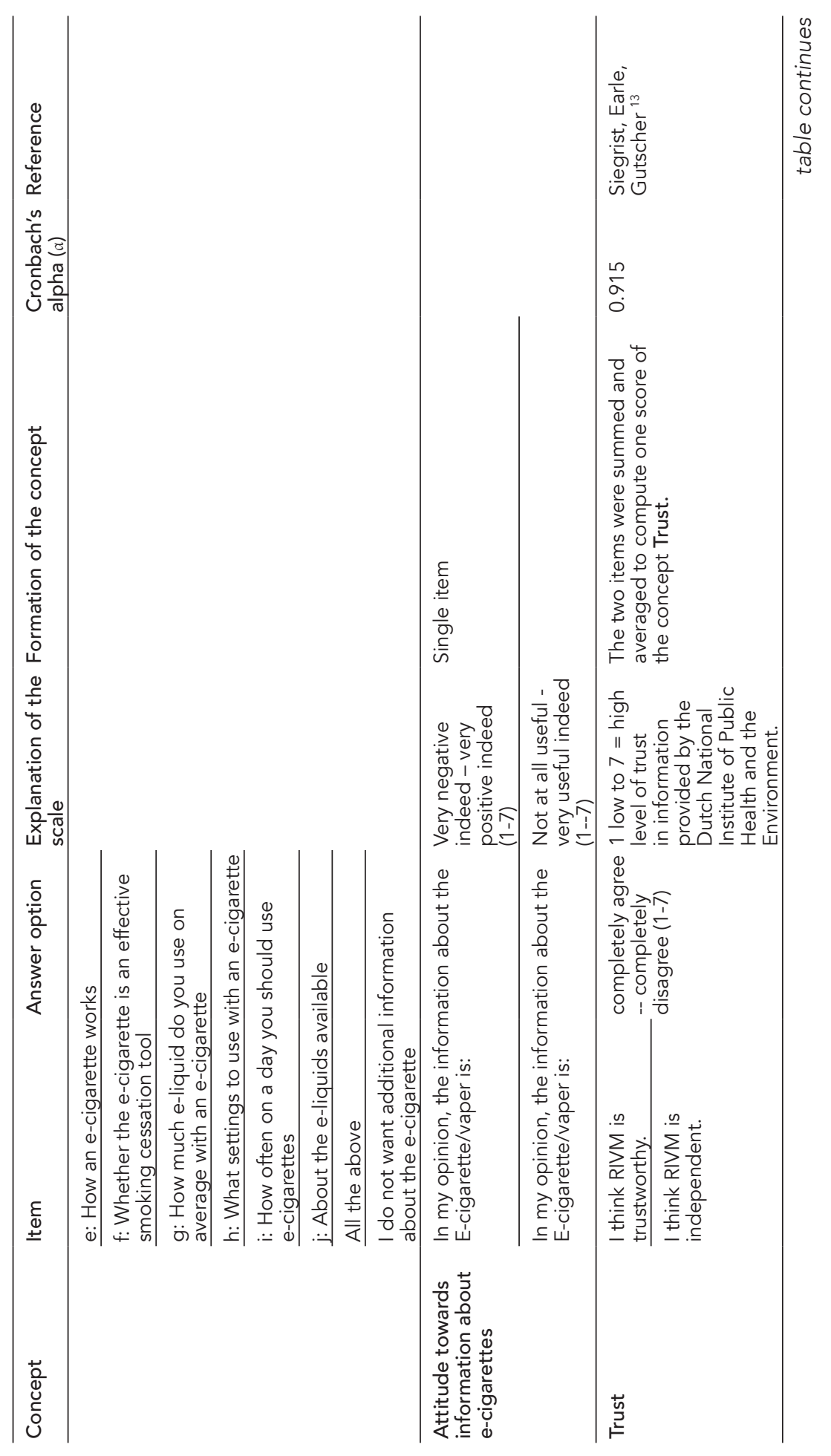




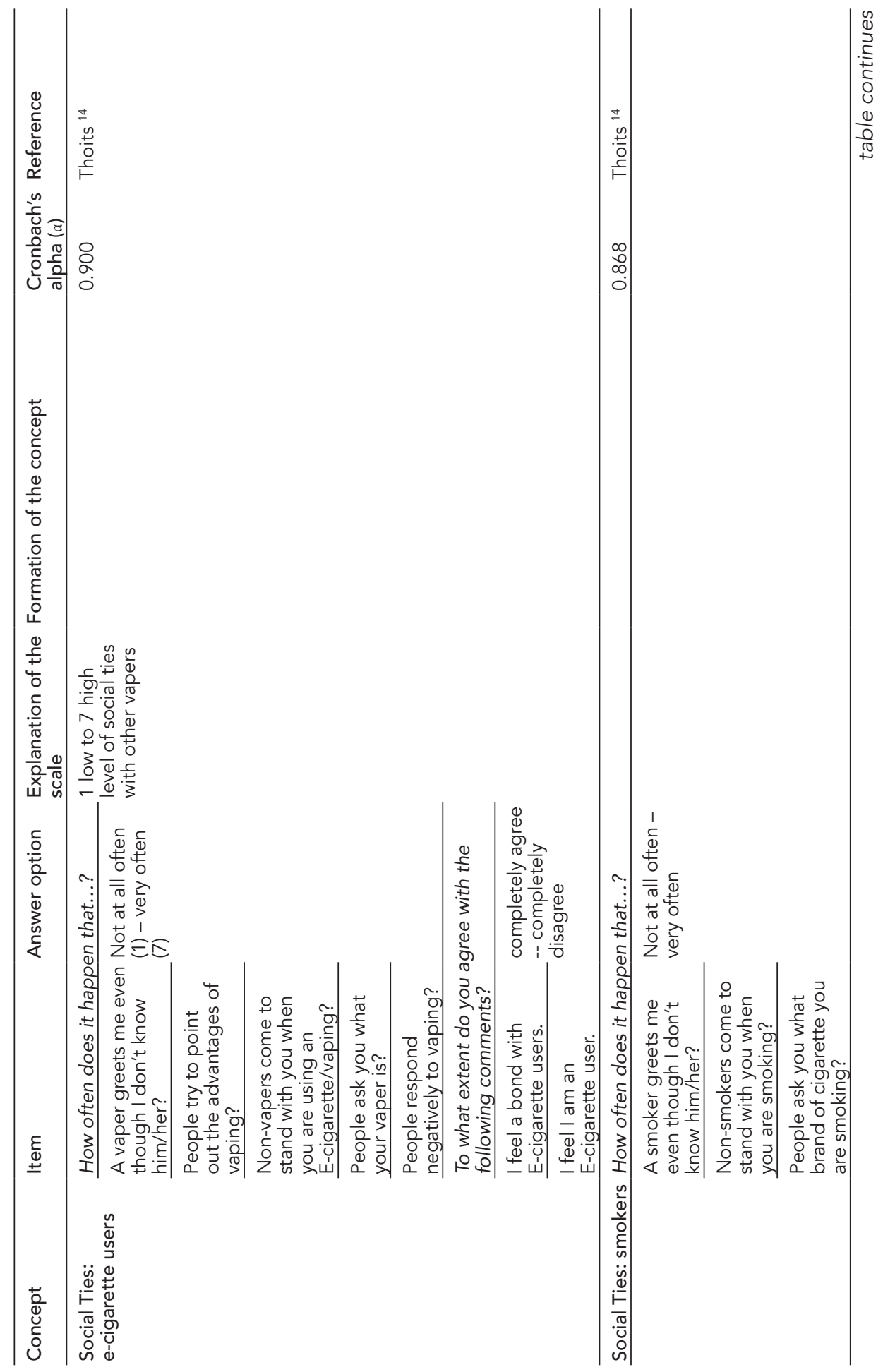




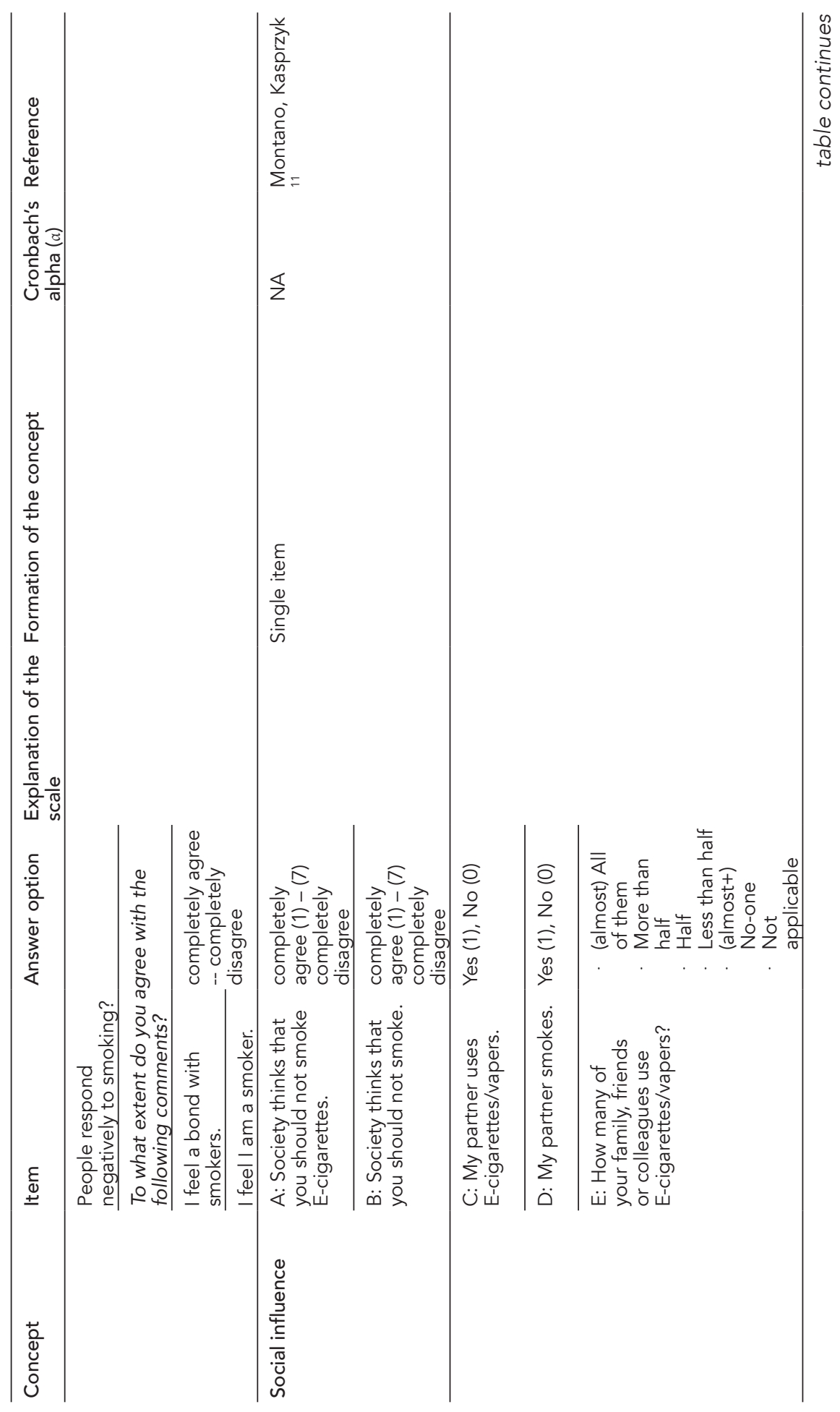




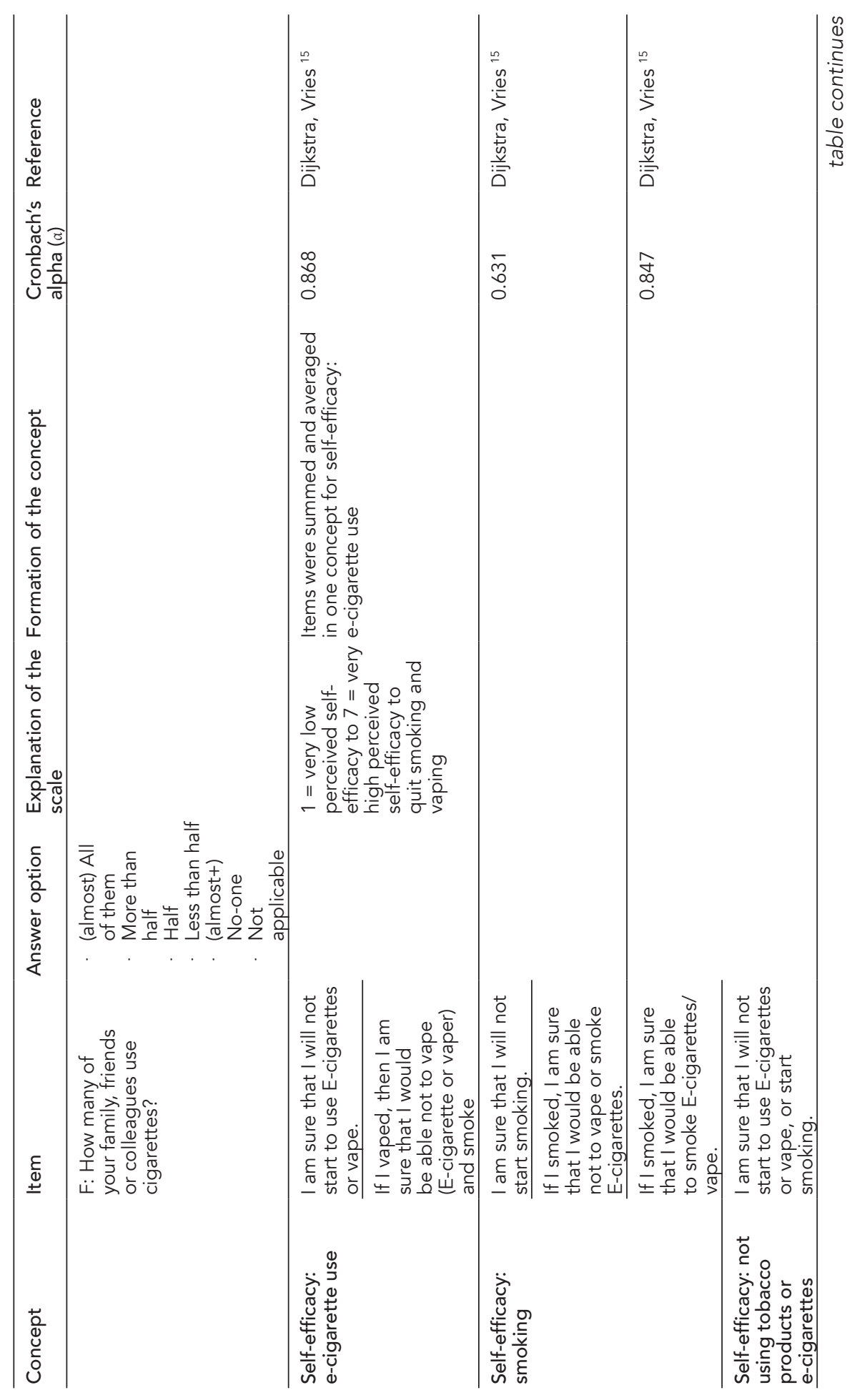




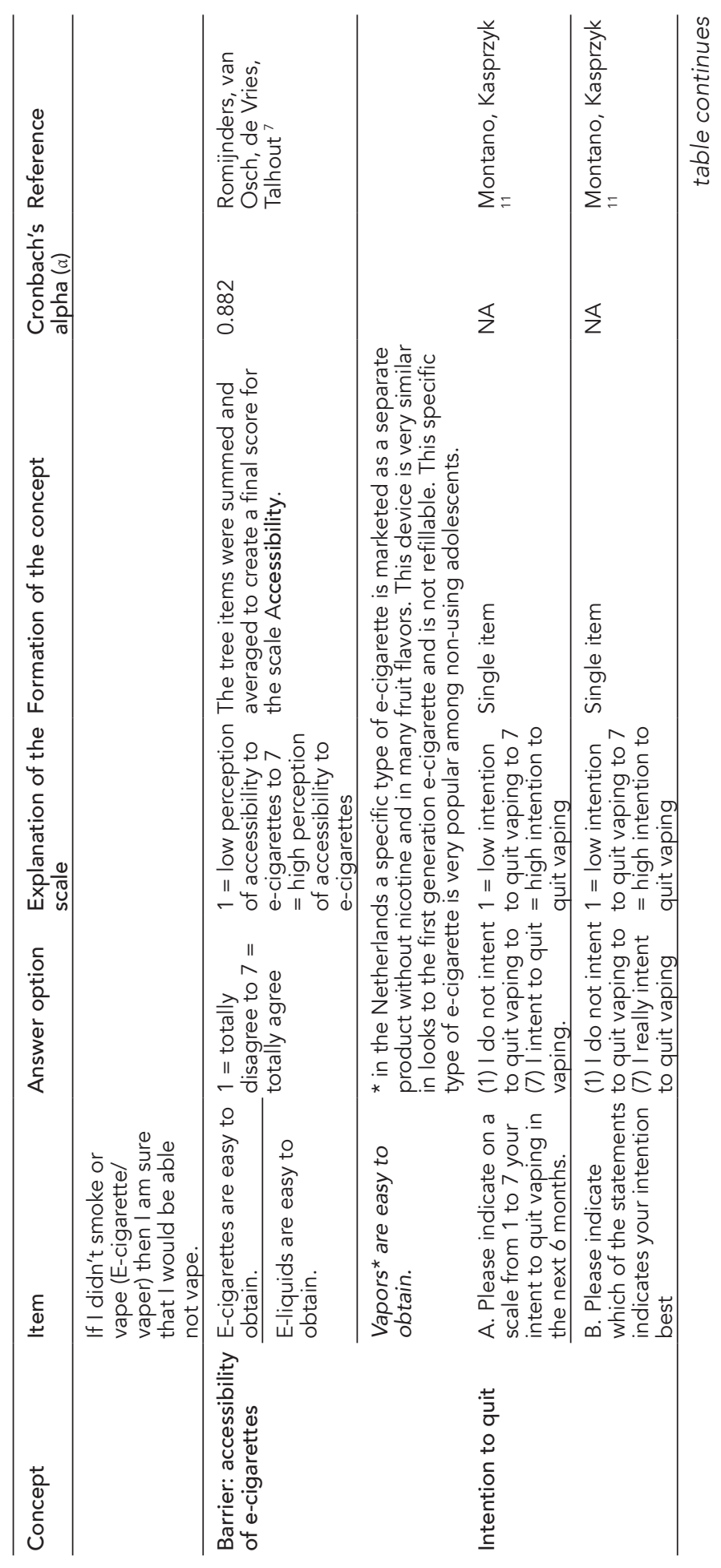




\section{References}

1. Centraal Bureau voor Statistiek (CBS). [International Standard Classification of Education (ISCED)]. Heerlen: Centraal Bureau voor Statistiek (CBS);2018.

2. Pearson JL, Hitchman SC, Brose LS, et al. Recommended core items to assess e-cigarette use in population-based surveys. Tob Control. 2018;27(3):341-346.

3. Amato MS, Boyle RG, Levy D. How to define e-cigarette prevalence? Finding clues in the use frequency distribution. Tob Control. 2016;25(e1):e24-29.

4. International Tobacco Control Policy Evaluation Project. ITC Netherlands (NL11_ Pw). International Tobacco Control (ITC). 2017. https://www.itcproject.org/files/ ITC_NL11_Replenishment_S_web_Eng_Dut.pdf. Accessed 10, Jan, 2018, 2018.

5. Heatherton TF, Kozlowski LT, Frecker RC, Fagerstrom KO. The Fagerstrom Test for Nicotine Dependence: a revision of the Fagerstrom Tolerance Questionnaire. British journal of addiction. 1991;86(9):1119-1127.

6. Romijnders K, van Osch $L$, de Vries H, Talhout R. Perceptions and Reasons Regarding E-Cigarette Use among Users and Non-Users: A Narrative Literature Review. Int J Environ Res Public Health. 2018;15(6).

7. Romijnders K, van Osch L, de Vries H, Talhout R. A Deliberate Choice? Exploring the Decision to Switch from Cigarettes to E-Cigarettes. Int J Environ Res Public Health. 2019;16(4).

8. Krusemann EJZ, Boesveldt S, de Graaf K, Talhout R. An E-Liquid Flavor Wheel: A Shared Vocabulary Based on Systematically Reviewing E-Liquid Flavor Classifications in Literature. Nicotine Tob Res. 2019;21(10):1310-1319.

9. Yingst JM, Veldheer S, Hammett E, Hrabovsky S, Foulds J. A Method for Classifying User-Reported Electronic Cigarette Liquid Flavors. Nicotine Tob Res. 2017;19(11):1381-1385.

10. Lehmann BA, de Melker HE, Timmermans DRM, Mollema L. Informed decision making in the context of childhood immunization. Patient Educ Couns. 2017;100(12):2339-2345.

11. Montano DE, Kasprzyk D. Theory of Reasoned Action, Theory of Planned Behavior, and the Integrated Behavioral Model. In: Glanz K, Rimer BK, Viswanath K, eds. Health Behavior and Health Education: Theory, Research and Practice. 4th ed. New Jersey: John Wiley \& Sons; 2008:67-96.

12. Sandefer RH, Westra BL, Khairat SS, Pieczkiewicz DS, Speedie SM. Determinants of Consumer eHealth Information Seeking Behavior. AMIA Annu Symp Proc. 2015;2015:1121-1129.

13. Siegrist M, Earle TC, Gutscher H. Test of a trust and confidence model in the applied context of electromagnetic field (EMF) risks. Risk Anal. 2003;23(4):705716.

14. Thoits PA. Mechanisms linking social ties and support to physical and mental health. J Health Soc Behav. 2011;52(2):145-161.

15. Dijkstra A, Vries HD. Self-efficacy expectations with regard to different tasks in smoking cessation. Psychology \& Health. 2000;15(4):501-511. 


\section{Appendix 7 differences between dual users and exclusive e-cigarette users}

\begin{tabular}{|c|c|c|c|c|c|c|c|}
\hline $\begin{array}{l}\text { Chapter } 5 \\
\text { A Combination c } \\
\text { Socio-Cognitive } \\
\text { User }\end{array}$ & $\begin{array}{l}\text { actors } \\
\text { tors a }\end{array}$ & $\begin{array}{l}\text { lated to Sm } \\
\text { mportant to }\end{array}$ & $\begin{array}{l}\text { ing Be } \\
\text { istingu }\end{array}$ & $\begin{array}{l}\text { ehavior, Attra } \\
\text { uish a Dual U }\end{array}$ & $\begin{array}{l}\text { ctive Product } \\
\text { Jser from an Ex }\end{array}$ & $\begin{array}{l}\text { Characteristi } \\
\text { kclusive E-Cig }\end{array}$ & $\begin{array}{l}\text { cs, and } \\
\text { yarette }\end{array}$ \\
\hline Scale and items & $\begin{array}{l}\text { Dual } \\
\text { users } \\
\text { (n) }\end{array}$ & $\begin{array}{l}\text { Dual users } \\
\text { (mean/ } \\
\text { percentage) }\end{array}$ & $\begin{array}{l}\text { Dual } \\
\text { users } \\
\text { (SD) }\end{array}$ & $\begin{array}{l}\text { E-cigarette } \\
\text { users }(n)\end{array}$ & $\begin{array}{l}\text { E-cigarette } \\
\text { users (mean/ } \\
\text { percentage) }\end{array}$ & $\begin{array}{l}\text { E-cigarette } \\
\text { users (SD) }\end{array}$ & $\mathrm{p}$-value \\
\hline Participant Char & eristics & & & & & & \\
\hline Age & 80 & 47.8 & 13.40 & 36 & 51.9 & 9.80 & 0.10 \\
\hline Gender & 80 & & & 36 & & & 0.31 \\
\hline male & & $46.3 \%$ & & & $36.1 \%$ & & \\
\hline female & & $53.8 \%$ & & & $63.9 \%$ & & \\
\hline Education & 80 & & & 36 & & & 0.70 \\
\hline low & & $30.0 \%$ & & & $19.4 \%$ & & \\
\hline middle & & $40.0 \%$ & & & $55.6 \%$ & & \\
\hline high & & $30.0 \%$ & & & $25.0 \%$ & & \\
\hline
\end{tabular}

Differences in past and current smoking and vaping behavior

\begin{tabular}{|c|c|c|c|c|}
\hline $\begin{array}{l}\text { lifetime status of } \\
\text { tobacco smoking } \\
\text { (Fagerstrom index) }\end{array}$ & 80 & 36 & & 0.02 \\
\hline $\begin{array}{l}<100 \text { cigarettes } \\
\text { in life }\end{array}$ & $6.30 \%$ & & $0.00 \%$ & \\
\hline $\begin{array}{l}>100 \text { cigarettes } \\
\text { in life }\end{array}$ & $93.70 \%$ & & $100.00 \%$ & \\
\hline $\begin{array}{l}\text { onset of tobacco } \\
\text { smoking }\end{array}$ & 80 & 36 & & 0.06 \\
\hline$<6$ months & $1.3 \%$ & & $2.8 \%$ & \\
\hline 6-12 months & $1.3 \%$ & & $0.0 \%$ & \\
\hline $1-5$ years & $8.8 \%$ & & $0.0 \%$ & \\
\hline $5-10$ years & $11.3 \%$ & & $0.0 \%$ & \\
\hline$>10$ years & $77.5 \%$ & & $97.2 \%$ & \\
\hline $\begin{array}{l}\text { quantity of tobacco } \\
\text { cigarettes smoked } \\
\text { in their past } \\
\text { (e-cigarette users) } \\
\text { or current (dual } \\
\text { users) smoking } \\
\text { behavior }\end{array}$ & & 36 & & 0.00 \\
\hline$<1 / 2$ package/day & $16.3 \%$ & & $2.8 \%$ & \\
\hline 1/2-1 package/day & $63.7 \%$ & & $36.1 \%$ & \\
\hline 1 package/day & $13.8 \%$ & & $22.2 \%$ & \\
\hline > 1 package/day & $6.3 \%$ & & $38.9 \%$ & \\
\hline
\end{tabular}




\begin{tabular}{|c|c|c|c|c|c|c|c|}
\hline Scale and items & $\begin{array}{l}\text { Dual } \\
\text { users } \\
\text { (n) }\end{array}$ & $\begin{array}{l}\text { Dual users } \\
\text { (mean/ } \\
\text { percentage) }\end{array}$ & $\begin{array}{l}\text { Dual } \\
\text { users } \\
\text { (SD) }\end{array}$ & $\begin{array}{l}\text { E-cigarette } \\
\text { users }(n)\end{array}$ & $\begin{array}{l}\text { E-cigarette } \\
\text { users (mean/ } \\
\text { percentage) }\end{array}$ & $\begin{array}{l}\text { E-cigarette } \\
\text { users (SD) }\end{array}$ & $\mathrm{p}$-value \\
\hline onset of vaping & 80 & & & 36 & & & 0.01 \\
\hline$<6$ months & & $35.0 \%$ & & & $13.9 \%$ & & \\
\hline 6-12 months & & $20.0 \%$ & & & $16.7 \%$ & & \\
\hline $1-5$ years & & $41.3 \%$ & & & $61.1 \%$ & & \\
\hline $5-10$ years & & $3.8 \%$ & & & $8.3 \%$ & & \\
\hline vaping status $\mathrm{ml}$ & 80 & 18.35 & 18.99 & 36 & 16.78 & 18.92 & 0.68 \\
\hline vaping status liquid & 80 & & & 36 & & & 0.75 \\
\hline $\begin{array}{l}\text { less than half a } \\
\text { container }\end{array}$ & & $67.5 \%$ & & & $77.8 \%$ & & \\
\hline $\begin{array}{l}\text { a little bit more } \\
\text { than half a } \\
\text { container }\end{array}$ & & $15.0 \%$ & & & $2.8 \%$ & & \\
\hline $\begin{array}{l}\text { about three } \\
\text { quarters of a } \\
\text { container }\end{array}$ & & $7.5 \%$ & & & $11.1 \%$ & & \\
\hline $\begin{array}{l}\text { a little bit less than } \\
\text { a container }\end{array}$ & & $2.5 \%$ & & & $2.8 \%$ & & \\
\hline a container at max & & $2.5 \%$ & & & $0.0 \%$ & & \\
\hline $\begin{array}{l}\text { little more than } \\
\text { one container }\end{array}$ & & $1.3 \%$ & & & $0.0 \%$ & & \\
\hline \multicolumn{8}{|c|}{ Differences in product characteristics used } \\
\hline Flavors situation & 80 & 3.6 & 2.08 & 36 & 3.14 & 2.45 & 0.29 \\
\hline nicotine current & & & & 36 & & & 0.96 \\
\hline None & & $17.5 \%$ & & & $8.30 \%$ & & \\
\hline $1-8 \mathrm{mg} / \mathrm{mL}$ & & $27.5 \%$ & & & $41.70 \%$ & & \\
\hline $9-14 \mathrm{mg} / \mathrm{mL}$ & & $18.8 \%$ & & & $16.70 \%$ & & \\
\hline $15-24 \mathrm{mg} / \mathrm{mL}$ & & $25.0 \%$ & & & $25.00 \%$ & & \\
\hline$>25 \mathrm{mg} / \mathrm{mL}$ & & $2.5 \%$ & & & 0 & & \\
\hline$>36 \mathrm{mg} / \mathrm{mL}$ & & $1.3 \%$ & & & $2.80 \%$ & & \\
\hline nicotine first & 80 & & & 36 & & & 0.48 \\
\hline None & & $13.8 \%$ & & & $8.3 \%$ & & \\
\hline $1-8 \mathrm{mg} / \mathrm{mL}$ & & $17.5 \%$ & & & $13.9 \%$ & & \\
\hline 9-14 mg/mL & & $25.0 \%$ & & & $25.0 \%$ & & \\
\hline $15-24 \mathrm{mg} / \mathrm{mL}$ & & $26.3 \%$ & & & $41.7 \%$ & & \\
\hline$>25 \mathrm{mg} / \mathrm{mL}$ & & $3.8 \%$ & & & $2.8 \%$ & & \\
\hline$>36 \mathrm{mg} / \mathrm{mL}$ & & $1.3 \%$ & & & $1.6 \%$ & & \\
\hline $\begin{array}{l}\text { future intention } \\
\text { e-cigarette use }\end{array}$ & 80 & 4.75 & 1.89 & 36 & 5.25 & 1.95 & 0.20 \\
\hline $\begin{array}{l}\text { future intention } \\
\text { e-cigarette nicotine } \\
\text { content }\end{array}$ & 80 & 4.24 & 1.94 & 36 & 4.33 & 1.80 & 0.80 \\
\hline $\begin{array}{l}\text { quantity } \\
\text { e-cigarettes used }\end{array}$ & 80 & & & 36 & & & 0.32 \\
\hline
\end{tabular}




\begin{tabular}{|c|c|c|c|c|c|c|c|}
\hline Scale and items & $\begin{array}{l}\text { Dual } \\
\text { users } \\
\text { (n) }\end{array}$ & $\begin{array}{l}\text { Dual users } \\
\text { (mean/ } \\
\text { percentage) }\end{array}$ & $\begin{array}{l}\text { Dual } \\
\text { users } \\
\text { (SD) }\end{array}$ & $\begin{array}{l}\text { E-cigarette } \\
\text { users }(n)\end{array}$ & $\begin{array}{l}\text { E-cigarette } \\
\text { users (mean/ } \\
\text { percentage) }\end{array}$ & $\begin{array}{l}\text { E-cigarette } \\
\text { users (SD) }\end{array}$ & p-value \\
\hline $\begin{array}{l}\text { I don't own my } \\
\text { own e-cigarette }\end{array}$ & & $2.5 \%$ & & & $5.6 \%$ & & \\
\hline 1 & & $68.8 \%$ & & & $52.8 \%$ & & \\
\hline 2 & & $22.5 \%$ & & & $30.6 \%$ & & \\
\hline more than 3 & & $6.3 \%$ & & & $11.1 \%$ & & \\
\hline $\begin{array}{l}\text { type e-cigarette } \\
\text { used }\end{array}$ & 80 & & & 36 & & & 0.80 \\
\hline $\begin{array}{l}\text { Disposable } \\
\text { e-cigarettes }\end{array}$ & & $58.8 \%$ & & & $58.3 \%$ & & \\
\hline $\begin{array}{l}\text { Refillable and } \\
\text { chargeable } \\
\text { e-cigarettes }\end{array}$ & & $18.8 \%$ & & & $13.9 \%$ & & \\
\hline Mods & & $8.8 \%$ & & & $13.9 \%$ & & \\
\hline other & & $13.8 \%$ & & & $13.9 \%$ & & \\
\hline $\begin{array}{l}\text { AWARENESS } \\
\text { FIRST }\end{array}$ & 80 & & & 36 & & & 0.88 \\
\hline GP & & $0.0 \%$ & & & $2.8 \%$ & & \\
\hline Internet & & $32.5 \%$ & & & $30.6 \%$ & & \\
\hline Commercials on tv & & $7.5 \%$ & & & $0.0 \%$ & & \\
\hline $\begin{array}{l}\text { Through my social } \\
\text { network }\end{array}$ & & $47.5 \%$ & & & $55.6 \%$ & & \\
\hline Advertisements & & $6.3 \%$ & & & $2.8 \%$ & & \\
\hline Other & & $6.3 \%$ & & & $8.3 \%$ & & \\
\hline DRYHIT & 80 & & & 61 & & & 0.13 \\
\hline very often & & $2.5 \%$ & & & $5.6 \%$ & & \\
\hline often & & $8.8 \%$ & & & $16.7 \%$ & & \\
\hline sometimes & & $17.5 \%$ & & & $25.0 \%$ & & \\
\hline rarely & & $20.0 \%$ & & & $47.2 \%$ & & \\
\hline never & & $40.0 \%$ & & & $36.1 \%$ & & \\
\hline unknown & & $11.3 \%$ & & & $5.6 \%$ & & \\
\hline \multicolumn{8}{|c|}{ Current e-liquid flavors used (\% of flavor category used) } \\
\hline $\begin{array}{l}\text { FLAVOR } \\
\text { TOBACCO }\end{array}$ & 79 & $55.7 \%$ & & 35 & $54.3 \%$ & & 0.89 \\
\hline $\begin{array}{l}\text { FLAVOR } \\
\text { MENTHOL }\end{array}$ & 79 & $24.1 \%$ & & 35 & $11.4 \%$ & & 0.09 \\
\hline FLAVOR NUTS & 79 & $0.0 \%$ & & 35 & $0.0 \%$ & & NA \\
\hline FLAVOR SPICES & 79 & $0.0 \%$ & & 35 & $0.0 \%$ & & NA \\
\hline $\begin{array}{l}\text { FLAVOR COFFEE } \\
\text { or TEA }\end{array}$ & 79 & $3.8 \%$ & & 35 & $2.9 \%$ & & 0.79 \\
\hline $\begin{array}{l}\text { FLAVOR } \\
\text { ALCOHOL }\end{array}$ & 79 & $0.0 \%$ & & 35 & $0.0 \%$ & & NA \\
\hline $\begin{array}{l}\text { FLAVOR OTHER } \\
\text { BEVERAGES }\end{array}$ & 79 & $0.0 \%$ & & 35 & $0.0 \%$ & & NA \\
\hline FLAVOR FRUIT & 79 & $8.9 \%$ & & 35 & $11.4 \%$ & & 0.69 \\
\hline
\end{tabular}

table continues 


\begin{tabular}{|c|c|c|c|c|c|c|c|}
\hline Scale and items & $\begin{array}{l}\text { Dual } \\
\text { users } \\
(\mathrm{n})\end{array}$ & $\begin{array}{l}\text { Dual users } \\
\text { (mean/ } \\
\text { percentage) }\end{array}$ & $\begin{array}{l}\text { Dual } \\
\text { users } \\
\text { (SD) }\end{array}$ & $\begin{array}{l}\text { E-cigarette } \\
\text { users }(n)\end{array}$ & $\begin{array}{l}\text { E-cigarette } \\
\text { users (mean/ } \\
\text { percentage) }\end{array}$ & $\begin{array}{l}\text { E-cigarette } \\
\text { users (SD) }\end{array}$ & $\mathrm{p}$-value \\
\hline FLAVOR DESSERT & 79 & $1.3 \%$ & & 35 & $2.9 \%$ & & 0.61 \\
\hline FLAVOR CANDY & 79 & $0.0 \%$ & & 35 & $5.7 \%$ & & 0.16 \\
\hline $\begin{array}{l}\text { FLAVOR OTHER } \\
\text { SWEETS }\end{array}$ & 79 & $6.3 \%$ & & 35 & $5.7 \%$ & & 0.90 \\
\hline $\begin{array}{l}\text { FLAVOR } \\
\text { UNFLAVORED }\end{array}$ & 79 & $0.0 \%$ & & 35 & $2.9 \%$ & & 0.32 \\
\hline $\begin{array}{l}\text { FLAVOR OTHER } \\
\text { FLAVOR }\end{array}$ & 79 & $0.0 \%$ & & 35 & $2.9 \%$ & & 0.32 \\
\hline \multicolumn{8}{|c|}{ First e-liquid flavors used (\% of flavor category used) } \\
\hline $\begin{array}{l}\text { FLAVOR } \\
\text { TOBACCO }\end{array}$ & 79 & $62.0 \%$ & & 35 & $74.3 \%$ & & 0.19 \\
\hline $\begin{array}{l}\text { FLAVOR } \\
\text { MENTHOL }\end{array}$ & 79 & $19.0 \%$ & & 35 & $17.1 \%$ & & 0.81 \\
\hline FLAVOR NUTS & 79 & $0.0 \%$ & & 35 & $0.0 \%$ & & NA \\
\hline FLAVOR SPICES & 79 & $0.0 \%$ & & 35 & $0.0 \%$ & & NA \\
\hline $\begin{array}{l}\text { FLAVOR COFFEE } \\
\text { or TEA }\end{array}$ & 79 & $2.5 \%$ & & 35 & $2.9 \%$ & & 0.92 \\
\hline $\begin{array}{l}\text { FLAVOR } \\
\text { ALCOHOL }\end{array}$ & 79 & $1.3 \%$ & & 35 & $0.0 \%$ & & 0.32 \\
\hline $\begin{array}{l}\text { FLAVOR OTHER } \\
\text { BEVERAGES }\end{array}$ & 79 & $0.0 \%$ & & 35 & $0.0 \%$ & & NA \\
\hline FLAVOR FRUIT & 79 & $6.3 \%$ & & 35 & $2.9 \%$ & & 0.38 \\
\hline FLAVOR DESSERT & 79 & $0.0 \%$ & & 35 & $0.0 \%$ & & NA \\
\hline FLAVOR CANDY & 79 & $1.3 \%$ & & 35 & $0.0 \%$ & & 0.32 \\
\hline $\begin{array}{l}\text { FLAVOR OTHER } \\
\text { SWEETS }\end{array}$ & 79 & $7.6 \%$ & & 35 & $0.0 \%$ & & 0.01 \\
\hline $\begin{array}{l}\text { FLAVOR OTHER } \\
\text { FLAVOR }\end{array}$ & 79 & $0.0 \%$ & & 35 & $2.9 \%$ & & 0.32 \\
\hline $\begin{array}{l}\text { FLAVOR } \\
\text { UNFLAVORED }\end{array}$ & 79 & $0.0 \%$ & & 35 & $0.0 \%$ & & NA \\
\hline $\begin{array}{l}\text { FLAVOR } \\
\text { UNFLAVORED }\end{array}$ & 79 & $0.0 \%$ & & 35 & $0.0 \%$ & & NA \\
\hline
\end{tabular}

Differences in attractiveness and reasons related to cigarettes and e-cigarettes

Attractiveness of e-cigarettes

\begin{tabular}{lccccc}
\hline $\begin{array}{l}\text { The product looks } \\
\text { nice }\end{array}$ & 80 & $18.8 \%$ & 36 & $5.6 \%$ & 0.03 \\
$\begin{array}{l}\text { Due to all the } \\
\text { different flavors }\end{array}$ & 80 & $46.3 \%$ & 36 & $25.0 \%$ & 0.02 \\
$\begin{array}{l}\text { Because it is } \\
\text { possible to alter } \\
\text { the setting of the }\end{array}$ & 80 & $20.0 \%$ & 36 & $38.9 \%$ & 0.05 \\
$\begin{array}{l}\text { E-cigarette to my } \\
\text { wishes }\end{array}$ & & & & \\
$\begin{array}{l}\text { Due to its varying } \\
\text { designs }\end{array}$ & 80 & $10.0 \%$ & 36 & $2.8 \%$ & 0.10 \\
\hline
\end{tabular}




\begin{tabular}{|c|c|c|c|c|c|c|c|}
\hline Scale and items & $\begin{array}{l}\text { Dual } \\
\text { users } \\
\text { (n) }\end{array}$ & $\begin{array}{l}\text { Dual users } \\
\text { (mean/ } \\
\text { percentage) }\end{array}$ & $\begin{array}{l}\text { Dual } \\
\text { users } \\
\text { (SD) } \\
\end{array}$ & $\begin{array}{l}\text { E-cigarette } \\
\text { users }(n)\end{array}$ & $\begin{array}{l}\text { E-cigarette } \\
\text { users (mean/ } \\
\text { percentage) }\end{array}$ & $\begin{array}{l}\text { E-cigarette } \\
\text { users (SD) }\end{array}$ & $\mathrm{p}$-value \\
\hline $\begin{array}{l}\text { Due to the price of } \\
\text { the product }\end{array}$ & 80 & $22.5 \%$ & & 36 & $13.9 \%$ & & 0.25 \\
\hline $\begin{array}{l}\text { Due to the price of } \\
\text { the E-liquids }\end{array}$ & 80 & $28.8 \%$ & & 36 & $36.1 \%$ & & 0.45 \\
\hline $\begin{array}{l}\text { Because the } \\
\text { nicotine level can } \\
\text { be varied }\end{array}$ & 80 & $45.0 \%$ & & 36 & $66.7 \%$ & & 0.03 \\
\hline $\begin{array}{l}\text { Because you can } \\
\text { blow nice smoke } \\
\text { clouds with it }\end{array}$ & 80 & $2.5 \%$ & & 36 & $0.0 \%$ & & 0.16 \\
\hline $\begin{array}{l}\text { Not applicable, } \\
\text { I do not find the } \\
\text { E-cigarette/vaper } \\
\text { attractive }\end{array}$ & 80 & $8.8 \%$ & & 36 & $0.0 \%$ & & 0.01 \\
\hline \multicolumn{8}{|c|}{ Unattractiveness of e-cigarettes } \\
\hline $\begin{array}{l}\text { The appearance of } \\
\text { the E-cigarette }\end{array}$ & 80 & $17.5 \%$ & & 36 & $22.2 \%$ & & 0.57 \\
\hline Its many flavors & 80 & $15.0 \%$ & & 36 & $11.1 \%$ & & 0.56 \\
\hline $\begin{array}{l}\text { The price of the } \\
\text { product }\end{array}$ & 80 & $22.5 \%$ & & 36 & $13.9 \%$ & & 0.25 \\
\hline $\begin{array}{l}\text { The price of the } \\
\text { E-liquids }\end{array}$ & 80 & $15.0 \%$ & & 36 & $16.7 \%$ & & 0.82 \\
\hline $\begin{array}{l}\text { The weight of the } \\
\text { E-cigarette (the } \\
\text { apparatus) }\end{array}$ & 80 & $17.5 \%$ & & 36 & $8.3 \%$ & & 0.15 \\
\hline $\begin{array}{l}\text { The shape of the } \\
\text { E-cigarette }\end{array}$ & 80 & $8.8 \%$ & & 36 & $11.1 \%$ & & 0.70 \\
\hline $\begin{array}{l}\text { How the product } \\
\text { feels in my hand, } \\
\text { it is different to a } \\
\text { cigarette }\end{array}$ & 80 & $20.0 \%$ & & 36 & $19.4 \%$ & & 0.95 \\
\hline $\begin{array}{l}\text { Not applicable, } \\
\text { I do not find the } \\
\text { E-cigarette/vaper } \\
\text { attractive }\end{array}$ & 80 & $27.5 \%$ & & 36 & $36.1 \%$ & & 0.37 \\
\hline \multicolumn{8}{|c|}{ Attractiveness of cigarettes } \\
\hline $\begin{array}{l}\text { The product looks } \\
\text { nice }\end{array}$ & 80 & $7.5 \%$ & & 36 & $0.0 \%$ & & 0.01 \\
\hline $\begin{array}{l}\text { Due to all the } \\
\text { different flavors }\end{array}$ & 80 & $30.0 \%$ & & 36 & $11.1 \%$ & & 0.01 \\
\hline $\begin{array}{l}\text { Because you can } \\
\text { smoke different } \\
\text { brands }\end{array}$ & 80 & $26.3 \%$ & & 36 & $5.6 \%$ & & 0.00 \\
\hline $\begin{array}{l}\text { Due to the price of } \\
\text { the product }\end{array}$ & 80 & $7.5 \%$ & & 36 & $2.8 \%$ & & 0.25 \\
\hline $\begin{array}{l}\text { Because smoking } \\
\text { looks cool and } \\
\text { classy }\end{array}$ & 80 & $6.3 \%$ & & 36 & $2.8 \%$ & & 0.37 \\
\hline
\end{tabular}




\begin{tabular}{|c|c|c|c|c|c|c|c|}
\hline Scale and items & $\begin{array}{l}\text { Dual } \\
\text { users } \\
\text { (n) }\end{array}$ & $\begin{array}{l}\text { Dual users } \\
\text { (mean/ } \\
\text { percentage) }\end{array}$ & $\begin{array}{l}\text { Dual } \\
\text { users } \\
\text { (SD) }\end{array}$ & $\begin{array}{l}\text { E-cigarette } \\
\text { users }(n)\end{array}$ & $\begin{array}{l}\text { E-cigarette } \\
\text { users (mean/ } \\
\text { percentage) }\end{array}$ & $\begin{array}{l}\text { E-cigarette } \\
\text { users (SD) }\end{array}$ & $\mathrm{p}$-value \\
\hline $\begin{array}{l}\text { Because it looks } \\
\text { cool when other } \\
\text { people smoke }\end{array}$ & 80 & $3.8 \%$ & & 36 & $0.0 \%$ & & 0.08 \\
\hline $\begin{array}{l}\text { Because you can } \\
\text { blow nice smoke } \\
\text { clouds with it }\end{array}$ & 80 & $1.3 \%$ & & 36 & $2.8 \%$ & & 0.62 \\
\hline $\begin{array}{l}\text { Not applicable, } \\
\text { I do not find the } \\
\text { cigarette attractive }\end{array}$ & 80 & $28.8 \%$ & & 36 & $72.2 \%$ & & 0.00 \\
\hline \multicolumn{8}{|c|}{ Unattractiveness of cigarettes } \\
\hline $\begin{array}{l}\text { The appearance of } \\
\text { the cigarette }\end{array}$ & 80 & $5.0 \%$ & & 36 & $2.8 \%$ & & 0.55 \\
\hline Its many flavors & 80 & $8.8 \%$ & & 36 & $11.1 \%$ & & 0.70 \\
\hline $\begin{array}{l}\text { The price of the } \\
\text { product }\end{array}$ & 80 & $35.0 \%$ & & 36 & $58.3 \%$ & & 0.02 \\
\hline The many brands & 80 & $8.8 \%$ & & 36 & $2.8 \%$ & & 0.16 \\
\hline $\begin{array}{l}\text { The smell of } \\
\text { cigarettes }\end{array}$ & 80 & $31.3 \%$ & & 36 & $38.9 \%$ & & 0.44 \\
\hline $\begin{array}{l}\text { Packaging of } \\
\text { cigarettes }\end{array}$ & 80 & $10.0 \%$ & & 36 & $5.6 \%$ & & 0.39 \\
\hline $\begin{array}{l}\text { Because you stink } \\
\text { after you have } \\
\text { smoked a cigarette }\end{array}$ & 80 & $43.8 \%$ & & 36 & $66.7 \%$ & & 0.02 \\
\hline $\begin{array}{l}\text { Not applicable, I } \\
\text { find the cigarette } \\
\text { attractive }\end{array}$ & 80 & $13.8 \%$ & & 36 & $5.6 \%$ & & 0.14 \\
\hline \multicolumn{8}{|c|}{ Reasons for e-cigarette use } \\
\hline $\begin{array}{l}\text { Because } \\
\text { E-cigarettes/vapers } \\
\text { are easy to get. }\end{array}$ & 80.00 & $5.0 \%$ & & 36.00 & $11.1 \%$ & & 0.30 \\
\hline $\begin{array}{l}\text { Because they are } \\
\text { easy to use. }\end{array}$ & 80.00 & $27.5 \%$ & & 36.00 & $19.4 \%$ & & 0.34 \\
\hline $\begin{array}{l}\text { Due to the cost: } \\
\text { less expensive } \\
\text { than cigarettes/ } \\
\text { affordable }\end{array}$ & 80.00 & $41.3 \%$ & & 36.00 & $52.8 \%$ & & 0.26 \\
\hline $\begin{array}{l}\text { For their health } \\
\text { advantages: effects } \\
\text { on health, fewer } \\
\text { ingredients than a } \\
\text { cigarette. }\end{array}$ & 80.00 & $42.5 \%$ & & 36.00 & $72.2 \%$ & & 0.00 \\
\hline $\begin{array}{l}\text { As an aid to } \\
\text { smoking fewer } \\
\text { cigarettes or } \\
\text { giving them } \\
\text { up completely: } \\
\text { a method of } \\
\text { stopping smoking, } \\
\text { to prevent me } \\
\text { going back to } \\
\text { cigarettes. }\end{array}$ & 80.00 & $42.5 \%$ & & 36.00 & $61.1 \%$ & & 0.07 \\
\hline
\end{tabular}




\begin{tabular}{|c|c|c|c|c|c|c|c|}
\hline Scale and items & $\begin{array}{l}\text { Dual } \\
\text { users } \\
\text { (n) }\end{array}$ & $\begin{array}{l}\text { Dual users } \\
\text { (mean/ } \\
\text { percentage) }\end{array}$ & $\begin{array}{l}\text { Dual } \\
\text { users } \\
\text { (SD) }\end{array}$ & $\begin{array}{l}\text { E-cigarette } \\
\text { users }(n)\end{array}$ & $\begin{array}{l}\text { E-cigarette } \\
\text { users (mean/ } \\
\text { percentage) }\end{array}$ & $\begin{array}{l}\text { E-cigarette } \\
\text { users (SD) }\end{array}$ & $\mathrm{p}$-value \\
\hline $\begin{array}{l}\text { Because it is } \\
\text { less addictive } \\
\text { than cigarettes, } \\
\text { variation in nicotine } \\
\text { level is possible. }\end{array}$ & 80.00 & $28.8 \%$ & & 36.00 & $36.1 \%$ & & 0.45 \\
\hline $\begin{array}{l}\text { To cope with } \\
\text { cravings and to } \\
\text { prevent/cope } \\
\text { with withdrawal } \\
\text { symptoms }\end{array}$ & 80.00 & $11.3 \%$ & & 36.00 & $13.9 \%$ & & 0.70 \\
\hline $\begin{array}{l}\text { As an alternative } \\
\text { to cigarettes: it is } \\
\text { like the smoking } \\
\text { or because of the } \\
\text { throat hit (add info- } \\
\text { button). }\end{array}$ & 80.00 & $28.8 \%$ & & 36.00 & $50.0 \%$ & & 0.04 \\
\hline $\begin{array}{l}\text { To get around } \\
\text { the smoking ban } \\
\text { (to be able to } \\
\text { vape in places } \\
\text { where smoking } \\
\text { is normally } \\
\text { forbidden). }\end{array}$ & 80.00 & $22.5 \%$ & & 36.00 & $5.6 \%$ & & 0.01 \\
\hline $\begin{array}{l}\text { To help me to } \\
\text { focus and improve } \\
\text { my performance, } \\
\text { to reduce stress or } \\
\text { to prevent weight } \\
\text { gain. }\end{array}$ & 80.00 & $7.5 \%$ & & 36.00 & $5.6 \%$ & & 0.69 \\
\hline $\begin{array}{l}\text { Due to improved } \\
\text { sense of taste and } \\
\text { smell: because it } \\
\text { tastes better than } \\
\text { cigarettes, and to } \\
\text { be discreet (you } \\
\text { can hide the fact } \\
\text { that you smoke, no } \\
\text { unpleasant smells). }\end{array}$ & 80.00 & $13.8 \%$ & & 36.00 & $22.2 \%$ & & 0.30 \\
\hline $\begin{array}{l}\text { This is a real } \\
\text { experience, one } \\
\text { that can only be } \\
\text { experienced by } \\
\text { doing it. }\end{array}$ & 80.00 & $1.3 \%$ & & 36.00 & $5.6 \%$ & & 0.30 \\
\hline $\begin{array}{l}\text { To try something } \\
\text { new: out of } \\
\text { curiosity about new } \\
\text { products, different } \\
\text { flavors, different } \\
\text { apparatus/designs, } \\
\text { for pleasure, as a } \\
\text { hobby, or because } \\
\text { it is cool/trendy/ } \\
\text { classy. }\end{array}$ & 80.00 & $11.3 \%$ & & 36.00 & $0.0 \%$ & & 0.00 \\
\hline
\end{tabular}

table continues 


\begin{tabular}{|c|c|c|c|c|c|c|c|}
\hline Scale and items & $\begin{array}{l}\text { Dual } \\
\text { users } \\
\text { (n) }\end{array}$ & $\begin{array}{l}\text { Dual users } \\
\text { (mean/ } \\
\text { percentage) }\end{array}$ & $\begin{array}{l}\text { Dual } \\
\text { users } \\
\text { (SD) }\end{array}$ & $\begin{array}{l}\text { E-cigarette } \\
\text { users }(n)\end{array}$ & $\begin{array}{l}\text { E-cigarette } \\
\text { users (mean/ } \\
\text { percentage) }\end{array}$ & $\begin{array}{l}\text { E-cigarette } \\
\text { users (SD) }\end{array}$ & $\mathrm{p}$-value \\
\hline $\begin{array}{l}\text { For social reasons: } \\
\text { because it was } \\
\text { recommended by } \\
\text { friends or family, } \\
\text { due to pressure } \\
\text { from the people } \\
\text { around met, } \\
\text { to extend my } \\
\text { social network } \\
\text { or because it is } \\
\text { socially acceptable. }\end{array}$ & 80.00 & $10.0 \%$ & & 36.00 & $5.6 \%$ & & 0.39 \\
\hline NA & 80.00 & $2.5 \%$ & & 36.00 & $0.0 \%$ & & 0.16 \\
\hline
\end{tabular}

\section{Differences in socio-cognitive factors}

\begin{tabular}{|c|c|c|c|c|c|c|c|}
\hline \multicolumn{8}{|l|}{$\begin{array}{l}\text { Socio-cognitive } \\
\text { factors }\end{array}$} \\
\hline Attitude never use & 80 & 5.15 & 1.23 & 36 & 5.34 & 1.14 & 0.43 \\
\hline Attitude smoking & 80 & 3.28 & 1.11 & 36 & 2.69 & 1.17 & 0.01 \\
\hline Attitude vaping & 80 & 4.50 & 0.75 & 36 & 5.03 & 0.82 & 0.00 \\
\hline $\begin{array}{l}\text { Barrier: } \\
\text { accessibility of } \\
\text { e-cigarettes }\end{array}$ & 80 & 5.17 & 1.13 & 36 & 4.84 & 1.52 & 0.25 \\
\hline $\begin{array}{l}\text { Deliberation } \\
\text { about not using } \\
\text { E-cigarettes or } \\
\text { cigarettes }\end{array}$ & 80 & 4.48 & 1.42 & 36 & 3.92 & 1.28 & 0.04 \\
\hline $\begin{array}{l}\text { Deliberation about } \\
\text { the pros and cons } \\
\text { of tobacco product } \\
\text { use }\end{array}$ & 80 & 4.43 & 1.24 & 36 & 4.02 & 1.29 & 0.11 \\
\hline $\begin{array}{l}\text { Deliberation of the } \\
\text { pros and cons of } \\
\text { smoking. }\end{array}$ & 80 & 4.50 & 1.30 & 36 & 4.07 & 1.56 & 0.16 \\
\hline $\begin{array}{l}\text { Deliberation on the } \\
\text { pros and cons of } \\
\text { E-cigarette use }\end{array}$ & 80 & 4.32 & 1.31 & 36 & 4.07 & 1.33 & 0.37 \\
\hline $\begin{array}{l}\text { Intention to quit } \\
\text { vaping A. Please } \\
\text { indicate on a } \\
\text { scale from } 1 \text { to } 7 \\
\text { your intent to quit } \\
\text { vaping in the next } \\
6 \text { months. }\end{array}$ & 80 & 3.76 & 2.00 & 36 & 2.86 & 1.82 & 0.02 \\
\hline $\begin{array}{l}\text { Intention to quit } \\
\text { vaping B. Please } \\
\text { indicate which of } \\
\text { the statements } \\
\text { indicates your } \\
\text { intention best }\end{array}$ & 80 & 3.56 & 2.38 & 36 & 2.25 & 1.81 & 0.00 \\
\hline Knowledge & 80 & 8.54 & 1.92 & 36 & 8.61 & 1.40 & 0.82 \\
\hline
\end{tabular}




\begin{tabular}{|c|c|c|c|c|c|c|c|}
\hline Scale and items & $\begin{array}{l}\text { Dual } \\
\text { users } \\
\text { (n) }\end{array}$ & $\begin{array}{l}\text { Dual users } \\
\text { (mean/ } \\
\text { percentage) }\end{array}$ & $\begin{array}{l}\text { Dual } \\
\text { users } \\
\text { (SD) }\end{array}$ & $\begin{array}{l}\text { E-cigarette } \\
\text { users }(n)\end{array}$ & $\begin{array}{l}\text { E-cigarette } \\
\text { users (mean/ } \\
\text { percentage) }\end{array}$ & $\begin{array}{l}\text { E-cigarette } \\
\text { users (SD) }\end{array}$ & $\mathrm{p}$-value \\
\hline $\begin{array}{l}\text { Risk perception } \\
\text { about e-cigarette } \\
\text { use (cognitive): A. } \\
\text { If I vape, then my } \\
\text { risk of developing } \\
\text { some form of } \\
\text { cancer during my } \\
\text { lifetime is... }\end{array}$ & 80 & 4.29 & 1.17 & 36 & 4.25 & 1.02 & 0.86 \\
\hline $\begin{array}{l}\text { Risk perception } \\
\text { about e-cigarette } \\
\text { use (cognitive): } \\
\text { B. I think that if I } \\
\text { vape, my risk of } \\
\text { developing some } \\
\text { form of cancer } \\
\text { during my lifetime: }\end{array}$ & 80 & 4.30 & 1.32 & 36 & 4.28 & 1.34 & 0.93 \\
\hline $\begin{array}{l}\text { Risk perception } \\
\text { ofe-cigarette use } \\
\text { (affective): A. My } \\
\text { feeling is that if I } \\
\text { vape, the risk of } \\
\text { developing some } \\
\text { form of cancer } \\
\text { during my lifetime: }\end{array}$ & 80 & 4.34 & 1.30 & 36 & 4.22 & 0.99 & 0.60 \\
\hline $\begin{array}{l}\text { Risk perception } \\
\text { of not using } \\
\text { E-cigarettes } \\
\text { or cigarettes } \\
\text { (affective) A. My } \\
\text { feeling is that the } \\
\text { risk of developing } \\
\text { some form of } \\
\text { cancer during my } \\
\text { lifetime: }\end{array}$ & 80 & 4.44 & 1.29 & 36 & 4.36 & 1.13 & 0.75 \\
\hline $\begin{array}{l}\text { Risk perception } \\
\text { of not using } \\
\text { E-cigarettes } \\
\text { or cigarettes } \\
\text { (affective): A. My } \\
\text { feeling is that if } \\
\text { don't smoke or } \\
\text { vape, then the } \\
\text { risk of developing } \\
\text { some form of } \\
\text { cancer during my } \\
\text { lifetime .... }\end{array}$ & 80 & 4.13 & 1.19 & 36 & 4.19 & 1.28 & 0.78 \\
\hline $\begin{array}{l}\text { Risk perception } \\
\text { of not using } \\
\text { E-cigarettes } \\
\text { or cigarettes } \\
\text { (cognitive): A. How } \\
\text { big a risk do you } \\
\text { think you have } \\
\text { of developing } \\
\text { some form of } \\
\text { cancer during your } \\
\text { lifetime? }\end{array}$ & 80 & 4.54 & 1.26 & 36 & 4.83 & 1.21 & 0.23 \\
\hline
\end{tabular}

table continues 


\begin{tabular}{|c|c|c|c|c|c|c|c|}
\hline Scale and items & $\begin{array}{l}\text { Dual } \\
\text { users } \\
\text { (n) }\end{array}$ & $\begin{array}{l}\text { Dual users } \\
\text { (mean/ } \\
\text { percentage) }\end{array}$ & $\begin{array}{l}\text { Dual } \\
\text { users } \\
\text { (SD) }\end{array}$ & $\begin{array}{l}\text { E-cigarette } \\
\text { users }(n)\end{array}$ & $\begin{array}{l}\text { E-cigarette } \\
\text { users (mean/ } \\
\text { percentage) }\end{array}$ & $\begin{array}{l}\text { E-cigarette } \\
\text { users (SD) }\end{array}$ & $\mathrm{p}$-value \\
\hline $\begin{array}{l}\text { Risk perception } \\
\text { of not using } \\
\text { E-cigarettes } \\
\text { or cigarettes } \\
\text { (cognitive): B. If } \\
\text { I don't smoke or } \\
\text { vape, then the risk } \\
\text { that I will develop } \\
\text { some form of } \\
\text { cancer during my } \\
\text { lifetime is... }\end{array}$ & 80 & 3.93 & 1.24 & 36 & 4.08 & 1.11 & 0.49 \\
\hline $\begin{array}{l}\text { Risk perception } \\
\text { of not using } \\
\text { E-cigarettes } \\
\text { or cigarettes } \\
\text { (cognitive): C. I } \\
\text { think that my risk } \\
\text { of developing } \\
\text { some form of } \\
\text { cancer during my } \\
\text { lifetime: }\end{array}$ & 80 & 4.29 & 1.32 & 36 & 4.36 & 1.05 & 0.75 \\
\hline $\begin{array}{l}\text { Risk perception } \\
\text { of smoking } \\
\text { (cognitive): A. If I } \\
\text { smoke, then my } \\
\text { risk of developing } \\
\text { some form of } \\
\text { cancer during my } \\
\text { lifetime is... }\end{array}$ & 80 & 5.08 & 1.29 & 36 & 5.22 & 1.31 & 0.58 \\
\hline $\begin{array}{l}\text { Risk perception } \\
\text { smoking (affective): } \\
\text { My feeling is that if } \\
\text { I smoke, the risk of } \\
\text { developing some } \\
\text { form of cancer } \\
\text { during my lifetime: }\end{array}$ & 80 & 4.71 & 1.34 & 36 & 5.11 & 1.30 & 0.14 \\
\hline $\begin{array}{l}\text { Risk perception } \\
\text { smoking } \\
\text { (cognitive): B. } \\
\text { I think that if I } \\
\text { smoke, my risk of } \\
\text { developing some } \\
\text { form of cancer } \\
\text { during my lifetime: }\end{array}$ & 80 & 4.73 & 1.28 & 36 & 5.31 & 1.06 & 0.01 \\
\hline $\begin{array}{l}\text { Self-efficacy: } \\
\text { e-cigarette use }\end{array}$ & 80 & 3.89 & 1.21 & 36 & 4.84 & 1.02 & 0.00 \\
\hline $\begin{array}{l}\text { Self-efficacy: not } \\
\text { using tobacco } \\
\text { products or } \\
\text { e-cigarettes }\end{array}$ & 80 & 3.37 & 1.34 & 36 & 3.77 & 1.26 & 0.12 \\
\hline $\begin{array}{l}\text { Self-efficacy: } \\
\text { smoking }\end{array}$ & 80 & 3.88 & 1.18 & 36 & 3.57 & 1.37 & 0.23 \\
\hline $\begin{array}{l}\text { Social Influence A: } \\
\text { Society thinks that } \\
\text { you should not } \\
\text { vape E-cigarettes. }\end{array}$ & 80 & 4.21 & 1.68 & 36 & 3.22 & 1.57 & 0.00 \\
\hline
\end{tabular}

table continues 


\begin{tabular}{|c|c|c|c|c|c|c|c|}
\hline Scale and items & $\begin{array}{l}\text { Dual } \\
\text { users } \\
\text { (n) }\end{array}$ & $\begin{array}{l}\text { Dual users } \\
\text { (mean/ } \\
\text { percentage) }\end{array}$ & $\begin{array}{l}\text { Dual } \\
\text { users } \\
\text { (SD) }\end{array}$ & $\begin{array}{l}\text { E-cigarette } \\
\text { users }(n)\end{array}$ & $\begin{array}{l}\text { E-cigarette } \\
\text { users (mean/ } \\
\text { percentage) }\end{array}$ & $\begin{array}{l}\text { E-cigarette } \\
\text { users (SD) }\end{array}$ & p-value \\
\hline $\begin{array}{l}\text { Social Influence B: } \\
\text { Society thinks that } \\
\text { you should not } \\
\text { smoke. }\end{array}$ & 80 & 5.56 & 1.52 & 36 & 5.31 & 2.05 & 0.50 \\
\hline $\begin{array}{l}\text { Social Influence } \\
\text { C: Vaping status } \\
\text { partner (\% of } \\
\text { yes): My partner } \\
\text { uses E-cigarettes/ } \\
\text { vapers. }\end{array}$ & 80 & & & 36 & & & 0.14 \\
\hline $\begin{array}{l}\text { Social influence } \\
\text { D: smoking status } \\
\text { partner (\% of } \\
\text { yes): My partner } \\
\text { smokes. }\end{array}$ & 80 & $33.8 \%$ & & 36 & $13.9 \%$ & & 0.01 \\
\hline $\begin{array}{l}\text { social influence } \\
\text { E: How many of } \\
\text { your family, friends } \\
\text { or colleagues } \\
\text { use E-cigarettes/ } \\
\text { vapers? }\end{array}$ & 80 & 4.41 & 0.98 & 36 & 4.61 & 0.93 & 0.30 \\
\hline $\begin{array}{l}\text { social influence F: } \\
\text { How many of your } \\
\text { family, friends or } \\
\text { colleagues use } \\
\text { cigarettes? }\end{array}$ & 80 & 3.59 & 1.13 & 36 & 4.06 & 1.12 & 0.04 \\
\hline $\begin{array}{l}\text { SOCIAL TIES with } \\
\text { other smokers }\end{array}$ & 79 & 3.34 & 1.09 & 36 & 2.32 & 1.22 & 0.00 \\
\hline $\begin{array}{l}\text { SOCIAL TIES with } \\
\text { other vapers }\end{array}$ & 80 & 3.00 & 1.24 & 36 & 3.09 & 0.99 & 0.68 \\
\hline $\begin{array}{l}\text { TRUST in } \\
\text { the National } \\
\text { Institute of Public } \\
\text { Health and the } \\
\text { Environment }\end{array}$ & 73 & 4.95 & 1.25 & 34 & 4.43 & 1.61 & 0.10 \\
\hline \multicolumn{8}{|c|}{ Information seeking behavior } \\
\hline $\begin{array}{l}\text { Source of } \\
\text { information used a: } \\
\text { Television }\end{array}$ & 80.00 & $13.8 \%$ & & 36.00 & $8.3 \%$ & & 0.37 \\
\hline $\begin{array}{l}\text { Source of } \\
\text { information used } \\
\text { b: Newspaper }\end{array}$ & 80.00 & $8.8 \%$ & & 36.00 & $8.3 \%$ & & 0.94 \\
\hline $\begin{array}{l}\text { Source of } \\
\text { information used c: } \\
\text { Radio }\end{array}$ & 80.00 & $1.3 \%$ & & 36.00 & $2.8 \%$ & & 0.62 \\
\hline $\begin{array}{l}\text { Source of } \\
\text { information used d: } \\
\text { Advertising (signs, } \\
\text { shop displays, } \\
\text { advertising folders, } \\
\text { pop-ups, YouTube } \\
\text { advertisements, } \\
\text { advertising } \\
\text { banners) }\end{array}$ & 80.00 & $6.3 \%$ & & 36.00 & $2.8 \%$ & & 0.37 \\
\hline
\end{tabular}




\begin{tabular}{|c|c|c|c|c|c|c|c|}
\hline Scale and items & $\begin{array}{l}\text { Dual } \\
\text { users } \\
\text { (n) }\end{array}$ & $\begin{array}{l}\text { Dual users } \\
\text { (mean/ } \\
\text { percentage) }\end{array}$ & $\begin{array}{l}\text { Dual } \\
\text { users } \\
\text { (SD) }\end{array}$ & $\begin{array}{l}\text { E-cigarette } \\
\text { users }(n)\end{array}$ & $\begin{array}{l}\text { E-cigarette } \\
\text { users (mean/ } \\
\text { percentage) }\end{array}$ & $\begin{array}{l}\text { E-cigarette } \\
\text { users (SD) }\end{array}$ & $\mathrm{p}$-value \\
\hline $\begin{array}{l}\text { Source of } \\
\text { information used e: } \\
\text { Internet }\end{array}$ & 80.00 & $67.5 \%$ & & 36.00 & $80.6 \%$ & & 0.13 \\
\hline $\begin{array}{l}\text { Source of } \\
\text { information used } \\
\text { f: Dutch National } \\
\text { Institute for Public } \\
\text { Health and the } \\
\text { Environment } \\
\text { (RIVM) }\end{array}$ & 80.00 & $5.0 \%$ & & 36.00 & $2.8 \%$ & & 0.55 \\
\hline $\begin{array}{l}\text { Source of } \\
\text { information used } \\
\text { g: Facebook or } \\
\text { Twitter }\end{array}$ & 80.00 & $1.3 \%$ & & 36.00 & $0.0 \%$ & & 0.32 \\
\hline $\begin{array}{l}\text { Source of } \\
\text { information used h: } \\
\text { Dutch Vape forum } \\
\text { or Acvoda (Active } \\
\text { for vaping) }\end{array}$ & 80.00 & $6.3 \%$ & & 36.00 & $22.2 \%$ & & 0.04 \\
\hline $\begin{array}{l}\text { Source of } \\
\text { information used } \\
\text { i: Friends, family, } \\
\text { acquaintances or } \\
\text { colleagues }\end{array}$ & 80.00 & $30.0 \%$ & & 36.00 & $33.3 \%$ & & 0.73 \\
\hline $\begin{array}{l}\text { Source of } \\
\text { information used } \\
\mathrm{j} \text { : Health care } \\
\text { professionals, such } \\
\text { as my family doctor } \\
\text { or practice nurse }\end{array}$ & 80.00 & $5.0 \%$ & & 36.00 & $11.1 \%$ & & 0.30 \\
\hline $\begin{array}{l}\text { Source of } \\
\text { information used } \\
\text { k: Not applicable. } \\
\text { I never look for } \\
\text { information about } \\
\text { the E-cigarette/ } \\
\text { vapers }\end{array}$ & 80.00 & $6.3 \%$ & & 36.00 & $0.0 \%$ & & 0.02 \\
\hline $\begin{array}{l}\text { Need of } \\
\text { information a: The } \\
\text { harmfulness of } \\
\text { e-cigarettes }\end{array}$ & 76.00 & $38.2 \%$ & & 36.00 & $47.2 \%$ & & 0.37 \\
\hline $\begin{array}{l}\text { Need of } \\
\text { information b: } \\
\text { Where you can by } \\
\text { e-cigarettes }\end{array}$ & 76.00 & $11.8 \%$ & & 36.00 & $19.4 \%$ & & 0.33 \\
\hline $\begin{array}{l}\text { Need of } \\
\text { information c: } \\
\text { E-liquids }\end{array}$ & 76.00 & $13.2 \%$ & & 36.00 & $8.3 \%$ & & 0.43 \\
\hline $\begin{array}{l}\text { Need of } \\
\text { information d: The } \\
\text { different types } \\
\text { of e-cigarettes } \\
\text { available }\end{array}$ & 76.00 & $9.2 \%$ & & 36.00 & $11.1 \%$ & & 0.76 \\
\hline
\end{tabular}

table continues 


\begin{tabular}{|c|c|c|c|c|c|c|c|}
\hline Scale and items & $\begin{array}{l}\text { Dual } \\
\text { users } \\
\text { (n) }\end{array}$ & $\begin{array}{l}\text { Dual users } \\
\text { (mean/ } \\
\text { percentage) }\end{array}$ & $\begin{array}{l}\text { Dual } \\
\text { users } \\
\text { (SD) }\end{array}$ & $\begin{array}{l}\text { E-cigarette } \\
\text { users }(n)\end{array}$ & $\begin{array}{l}\text { E-cigarette } \\
\text { users (mean/ } \\
\text { percentage) }\end{array}$ & $\begin{array}{l}\text { E-cigarette } \\
\text { users (SD) }\end{array}$ & p-value \\
\hline $\begin{array}{l}\text { Need of } \\
\text { information e: } \\
\text { How an e-cigarette } \\
\text { works }\end{array}$ & 76.00 & $10.5 \%$ & & 36.00 & $8.3 \%$ & & 0.71 \\
\hline $\begin{array}{l}\text { Need of } \\
\text { information } \mathrm{f}: \\
\text { Whether the } \\
\text { e-cigarette is an } \\
\text { effective smoking } \\
\text { cessation tool }\end{array}$ & 76.00 & $21.1 \%$ & & 36.00 & $27.8 \%$ & & 0.45 \\
\hline $\begin{array}{l}\text { Need of } \\
\text { information g: } \\
\text { How much e-liquid } \\
\text { do you use on } \\
\text { average with an } \\
\text { e-cigarette }\end{array}$ & 76.00 & $9.2 \%$ & & 36.00 & $8.3 \%$ & & 0.88 \\
\hline $\begin{array}{l}\text { Need of } \\
\text { information h: } \\
\text { What settings } \\
\text { to use with an } \\
\text { e-cigarette }\end{array}$ & 76.00 & $3.9 \%$ & & 36.00 & $0.0 \%$ & & 0.08 \\
\hline $\begin{array}{l}\text { Need of } \\
\text { information i: How } \\
\text { often on a day } \\
\text { you should use } \\
\text { e-cigarettes }\end{array}$ & 76.00 & $6.6 \%$ & & 36.00 & $2.8 \%$ & & 0.34 \\
\hline $\begin{array}{l}\text { Need of } \\
\text { information } \mathrm{j} \text { : } \\
\text { About the e-liquids } \\
\text { available }\end{array}$ & 76.00 & $7.9 \%$ & & 36.00 & $0.0 \%$ & & 0.01 \\
\hline $\begin{array}{l}\text { Need of } \\
\text { information all: All } \\
\text { the above }\end{array}$ & 76.00 & $15.8 \%$ & & 36.00 & $8.3 \%$ & & 0.24 \\
\hline $\begin{array}{l}\text { Need of } \\
\text { information } \\
\text { none: I do not } \\
\text { want additional } \\
\text { information about } \\
\text { the e-cigarette }\end{array}$ & 76.00 & $21.1 \%$ & & 36.00 & $19.4 \%$ & & 0.84 \\
\hline $\begin{array}{l}\text { Attitude towards } \\
\text { information about } \\
\text { e-cigarettes }\end{array}$ & 76 & 4.54 & 1.11 & 36 & 4.42 & 1.39 & 0.63 \\
\hline $\begin{array}{l}\text { Reliability of } \\
\text { information a: Only } \\
\text { if researchers have } \\
\text { influence on how } \\
\text { the research is } \\
\text { carried out }\end{array}$ & 80 & $32.5 \%$ & & 36 & $27.8 \%$ & & 0.61 \\
\hline $\begin{array}{l}\text { Reliability of } \\
\text { information b: Only } \\
\text { if researchers have } \\
\text { influence on how } \\
\text { the research results } \\
\text { are interpreted }\end{array}$ & 80 & $26.3 \%$ & & 36 & $22.2 \%$ & & 0.64 \\
\hline
\end{tabular}

table continues 


\begin{tabular}{|c|c|c|c|c|c|c|c|}
\hline Scale and items & $\begin{array}{l}\text { Dual } \\
\text { users } \\
\text { (n) }\end{array}$ & $\begin{array}{l}\text { Dual users } \\
\text { (mean/ } \\
\text { percentage) }\end{array}$ & $\begin{array}{l}\text { Dual } \\
\text { users } \\
\text { (SD) }\end{array}$ & $\begin{array}{l}\text { E-cigarette } \\
\text { users }(n)\end{array}$ & $\begin{array}{l}\text { E-cigarette } \\
\text { users (mean/ } \\
\text { percentage) }\end{array}$ & $\begin{array}{l}\text { E-cigarette } \\
\text { users (SD) }\end{array}$ & $\mathrm{p}$-value \\
\hline $\begin{array}{l}\text { Reliability of } \\
\text { information c: Only } \\
\text { if researchers have } \\
\text { influence on how } \\
\text { the research results } \\
\text { are communicated }\end{array}$ & 80 & $27.5 \%$ & & 36 & $19.4 \%$ & & 0.34 \\
\hline $\begin{array}{l}\text { Reliability of } \\
\text { information d: If all } \\
\text { the research results } \\
\text { are made known } \\
\text { and not just the } \\
\text { desired results }\end{array}$ & 80 & $66.3 \%$ & & 36 & $75.0 \%$ & & 0.34 \\
\hline $\begin{array}{l}\text { Reliability of } \\
\text { information e: If } \\
\text { the researchers } \\
\text { have no conflict of } \\
\text { interest to declare }\end{array}$ & 80 & $51.3 \%$ & & 36 & $75.0 \%$ & & 0.01 \\
\hline $\begin{array}{l}\text { Reliability of } \\
\text { information f: If } \\
\text { the research is not } \\
\text { financed by the } \\
\text { tobacco industry }\end{array}$ & 80 & $37.5 \%$ & & 36 & $55.6 \%$ & & 0.08 \\
\hline $\begin{array}{l}\text { Reliability of } \\
\text { information g: If } \\
\text { the research is } \\
\text { under the auspices } \\
\text { of the national } \\
\text { government, } \\
\text { if there is a } \\
\text { governmental logo }\end{array}$ & 80 & $16.3 \%$ & & 36 & $8.3 \%$ & & 0.21 \\
\hline $\begin{array}{l}\text { Independence } \\
\text { of information a: } \\
\text { Only if researchers } \\
\text { have influence on } \\
\text { how the research is } \\
\text { carried out. }\end{array}$ & 80 & $35.0 \%$ & & 36 & $36.1 \%$ & & 0.91 \\
\hline $\begin{array}{l}\text { Independence of } \\
\text { information b: Only } \\
\text { if researchers have } \\
\text { influence on how } \\
\text { the research results } \\
\text { are interpreted. }\end{array}$ & 80 & $27.5 \%$ & & 36 & $27.8 \%$ & & 0.98 \\
\hline $\begin{array}{l}\text { Independence of } \\
\text { information c: Only } \\
\text { if researchers have } \\
\text { influence on how } \\
\text { the research results } \\
\text { are communicated. }\end{array}$ & 80 & $27.5 \%$ & & 36 & $22.2 \%$ & & 0.54 \\
\hline $\begin{array}{l}\text { Independence of } \\
\text { information d: If all } \\
\text { the research results } \\
\text { are made known } \\
\text { and not just the } \\
\text { desired results. }\end{array}$ & 80 & $62.5 \%$ & & 36 & $72.2 \%$ & & 0.30 \\
\hline
\end{tabular}




\begin{tabular}{|c|c|c|c|c|c|c|c|}
\hline Scale and items & $\begin{array}{l}\text { Dual } \\
\text { users } \\
\text { (n) }\end{array}$ & $\begin{array}{l}\text { Dual users } \\
\text { (mean/ } \\
\text { percentage) }\end{array}$ & $\begin{array}{l}\text { Dual } \\
\text { users } \\
\text { (SD) }\end{array}$ & $\begin{array}{l}\text { E-cigarette } \\
\text { users }(n)\end{array}$ & $\begin{array}{l}\text { E-cigarette } \\
\text { users (mean/ } \\
\text { percentage) }\end{array}$ & $\begin{array}{l}\text { E-cigarette } \\
\text { users (SD) }\end{array}$ & $\mathrm{p}$-value \\
\hline $\begin{array}{l}\text { Independence of } \\
\text { information e: If } \\
\text { the researchers } \\
\text { themselves have } \\
\text { no vested interests } \\
\text { in the results. }\end{array}$ & 80 & $50.0 \%$ & & 36 & $72.2 \%$ & & 0.02 \\
\hline $\begin{array}{l}\text { Independence of } \\
\text { information f: If } \\
\text { the research is not } \\
\text { financed by the } \\
\text { tobacco industry. }\end{array}$ & 80 & $38.8 \%$ & & 36 & $50.0 \%$ & & 0.27 \\
\hline $\begin{array}{l}\text { Independence } \\
\text { of information h: } \\
\text { If the research is } \\
\text { under the auspices } \\
\text { of the national } \\
\text { government, } \\
\text { if there is a } \\
\text { governmental } \\
\text { logo. }\end{array}$ & 80 & $18.8 \%$ & & 36 & $5.6 \%$ & & 0.03 \\
\hline
\end{tabular}




\section{Appendix 8 Participants characteristics and alias}

\begin{tabular}{|c|c|c|c|c|}
\hline $\begin{array}{l}\text { Chapter } 6 \\
\text { A Deliberate } \\
\text { vaccination a }\end{array}$ & $\begin{array}{l}\text { Exp } \\
\text { Ecept }\end{array}$ & $\begin{array}{l}\text { related to inf } \\
\text { and partial ac }\end{array}$ & cision-making abo & childhood \\
\hline Alias & Gender & Country of birth & Level of education & Year of birth \\
\hline 1_ACCEPT & Female & the Netherlands & High & \\
\hline 2_ACCEPT & Female & the Netherlands & High & 1974 \\
\hline 3_ACCEPT & Female & the Netherlands & High & 1977 \\
\hline 4_ACCEPT & Female & the Netherlands & High & 1973 \\
\hline 5_ACCEPT & Female & the Netherlands & High & 1986 \\
\hline 6_ACCEPT & Female & the Netherlands & High & 1975 \\
\hline 7_REFUSE & Female & the Netherlands & High & 1980 \\
\hline 8_REFUSE & Female & the Netherlands & High & 1980 \\
\hline 9_REFUSE & Female & the Netherlands & High & 1979 \\
\hline 10_REFUSE & Female & the Netherlands & High & 1979 \\
\hline 11_REFUSE & Female & the Netherlands & High & 1978 \\
\hline 12_REFUSE & Female & the Netherlands & High & 1978 \\
\hline 13_PARTIAL & Female & the Netherlands & High & 1972 \\
\hline 14_PARTIAL & Female & the Netherlands & High & 1973 \\
\hline 15_PARTIAL & Female & the Netherlands & High & 1968 \\
\hline 16_PARTIAL & Female & the Netherlands & High & 1983 \\
\hline 17_PARTIAL & Female & the Netherlands & High & 1977 \\
\hline 18_PARTIAL & Female & the Netherlands & High & 1987 \\
\hline 19_PARTIAL & Female & the Netherlands & High & 1982 \\
\hline 20_PARTIAL & Female & the Netherlands & High & 1980 \\
\hline 21_ACCEPT & Female & the Netherlands & High & 1983 \\
\hline 22_ACCEPT & Female & Surinam & High & 1985 \\
\hline 23_ACCEPT & Female & the Netherlands & High & 1982 \\
\hline 24_ACCEPT & Female & Germany & High & 1973 \\
\hline 25_ACCEPT & Female & Canada & High & 1974 \\
\hline 26_ACCEPT & Female & the Netherlands & High & 1981 \\
\hline 27_ACCEPT & Female & the Netherlands & High & 1976 \\
\hline 28_REFUSE & Female & the Netherlands & High & 1971 \\
\hline 29_REFUSE & Female & the Netherlands & High & 1980 \\
\hline 30_PARTIAL & Female & the Netherlands & High & 1959 \\
\hline 31_PARTIAL & Female & the Netherlands & High & 1990 \\
\hline 32_PARTIAL & Female & the Netherlands & High & \\
\hline 33_PARTIAL & Female & Slovakia & High & 1977 \\
\hline 34_PARTIAL & Female & the Netherlands & High & 1976 \\
\hline 35_PARTIAL & Female & the Netherlands & High & 1980 \\
\hline 36_PARTIAL & Female & the Netherlands & High & 1977 \\
\hline
\end{tabular}

table continues 


\begin{tabular}{lllll}
\hline Alias & Gender & Country of birth & Level of education & Year of birth \\
\hline 37_PARTIAL & Female & the Netherlands & High & 1978 \\
38_PARTIAL & Female & the Netherlands & High & 1970 \\
39_PARTIAL & Female & the Netherlands & High & 1985 \\
40_PARTIAL & Female & Seoul & High & 1977 \\
41_PARTIAL & Female & the Netherlands & Middle & 1982 \\
42_PARTIAL & Female & the Netherlands & High & 1971 \\
43_ACCEPT & Female & the Netherlands & High & 1974 \\
44_ACCEPT & Female & the Netherlands & High & 1978 \\
45_ACCEPT & Female & the Netherlands & High & 1985 \\
46_ACCEPT & Female & the Netherlands & High & 1974 \\
47_ACCEPT & Female & the Netherlands & High & 1985 \\
48_ACCEPT & Female & the Netherlands & Low & 1972 \\
49_REFUSE & Female & the Netherlands & High & \\
50_REFUSE & Female & the Netherlands & High & 1975 \\
51_REFUSE & Female & the Netherlands & High & 1980 \\
52_PARTIAL & Female & the Netherlands & High & 1983 \\
53_PARTIAL & Female & the Netherlands & High & 1990 \\
54_PARTIAL & Female & the Netherlands & High & 1977 \\
55_REFUSE & Female & Australia & High & 1982 \\
\hline Nete & &
\end{tabular}

Note the alias reflects the decision about childhood vaccination of participants 


\section{Appendix 9 Topic guide: exploring decision-making about childhood vaccination}

\section{Chapter 6}

A Deliberate Choice? Exploring the Decision to Switch from Cigarettes to E-Cigarettes

Note: All participants have to sign an informed consent before the start of the introduction. Introduction by interviewer

Welcome! My name is ... and this is ..., who will be helping me with the discussion today. I work for ... and I my research is about....

Today we are discussing childhood vaccination. Your opinion as a parent is very important. We would like to talk to you about childhood vaccination and this discussion will take approximately two hours, with a break. At the end of our discussion we have time for general questions about childhood vaccination.

We would like to stress that there are no correct or wrong answers. Today is all about your experiences and your ideas. We will be hearing a lot of different ideas and experiences, so I would like to ask you to respect each other. Please listen carefully to each other and please let each other finish speaking.

This group discussion will be audio recorded. - Turn on audio recording-All personal information will be made anonymous, and please remember that your participation is voluntary. This means that you can leave at all times, you do not have to explain yourself.

Are there any remaining questions before we start?

Introduction participants

Please introduce yourself shortly. Please share the vaccination status of your child. What do you enjoy doing in your daily live?

Make name tags

General prompts

What do you mean?

Can you tell me more about that?

What comes to mind?

Can you explain that to me?

Is there anything else that you can think of?

\section{Topic guide: exploring decision making process of childhood vaccination}

\section{Knowledge about childhood vaccination}

What do you know about childhood vaccination? [use flip-over to collect ideas]

Prompts

Risks, NIP, different childhood vaccination schedules, religion, herd immunity, VPDs, side-effects

\section{Attitude}

What is your opinion about childhood vaccination?

Prompts

How do you feel about it? What are advantages and disadvantages?

table continues 


\section{Deliberation}

When did you start thinking about childhood vaccination?

How did you consider the pros and cons of childhood vaccination?

Who played a role in your decision?

What played a role in your decision?

How difficult was it to make a decision?

Did you have any doubts about your decision?

Prompts Did you consider an alternative (schedule)? How do you deal with the risks of refusing childhood vaccinations? Is it one big decision, or several small ones? Are you happy with your decision? Would you do it differently? What would have made it easier for you to make a decision about childhood vaccination?

[use these prompts to link to next topic]

\section{Information need}

What information is important to make a decision about childhood vaccination?

Where did you look for information about childhood vaccination?

Did you understand the information provided at the CWC?

Prompts

Which information was important to you? Which source was important to you? How do you know how to trust information? Which information do you still miss? Could the CVPs answer your questions? Do you feel that the CVPs take your questions seriously?

\section{Closing}

Is there anything we did not cover today that you find important related to childhood vaccination?

Do you have any questions left?

Note: due to the semi-structured protocol these questions are examples and may slightly very in each focus group in both style and order. 


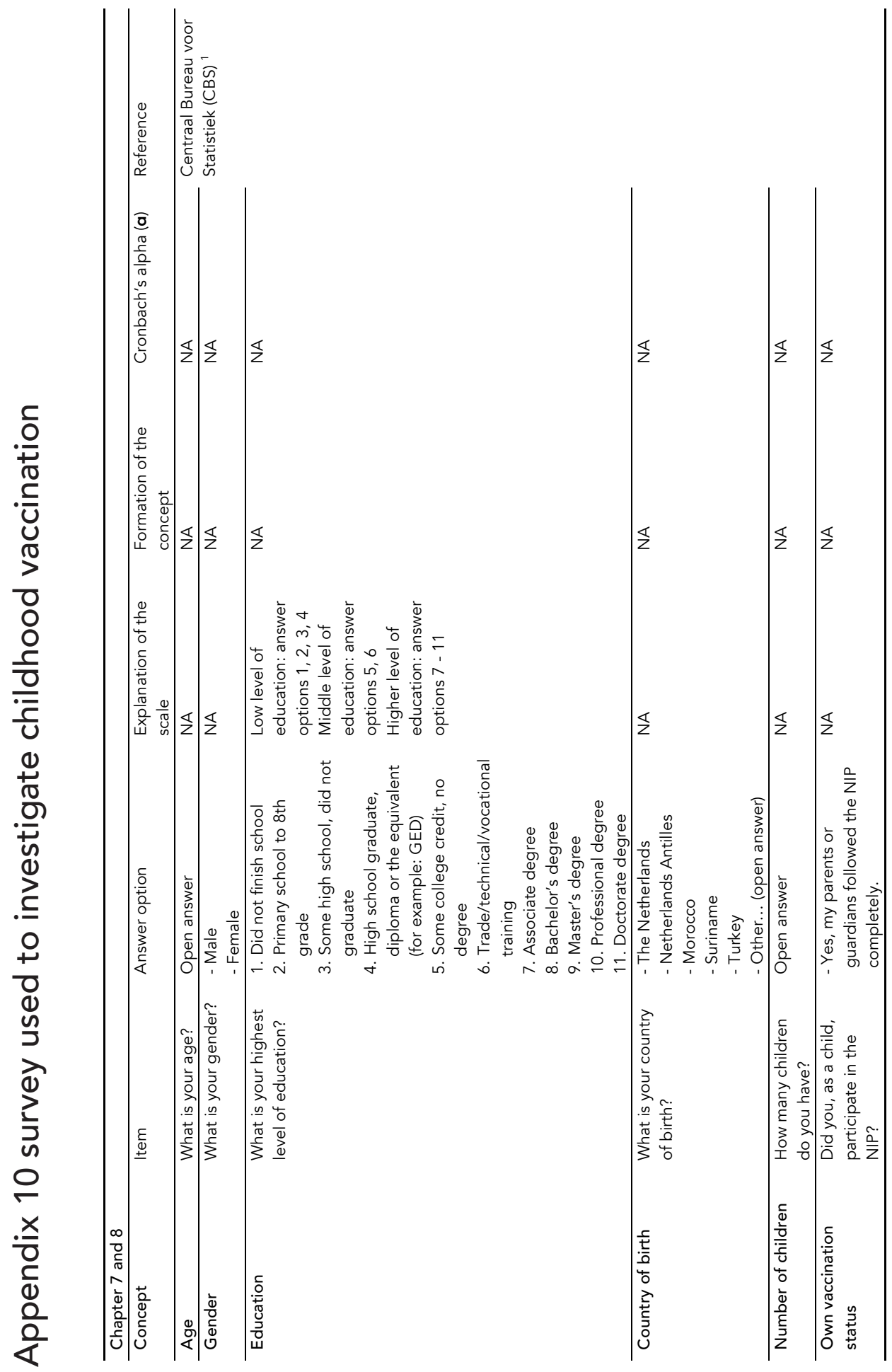




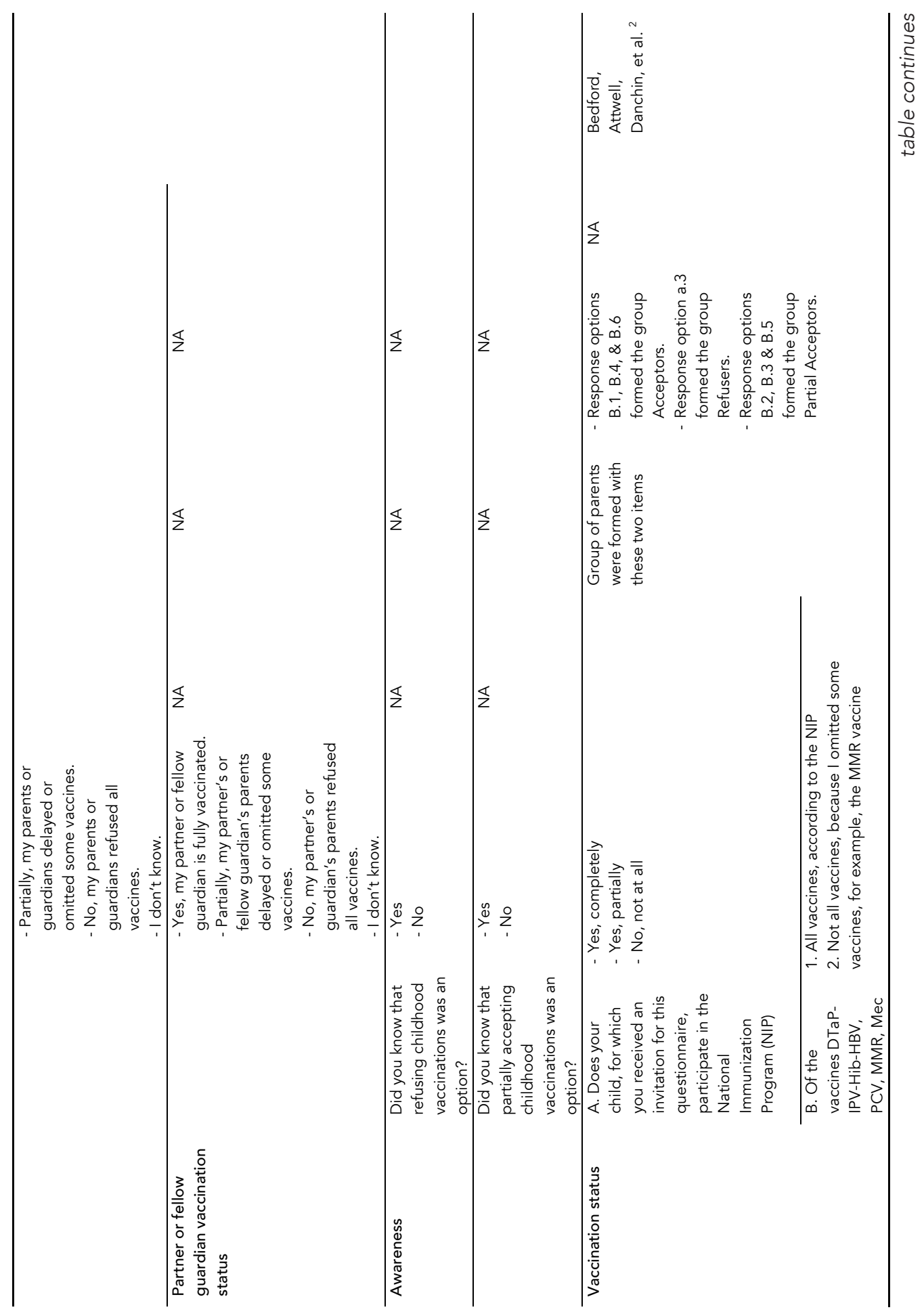




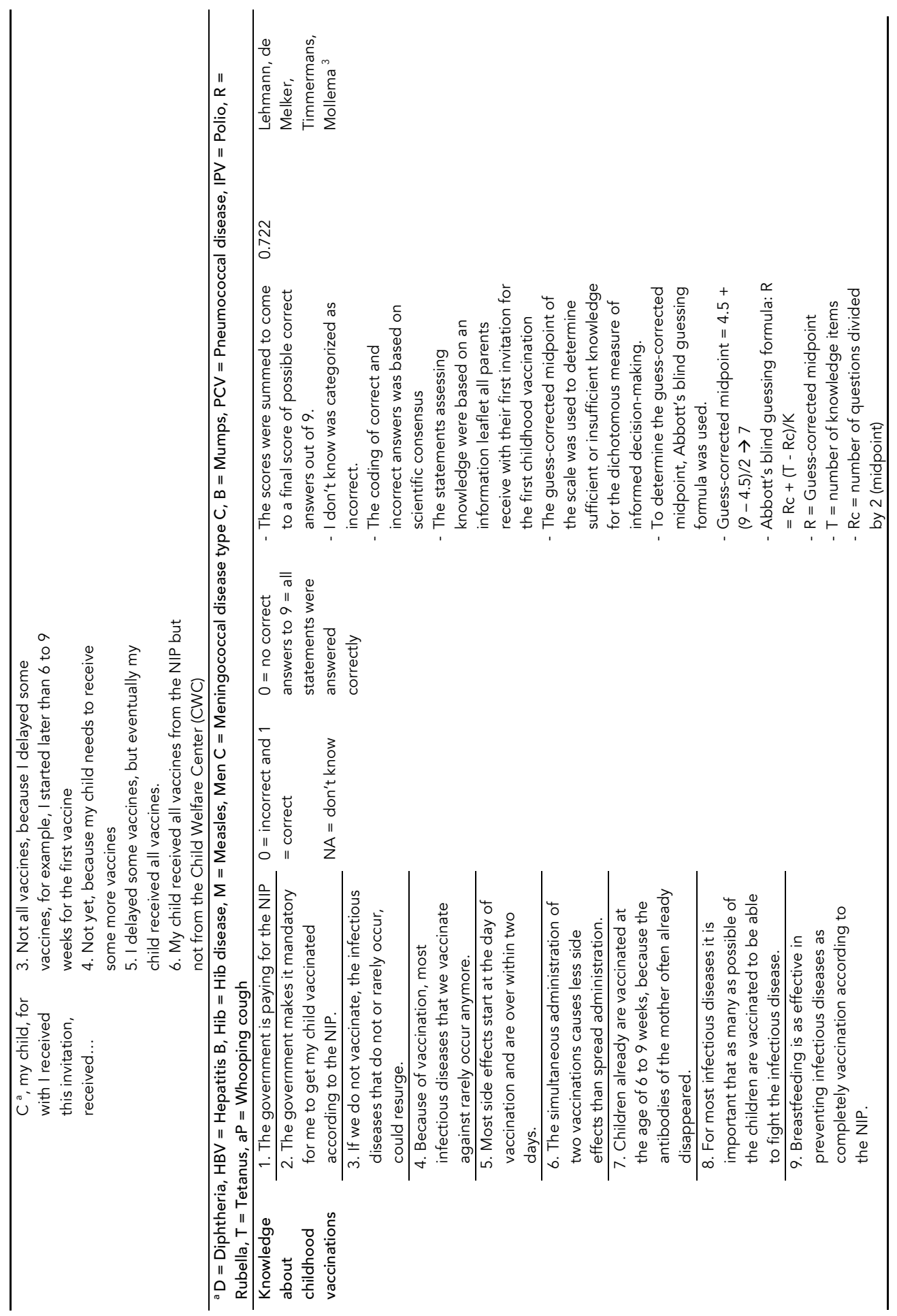




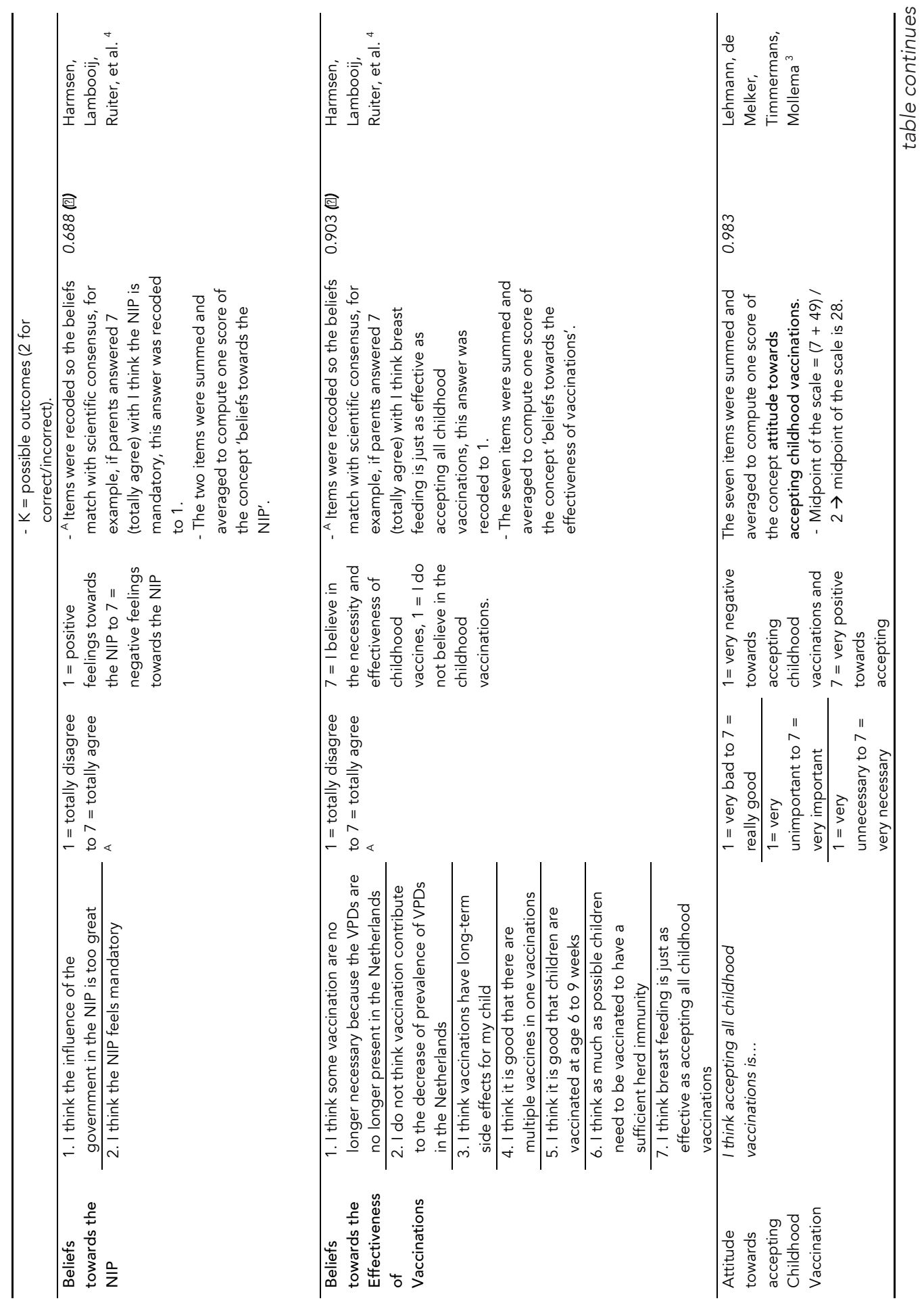




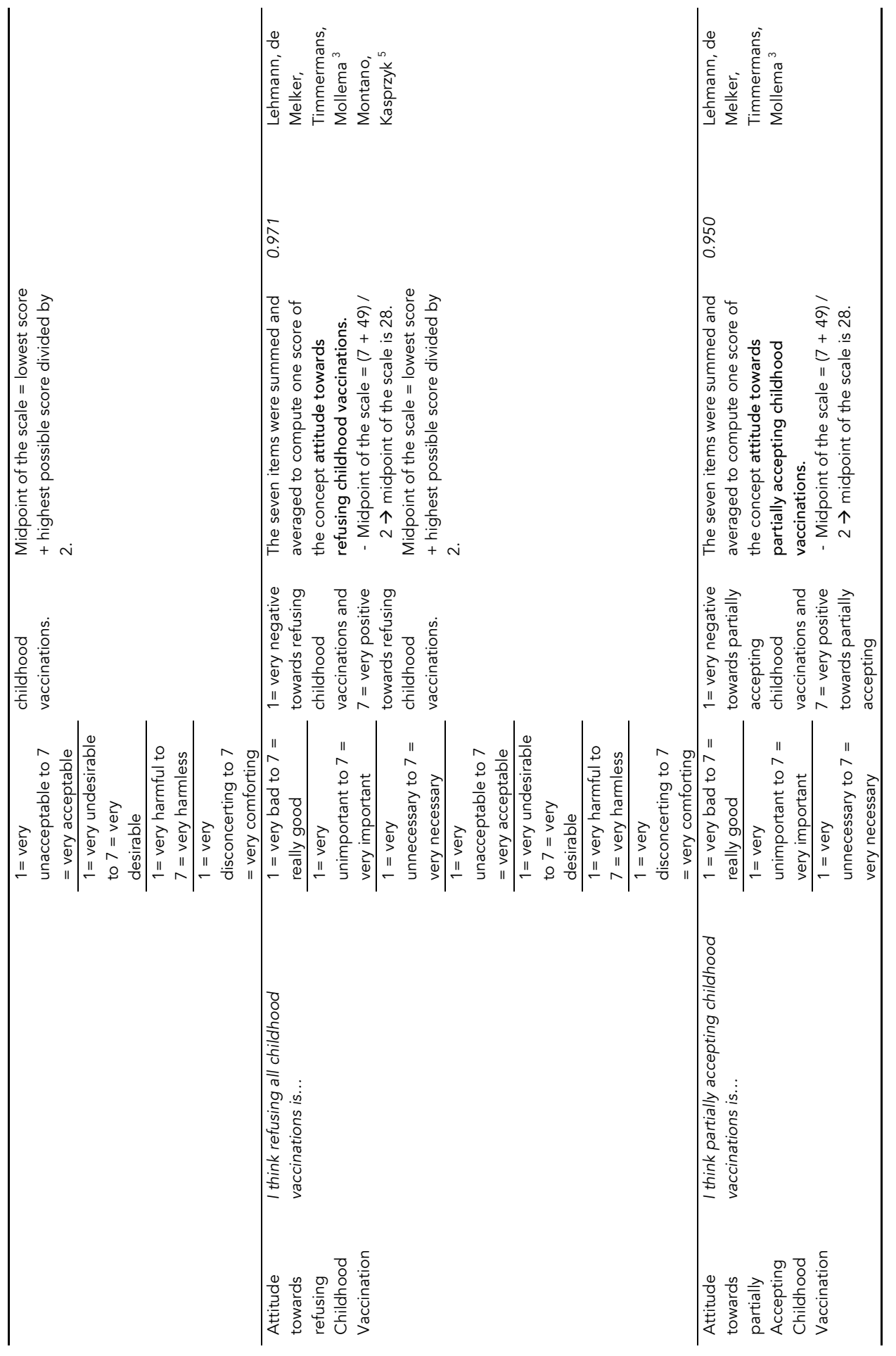




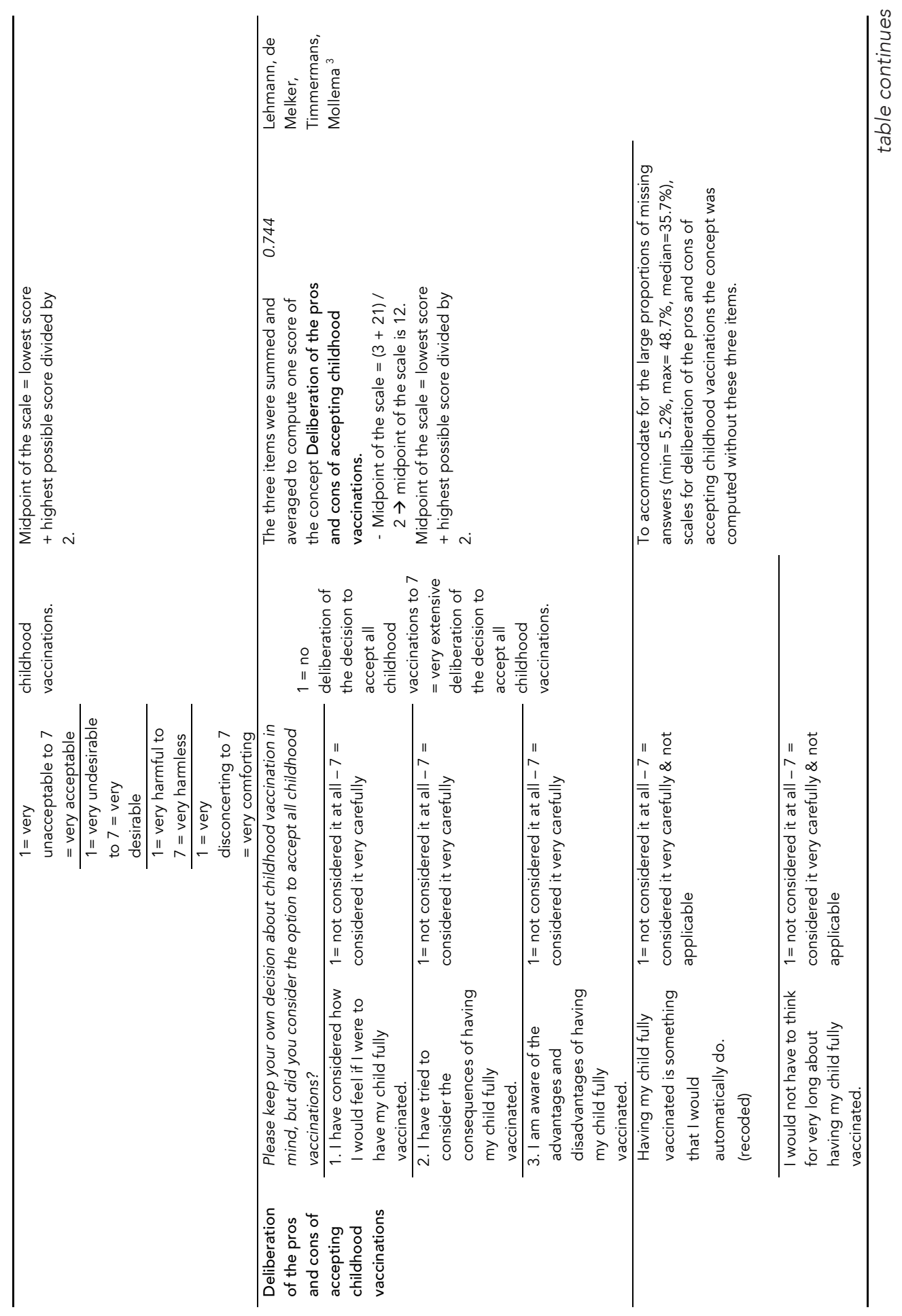




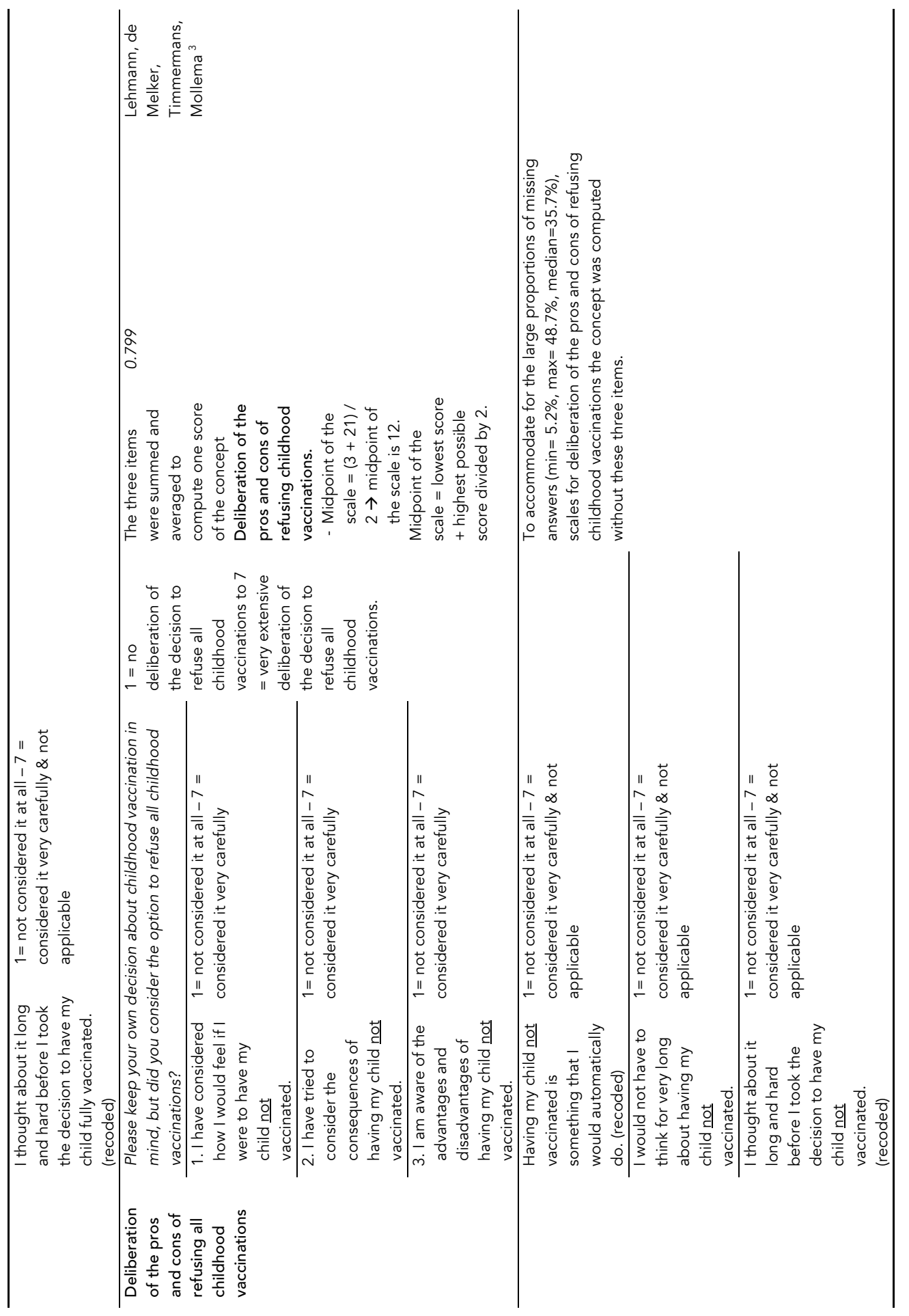




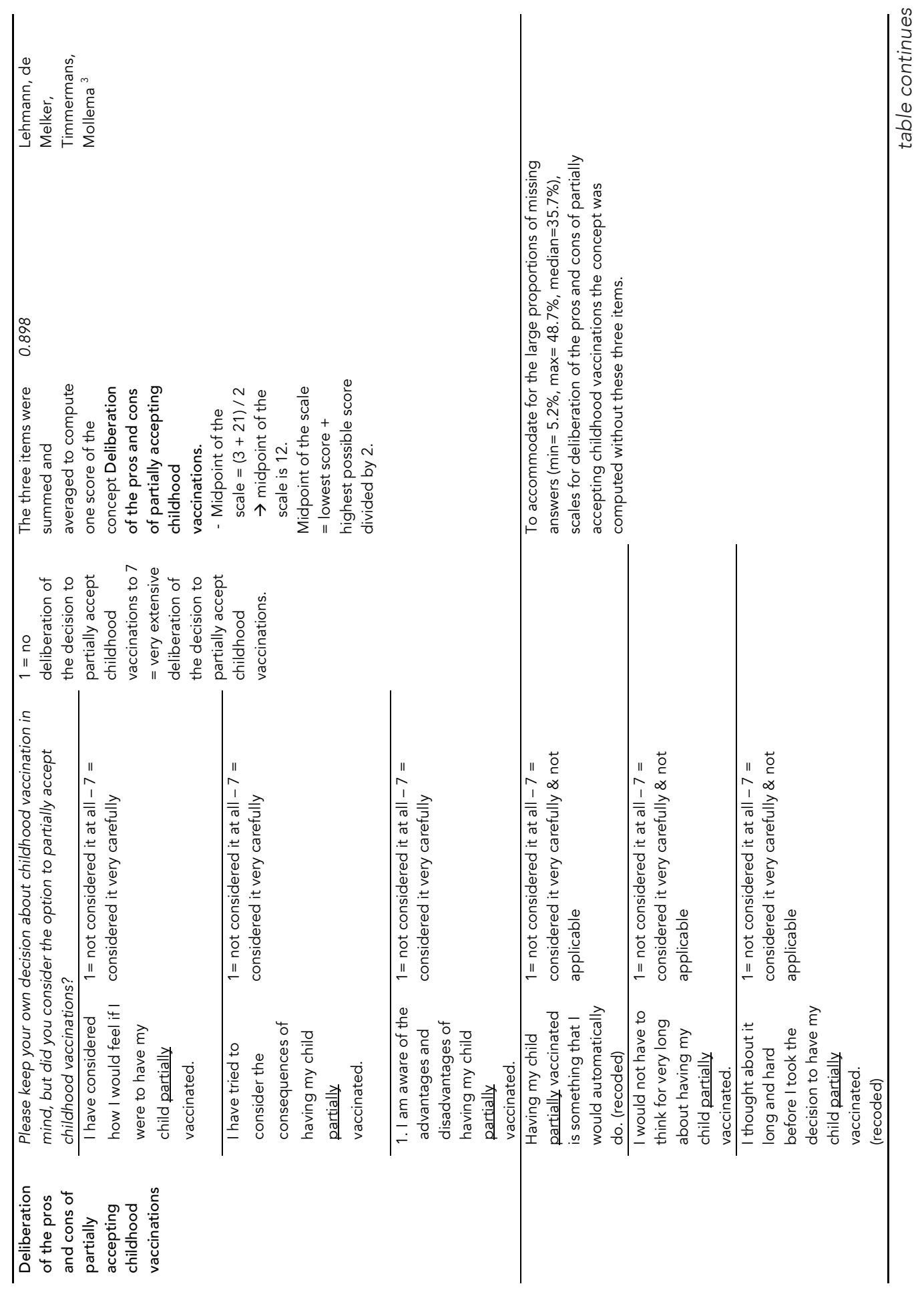




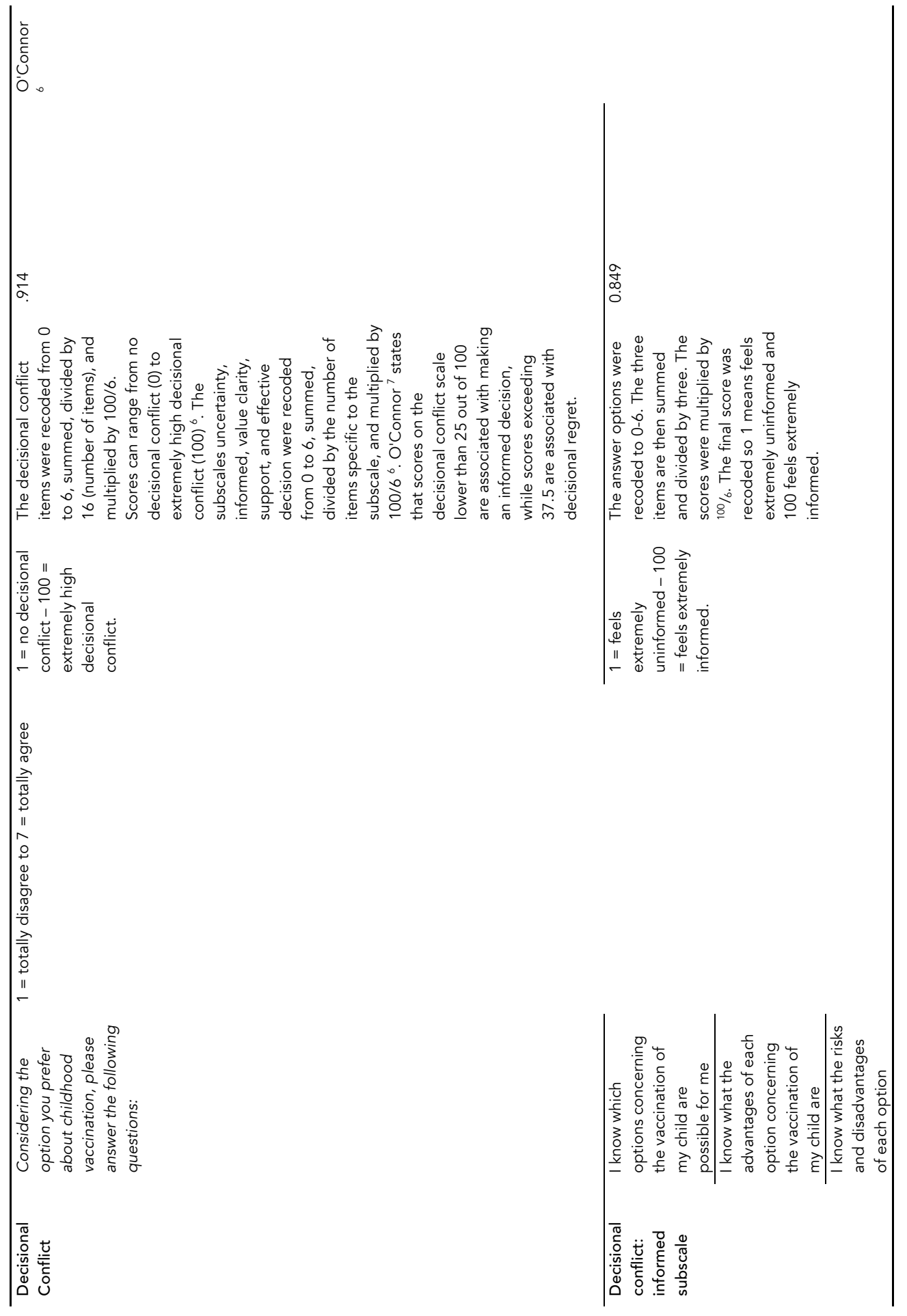




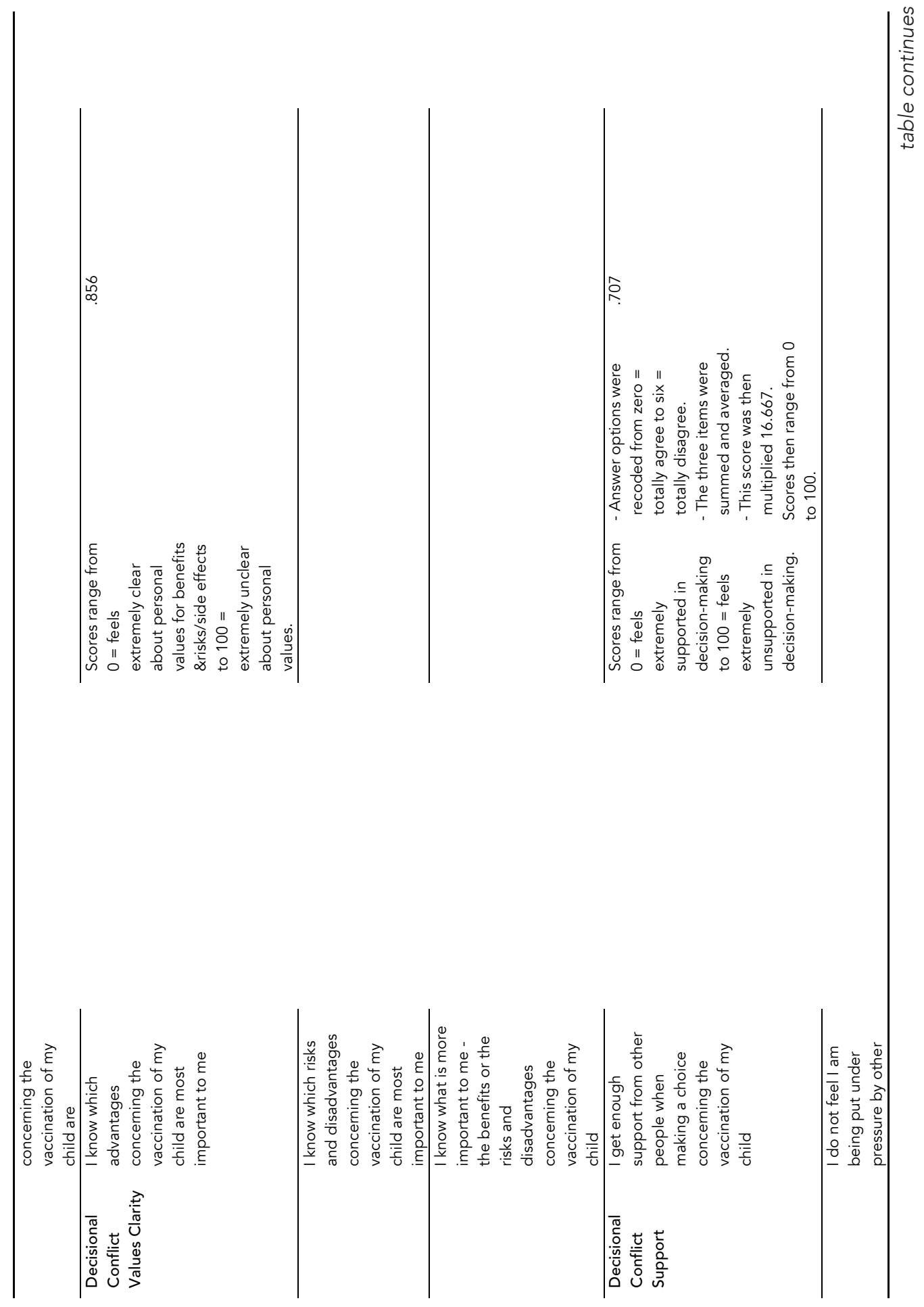



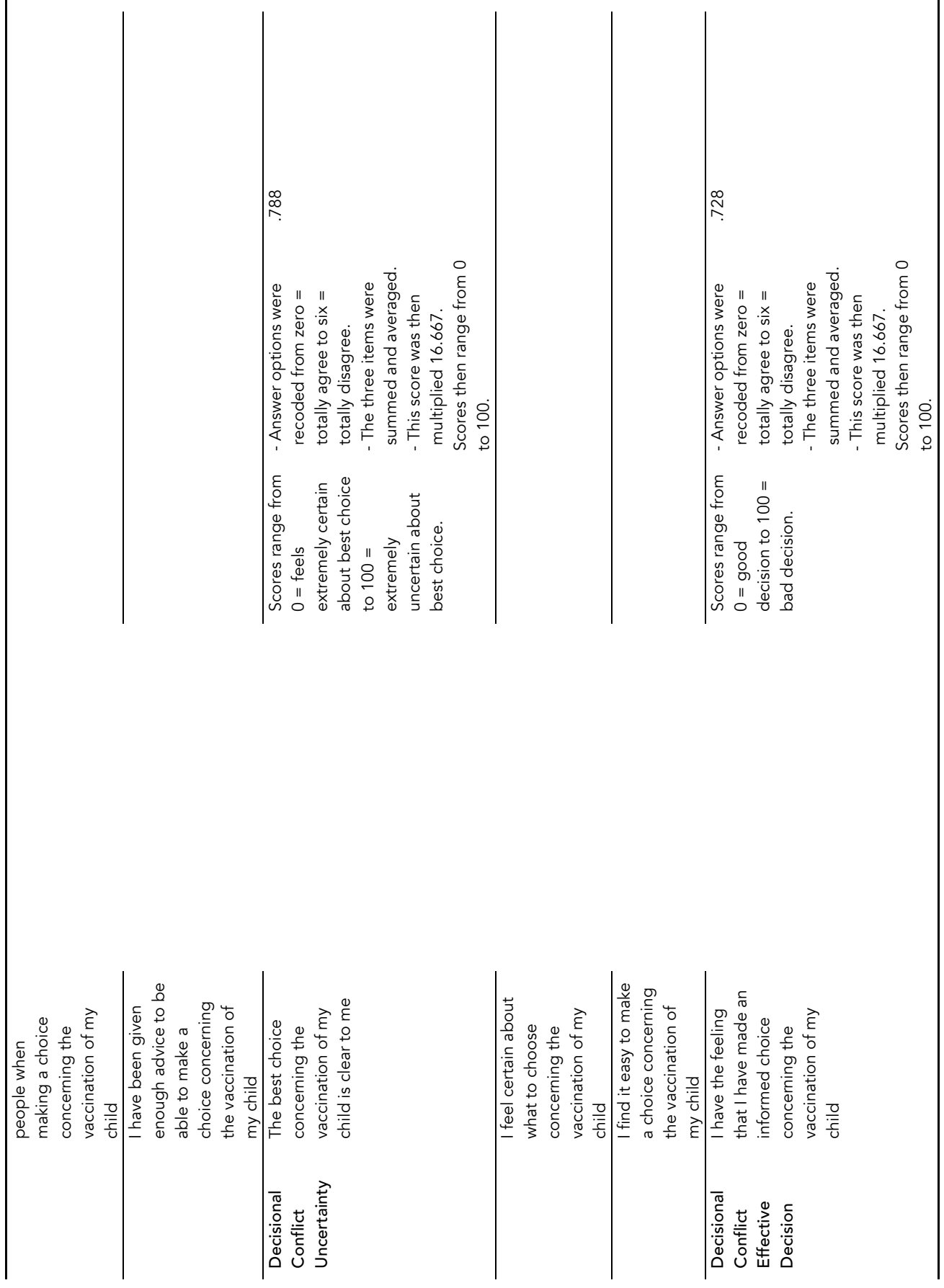


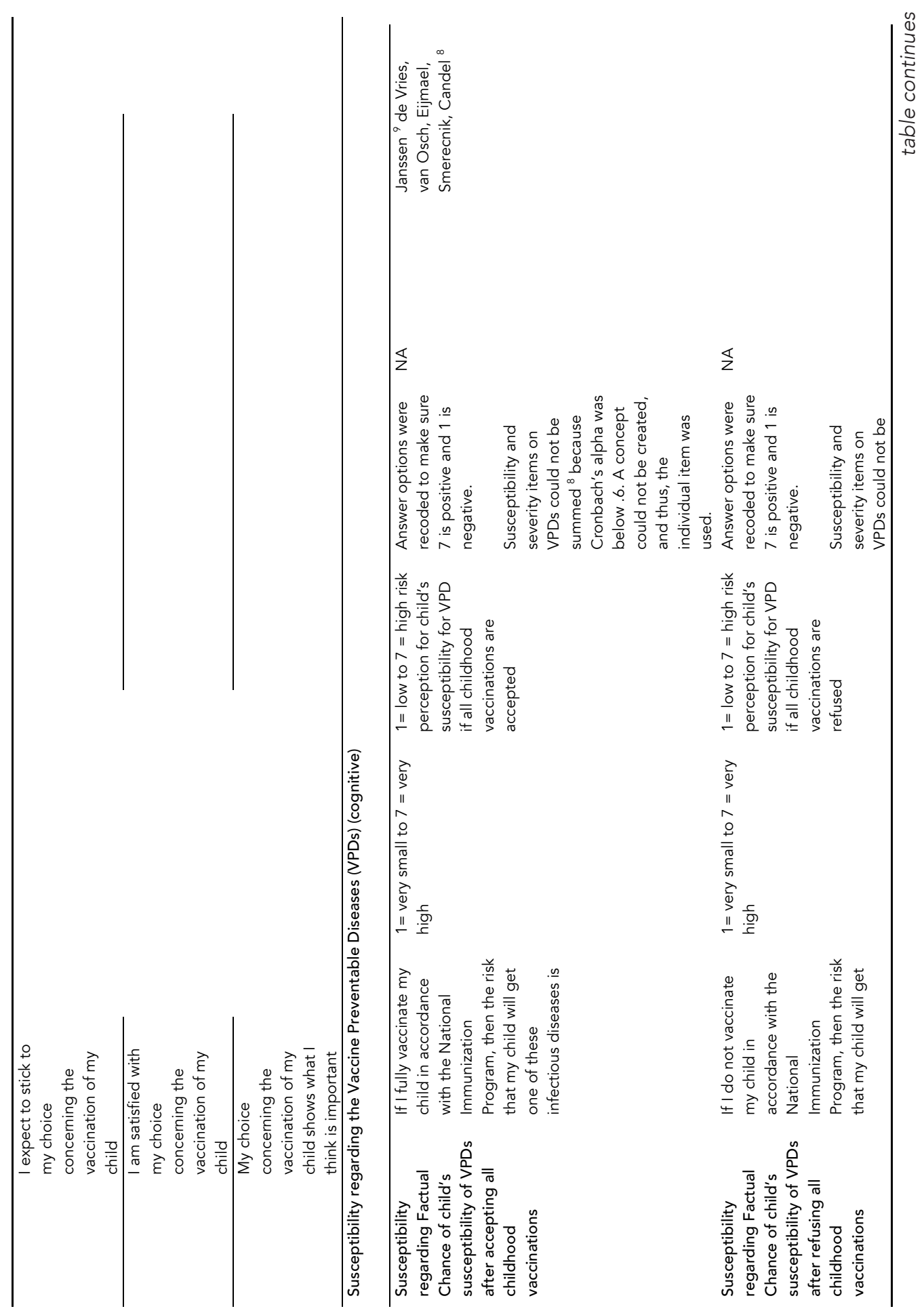




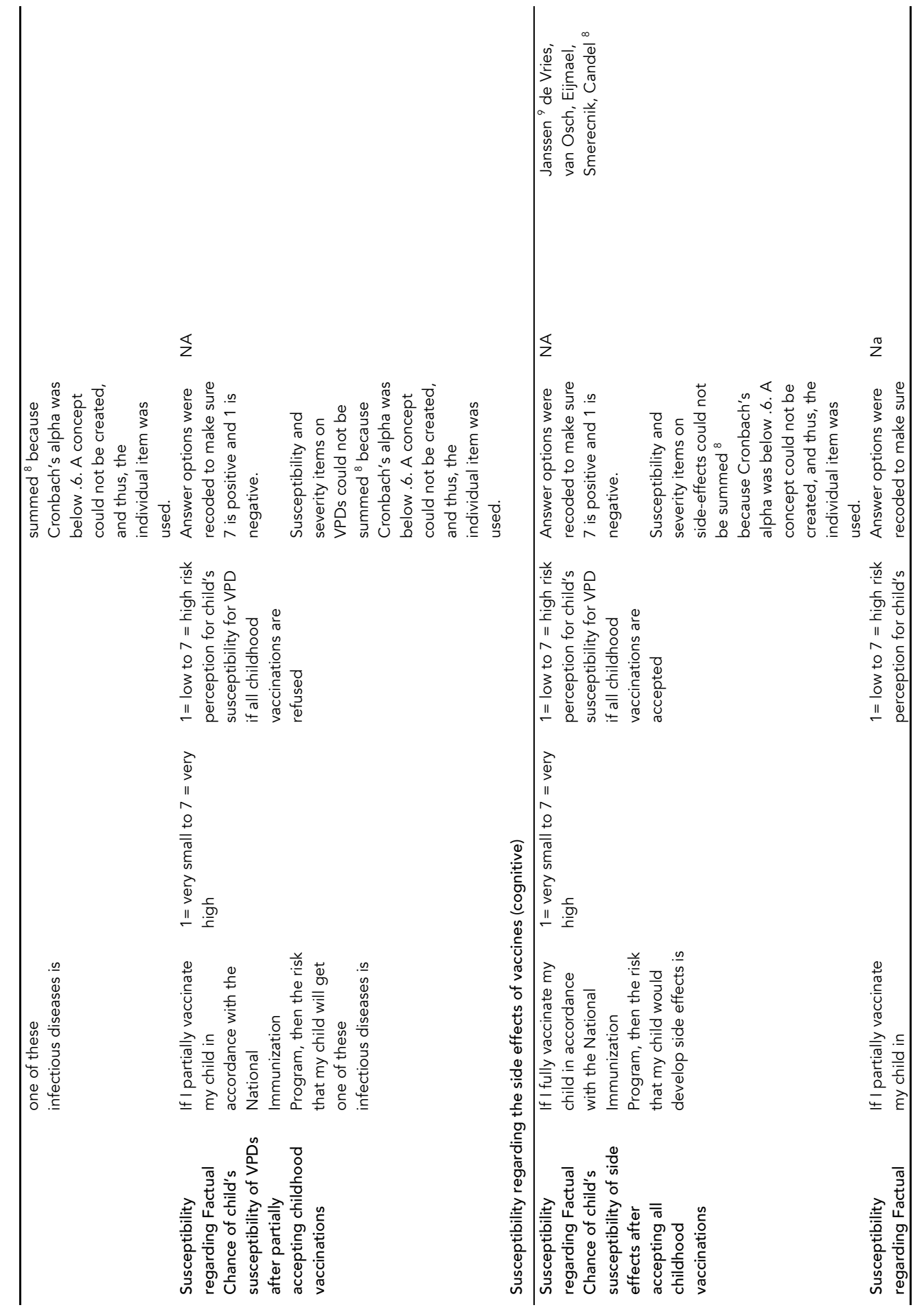




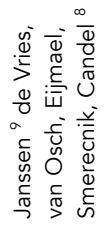

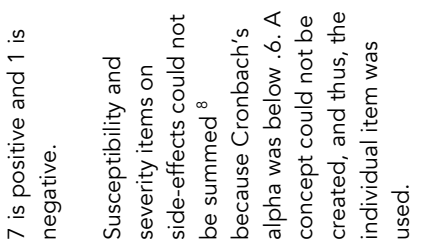

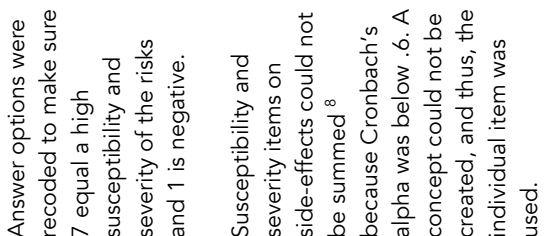
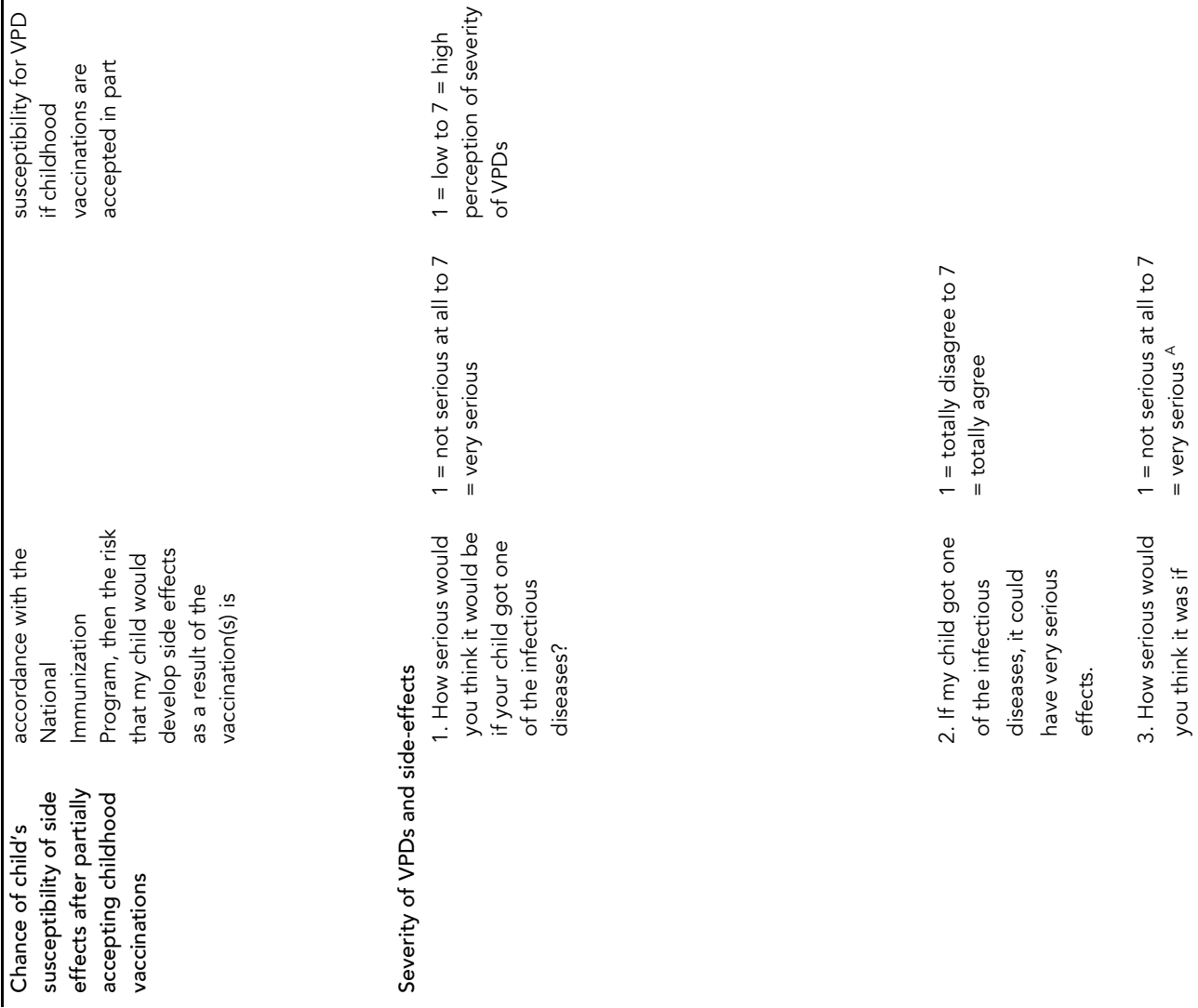


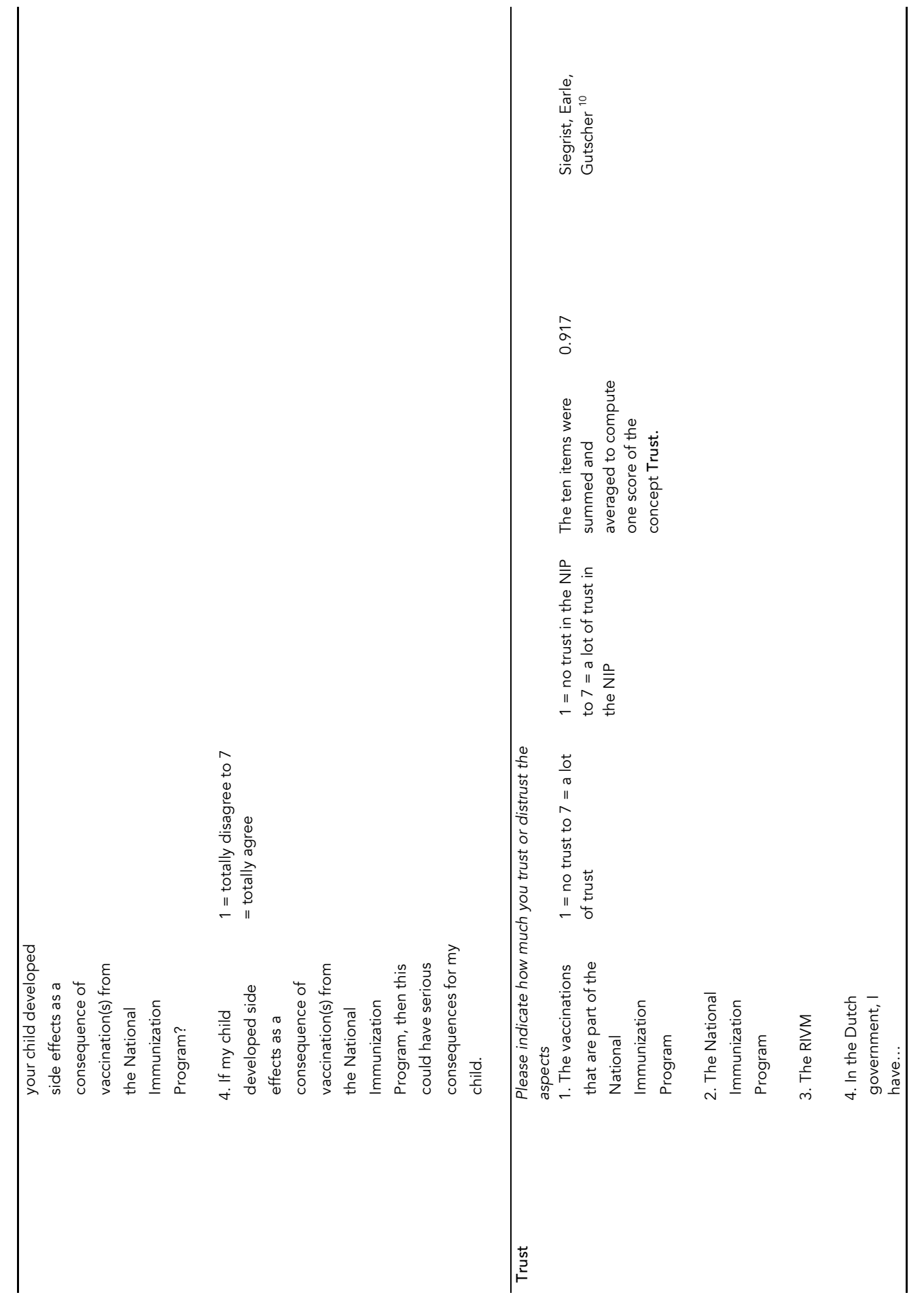




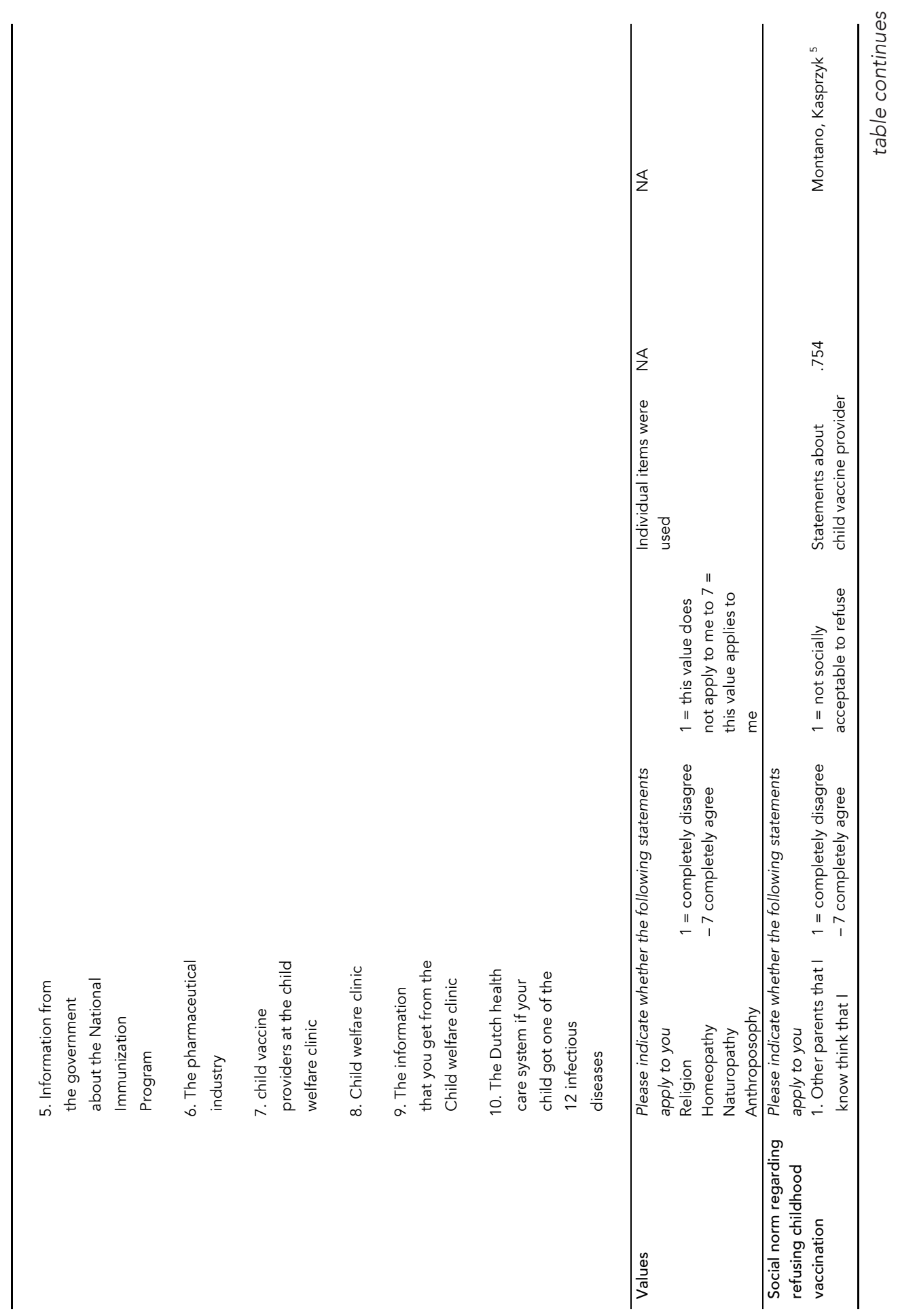

Appendices 369 


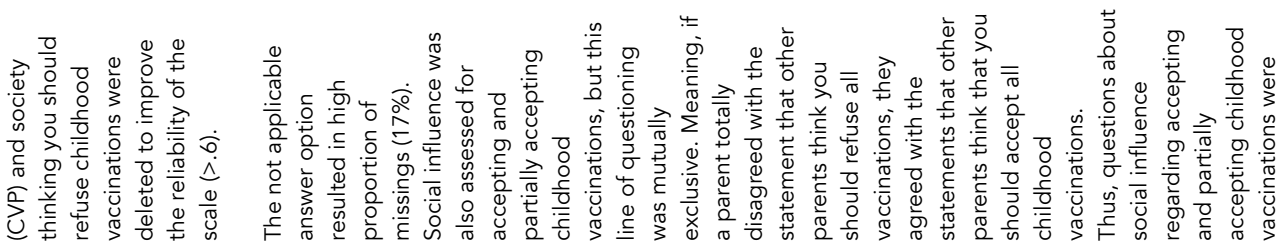

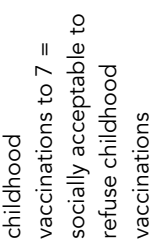

$\frac{0}{0}$
$\frac{0}{0}$
$\frac{0}{0}$
$\frac{0}{0}$
0
0
$\frac{0}{\infty}$
$\infty$

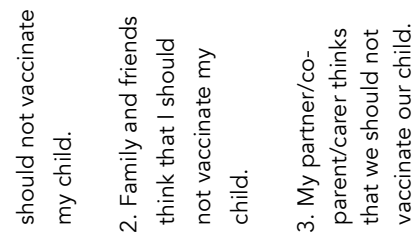




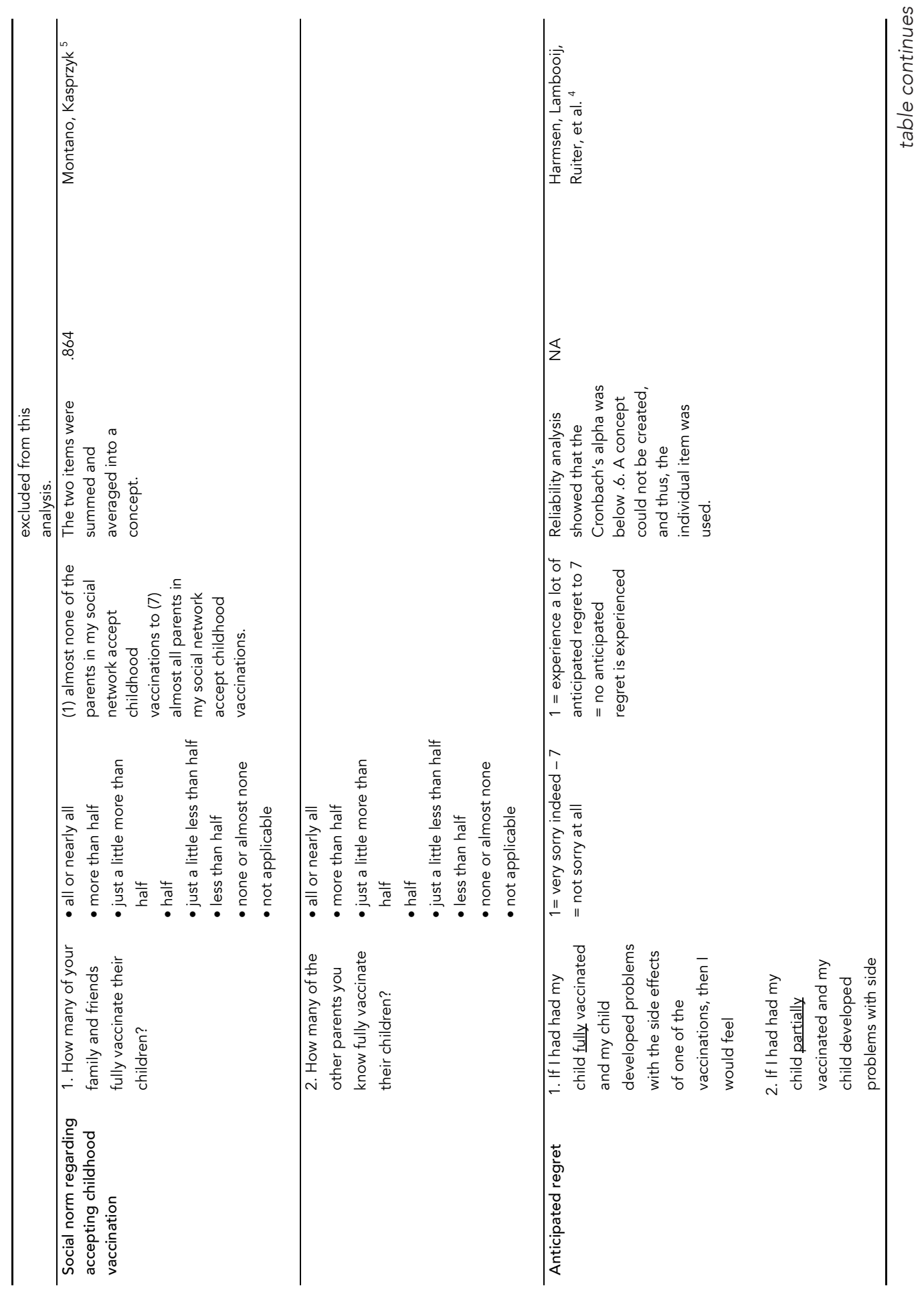




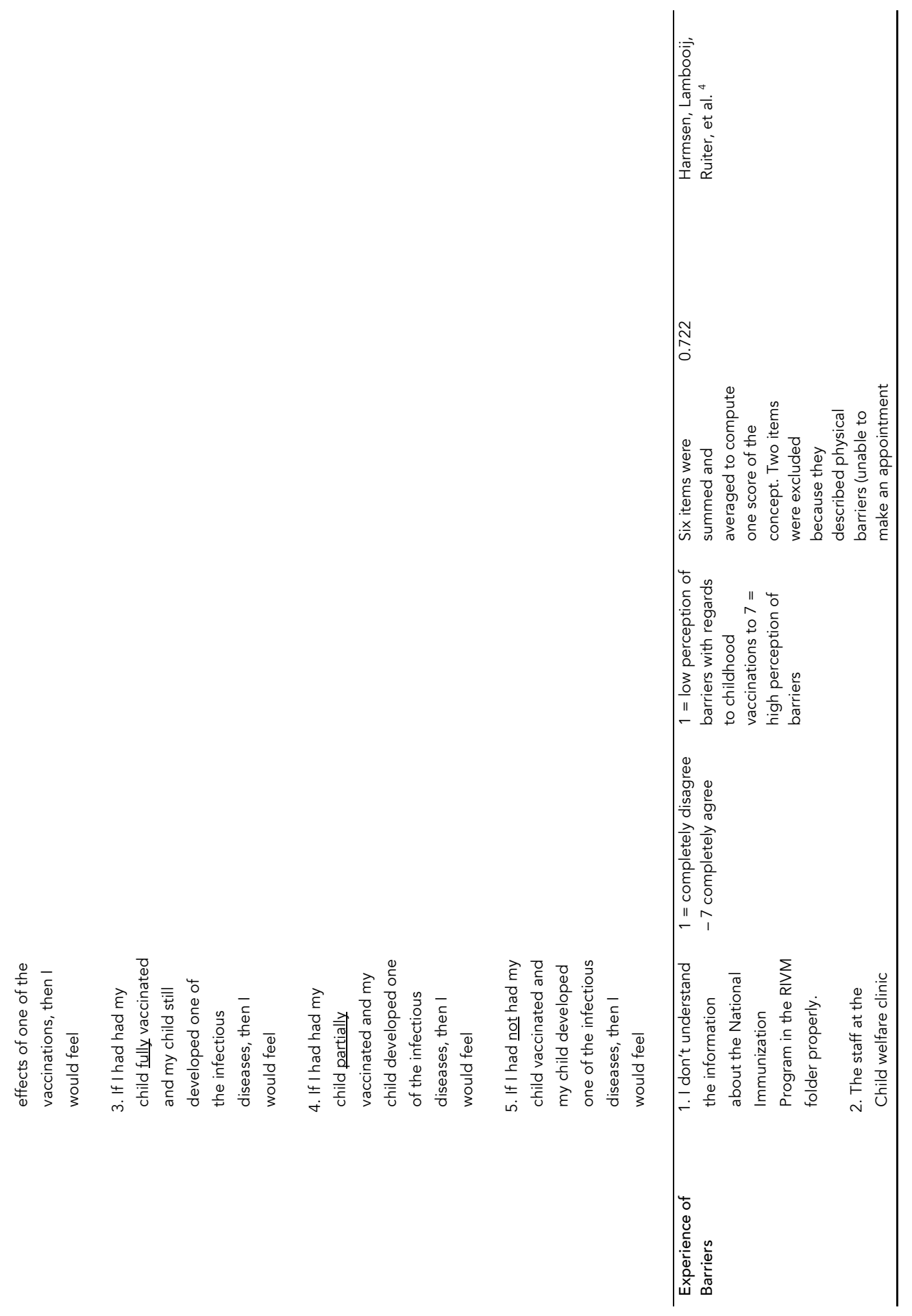




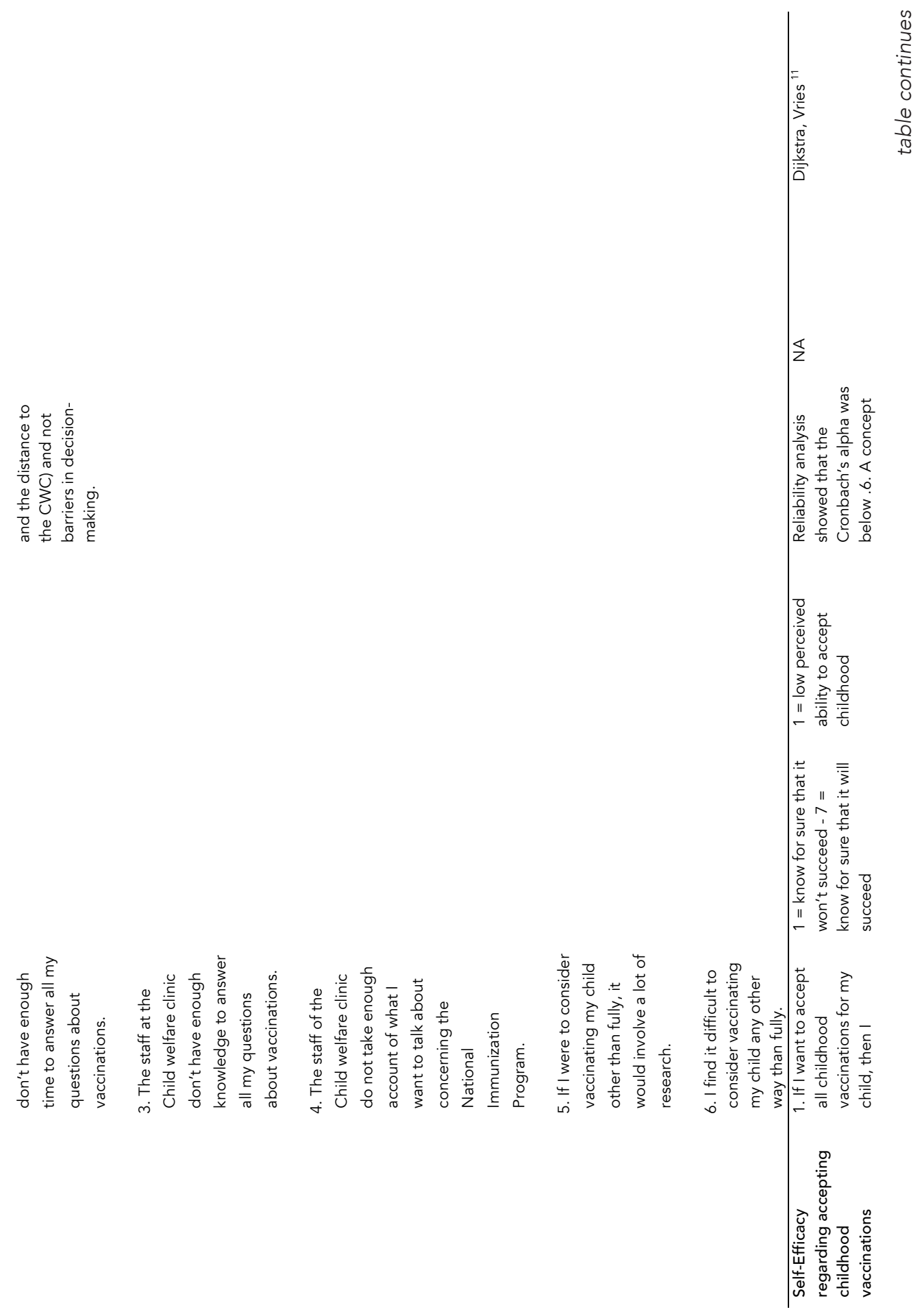




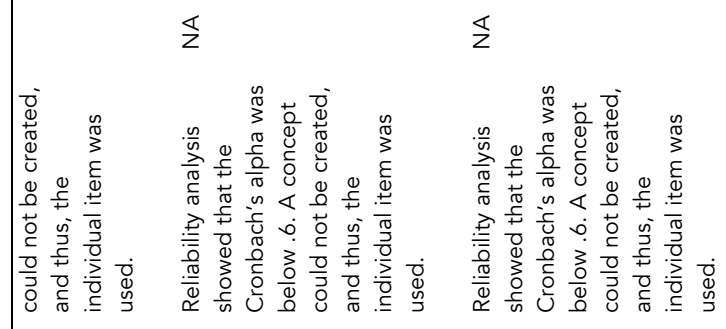

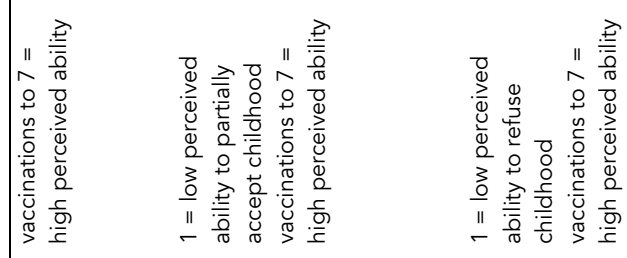

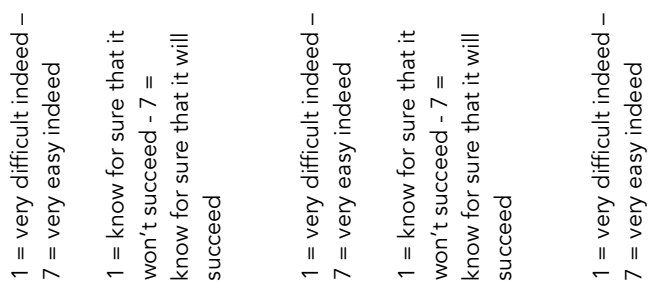

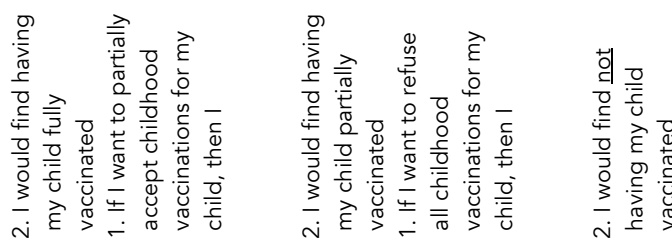

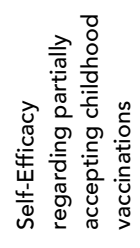

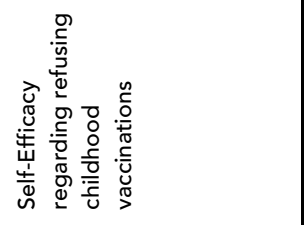




\section{References}

1. Centraal Bureau voor Statistiek (CBS). [International Standard Classification of Education (ISCED)]. Heerlen: Centraal Bureau voor Statistiek (CBS);2018.

2. Bedford $H$, Attwell $K$, Danchin $M$, et al. Vaccine hesitancy, refusal and access barriers: The need for clarity in terminology. Vaccine. 2018;36(44):6556-6558.

3. Lehmann BA, de Melker HE, Timmermans DRM, Mollema L. Informed decision making in the context of childhood immunization. Patient Educ Couns. 2017;100(12):2339-2345.

4. Harmsen IA, Lambooij MS, Ruiter RA, et al. Psychosocial determinants of parents' intention to vaccinate their newborn child against hepatitis B. Vaccine. 2012;30(32):4771-4777.

5. Montano DE, Kasprzyk D. Theory of Reasoned Action, Theory of Planned Behavior, and the Integrated Behavioral Model. In: Glanz K, Rimer BK, Viswanath K, eds. Health Behavior and Health Education: Theory, Research and Practice. 4th ed. New Jersey: John Wiley \& Sons; 2008:67-96.

6. O'Connor A. user Manual - Decisional Conflict Scale. 1993 [updated 2010].

7. O'Connor AM. Validation of a decisional conflict scale. Med Decis Making. 1995;15(1):25-30.

8. de Vries H, van Osch L, Eijmael K, Smerecnik C, Candel M. The role of risk perception in explaining parental sunscreen use. Psychol Health. 2012;27(11):1342-1358.

9. Janssen E. Feelings of cancer risk [Dissartation ]. Maastricht: Department of Health Promotion, Maastricht University; 2013.

10. Siegrist M, Earle TC, Gutscher H. Test of a trust and confidence model in the applied context of electromagnetic field (EMF) risks. Risk Anal. 2003;23(4):705716.

11. Dijkstra A, Vries HD. Self-efficacy expectations with regard to different tasks in smoking cessation. Psychology \& Health. 2000;15(4):501-511. 
